\title{
Community Resilience, Disaster Risk Reduction and Climate Change Adaption: Learning with Coastal Communities in Central Vietnam
}

\author{
by
}

Nguyen Huu Trung

A thesis submitted to the Faculty of Graduate and Postdoctoral Affairs in partial fulfilment of the requirements for the degree of

Doctor of Philosophy

in

Geography

Carleton University

Ottawa, Ontario

(C) 2016, Nguyen Huu Trung 


\section{ABSTRACT}

Vietnam has made significant efforts through disaster risk reduction (DRR) and climate change adaptation (CCA) programs to enhance the resilience of its coastal communities and reduce climate risks. These programs have contributed to significant declines in weather-related human fatalities, but the increases in human injuries and economic losses over the last two decades reveals that these programs have not been fully successful.

This research explores and evaluates factors shaping the success of the recent DRR and CCA efforts in central Vietnam's coastal communities and investigates opportunities to enhance community resilience (CR) and thereby reduce risks of future climate change. The empirical part of this research relied on community-based participatory action research approaches to engage local residents in Tuong Van community and their representatives from local to provincial agencies. Findings from the case study showed that the success of DRR and CCA programs in enhancing CR and reducing climate risks were shaped by the availability, quality and interplay of five forms of capital (physical, financial, natural, human and social resources) as well as the quality of DRR and CCA governance across multiple scales. Factors that need to be addressed in the transition towards more resilient coastal communities in central Vietnam include limited public participation, low transparency and accountability, as well as lack of responsibility of, poor collaboration and co-ordination amongst actors at local through national levels in the development and implementation of the two programs aimed at reducing climate risks.

Overall this research reinforces recent efforts to engage local communities in global environmental change research. It not only contributes to efforts to reduce the 
uncertainties about global climate change and its impacts at the community level, but also advances our knowledge about the interplay between DRR and CCA approaches (concepts and practices) to enhancing $\mathrm{CR}$ and reducing climate risks. The research also shows that fostering the development of climate-resilient communities will depend in part on our capacity to further integrate five research themes: climate change, the five capitals, CR, DRR and CCA. 


\section{ACKNOWLEDGEMENTS}

This thesis was completed with the extraordinary support and helps of many people and institutions. First and foremost, I express my special thanks to my supervisor, Dr. Mike Brklacich for his invaluable guidance and support throughout my academic journey. He gave me broad and insightful suggestions to think beyond each of social and natural sciences, towards merging them to address the complexity of coupled nature-human systems. I am also grateful for letters of his strong nomination for a number of valuable scholarships and awards.

My advisors, Dr. Peter Ricketts and Dr. Nguyen Quang Dung, also provided me with useful and constructive suggestions and encouraged me to think more deeply about my research results. My sincerely thanks to Peter, not only for his valuable and timely advice on my thesis, but also for giving me a wonderful opportunity to participate in the Coastal Zone Canada 2014 Conference in Halifax, where I learnt and got inspired by efforts of scholars and practitioners from various parts of Canada and different countries. To Dung, besides his insightful suggestions for my thesis, I owe his valuable introduction to provincial and national agencies, which allowed me to address practical issues during my field research in Vietnam in a timely manner.

To leaders of institutions, my thesis could not be completed without their accepting and welcoming me at their doorsteps. Special thanks to Mr. Pham Trong Yen from Ministry of Agriculture and Rural Development, Mr. Hoang Dinh Lien from Quang Tri's provincial Department of Agriculture and Rural Development (DARD), Ms. Nguyen Hien Thi of Oxfam Hong Kong for their valuable advices while I finalized my research proposal, introducing me with welcoming words to government agencies from national to 
local level. To leaders of Trieu An commune, I highly acknowledge the enabling environment they created and the productive workshops they held for communal officials to share experiences and provide feedback to the preliminary findings of the research.

I highly appreciate the strong collaboration and support from Mr. Nguyen Huu Nam, Ms. Bui Thi Thuy Nhi, Ms. Nguyen Thi Van from Quang Tri's provincial Department of Natural Resources and Environment (DONRE). Their ideas and open communication as well as their rich experiences with local communities in Quang Tri were helpful for me to conduct my field research. To Tuong Van villagers, I much appreciate their welcome when I visited their village and their active involvement in long and lively discussions, and accepting me as a member of their football and volleyball games.

I give my sincere thanks to members of the research team, Mr. Nguyen Van Hoa of DARD, Ms. Truong Thi Ngoc Thao of DONRE, Mr. Nguyen Minh Kiem, Mr. Pham Xuan The and Mr. Tran Van Dung on the leadership board of Tuong Van village, for all the time they spent with me. Their ideas, experiences with governmental activities and local collaboration, and contribution to my field research were significant for successful completion of this thesis. I also appreciate interesting moments following focus group discussions we spent to share experiences about our family lives and friendships.

I would like to thank my late Mom and my brother. They always keep me spiritually warm and encourage me to move forwards with my aspirations. I am also indebted to my wife. She put her career on hold to accompany me to a new land to shoulder the duties of looking after my own family in my stead. She has shared in happiness and in the difficulties of my academic works with me throughout the process. To my daughters, Nhat Mai and Ha Lan, I am proud of your academic and art medals you achieved each 
past year despite your study in a foreign language and a little support from your busy Daddy. While you have strongly encouraged and empowered me, I owe you many games that you have missed over the long years.

I acknowledge my financers as without their support this thesis could not be fruitful. I am grateful for graduate scholarship (2011-2015), Canadian Standards Association Pat Keindel Graduate Scholarship in Climate Change (2012-2014), Ina Hutchison Award in Geography (2013-2015), Torrance Graduate Research Award (2013-2014), and Neil Huckavle Memorial scholarship (2014-2015) from Carleton University. I especially thank the International Development and Research Centre (IDRC) for granting me an IDRC Doctoral Research Award to undertake my four month fieldwork in Vietnam. The awards not only provided me with financial support, but also complemented my academic training with valuable, practical experiences.

Finally, I would like to thank all staff and faculty of the Department of Geography and Environmental Studies (DGES) for its warm and friendly environment for foreign students. In particular, I specially thank Dr. Fran Klodawsky for giving me not only valuable advice to become a social scientist and a letter of her strong recommendation for my IDRC award, but also her warm concern about my family. To Dr. Chris Burn, Natalia Pressburger and Erin Johnston, I appreciate their great help throughout my study at Carleton. I am also indebted to my friends in DGES, especially Beth Mburu, Gary Martin, Andrea Carrion and Gabrielle Hardy for their warm and caring concerns about my family and their help in my academic life. 


\section{TABLE OF CONTENTS}

ABSTRACT

ACKNOWLEDGEMENTS ........................................................................................................iii

TABLE OF CONTENTS .............................................................................................................. vi

LIST OF TABLES ............................................................................................................................. viii

LIST OF FIGURES .................................................................................................................... $\mathrm{x}$

LIST OF APPENDICES ……........................................................................................... xi

LIST OF ACRONYMS ......................................................................................................................

1. CHAPTER 1: INTRODUCTION............................................................................................ 1

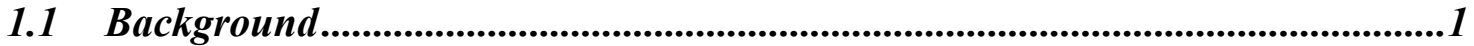

1.2 Goals, research questions and strategy ……......................................................5

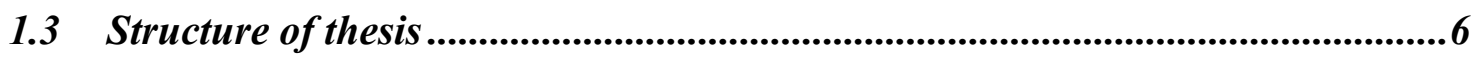

1.4 Significance of the research ...............................................................................8

2. CHAPTER 2: INTELLECTUAL ROOTS: UNDERSTANDING CLIMATE RISK AND COMMUNITY RESILIENCE.............................................................................. 10

2.1 Overarching concepts and their relationships......................................................10

2.2 Methodological approaches................................................................................24

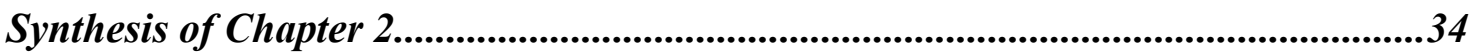

3. CHAPTER 3: CLIMATE RISKS AND RECENT EFFORTS OF VIETNAM IN BUILDING CLIMATE-RESILIENT COMMUNITIES ......................................................36

3.1 An overview of biophysical and social-economic conditions in Vietnam and coastal zones....................................................................................................................36

3.2 Vietnam's recent efforts in response to a changing climate .................................40

3.3 Recent trends of community resilience and climate impacts in coastal Vietnam50

Synthesis of Chapter 3.....................................................................................................59

4. CHAPTER 4: RESEARCH FRAMEWORK AND METHODOLOGIES .......................62

4.1 Methodological decisions.................................................................................62

4.2 Understanding the study area..........................................................................63

4.3 Development of an investigative framework............................................................77

4.4 Implementing the investigative framework...............................................................83

4.5 Moving beyond data: analysis and interpretation of the collected data .............96

Synthesis of Chapter 4........................................................................................................97

5. CHAPTER 5: COMMUNITY PERSPECTIVES ON THE IMPACTS OF CLIMATE HAZARDS 
5.1 Recent characteristics of Tuong Van community

5.2 Complex impacts of climate hazards on Tuong Van community

Synthesis of Chapter 5.

6. CHAPTER 6: DISASTER RISK REDUCTION AND CLIMATE CHANGE ADAPTATION IN TUONG VAN COMMUNITY

6.1 Flood and storm DRR efforts in Tuong Van community.............................133

6.2 Mainstreaming CCA with DRR..............................................................146

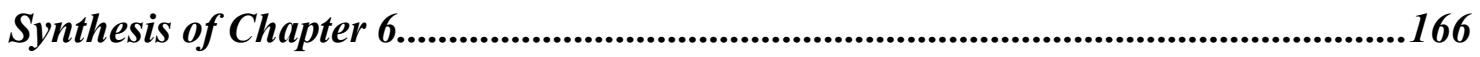

7. CHAPTER 7: MULTIDIMENSIONAL FACTORS AFFECTING THE SUCCESS OF RECENT INTERVENTIONS............................................................................... 170

7.1 An overview about the success and limitations of DRR and CCA practices...170

7.2 Multi-level governance perspectives: Six key themes......................................173

7.3 Adequacy of five capitals in DRR and CCA: availability, quality and interactions.............................................................................................................184

Synthesis of Chapter 7 ..................................................................................198

8. CHAPTER 8: STRATEGIES FOR BUILDING A RESILIENT COMMUNITY IN THE FACE OF CHANGING CLIMATE ...................................................................202

8.1. A vision for Tuong Van community in the face of changing climate..............202

8.2. Portfolio of essential projects for realizing the vision .......................................206

8.3. Strategies for navigating transitions towards a resilient community in the face of a changing climate..........................................................................210

Synthesis of Chapter 8...........................................................................................224

9. CHAPTER 9: CONCLUSIONS, IMPLICATIONS AND RECOMMENDATIONS

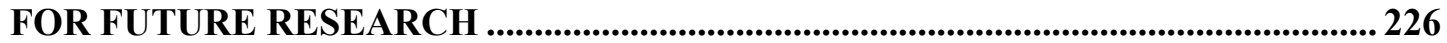

9.1 Overview of the Research Process......................................................................226

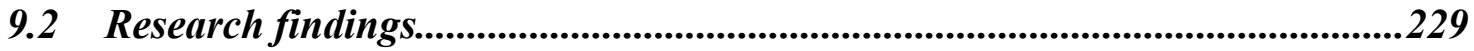

9.3 Research contributions.................................................................................243

9.4 Research limitations and future research .................................................246

Concluding remarks ............................................................................................249

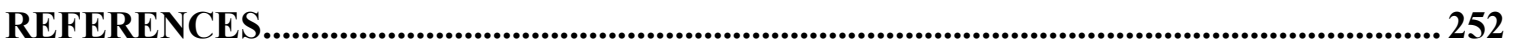

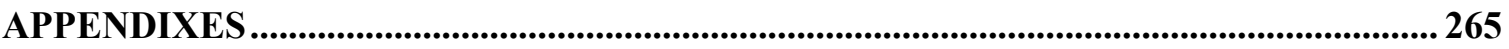




\section{LIST OF TABLES}

Table 3-1: Overviews of the National Strategy on Disaster Prevention, Response and Mitigation to 2020 (NSD) and the National Target Program on Response to Climate Change (NTP)

Table 3-2: Categories of disaster risk reduction measures funded by the Vietnamese government to support the National Target Program on Response to Climate Change towards 2020

Table 3-3: The demographic change and development of economic activities in Vietnam and coastal zone between 1995 and 2012

Table 3-4: Human and economic impacts of key natural hazards in Vietnam during 1989 and 2010

Table 4-1: An overview about important changes of Quang Tri policies in response to the changing climate over the last three decades.

Table 4-2: Example policies other than DRR and CCA programs used by Quang Tri to enhance community resilience over the last three decades.

Table 4-3: Demographic characteristics of Trieu An commune in 2012

Table 4-4: Impacts of key storms and floods on Trieu An commune between 1983 and 2006..... 74

Table 4-5: Guiding questions for focus group discussions (FG) 87

Table 4-6: Guiding questions for the participatory planning process 91

Table 4-7: The criteria and their definition used to prioritize proposed projects. .93

Table 5-1: Distribution and ownership of natural resources across Tuong Van community ........ 106

Table 5-2: Distribution and ownership of physical resources across Tuong Van community..... 107

Table 5-3: The differences in biophysical conditions between Tuong Van Lang and Tuong Van Dong

Table 5-4: Temporal pattern of climate-related events in Tuong Van. 115

Table 5-5: Overall impact index of individual hazards on the five capitals in Tuong Van community

Table 5-6: Specific impact indices of climate hazards on physical resources in Tuong Van community .....

Table 5-7: Specific impact indices of climate hazards on natural resources in Tuong Van community ....

Table 5-8: Specific impact index of climate hazards on financial resources in Tuong Van community .....

Table 5-9: Impact indices of hazards by individual human resources in Tuong Van community

Table 6-1: Examples of resources mobilized and used for DRR during rainy seasons

Table 6-2: Example measures to mobilize and use resources for the responses prior to the occurrence of storms and floods 
Table 6-3: Example measures to mobilize and use resources for responses during storms and floods

Table 6-4: Example measures to mobilize and use resources for responses following storms and floods

Table 6-5: Temporal rotation of natural resource-based livelihoods in Tuong Van community. 165

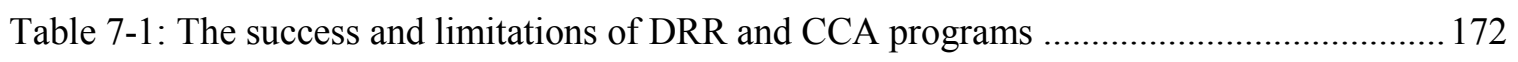

Table 7-2: The availability of key physical resources for DRR and CCA in Tuong Van ........... 184

Table 7-3: The quality of key physical resources for DRR and CCA in Tuong Van .................. 185

Table 7-4: The availability of financial resources for DRR and CCA in Tuong Van.................. 187

Table 7-5: Roles and the availability of key natural resources for DRR and CCA in Tuong Van 188

Table 7-6: Problems of key physical resources in Tuong Van and their causes .......................... 195

Table 7-7: Problems of financial capital in Tuong Van and their causes .................................... 196

Table 7-8: Problems of natural capital in Tuong Van and their causes ...................................... 196

Table 7-9: Problems of human capital in Tuong Van and their causes ...................................... 197

Table 7-10: The problems of social capital in Tuong Van and their causes ............................... 198

Table 8-1: Vision elements identified by participants in the first set of planning workshops ..... 203

Table 8-2: Essential projects proposed by participants and their role in addressing climate hazards

209

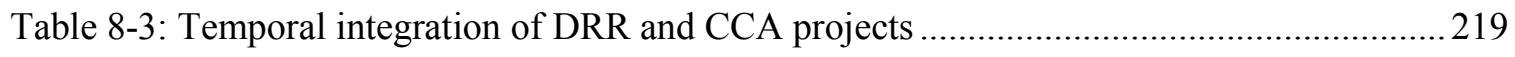

Table 8-4: The priority of the 17 proposed projects ranked by community members ................. 221

Table 9-1: Summary of research contributions to five areas of existing literature: climate change, the five capitals, community resilience, disaster risk reduction, and climate change adaptation 


\section{LIST OF FIGURES}

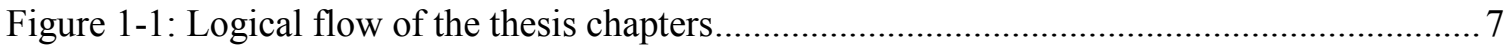

Figure 2-1: Global disaster trend over the last three decades ................................................... 13

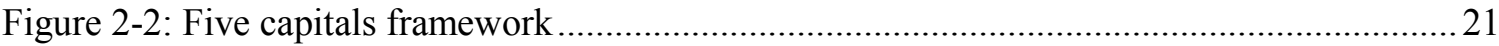

Figure 3-1: Map of Vietnam and monthly average temperature and rainfall (line graphs) in coastal Vietnam as well as the average frequency of storm over the past 50 years .................37

Figure 3-2: Trends in sectoral contribution to Vietnam's gross domestic products ...................... 38

Figure 3-3: Institutional framework for the National Strategy on Disaster Prevention, Response

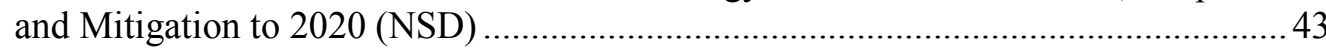

Figure 3-4: Institutional framework for the National Target Program on Response to Climate

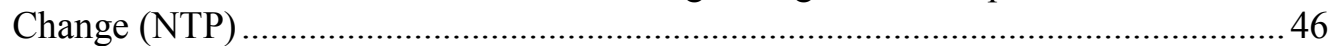

Figure 3-5: The pattern of the 2013 migration by provinces (the first two left maps) and by the 2009 age structure (the three first right maps). 53

Figure 3-6: Spatial impacts of climate hazards in Vietnam between 1989 and 2010 ..... .56

Figure 3-7: Spatial pattern (map) and frequency (graph) of flood, landslide, flash flood, storm and hailstorm disasters across Vietnam between 1989 and 2010 57

Figure 3-8: The disaster frequency (left graph) as well as human and economic impacts (right graph) of natural hazards in Vietnam during 1989 and 2009. .58

Figure 4-1: Maps of central Vietnam (shaded area of the left map) and Quang Tri province (right)

Figure 4-2: Climate impact trends in Quang Tri province for the period of 1991 and 2012. .66

Figure 4-3: The institutional framework for Quang Tri to implement the National Strategy on Disaster Prevention, Response and Mitigation to 2020 and the National Target Program on Response to Climate Change. .70

Figure 4-4: Location of Trieu An commune and local administrative structure .73

Figure 4-5: Interactions across multiple scales in Tuong Van .77

Figure 4-6: Research framework 82

Figure 4-7: Key activities during the two field trips of the empirical research conducted in Vietnam. .84

Figure 4-8: Complementarity across multiple methods for data collection 96

Figure 5-1: Geographical location of Tuong Van and its connection with other villages of Trieu An

Figure 5-2: The proportion of households involving in different livelihoods in Lang against Dong

Figure 5-3: The importance index for individual resources perceived separately by Lang and Dong.

Figure 5-4: Monthly pattern of rainfall at Dong Ha station of Quang Tri between 1976 and 2012 
Figure 5-5: Rising sea level observed at Dong Ha hydrological station during 1976 to 2012 .... 117

Figure 5-6: The relationships of climate-related hazards in Tuong Van ................................... 124

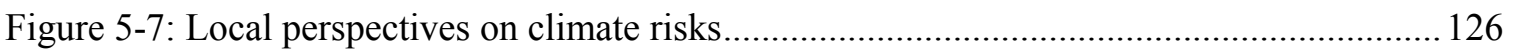

Figure 5-8: The mean of daily peak tides observed at Dong Ha hydrological station in October during 1976 and 2012 and of daily peak tides in October of 1983 and 1985 .......... 127

Figure 5-9: Example impacts of rain and tidal flooding in Tuong Van ...................................... 128

Figure 5-10: Interactions between climate change and Tuong Van community.......................... 129

Figure 6-1: Institutional arrangement for storm and flood DRR in Tuong Van community ....... 135

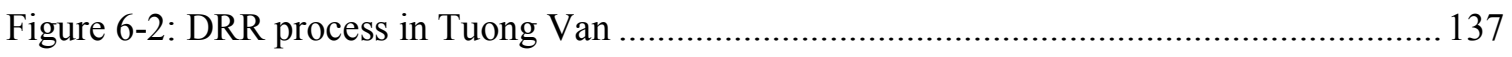

Figure 6-3: Percentage of households diversifying their livelihoods in Tuong Van ................... 161

Figure 6-4: Recent involvement of Lang and Dong residents in recent livelihoods.................... 161

Figure 6-5: Integration between disaster risk reduction (DRR), climate change adaptation (CCA) and community resilience (CR) to address changing climate in Tuong Van............. 167

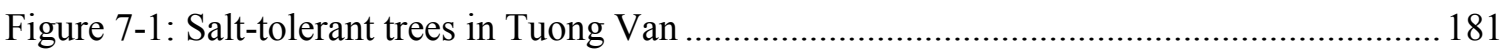

Figure 7-2: Damage to a house and a road during the storm in September 2013 ....................... 182

Figure 7-3: Emergency road and dyke in Lang eroded by floods and tidal flooding in 2013 ..... 186

Figure 7-4: Potential impacts of wild plants growing between stones of bank protection side of flood dykes in Tuong Van..................................................................................... 191

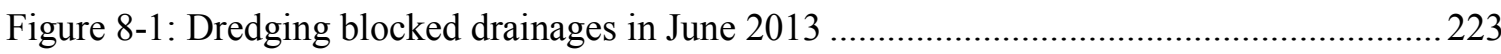

Figure 9-1: A framework for understanding and enhancing community resilience in the face of

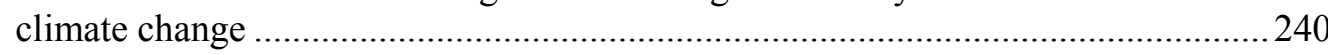

\section{LIST OF APPENDICES}

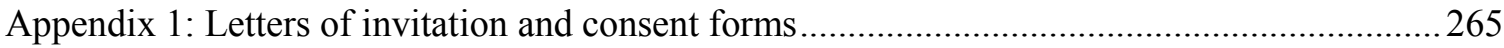

Appendix 2: Sample key questions for focus group discussions .............................................2 275

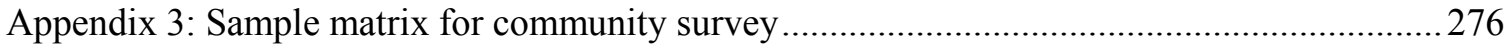

Appendix 4: Sample research questions for planning workshops ............................................ 279

Appendix 5: Sample research questions for in-depth interviews................................................ 281 


\section{LIST OF ACRONYMS}

\begin{tabular}{ll} 
Acronym & Definition \\
\hline CCA & Climate change adaptation \\
CC-FSC & Central Committee for Flood and Storm Control \\
CFS-SR & Committee for Flood and Storm Control, Search and Rescue \\
CR & Community resilience \\
DARD & Provincial Department of Agriculture and Rural Development \\
DONRE & Provincial Department of Natural Resources and Environment \\
DRR & Disaster risk reduction \\
FG & Focus group discussion \\
MARD & Vietnam's Ministry of Agriculture and Rural Development \\
MONRE & Vietnam's Ministry of Natural Resources and Environment \\
PAR & National Strategy for Natural Disaster Prevention, Response and \\
NSD & Mitigation to 2020 \\
\hline & National Target Program to Respond to Climate Change \\
& Commity-based participatory action research
\end{tabular}




\section{CHAPTER 1: INTRODUCTION}

\subsection{Background}

\subsubsection{Climate impacts and recent response to changing climate in central Vietnam}

Vietnam's coastal communities, especially those along the central coast have been routinely threatened by climate hazards such as storms, floods and droughts (GOV 2007b) and future climate change is expected to heighten these threats to the majority of Vietnam's population that lives along the coast (MONRE 2009). It is projected that about 63 million people and 1.1 million hectares of agricultural land will be at risk from sea level rise of one metre by 2100 (MONRE 2009), posing threats to human security as well as to local and regional food security (UNDP 2011a, b). These concerns have sparked calls from local communities and multiple levels of government to determine strategies for enhancing the resilience of these communities and reduce climate risks (GOV 2007b, 2011, Kirsch-Wood 2015).

Vietnam has made significant efforts to enhance the resilience of its coastal communities through disaster risk reduction (DRR) and climate change adaptation (CCA) programs with the ultimate goal to lessen the adverse impacts of recurrent hazards and future climate change. At the national level, the Vietnamese government initiated a national program on DRR in 1945 in order to enhance the capacity of communities across the country and reduce impacts of natural hazards, especially from storms and floods. Building on this long-standing experience, the national government launched a National Strategy for Natural Disaster Prevention, Response and Mitigation to 2020 (NSD) in 
2007 (GOV 2007b), and a National Target Program to Respond to Climate Change (NTP) in 2008 (GOV 2008). All provinces and sectoral ministries have implemented action plans for the first phase of both the NSD and NTP policies and they are currently reviewing and preparing new action plans (Kirsch-Wood 2015).

At the local level, various DRR and CCA projects have been implemented over the last three decades to reduce the impacts of climate hazards, for instance restoration of mangrove forests and building storm-resistant houses in many coastal communities (Tri et al. 1998, UNDP 2011a, Tong et al. 2012). Such interventions have appeared to promote the resilience of some communities and reduce climate-related disasters. For example, in 2005 the restored mangrove forests in the Kien Thuy district reduced the impact of a four-metre high storm surge to a $0.5 \mathrm{~m}$ surge onshore (UNDP 2011a) and more importantly, climate-induced disasters across the country have become less deadly over the last two decades (Luong et al. 2011).

Despite these considerable efforts, the frequency of natural disasters in Vietnam, mainly induced by climate hazards, continues to grow with increases in financial losses and property damage over the past two decades (Luong et al. 2011). The observed and projected impacts of changing climate have resulted in calls for action research to determine the underlying causes that have limited the effectiveness of recent responses by local communities, and to seek more effective strategies to improve their resilience and reduce risks from future climate change (GOV 2007b, 2008, McEvoy et al. 2014, KirschWood 2015). 


\subsubsection{Research problems}

Growing concerns over the limited success of responses to a changing climate are often associated with community resilience (CR), DRR and CCA approaches. CR is seen as the capacity of a community to cope with environmental and social-economic threats (Adger 2000, Tompkins and Adger 2004) and it is most often generated from a diverse set of factors (Norris et al. 2008). Thus it is widely assumed that available resources are proportional to the resilience of a community. However, it remains unclear as to the extent that CR itself is dependent on the adequacy (availability, quality and interplay) of resources as well as on the characteristics of hazards that the communities are facing.

DRR and CCA have been deployed as key strategies to promote CR and reduce climate risks (UNDP 2012, UNISDR and UNDP 2012), but they are also critiqued from several perspectives. DRR is viewed as an effective tool to reduce disasters from extreme events such as storms and floods (UNISDR 2005a), but many argue that this approach tends to overlook gradual and new impacts of climate change (Wilbanks 2005, O'Brien et al. 2012). CCA is advocated as a means to address drawbacks of DRR via consideration of the longer-term impacts of climate change at larger scales such as global warming and sea level rise (O’Brien et al. 2012). Yet, CCA also has limitations, for example its limited ability to reduce costs from abrupt and destructive events (Wilbanks 2005). As the strengths of one approach can address weaknesses of the other, many suggest that CCA should be integrated with DRR to reduce climate risks (IPCC 2012). However, the relationships between DRR and CCA approaches and how they should be integrated remain questionable (Gero et al. 2011, Lei and Wang 2014, Kirsch-Wood 2015, Rivera et al. 2015). 
Another concern about the limited success of recent efforts is the limited integration across jurisdictional and spatial scales into the process of formulating and implementing DRR and CCA (Gibson et al. 2000, Adger et al. 2005a). Although various studies have addressed climate change problems facing communities, many such efforts have limited engagement with local communities. For instance, in Vietnam, national and provincial action plans in response to climate change are developed mainly based on global and regional climate models (MONRE 2009). The use of large-scale climate models has the advantages of setting broader environmental parameters for planning, but these do not fully reflect local contexts (van Aalst et al. 2008) nor do they explicitly factor in other drivers of change (e.g. economic development policy, urbanization and globalization). Many suggest that the use of community-based participatory action research (PAR) approaches can reduce the limitations of such efforts because they provide local communities with opportunities to discuss climate impacts facing them and identify practical strategies to solve problems in their local contexts (van Aalst et al. 2008, Khailani and Perera 2012).

In short, coastal communities in Vietnam, especially those in central provinces, have been threatened by climate hazards, especially storms and floods and the impacts of such hazards are likely to be magnified by future climate change (GOV 2007b, IPCC 2007, MONRE 2009). Despite the significant efforts to enhance CR through DRR and CCA over the last three decades, the frequency of disasters and economic losses continues to grow across the country (Luong et al. 2011). This has resulted in increasing calls for research that determines factors shaping the success of responses by local communities and seeks practical strategies to improve CR and reduce climate risks (GOV 2007b, 2008, 
Kirsch-Wood 2015). CR, DRR and CCA are advocated as essential approaches to reducing climate impacts, but there is a growing concern over their drawbacks of and relationships across the three approaches.

\subsection{Goals, research questions and strategy}

The goal of this research is to explore and evaluate the factors that have promoted and impeded recent DRR and CCA efforts in central Vietnam's coastal communities, and search for alternative strategies to enhance $\mathrm{CR}$ and reduce risks from future climate change. The overarching question framing this study asks "What are the constraints and opportunities for enhancing the resilience of central Vietnam's coastal communities in the face of a changing climate?" This overall goal is approached by breaking it down into the following four research sub-questions:

1. How have climate hazards recently impacted central Vietnam's coastal communities?

2. How have coastal communities in central Vietnam recently responded to climate hazards?

3. Why have some of the recent responses of central Vietnam's coastal communities reduced impacts of climate hazards, while some others have been less successful?

4. What strategies could provide central Vietnam's coastal communities with opportunities to enhance community resilience and reduce risks from future climate change?

Questions 1 - 3 consider climate hazards and responses by central Vietnam's coastal communities over the three decades and are designed to provide insight into conditions 
that have improved or diminished the resilience of the communities over this period and leading up to the current context in 2011 and 2014. In Question 4, there is a shift from understanding the recent climate hazards and the focus changes to how well-prepared the communities are to cope with and adapt to future climate change.

In response to these research sub-questions, this study focused on a single coastal village in Central Vietnam as a case study in order to foster an in-depth analysis of complex phenomena that shape the vulnerability and resilience of a rural community. The study also used PAR approaches to work jointly with a research team and members of the community. The research team was led by the $\mathrm{PhD}$ candidate and the development of the research plan and its implementation was with assistance from provincial government officials and community leaders. In addition, members of the village were engaged throughout the research process in order to contextualize climate impacts that have been experienced throughout their lives, to evaluate the success and limitations of their recent responses, and to develop alternative strategies to promote the resilience of their community and reduce risks of future climate change.

\subsection{Structure of thesis}

This thesis is structured into nine chapters, which have bi-directional flows (Figure 1-1). The introductory chapter locates the thesis in the practical (e.g. biophysical and socialeconomic issues facing local communities) and conceptual (e.g. the emergency of CR and CCA scholarship) contexts. In addition, it establishes the overall purpose of the research and the specific research questions. 


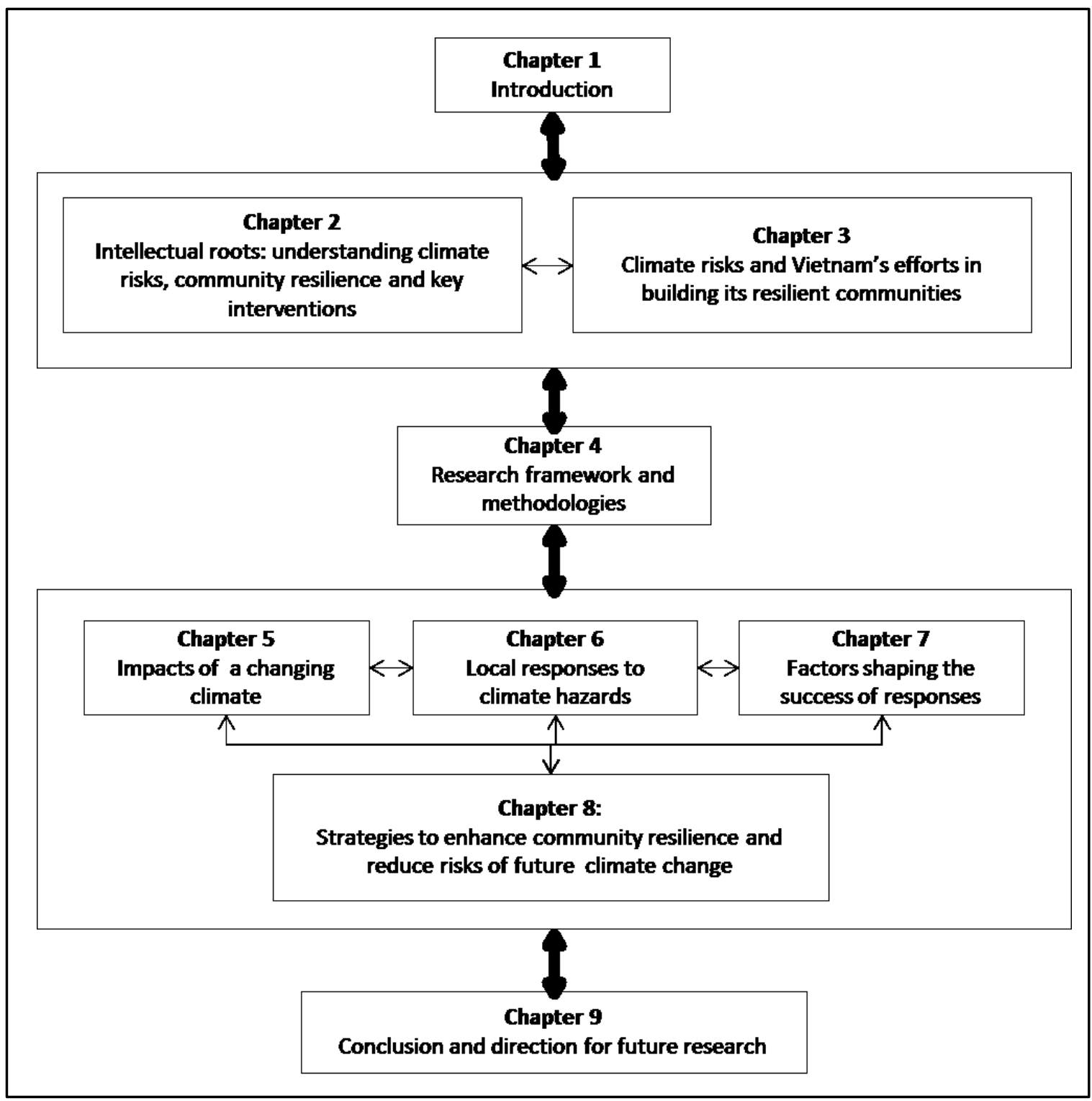

Figure 1-1: Logical flow of the thesis chapters

Chapters 2 and 3, respectively provide critical reviews of intellectual roots and Vietnam's efforts to improve $\mathrm{CR}$, and thereby creating a foundation for the remainder of the thesis. Chapter 4 presents an investigative framework and methodologies for the field research and builds a bridge across Chapters 2 and 3 .

Chapters 5 through 8 illustrate and discuss the results of the empirical research and they build on each other. Chapter 5 identifies climate hazards and assesses impacts of the 
individual hazards and their interactions on different components of the collaborating community. Chapter 6 explores recent DRR and CCA programs adopted by the community to address a changing climate. In addition, this chapter sets the foundation for the evaluation of the successes and limitations of the two programs in Chapter 7. Finally, Chapter 8 develops strategies that should help the community navigate critical transitions towards a more resilient state over the next five years.

The thesis ends in Chapter 9 with an overview of the research process, a synthesis of the empirical findings and potential contributions to CR scholarship.

\subsection{Significance of the research}

This research contributes to the climate change, DRR, CCA and CR literature. Specifically, the research provides better insight into the roles of and relationships amongst DRR, CCA and CR approaches to reduce climate risks. Secondly, the research identifies factors across temporal, spatial and jurisdictional scales that have shaped the success of recent efforts employed by central Vietnam's coastal communities. Finally, this investigation addresses the limitations of top-down interventions involving largescale climate models through the use of PAR approaches, which engaged local communities to contextualize their experiences of climate impacts and develop solutions to address such problems.

Many coastal provinces in Vietnam have completed the first phase of the NSD and NTP programs and they are currently reviewing and developing action plans for the second phase (Kirsch-Wood 2015). This research contributes to the review process and preparation of these action plans. The findings will be likely mainstreamed into the 
policy-making process at appropriate government levels. Furthermore, the research engaged local officials as co-researchers and they will potentially advocate for the incorporation of local community issues into the policy making process. In addition, the co-researchers will likely be involved in the process of DRR, CCA and CR planning for other coastal communities.

Various people and organizations benefit from this research. First, community members had an opportunity to communicate the concerns of their community with governmental officials in the development of community action plans that could be used to request funding for DRR and CCA interventions. Secondly, the research provided the coresearchers with benefits, for instance the enhancement of their knowledge about DRR, CCA and CR. In addition, the co-researchers shared their knowledge and skills with their respective agency, and will most likely use this knowledge to assist other communities in their province. Finally, this case study will serve as an example to other communities taking similar actions to enhance community resilience and reduce climate risks. 


\section{CHAPTER 2: INTELLECTUAL ROOTS: UNDERSTANDING CLIMATE RISK AND COMMUNITY RESILIENCE}

Chapter 2 reviews the intellectual roots guiding this thesis and it provides an overview of conceptual and methodological foundations that will be used to contextualize climate risks facing central Vietnam's coastal communities and efforts in reducing the risks in Chapter 3. In addition, this chapter will be used in the eventual development of an investigative framework as well as to select appropriate methods for data collection and analysis in Chapter 4.

Chapter 2 is structured into two sections. It starts with describing and critiquing five overarching concepts: climate risk, disaster risk reduction, climate change adaptation, community resilience and "five capitals". The chapter then examines rationales for the use of case study and for community-based participatory action research approaches for community resilience research.

\subsection{Overarching concepts and their relationships}

\subsubsection{Climate risk}

Risk is a common word in daily life, but used variously by different schools of thought. Within a climate context, risk most often refers to the probability of potential disasters or expected loss resulting from the interactions between hazards and vulnerable conditions, and thus it is commonly expressed as a function of hazards and vulnerability (UNDP 2004, Brooks et al. 2005, Cardona 2011). Climate risk facing a community can only exist when both vulnerability and climate hazards occur concurrently. As such the strategy for 
climate risk management should be formulated based on knowledge about climate hazards and the vulnerability of communities (UNISDR 2005b).

Not all climatic events occurring in the daily life of communities are hazardous, but they become hazards when they pose threats to the communities and their property (Bryant 2005). A hazard can become a disaster when it causes significant damage to life and/or property. In the context of this research, the term "disaster" refers to a situation of significant loss such as human deaths or/and damage to many houses in a community. It is also essential to note that the term disaster is defined variously by different people and organizations and in this thesis the term disaster will be only used when signficant loss from hazards is clearly defined.

Climatic events vary in magnitude, frequency, duration, area of extent, speed of onset, as well as spatial and temporal scales (UNDP 2004). Thus potential impacts of a hazard are partially dependent on the characteristic of the event such as typology as well as temporal and spatial dynamics. In addition, climate hazards do not occur independently, but rather they interact with other environmental and social-economic factors. For instance, the 2009 Ketsana storm in Vietnam coupled with resulting violent floods, threatened significant populations residing in the low lying areas (CCFSC 2009b). Moreover, many hazards occur as a result of complex, multidimensional, interrelated processes, either concurrently or in chain reactions (Lechat 1990, Thomalla et al. 2006).

Understanding climate hazards is a necessary step in the development of climate risk reducion plans, but the risks might not be significantly reduced without knowledge about the vulnerability of communities. Community vulerability is the state of susceptibility of the communities to be harmed from their exposure to hazards and from the absence of 
their adaptive capacity (Adger 2006, Cardona 2011). Thus, the success in disaster relief efforts can be enhanced by reducing exposure to the hazards, for example relocating communities from unsafe to favorable areas (Keogh et al. 2010). However, in many communities, reducing exposure is not suffient if the capacity of the communities remain limited. For instance, poor households might not have enough money or other resources to relocate to safer places (Wisner 2004). Thus development of strategies to reduce climate risks needs knowledge not only about the extent to which communities are exposed to climate hazards, but also about their capacity to deal with the threats.

\subsubsection{Disaster risk reduction and climate change adaptation}

Many communities around the world have suffered from climate hazards, with growing financial losses over the last three decades (Figure 2-1), stemming from environmental and socio-economic changes (Adger et al. 2005b, IPCC 2014b). The impacts of many climate-related threats are expected to be magnified by future climate change, especially in rural communities, which often depend heavily on ecosystem services and functions to meet their livelihood needs (IPCC 2007). The observed increase in disaster frequency and anticipated impacts of climate change has precipitated calls for environmental and community research that identifies effective strategies to reduce risks of future climate change (UNISDR 2005b, IPCC 2014b).

One of the most important changes in climate change research over the last three decades has involved moving beyond the understanding physical processes of climate systems to formulating and implementing applicable solutions to reduce climate risks. A number of climate models have evolved and provided some success in predicting the occurrence and location of climate hazards such as the 2005 hurricane Katrina in New Orleans (Colten et 
al. 2008). However, most impacts of climate change are more difficult to recognise and forecast (Thomalla et al. 2006). Knowledge about physical processes remains important, but there is also an urgent need to identify applicable measures in order to build resilient communities, which have the capacity to minimize effectively the adverse impacts from complex environmental changes (UNISDR 2005b, UNDP 2012).

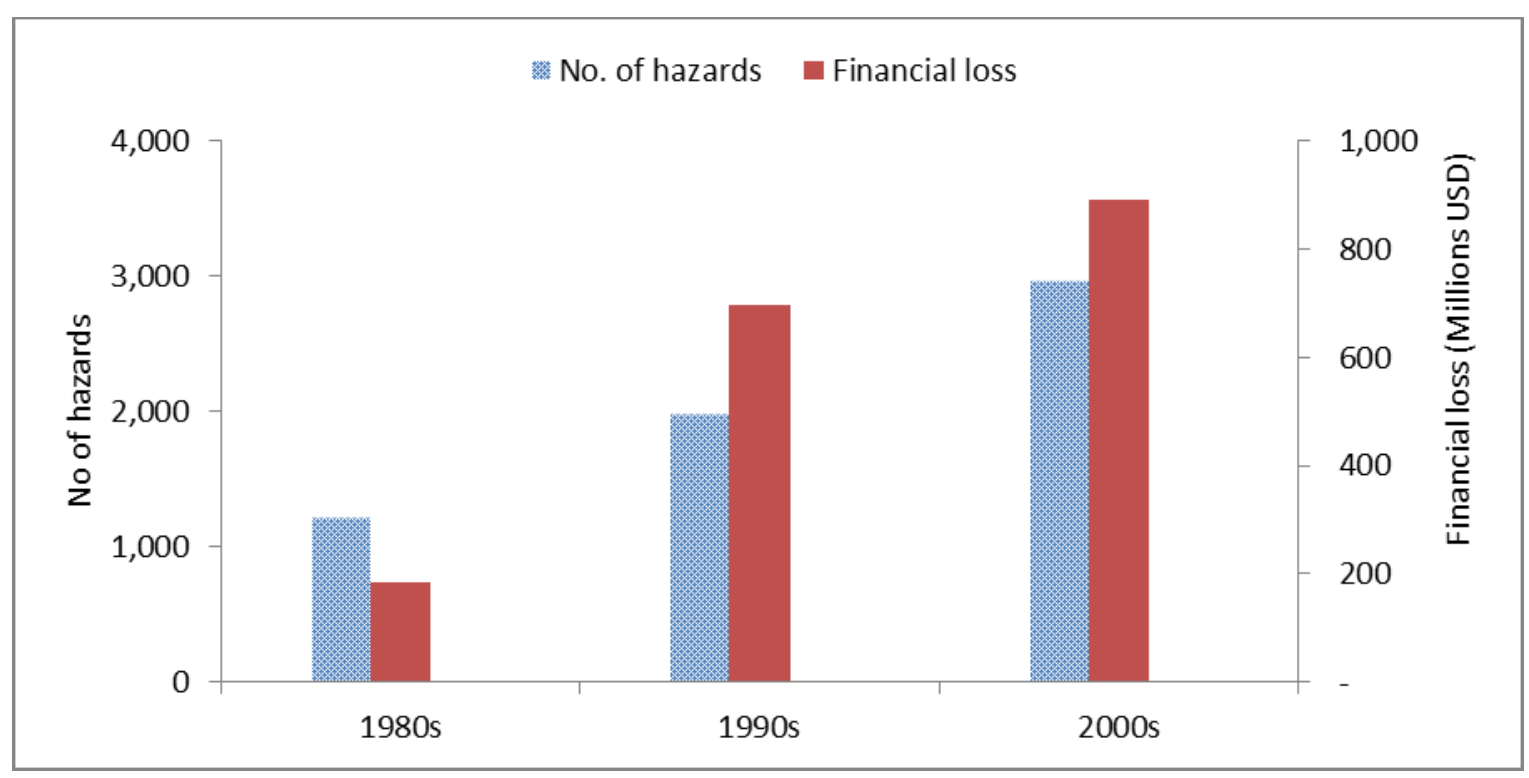

Figure 2-1: Global disaster trend over the last three decades

Source: data was retrieved from EM-DAT (2012) and the graph was produced by the author Disaster risk reduction (DRR) and climate change adaptation (CCA) are seen as important strategies to enhance the resilience and/or reduce the vulnerability of communities, and thereby minimizing climate risks (UNISDR 2005b, IPCC 2007). Yet, there are two important concerns about the two approaches. First, it remains unclear about which strategies should be adopted by local communities to reduce climate risks. Secondly, the limited success of recent interventions over the last three decades raises two critical questions: what and how have political, socio-economic and environmental factors across multiple scales shaped the success of DRR and CCA measures? 
DRR is seen as one of the most important strategies to reduce loss of human life and damage to properties. It is often viewed as the systematic development and application of policies, strategies and practices to minimize community vulnerabilities by reducing the exposure to and increasing adaptability of the communities to climate hazards (UNDP 2004, UNISDR and UNDP 2012). DRR can help communities to minimize climate risks over time by avoiding (prevention) or limiting (mitigation and preparedness) the adverse impacts of climate hazards (UNISDR 2005b). However, it also has some limitations in the context of climate change.

First, DRR emphasizes rapid onset hazards such as storms and floods and tends to overlook gradual and prolonged but equaly important stressors such as changes in precipitation and sea level (O'Brien et al. 2012). Secondly, it is critiqued that DRR focuses on existing risks with resulting strategies built upon past experiences, while some impacts of climate change will be new to a specific region, thus coping strategies based solely on previous experiences might not be as effective in the future (Sperling and Szekely 2005, Mercer 2010). Furthermore, for many hazards, there exists considerable knowledge and certainty about their characteristics, but most impacts of future climate change are much more difficult to predict and measure (Thomalla et al. 2006).

In the face of changing climate, $\mathrm{CCA}$ is increasingly accepted as an essential approach to reduce the vulnerability of communities (Smit and Wandel 2006, IPCC 2007). CCA is defined as the adjustment in natural or human systems to respond to actual or expected climatic stimuli or their effects, which moderates harm or exploits beneficial opportunities (IPCC 2007). Such adjustment involves change or transformation of a system once its current ecological, social, or economic conditions become untenable or 
are undesirable (Nelson et al. 2007, Denton et al. 2014). Such adaption involves navigating critical transitions of the system from an untenable to more preferable state (Olsson et al. 2006, Nelson et al. 2007, Scheffer 2009).

CCA has various advantages that can help to address limitations of DRR. For instance, it address not only current climatic conditions but also long-term impacts of climate change at larger scales such as sea level rise and global warming, which DRR overlooks (O’Brien et al. 2012). However, CCA also has several limitations. First, CCA is limited in its ability to reduce costs from abrupt events (Wilbanks 2005). Communities can adjust to some climatic events such as droughts and flooding, but they might not be able to deal with destructive events such as violent floods and storms solely by adjusting; rather the communities might need emergency responses such as evacution to safer places to reduce disasters. Secondly, CCA is critiqued as a top-down approach as it is built on large-scale climate models, which are disconnected from local communities, while they are directly affected by climate change (van Aalst et al. 2008). In addition, these climate models contain a high degree of uncertainty although the quality of these models have improved (Dowlatabadi and Morgan 1993, Byg and Salick 2009). In contrast, DRR grew from localized, specific response perspectives to respond to rapid onset events (Sperling and Szekely 2005).

Over the last decade, there has been a growing demand to integrate DRR and CCA approaches for enhancing CR and reducing risks of future climate change (IPCC 2012, Rivera et al. 2015, Serrao-Neumann et al. 2015). The reason behind this suggestion is that the two approaches have both strengths and weaknesses and more importantly, the strengths of one approach can offset the weaknesses of the other. For instance, CCA 
helps to reduce future impacts of climate change across global and regional scales that DRR tends to overlook, while DRR could provide CCA practices with localized and specific experiences on climate change (Sperling and Szekely 2005, IPCC 2012). Furthermore, the two approaches have substantial similarity in concepts and practices, thus the integration can help to minimize their overlaps (UNISDR and UNDP 2012). Yet, there remains much concern about the relationships between the two approaches and how they should be integrated (Gero et al. 2011, Lei and Wang 2014, Kirsch-Wood 2015, Rivera et al. 2015).

\subsubsection{Community resilience}

With roots in the science of physics, the term "resilience" was originally used to describe the ability of a material to return to equilibrium after a displacement by bending or bouncing back rather than breaking (Norris et al. 2008). Since then it has been widely used as an important concept in various disciplines to obtain insight into the capacity of various systems such as ecosystems or communities to absorb disturbance while retaining their basic structure and functions (Adger 2000, Walker et al. 2004). When applied to a human community, resilience is defined as the capacity of individuals, groups of people, or the community as a whole to cope with disturbances as a result of social, political and environmental change (Adger 2000, Tompkins and Adger 2004, IPCC 2007). As such enhancing community resilience (CR) is increasingly recognized as a promising solution to reduce climate risks (UNISDR 2005b, IPCC 2007) and it is widely assumed that resilient communities are far less vulnerable to the changing climate (Klein et al. 2003).

Resilience approaches have been increasingly adopted to reduce climate risks, but also have some limitations. Many natural hazards such as Hurricanes Katrina in 2005 and 
Sandy in 2012 in the US can exceed the coping capacity of communities (Colten et al. 2008, Powell et al. 2012), indicating building resilient communities might not be a solution by itself. In addition, the capacity to cope with threats and return to original states is less useful when it applies to human communities (Klein et al. 2003). This is true when communities are already in undesired conditions such as poverty and violence, thus they need a significant transition to more favourable states (Denton et al. 2014). Yet, the ability to resist and absorb remains important as it enables communities to recover more quickly from disasters and reduce the likelihood of secondary impacts, such as epidemics of diarrhoea following floods (Kouadio et al. 2012).

Enhancing CR is often described as a process comprising a series of both structural and non-structural actions that can be undertaken by the communities through different steps to generate a set of capacities to reduce risks from environmental threats (Manyena 2006). DRR and CCA are essential for enhancing CR because they provide the communities with a source of capacities not only to anticipate and plan to ameliorate future impacts of climate change, but also to effectively respond to disasters if they occur, and reorganize to adapt to the future threats (Adger et al. 2005b, IPCC 2007, Cutter et al. 2008). For instance, through building radio warning systems, DRR can offer coastal communities in Vietnam with early information to relocate before the onset of violent floods and storms (Tong et al. 2012), while adaptation by restoring mangrove forests can provide the communities with improved livelihoods and natural buffers from the threats (Tri et al. 1998, UNDP 2011a).

Community resilience is generated from a set of resources such as personal health and household income (Norris et al. 2008) and from multiple actions embedded in DRR and 
CCA processes (UNISDR 2005b, Manyena 2006, IPCC 2012). DRR and CCA actions are essential tools to enhance $\mathrm{CR}$, but they cannot be undertaken without available resources. As such it is widely assumed that promoting the availability of resources will enhance CR. However, the availability of a resource might not be sufficient for building a resilient community because the resource could be less useful or even useless if it has low quality. In addition, different resources might not provide communities with the same capacities because they have different characteristics and functions. Thus building a resilient community requires insight into the availability and quality of resources as well as their roles in reducing risks from environmental threats.

\subsubsection{Five capitals framework}

The five capitals framework has been used to assess the adequacy of basic resources that communities need to enhance their resilience (Baral and Stern 2011). In the context of climate change, communities often invest and use a wide range of resources to promote the capacity to address climate climate risks and these resources are commonly classified into five forms of capital (Porritt 2007, Tinch et al. 2015). First, financial capital denotes economic resources, which exist in different forms including cash, savings, income, insurance, and credit (Mayunga 2009). Financial capital might shape the success of measures to enhance $\mathrm{CR}$ and reduce climate risks. For instance, available money allowed communities on the island of Samarto in Philippines to build storm-resistant houses (Gaillard et al. 2009), while insufficient financial resources prevented residents of the Hai An commune in Quang Tri province from purchasing the nessessary boats to respond to annual floods (Few and Tran 2010). 
Secondly, social capital refers to social resources that are embedded in social relationships (Lin 2001). Social capital consists of networks, trust and norms, which enable actors to act together more effectively to pursue shared objectives (Putnam 1995). As such, some contend that social capital is an essential element for CR (Aldrich and Meyer 2015). For example, a high level of trust among members of a network helps them feel self-confident and safe, while mistrust might make them feel insecure about providing their personal information (Pretty 2003). This example also suggests that assessments of social capital should consider the availability and quality of social resources and their interplays.

Another important resource for CR is human capital, which refers to resources embodied in individuals rather than social relationships (Lin 2001). Knowledge, skills, attitude, behaviour, and health of individuals (Pennings et al. 1998, OECD 2001, Brondizio et al. 2009) are considered as important dimensions of human capital for building resilient communities. For instance, individuals with good health might better withstand climatic stresses than those who have ill health (Poortinga 2012). Another example is that people with developed engagement skills commonly have the ability to facilitate and mobilize efforts from other members, and to promote the collective capacity of their community as a whole (Goodman et al. 1998). Yet, human resources such as skills and knowledge might not automatically generate the overall resilience of communities because they are also dependent on the attitudes and behaviours of community members.

Communities cannot exist without natural capital, which refers to both non-renewable resources such as coal and oil reserves and renewable resources, for instance plants and fresh water (Costanza and Daly 1992). Since natural capital exists in diverse forms, it can 
offer communities various capacities to adapt to climate change. For example, coral reefs provide coastal communities with income through fisheries and tourism (Cinner et al. 2011), while mangrove forests are not only natural barriers against storms, but also serve as accumulation sites for sediment and contaminants (Tri et al. 1998, Alongi 2002, UNDP 2011a). Yet benefits from coral reefs and mangrove forests can be reduced or even lost if these resources are damaged (Cinner et al. 2009b). Hence, it is essential to examine states of natural capital that coastal communities have for building their resilience.

Finally, enhancing CR requires physical capital, which exists in produced materials such as buildings, roads, and vehicles (Porritt 2007). Different physical resources might not provide communities with the same capacities as they have different attributes and functions. For example, warning systems provide communities with timely information to evacuate to safer areas, while early emergency systems are used to anticipate climatic conditions and plan for risk reduction (Ewing et al. 2010). In some cases, more resistant materials might provide communities with higher levels of $\mathrm{CR}$, but the resistant capacity of physical materials is not infinite and can be broken if the disturbance exceeds their resistance, such as the failure of levee systems by flood surges induced from the Hurricane Katrina in August 2005 (Colten et al. 2008).

Many studies on DRR, CCA and CR have explored and evaluated the essence of each capital for reducing climate risks (Adger 2003, Colten et al. 2008, Cinner et al. 2009a, Baral and Stern 2011, Poortinga 2012), but little effort has been made to gain insight into the interplay among all the five capitals. For instance, although Baral and Stern (2011) used a quantitative approach to identify the correlations amongst the five capitals, the 
knowledge about how each capital is shaped by the availability and quality of others remains unclear. Each capital uniquely produces CR and the success of DRR and CCA, but it might also be dependent on others (Figure 2-2). For example, many residents in the Nam Dinh province of Vietnam found jobs in Hanoi through their social networks (Adger et al. 2002) and these networks can only be built and maintained on the basis of social trust among actors (Pretty 2003). Therefore, CR and the success of DRR and CCA measures can be shaped not only by each of the five capitals, but also by their interplays.

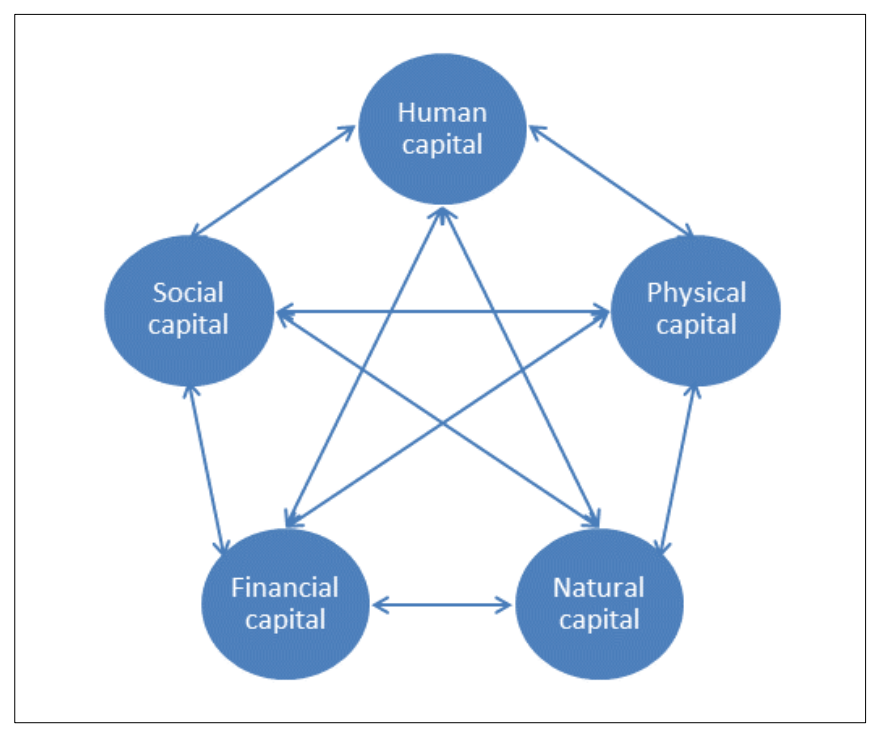

Figure 2-2: Five capitals framework

Source: adapted from Bebbington (1999) and Porritt (2007)

\subsubsection{Roles of multiple scales in evaluating responses to climate change}

Temporal, spatial and jurisdictional scales (Gibson et al. 2000) are commonly considered for evaluating opportunities and constraints of responses by coastal communities to a changing climate. First, temporal scale is used to understand how social-economic and environmental phenomena such as climate hazards vary and how communities deal with the threats over time. For example, local knowledge on the seasonal variability of 
weather and climate can provide farmers with information on when weather is favourable to start their rice crops, while the estimation of sea level rise from climate models is useful for coastal communities to develop long-term action plans in response to future climate change.

Secondly, some events can occur at certain locations, but others involve biophysical and socio-economic processes that vary geographically. Thus the assessment and development of DRR and CCA strategies to enhance CR requires knowledge about dynamics of such processes across multiple spatial scales. For example, downstream floods can be a consequence of upstream deforestation, which results from the use of fuel-wood and competition for agriculture land (Smil 1983, De La Paix et al. 2011). Therefore, spatial scale should be considered in the process of assessing climate risks and of enhancing CR.

Finally, CR is shaped by interactions across jurisdictional scale, which is defined by Cash et al. (2006) as linkages of political units such as communes and provinces. Since CR results from DRR and CCA policies, it depends on decisions made by actors across political structures. Actors with higher power tend to be given the opportunity to make decisions on allocation and distribution of resources (Lin 2001, Mustafa 2002). As such assessment of local interventions and development of strategies for enhancing CR and reducing risks of future climate change need to involve diverse actors across multiple jurisdictional levels.

Successful evaluation of $\mathrm{CR}$ as well as the success of DRR and CCA requires knowledge about interactions across the three scales (Cash et al. 2006). For instance, rice farming is currently an important livelihood in the Mekong Delta, but it will likely be replaced with 
shrimp aquaculture if rice farms are flooded by sea level rise in the future. However, farmers might not be allowed to convert their rice to shrimp farms if the decisions for the conversion have not been made by their provincial or district government.

In summary, this section critically reviewed the literature on climate risk, the five capitals CR, DRR and CCA. Research on climate risk is used to examine the actual or potential impacts that a climate hazard might have on a community. The impacts of a climate hazard are determined not only by the characteristics of the hazard including its typology, frequency, location, as well as spatial and temporal patterns, but also by those of the community including its vulnerability and resilience to the hazard. As such climate risk assessment needs to examine characteristics of both the hazard and the community.

The concepts of DRR and CCA are used to explore responses that communities employ to enhance their resilience and reduce climate risks, while CR is employed to obtain insight into the capacity that communities have and invest to address climate hazards through DRR and CCA. Specifically, knowledge about resources is useful to unpack factors that influence $\mathrm{CR}$ and the success of DRR and CCA practices. In addition, without considering spatial, temporal and jurisdictional interactions of these factors, $\mathrm{CR}$ might not be fully understood and enhanced.

In practice, CR, DRR and CCA have been increasingly accepted as key approaches to reducing climate risks. It is widely assumed that resilient communities are far less vulnerable to climate hazards (Klein et al. 2003, Cutter et al. 2008), thus enhancing CR is seen as a promising strategy to reduce the vulnerability of the community and climate risks (UNISDR 2005b, UNDP 2012). Recent research and practices tend to enhance CR by promoting the availability of resources. However, the availability of a resource is just 
an essential condition, but it is insufficient because the resource might be less useful or useless if it is of low quality or it damages others. As such evaluating and developing strategies for building resilient communities also need to consider the quality and the interplays amongst resources.

A growing body of research reveals that DRR and CCA are key approaches to enhancing $\mathrm{CR}$ and reducing climate risks because they provide communities with a diverse set of resources that are used for the communities to address climate threats (UNDP 2012, UNISDR and UNDP 2012). In addition, recent research also reveals that these approaches have both advantages and limitations and more importantly advantages of one approach could address drawbacks of the other (Wilbanks 2005, Mercer 2010, O'Brien et al. 2012). Thus the integration between the two approaches to enhance CR and reduce risks of future climate change has received an increasing attention from international communities and academics over the last decades (UNISDR 2005b, IPCC 2012, Rivera et al. 2015). However, the interactions between the two approaches and how they are integrated to successfully enhance $\mathrm{CR}$ and reduce climate risks remain questionable (Birkmann and von Teichman 2010, Lei and Wang 2014).

\subsection{Methodological approaches}

The purpose of this section is to discuss the rationales behind the use of a case study and of participatory action research (PAR) approaches for this research. In addition, the section provides a foundation for the effective use of these methods throughout the empirical research at later stages. It begins with a discussion about the benefits and drawbacks of quantitative and qualitative case studies. The section will then highlight the 
strengths and challenges of PAR and more importantly discuss strategies that could promote strengths and address challenges of PAR approaches.

\subsubsection{Case studies: quantitative and qualitative}

Case studies have been widely used as tools for generating and testing hypotheses in both natural and social sciences (Gerring 2004). They are useful for exploratory questions including "how", "why" and "what" questions because they foster an in-depth exploration of a single unit such as a project or a community in order to understand a larger class of similar units (Yin 1994, Gerring 2004, Simons 2009). Despite some limitations, such as less capacity for generalization and testing theories (Ragin et al. 2003), case studies are useful for research on complex phenomena as they allow the investigation of multiple perspectives of a subject in its real-life context (Simons 2009). A case study is also suited for a close examination of complex empirical processes, and for assessing the meanings that actors attach to their actions (Ragin et al. 2003).

A case study can use both quantitative and qualitative methods, but which method is appropriate for assessment of climate risks and $\mathrm{CR}$ is an important question because they both have advantages and limitations. Some prefer the former as it has a number of strengths that the latter cannot provide. For instance, quantitative methods can provide objective measurements, while observations from the qualitative methods are subjective and context-dependent. Another preference of quantitative methods is their ability to generalize and predict phenomenon, at certain levels of confidence, through statistical tests. For instance, Sherrieb et al. (2010) and Chen et al. (2008) use quantitative measurements to determine relationships between $\mathrm{CR}$ and biophysical and socialeconomic factors. 
Besides their strengths, quantitative methods also have limitations. To generalize and predict phenomenon, quantitative methods requires the statistically sufficient number of samples, while the large sample size usually requires significant logistical arrangement and high cost. Moreover, quantitative methods require homogeneity of study populations to generalize phenomenon, while most communities are highly stratified because they are characterized by diverse groups such as farmers involved in agriculture and aquaculture.

Even though qualitative methods have drawbacks, they can reinforce the limitations of quantitative research. The latter is less useful for heterogeneous communities or those in which only a few community members are involved in the case study. In these communities, the qualitative methods have their own advantages. For instance, an indepth interview with a few local residents from each group of a community can provide deep insight into their feelings, impressions and viewpoints or explore the root causes of attitudes rather than generalization through the statistical and numeral measurements.

\subsubsection{Community-based participatory action research}

\subsubsection{Importance of PAR for community resilience studies}

A large number of environmental change and CR studies are conducted with the aim of addressing climate change problems facing local communities. However, many such efforts have used communities as laboratories without engaging them in the research development and implementation process. For instance, in Vietnam studies that begin with climate change scenarios derived from global and regional climate models (MONRE 2009) have been widely used to assess climate impacts and formulate action plans at national and provincial levels (Kirsch-Wood 2015). Some contend that this research has the advantage of setting broader parameters for planning as the climate scenarios are 
framed within braider narratives regarding the future (e.g. broad themes for global development) (Urwin and Jordan 2008), but others also critique these approaches for not fully reflecting local contexts (van Aalst et al. 2008).

Various models of community engagement research exist, for instance community-based research, PAR, and community-centred research (Israel et al. 1998, Ross et al. 2010b). The terms are used interchangeably in the literature (Israel et al. 1998, Macaulay et al. 1999), but a fundamental distinction is the extent to which communities are engaged in the research process. For example, community-based research often emphasizes on placed-based research, which does not necessarily engage community members (Israel et al. 1998), while PAR focus on collaborative partnerships and co-learning between communities and researchers (Minkler 2005, Mapfumo et al. 2013).

PAR is defined variously, but it is widely accepted as a process in which community members who experience a problem collaborate with researchers as partners to develop practical measures to resolve the problem (Israel et al. 1998, Dakubo 2010). PAR is advocated for DRR, CCA, and CR because it provides the communities and researchers with various benefits. First, it can offer the communities with opportunities to be involved in the research process so that they identify climate risks and develop DRR and CCA strategies (IDRC 2012, Mapfumo et al. 2013). Some might argue that knowledge about CR can be obtained through approaches that do not need to engage communities. For example, the exposure of a community to floods can be estimated solely based on land elevation and flood mapping generated from remote sensing and GIS technology. However, without community consultation these approaches might not be able to identify 
who would be affected by the floods and to what extent, and perhaps the most importantly, the applicability of potential responses within the community.

In addition, PAR plays an important role in co-producing knowledge from multiple disciplines and various actors inside and outside of communities (Israel et al. 1998, Mapfumo et al. 2013). It can be used to involve diverse groups of community members such as groups of aquaculture, rice and fishery farmers and commodity traders. For instance, through participation, farmers can provide information about their production methods, while traders can provide farmers with market information. Another benefit of PAR is to strengthen collaboration among different actors within communities and brings different organizations together for a common purpose, thus promoting new relationships. For example, farmers and traders not only meet and share their experiences, but they also have opportunities to negotiate about their sales contracts for upcoming crops. However, the extent to which PAR is beneficial to both researchers and communities is dependent on how the approach is used.

\subsubsection{Challenges for PAR approach for community resilience studies}

\section{Complexity of communities}

The term "community" is used variably in literature. A community is a group of people with defining or shared characteristics. Community members can live in a geographically defined area such as a village or a country, or in distant places but they share some degree of identity such as interests, culture and/or beliefs (Cutter et al. 2008, Norris et al. 2008, Hardcastle et al. 2011). A shared identity is an essential element for the existence of a community, but contiguous geographical borders might not be necessary. For example, a 
group of aquaculture farmers can join together to become an aquaculture community even though they come from distant villages.

Communities can be but are not always homogenous units. In a community, there might be diverse groups of people as they share different identities, for example interests and norms (Kelly and Tullio 2011). These groups have different levels of social standing or political power, therefore they might have different roles and influence in decision making processes (Lin 2001, Wisner 2004). A small group of individuals might hold significant control over the rest of the community. For example, in Quang Tri province of Vietnam, only $2-3$ shrimp hatcheries operated during the 2000s, but most of shrimp larvae supply to shrimp farmers came from these hatcheries; thus the collapse of a small number of shrimp hatcheries could significantly affect shrimp producers within the province.

Communities can be considered as open systems, in which its entities not only interact with each other within the system, but also interplay with actors from outside. These relationships can be established among actors inside and/or outside the communities and they might be direct or indirect. For instance, villages in Vietnam are directly administrated by their communal government and they receive support from national policies through multiple levels of government. The interactions among communities and their external environment could be either positive or negative. For example, a community of shrimp producers can derive benefits from shrimp hatcheries, but they might be adversely affected by chemical factories nearby. 


\section{Risk from community engagement}

A growing body of research has engaged local communities in developing strategies to enhance their resilience and reduce adverse impacts of climate hazards and change. Earlier research reveals that community engagement might also bring physical, psychological, emotional, socio-political, economic harm to researchers and their collaborating communities (Ross et al. 2010b). Physical harm is commonly reported in biomedical studies such as drawing blood for samples (Prentice and Gordon 2001). In natural-social resilience studies, physical risks are seldom mentioned, but both researchers and communities can also be harmed when they are exposed to hazardous events, for instance conducting field surveys during storms and floods.

Community engagement might bring emotional harm to its participants. For instance, leaders of communal and provincial governments involved in a research can be embarrassed, or even lose respect if communities point out their corruption or excessive bureaucracy. Moreover, emotional risks also occur among community groups in meetings if their conflicts cannot be avoided or managed. As a result, the research can be vulnerable from the failure of collaboration or it may even be impossible to continue the project if the conflicts are not addressed in a timely manner.

Community members may be exposed to a variety of social risks when they are involved in research. In societies where democracy and freedom are low, human rights are not fully protected and people's lives are dependent on the support from governments, which is controlled and distributed by more powerful actors. In these societies, community members might be punished by others holding higher standing in different ways. For 
examples, local residents can be listed in "black books" and they would not be supported from their governments if they speak out their weaknesses and failures.

In many communities, especially in developing countries, men are often dominant in families and society, and women are more vulnerable to natural hazards (Wisner 2004). In these communities, women might be not allowed to take part in the research, and thus important issues of family, such as the violence that affect the daily life of women are not brought into discussions. Furthermore, when both men and women are participating in the research, the latter might not have opportunities to raise their ideas and opinions, they may not able to speak about them, or their voices may be simply overlooked or ignored. As a result, the concerns of women might be excluded from the research, and consequently measures to enhance the resilience of women are not considered.

Finally, community engagement is a dynamic and time-consuming process. For instance, researchers require time not only to create relationships with local communities through building trust and coordination, but also to train new members when someone from the research teams leave their position. As such the time needed for a project may exceed what researchers expect (Macaulay et al. 1999). For example, the participatory research of the UK researchers on integrated conservation and development was initially proposed for three years, but extended for 18 more months (Mistry et al. 2009).

\section{Enhancing effectiveness of community engagement}

Since community engagement not only provides benefits, but may also harm researchers and their collaborating communities, researchers need strategies and steps to maximize benefits and minimize risks from the research. The first step for community-engaged research is obtaining the acceptance of the community. Researchers might have 
opportunities to work with communities if they are welcomed, while the researchers will have difficulty learning communities if access is impeded.

Besides permission for physical access, community engagement might also need sociopolitical and cultural acceptance (Wüstenhagen et al. 2007). Fishermen in many coastal communities in Vietnam rarely welcome women on board their fishing boats. Some communities might ask researchers to show their informal references, while others may require official letters from agencies governing the communities. With these official letters, researchers can physically access and meet communities, but they might not be able to obtain useful information from their conversations if researcher(s) attitudes and behaviours annoy the communities.

Participation of communities is a necessary condition, but it might be less meaningful if they only participate passively. The research might not address the concerns of communities if research participants keep quiet and only offer passive responses and reception throughout the research (Mistry et al. 2009). Thus it is essential to promote community participation and this requires addressing a number of interrelated factors. One of the most important factors is trust among researchers and community members for two reasons. First, trust helps participants to be confident while interacting and collaborating; secondly mistrust commonly makes community members feel unsafe in providing their personal information (Ring and Van De Ven 1994, Pretty 2003).

Social trust is not static in any given relationships and it needs to be developed and maintained. Social trust can be built from preserving equality and fairness (Das and Teng 1998). For example, in a participatory workshop, a vulnerable group may mistrust the process if researchers only listen to advantaged members. In another case, trust could be 
lost if participants feel or believe they will receive less benefit than others, thus it is important to promote fairness and equality in terms of benefits and rights throughout the research process. Moreover, trust is also built and maintained from acknowledging personal and institutional histories, being present in the community and listening to community members, valuing the expertise of all partners (Christopher et al. 2008).

The effectiveness of community engagement could be enhanced through open communications. Throughout open discussions, communities provide information about their local context, and thereby research participants and researchers can identify their problems early and solve them before they get out of hand (Rogers 1987). Furthermore, open communications can also avoid unexpected misunderstanding between researchers and communities. For instance, community members can provide researchers with information about reasonable rates of payment, thereby researchers provide participants with appropriate compensation, and avoid misunderstanding that they are taking advantage of the community.

The success of community engagement also needs to provide incentives to research participants. There are many reasons why communities participate in research and why they might stop their participation. Participants may take part in research if they are paid (Mistry et al. 2009, Almany et al. 2010), or if they believe that participation can improve their knowledge and research skills as well as their relationship with other people. When the research does not provide benefits or incentives to the participants, their contribution or participation may be terminated. For instance, although partner researchers may not be interested in the research subject, they may participate just because they are assigned or 
forced to do so by their managers, and therefore they may not only work reluctantly and uncomfortably, but also produce low quality contributions to the research.

\section{Synthesis of Chapter 2}

Chapter 2 provided critical reviews of five areas of literature including climate risk, the five capitals, CR, DRR and CCA approaches, which have been used to address a changing climate. Although much effort has been made to explore the advantages and limitations of individual approaches, little has been known about implications resulted from their interplays. The reviews revealed that climate risk research is useful to provide insight into the biophysical and social-economic conditions that put communities at climate risk, while CR, DRR and CCA studies are employed to understand applicable ways to reduce the risks.

Enhancing CR is accepted as a promising tool to reduce climate risks because it provides communities with resources or a source of capacities to cope with changing climate. Recent studies tend to focus on the availability of several selected capitals, while less effort has been made to examine the quality of and interactions among the five capitals. Thus the evaluation and development of DRR and CCA strategies to enhance CR and reduce climate risks need collective examination of the five capitals as it provides better insight into the adequacy (availability, quality and interplay) of the five capitals.

In response to changing climate, DRR and CCA have been increasingly accepted as key approaches to enhancing $\mathrm{CR}$ and reducing climate risks as they provide communities

with a diverse suite of resources to address climate threats (UNDP 2012, UNISDR and UNDP 2012). These approaches have both advantages and drawbacks and more 
importantly the advantages of one approach could reduce the limitations of the other (Wilbanks 2005, Mercer 2010, O'Brien et al. 2012). As such the integration between the two approaches could promote $\mathrm{CR}$ and reduce the risks of future climate change (UNISDR 2005b, IPCC 2012). However, the interactions between the two approaches and how they are effectively integrated remain questionable.

Chapter 2 also provided a critical review of suitable approaches for CR research by examining the rationale behind the use of case studies and PAR approaches. Case studies are useful for examining complex processes and gaining deep insights into the feelings, impressions and concerns of local communities. PAR approaches provide communities with opportunities to be involved in the research process, in which they analyse climate risks and develop strategies to enhance their community's resilience and address the climate problems. However, the two approaches also have some challenges. For instance, $\mathrm{CR}$ research with use of PAR might fail if researchers are mistrusted by the communities. In order to enhance the success of PAR, various essential strategies should be adopted. For instance, researchers should consult with communities while developing the research proposal and constantly build trust with them throughout the research process. 


\section{CHAPTER 3: CLIMATE RISKS AND RECENT EFFORTS OF VIETNAM IN BUILDING CLIMATE-RESILIENT COMMUNITIES}

Chapter 3 provides insight into climate risks facing Vietnam's coastal communities and examines Vietnam's recent efforts to reduce these risks in order to provide a contextual foundation for designing and conducting the actual research. The chapter is structured into three sections. First, it offers an overview of biophysical and social-economic conditions that have placed the coastal communities at risk from a changing climate. Subsequently, the chapter critically reviews the efforts that Vietnam has recently adopted to enhance the resilience of its coastal communities and reduce the climate risk. Finally, it evaluates the success and limitations of these efforts before concluding the chapter.

\subsection{An overview of biophysical and social-economic conditions in Vietnam and coastal zones}

Vietnam is located in Southeast Asia and covers an area of about 332,000 $\mathrm{km}^{2}$. In 2013, the population of the country was approximately 90 million people (GSO 2014). Vietnam has about $3,260 \mathrm{~km}$ of coastline stretching across latitudes $8^{\circ} 27^{\prime} \mathrm{N}$ to $23^{\circ} 23^{\prime} \mathrm{N}$. The lowland areas of Vietnam are concentrated along the coast, mainly in two major river deltas, which are formed by the Red River in the north and the Mekong River in the south. The remaining three-quarters of the country are covered by mountains and hills and these topographical conditions create many short and steep rivers, causing violent floods in the downstream regions, especially those in the central coast (MONRE 2003).

The country has 28 coastal provinces and they are divided into three zones: North Coast, Central Coast and South Coast (Figure 3-1). The coast accommodates approximately 
$50 \%$ of the national population and has a higher density of population than the inland provinces, with 530,000 and 420,000 people per $\mathrm{km}^{2}$, respectively in 2013(GSO 2014).

The coastal population increased by 13\%, from 40 million in 1995 to 45 million people in 2013. The population density in both the South and North Coasts is approximately 800,000 people per $\mathrm{km}^{2}$, which is triple the population density in the Central Coast. However, the rural poverty rate in the Central Coast is nearly twice the average of Vietnam's entire coast (Arouri et al. 2015).

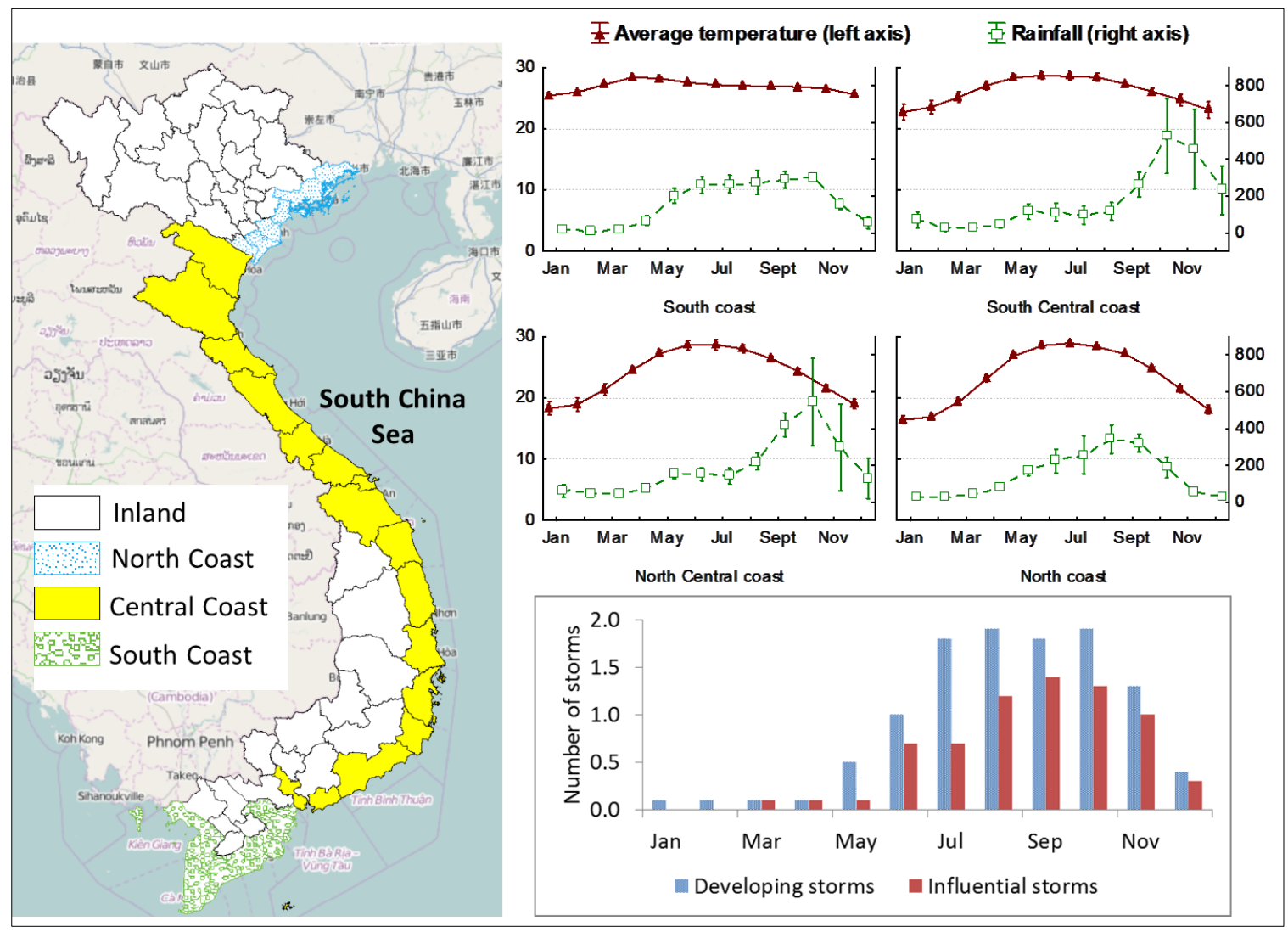

Figure 3-1: Map of Vietnam and monthly average temperature and rainfall (line graphs) in coastal Vietnam as well as the average frequency of storm over the past 50 years

Sources: data for line graphs come from Vietnam's National Hydro-meteorological Centre, while the bar graph was adapted from ISPONRE (2009)

Key economic activities such as agriculture, tourism and manufacturing industries are concentrated in the coastal zones and they have significantly contributed to national and 
local economies (Sekhar 2005, UNDP 2011a). Agriculture, aquaculture and fisheries used to play a major role in the national economy until 1992, when they were surpassed by the industrial and service sectors (Figure 3-2). Today, agriculture, aquaculture and fisheries contribute a smaller portion, approximately $19 \%$, to the national GDP, but they provide employment to $46 \%$ of the national population (MPI 2014).

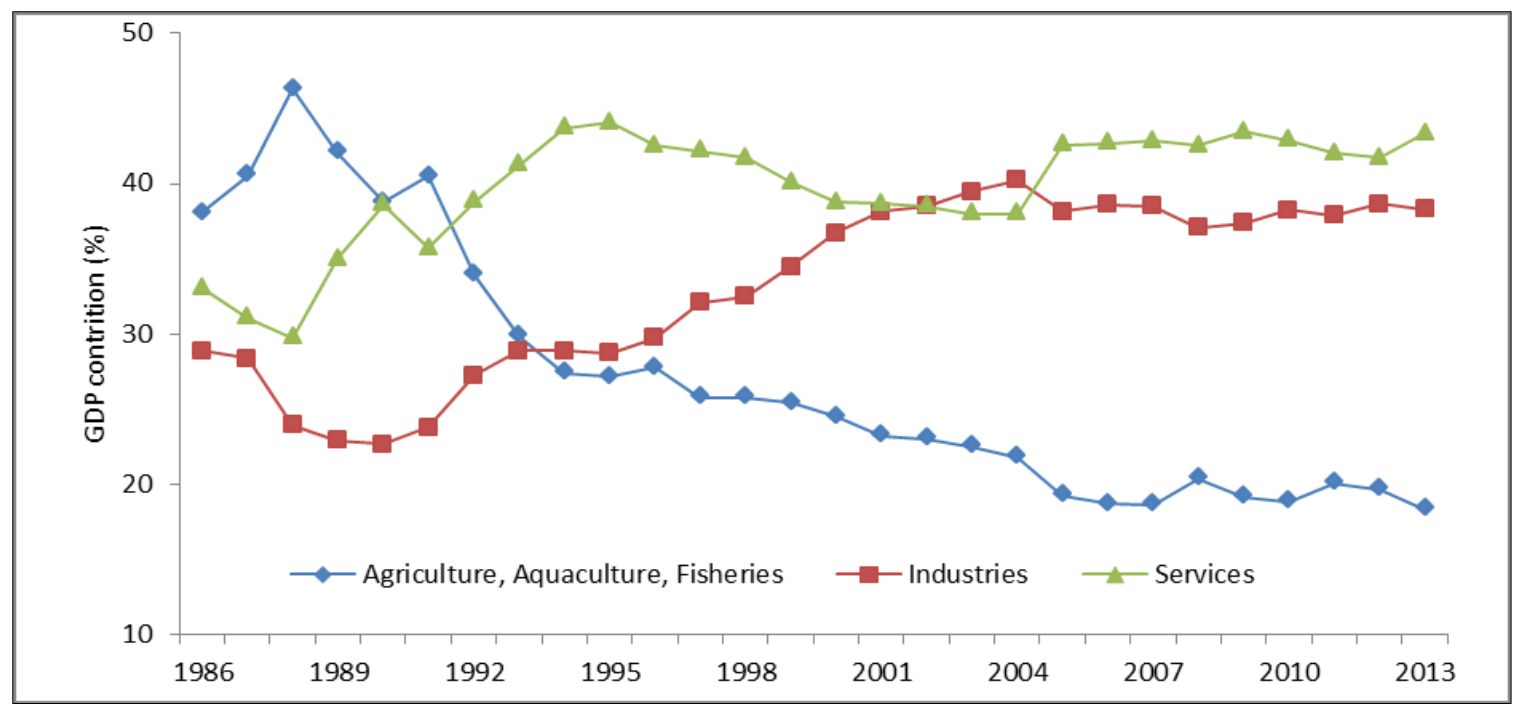

Figure 3-2: Trends in sectoral contribution to Vietnam's gross domestic products

Source: Data from Vietnam's General Statistics Office (GSO 2014) and the graph was produced by the author.

The coast is heavily affected by a combination of tropical monsoons and the South China Sea and such impacts vary across the country and over time (MONRE 2003). The South Coast has an equatorial climate characterized by a two-season cycle, with high temperatures throughout the year and rainfall is concentrated between May and November. In contrast, the North Coast is characterized by lower temperatures and dry climate between November and January, but high temperatures and concentrated rainfall occur between May and September. 
The Central Coast includes 13 provinces and is divided into North Central Coast and South Central Coast. There are different climate regimes between the two sub-regions because they are separated by Bach Ma Mountain, which is up to 1,400 meters high. The North Central Coast is characterized by both northeast and southeast monsoons with four seasons, but the South Central Coast is warm throughout the year and it has dry and wet seasons associated with the south-easterly wind (Figure 3-1). Both regions experience the dry season between January and July, while they are impacted by floods during August and November as the rainfall is concentrated in this period.

Given a long coastline as well as the geographical, topographical and climatic diversity, the climate risk across Vietnam's coastal communities is wide ranging and includes both gradual and rapid onset climate processes (GOV 2007b). Storms, floods, flash-floods, landslides and whirlwinds are well known as rapid hazards, while droughts, saline-water intrusion, and inundation are common prolonged and gradual stressors (CCFSC 2001). In addition, sea level rise and tidal flooding are reported as emerging impacts of climate change on coastal communities (MONRE 2009).

Lives and properties of coastal communities, especially in the central coast, are often disrupted and threatened by climate hazards. For instance, the 2009 Ketsana storm not only killed 179 people and injured 1,140 others, but it also damaged 9,770 houses, 13,147 clinic centres, and 5,581 schools across 15 central provinces (CCFSC 2009b). As a secondary disaster, the flood induced by the Ketsana storm caused a loss of 100,000 ha and 18,000 ha of rice and aquaculture production, respectively (CCFSC 2009b). In the long term, the impacts of climate hazards are projected to be aggravated by future climate change because most of Vietnam's population lives in low-lying river basins and the 
coastal areas (IPCC 2007, UNDP 2011a). The observed and expected impacts of the changing climate will be illustrated further in Section 3 .

\subsection{Vietnam's recent efforts in response to a changing climate}

The review in the preceding section reveals that coastal communities in Vietnam have been at risk from a wide range of climate hazards and climate risks will likely be magnified by future climate change. This section reviews the efforts the country has made over the last two decades to address the changing climate. It starts with illustrating the commitment of the Vietnamese government in response to climate threats. The section will then review the interventions that Vietnam has recently adopted to enhance the resilience of its communities and reduce risks from the changing climate.

\subsubsection{Commitment of Vietnam's national government in response to a changing climate}

The Vietnamese government has strongly committed to efforts to reduce adverse impacts of routine climate hazards and future climate change. It has participated in an international agenda, with its ratifications of the United Nations Framework Convention on Climate Change in 1994, the Kyoto Protocol in 2002, and the United Nations International Strategy for Disaster Reduction in 2005. At the national level, in 2007 the Vietnamese government approved a National Strategy on Disaster Prevention, Response and Mitigation to 2020 (NSD), and one year later a National Target Program on Response to Climate Change (NTP) was also launched.

The NSD builds on a long-standing institutional system established and executed by the Central Committee for Dyke Maintenance as soon as Vietnam obtained liberation 
following the Second World War in 1945. Since 1955, the system has been executed by the Central Committee for Flood and Storm Control with support from various legal enactments such as the Ordinance on Dykes (1989), the Ordinance on Flood and Storm Control (1993) and the Law on Dykes (2006). In 2007, the NSD was launched with the goals of reducing losses of human life and destruction of natural, economic and cultural resources (Table 3-1).

Table 3-1: Overviews of the National Strategy on Disaster Prevention, Response and Mitigation to 2020 (NSD) and the National Target Program on Response to Climate Change (NTP)

NTP

Strategic

objective or goal

Specific objectives

1. Enhance the capacities of forecasting natural disasters, for instance floods, storms, droughts;

2. Integrate the strategy and plans of disaster prevention, response and mitigation into master socio-economic plans and sectoral plans;

3. Strengthen the capacities of local staff and vulnerable communities about disaster prevention, response and mitigation;

4. Relocate populations at high risk to safety places.

5. Collaborate and coordinate forces of search and rescue for emergency responses;

6. Enhance the dyke systems;

7. Ensure safety for reservoirs;

8. Build storm shelters for boats and ships.

9. Provide all offshore fishing boats with on-sea safety equipment.
Assess climate change impacts on sectors and regions; develop feasible action plans to effectively respond to climate change; to ensure unstainable development; to develop towards a low carbon economy for climate change mitigation

1. Assess the impacts of climate change;

2. Identify appropriate responses

3. Developing a scientific-technical program;

4. Develop specific action plans to respond to climate change

5. Raise awareness across the country;

6. Enhance international cooperation;

7. Mainstream the NTP among sectors across multiple levels of government;

8. Strengthen capacity and the policy framework in the relevant organizations and institutions.

Sources: summarized from the NSD (GOV 2007b) and the NTP (GOV 2008).

In realising these goals, nine specific objectives were included in the NSD (Table 3-1).

Traditionally, Vietnam focused on preparedness and response, with a strong emphasis on 
structural measures such as dykes and seawalls (Smyle 2014). The NSD largely follows the same approach, but pays more attention to enhancing non-structural capacities. For instance, the NSD was expected to enhance the ability of forecasting natural disasters, especially floods and storms and the capacities of local staff and vulnerable communities for disaster prevention, response and mitigation (Table 3-1). The NSD implementation will be discussed later in this section.

The NTP was introduced with the ultimate goal of responding effectively to climate change in both the short and long-terms and to ensure the sustainable development of Vietnam toward 2020 (GOV 2008). The NTP provides a guiding framework for both climate change adaption and climate change mitigation and it is expected to support the NSD. The NTP program has been expected to realise its nine specific objectives by the year 2015. The NTP process starts with assessing impacts of climate change on sectors and communities across multiple scales. The outcomes of the assessment are then used to formulate action plans in response to climate change. Finally, action plans are deployed to address climate change. Discussions on how the NSD and NTP programs have been implemented to achieve these objectives will be made later in this section.

\subsubsection{Vietnam's recent efforts in response to the changing climate}

\subsubsection{Institutional arrangement and the implementation of the NSD}

The NSD is led by the Central Committee for Flood and Storm Control, which is chaired by the Ministry of Agriculture and Rural Development (MARD), with assistance from many other relevant ministries (Figure 3-3). This committee has three overarching responsibilities (GOV 2007b). First, it directs and inspects ministries and localities while

implementing the NSD. Second, the committee develops national action plans, identifies 
priorities, and assign the responsibilities for ministries, sectors and localities. Finally, it monitors and evaluates the implementation of the NSD.

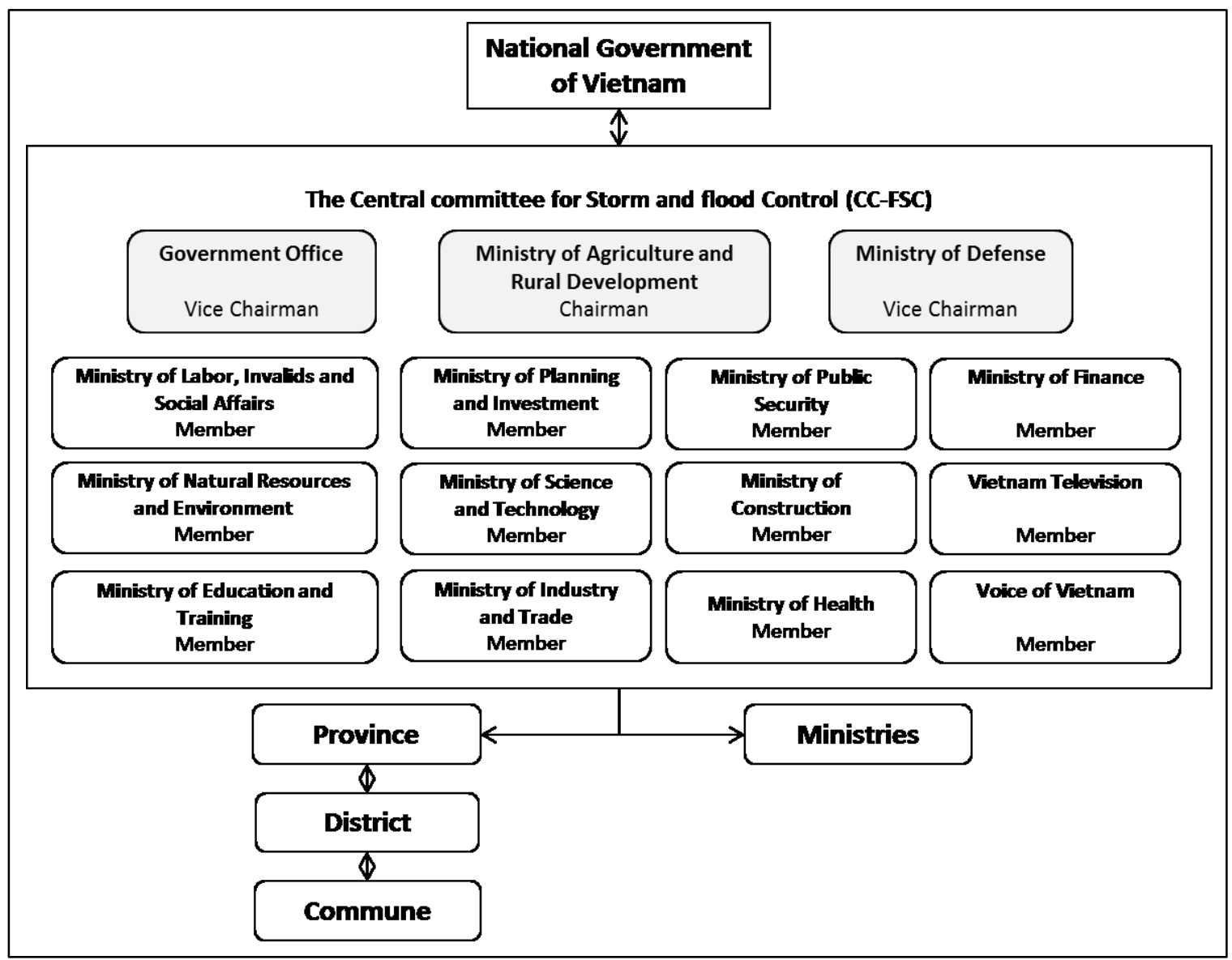

Figure 3-3: Institutional framework for the National Strategy on Disaster Prevention, Response and Mitigation to 2020 (NSD)

Source: synthesised from the NSD (GOV 2007b).

Diverse actors from all levels of government are involved in the process of formulating and implementing the NSD. Upon the approval of the NSD, all relevant ministries and provinces established their own committees and developed action plans to implement the NSD (Nguyen 2010a). Ministries and provinces are required to integrate their action plans horizontally and vertically. For instance, MARD is required to link its action plan with those of Ministry of Natural Resources and Environment (MONRE) and Quang Tri 
province. Yet, a review by Nguyen (2010a) shows that collaboration and coordination among sectors and across levels of government in many provinces remained weak.

At the provincial level, the NSD is executed by the provincial Committee for Flood and Storm Control, Search and Rescue, which is led by the Provincial People's Committee ${ }^{1}$ and receives the assistance from the provincial Department of Agriculture and Rural Development (DARD) as a standing vice-chair. DARD coordinates and directs other provincial departments as participating members. At lower levels, district and communal governments are also required to establish Committees for Flood and Storm Control, Search and Rescue.

Since the introduction of the NSD, a large number of projects have been deployed across the country, especially in the coast, to address natural hazards (Table 3-2). These projects are classified into two groups: non-structural and structural intervention. The former aims to improve the social, financial and human capacities as well as natural resources, while the latter is expected to enhance the physical capacities. However, structural projects concentrate on addressing floods and storms, for instance building and upgrading sea dyke systems and storm shelters for boats and ships, while the country is also threatened by many other hazards such as droughts and salinization.

\footnotetext{
${ }^{1}$ Vietnamese provinces are each controlled by a People's Council, which is elected by its inhabitants. The People's Council appoints a People's Committee, which acts as the executive arm of the provincial government. This arrangement is a simplified version of the situation in Vietnam's national government. Provincial governments are expected to be subordinate to the central government, and direct the government at district and communal levels.
} 
Table 3-2: Categories of disaster risk reduction measures funded by the Vietnamese government to support the National Target Program on Response to Climate Change towards 2020

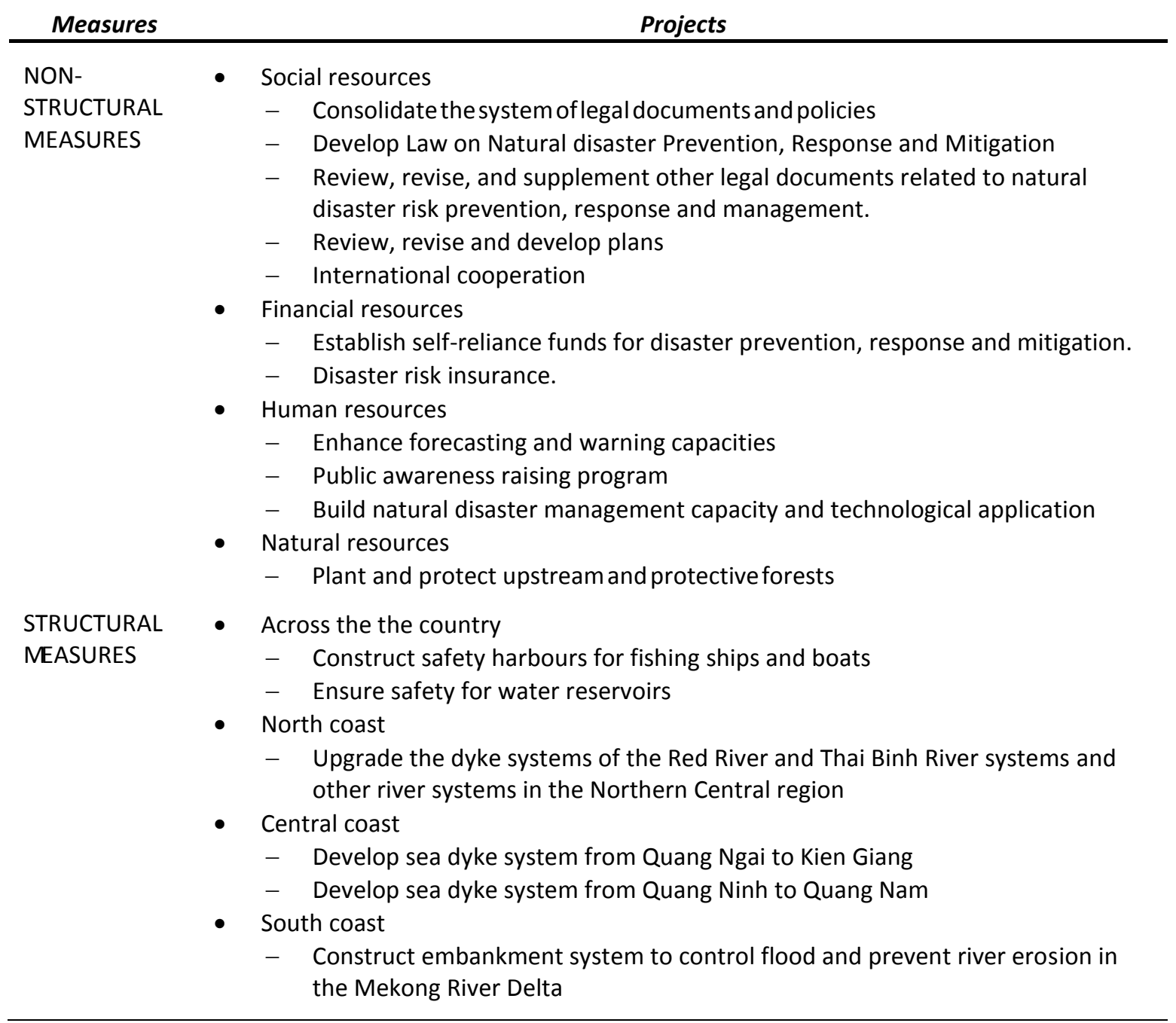

Source: summarized from the Implementation Plan of the National Strategy for National Disaster Prevention, Response and Mitigation to 2020 (CCFSC 2009a).

\subsubsection{Institutional arrangement and the implementation of the NTP}

The NTP is led by the National Steering Committee, in which MONRE is the national focal agency to direct and coordinate participating ministries and all activities in response to climate change (Figure 3-4). The committee receives assistance from its Executive Board, which consists of MONRE as a chair and other ministries as participating members. Like the NSD, all relevant ministries and provincial governments are required 
to establish their own steering committee, which is responsible for developing and implementing the action plans for the NTP in their sectors and provinces.

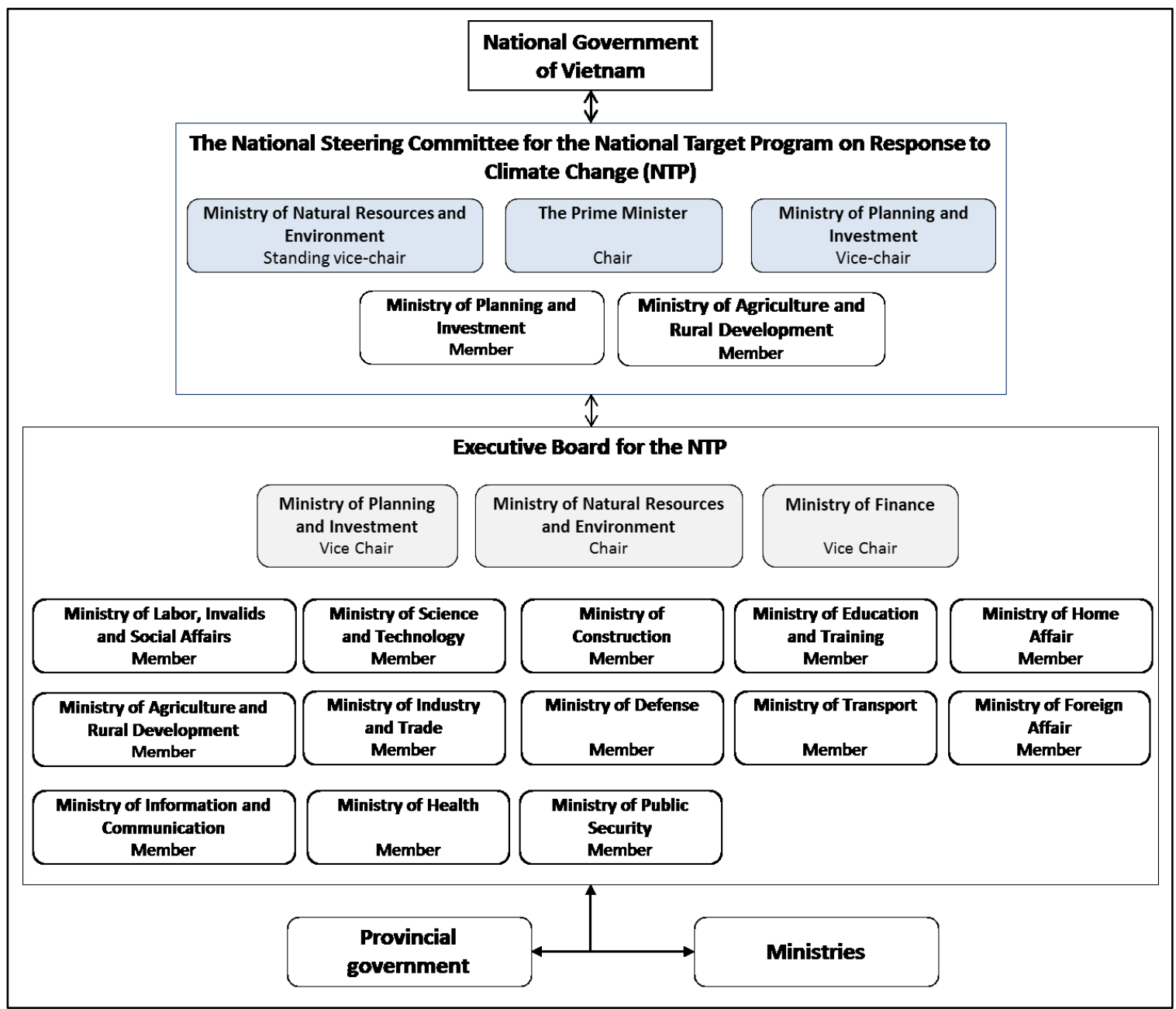

Figure 3-4: Institutional framework for the National Target Program on Response to Climate Change (NTP)

Source: synthesised from the NTP (GOV 2008).

Since the NTP was introduced, MONRE has initiated fundamental studies that provide relevant ministries and provinces with scientific foundations for formulating their action plans. For instance, MONRE conducted the assessment of climate change impacts and developed climate change scenarios, especially those for sea level rise along the Vietnam coast (MONRE 2009). In 2013, the action plan for the NTP implementation at the 
national level was approved by the Prime Minister. Some provinces such as Kien Giang and Da Nang developed their provincial action plans before 2013, while many other provinces and ministries waited for the guidance and the framework from the national action plan.

As of 2014, all provinces and most ministries and sectors had their own action plans for the NTP implementation towards 2020 and these plans were formulated mainly based on global and regional climate models (Kirsch-Wood 2015). The plans are particularly important for provinces and sectors because they provide guiding frameworks to address the changing climate. However, the climate models are critiqued for their high level of uncertainty (Dowlatabadi and Morgan 1993, Dowlatabadi 1995) and their disconnection from local conditions. Thus, the action plans of provinces and ministries might not fully reflect the local contexts.

\subsubsection{Integration between the NSD and NTP across multiple scales}

The NSD and NTP programs are executed by two separate institutional systems and they have substantial overlap. Some effort has been made to promote institutional connections between the two programs, such as national workshops, where ministries and provinces contributed their collective inputs to formulate the national action plans for disaster risk management and climate change impact assessment (Smyle 2014). Yet, the integration among institutions remains limited (Nguyen 2010a, Kirsch-Wood 2015).

Recognizing institutional and practical challenges of the NSD and NTP implementation and integration between the two programs, there is an urgent need for developing a national platform, which is used to collaborate, coordinate and mobilize the efforts from actors from both the institutional systems (Kirsch-Wood 2015). MARD was tasked, in 
collaboration with MONRE, to lead the process of establishing the national platform as soon as the NTP was issued. Several draft versions of the platform have been developed, but are not yet finalized and approved by the Vietnamese government.

\subsubsection{Addressing climate hazards at the community level}

The NSD and NTP programs were recently introduced, but Vietnam has a long history of dealing with climate hazards at the local level. For instance, $5,000 \mathrm{~km}$ of river dykes and $3,000 \mathrm{~km}$ of sea dykes have existed for over 1,000 years to protect coastal communities from annual floods (Chaudhry and Ruysschaert 2007). Since the 1990s, various DRR and CCA projects have been implemented to enhance CR and reduce climate impacts. For example, mangrove forests in many coastal communities of Thai Binh province were restored in the early 1990s (Tri et al. 1998), while in the past decade, a number of stormresistant houses and public shelters across the country were built (UNDP 2011a).

Coastal communities have addressed climate hazards through non-structural and structural interventions. For instance, local residents in Quang Tri province not only built concrete houses rather than less resilient cottages, but they were also trained in rescue and first aid skills and on how to prepare food for flood seasons (Oxfam 2008, Tong et al. 2012). Projects at the local level tend to combine structural and non-structural measures. For example, a project implemented in 2007 by Viet Nam Red Cross in eight provinces of North Coast and North Central Coast coupled plantation of mangrove forests with raising awareness of local communities about the importance of mangroves.

Five capitals (physical, human, social, natural and financial resources) in many coastal communities have been improved through DRR and CCA. For instance, Development Workshop France helped many families in Thua Thien Hue affected by the 2006 
Xangsane storm to rebuild houses and develop livelihoods as well as to raise their awareness of storms. In addition to these projects, Viet Nam Red Cross helped coastal communities in the northern and central provinces to plant and protect mangrove forests, while Care International in Viet Nam improved social resources across Vietnam by promoting community-based disaster risk management advocacy network initiatives. While recent projects addressed several capitals individually, efforts to combine and coordinate across all the five capitals to enhance $\mathrm{CR}$ and reduce climate risks have not received much attention.

In response to changing climate, coastal communities have received external assistance to implement DRR and CCA measures. For instance, Japanese Red Cross supported coastal communities of eight northern and north central provinces to plant mangroves forests against future storms and the resulting surges. The external assistance is important for local communities, but it is not always available (Well-Dang 2012). Thus local communities have developed their own measures to reduce disaster risks and adapt to climate change. For example, many residents in Thua Thien Hue elevated the floors of their houses to reduce flood risks (Okamoto et al. 2013).

Many projects, especially those sponsored by international agencies have used bottom-up approaches to engage local communities in formulating and implementing DRR and CCA measures. For instance, between 2001 and 2004, the Centre for International Studies and Development engaged Quang Dien and Phu Vang districts in the process of planning and implementing community-based adaptation strategies. However, some research reveals that many other projects used top-down approaches as a result of the 
centralized planning mechanism in the past decades (Tong et al. 2012), consequently local communities might not be actively involved in DRR and CCA projects.

\subsection{Recent trends of community resilience and climate impacts in coastal Vietnam}

This section evaluates the success and limitations of Vietnam's recent efforts to address

climate risks by examining the recent trend of $\mathrm{CR}$ and climate impacts in the coast of Vietnam. It starts with evaluating the extent to which the resilience of Vietnam's coastal communities has been improved over the last three decades. Secondly, the section evaluates the degree to which the recent effort of Vietnam has reduced historical impacts of climate hazards.

\subsubsection{The resilience of Vietnam's coastal communities in the face of changing climate}

Vietnam has had significant success in economic development over the last three decades. The country has transitioned from extremely poor in 1986 to a lower middle income country in 2009 , with an annual growth rate of national domestic products ranging from 5.8 to $8.5 \%$ for the period of 2000 and 2013 (GSO 2014). This economic success has enabled the country to implement many projects aiming to reduce climate risks as illustrated in Section 3.2. However, the rapid economic development has also eroded the resilience of and magnified the vulnerability of coastal communities in the face of changing climate. The impacts of the economic development on the resilience of Vietnam's coastal communities are illustrated as follows: 
Economic development on the western side of the country has made coastal communities on the eastern side more vulnerable to climate hazards. The development of hydropower plants on mountains in central provinces is an example. With the expectation to continue economic growth at $8.5 \%-9.0 \%$ for the period between 2006 and 2010, Vietnam promoted hydropower development to meet the growing demand of power supply (GOV 2007a). Hydropower plants have bloomed in most central provinces over the last two decades. These plants play a vital role for the national and local economies, but they have also made downstream communities more vulnerable to climate hazards. For example, local and national mass media reported the breakage of various hydropower dams due to floods induced by the tenth storm of 2013 in coastal provinces such as Thanh Hoa and Binh Dinh. The damage of the dams threatened thousands of people living in communities around the plants and the downstream regions.

It is widely known that the more a community and its property are exposed to hazards, the higher risk they might face. While Vietnam's coasts have been increasingly threatened by a changing climate, economic development has also magnified the property value of communities in coastal zones. Many places across the coast have become industrial centres. For instance, the number of manufacturing enterprises has increased by 1.5 times for the period of 2000 to 2007 (Table 3-3) and capital investment has increased by 5 times. Besides heavy industries, the number of coastal agricultural, aquaculture and fishery farms has been tripled, from 25,000 farms in year 2000 to 75,000 farms in 2010 . 
Table 3-3: The demographic change and development of economic activities in Vietnam and coastal zone between 1995 and 2012

\begin{tabular}{lcccc} 
Indicators & Year based & \multicolumn{2}{c}{ Increase (\%) } & Period \\
\hline & & Coastal provinces & National \\
Employment from enterprises & 2000 & 89 & 222 & $2000-2007$ \\
Out-migration & 2005 & 8 & NA & $2005-2011$ \\
Population & 1995 & 13 & 23 & $1995-2012$ \\
The number of farms & 2000 & 300 & 260 & $2000-2010$ \\
The number of fishing vessels & 1995 & 359 & 359 & $1995-2012$ \\
The number of manufacturing & 2000 & NA & 158 & $2000-2007$ \\
enterprises & & & 426 & $2000-2007$ \\
Capital of enterprises & 2000 & 503 & \\
\hline
\end{tabular}

Source: GSO (2012) and the table produced by the author. NA denotes no available data

Coastal industrialisation has significantly contributed to Vietnam's national and local economies and employment increased by $89 \%$ during the period from 2000 to 2007 (Table 3-3). However, the industrialisation has also caused demographic changes as a result of massive migration across the country. Approximately $8 \%$ of coastal population moved for work to larger cities and industrial zones such as Ho Chi Minh City and Binh Duong between 2005 and 2011 (Table 3-3). Outmigration also contributed to the growth of the coastal population, which increased by $13 \%$, from 40 million in 1995 to 45 million people in 2011. The growth of coastal population and density has made coastal communities more exposed to climate hazards.

Some argue that migration could provide migrants with various benefits such as jobs and the resulting remittances (Adger et al. 2002). However, the migration to industrial zones might also reduce the human and social capacities of Vietnam's coastal communities to address climate hazards for two reasons. First, a vast majority of migrants are commonly young and middle age (Paris et al. 2010) and this results in the loss of vital human resources to their families and communities and reduces their capacities to address climate hazards. Secondly, the migration of men and youth also puts rural communities at 
higher risk because they leave women, children and the elders at home and they are seen the most vulnerable members of the population in terms of hazard risk (Wisner 2004). For these two reasons, the provinces in the North Central Coast might have fewer human resources to address changing climate than those in the North Central and South Central because they have lower proportions of residents aged between 18 and 59 years old, while children and the elderly occupy a large majority of their populations (Figure 3-5).

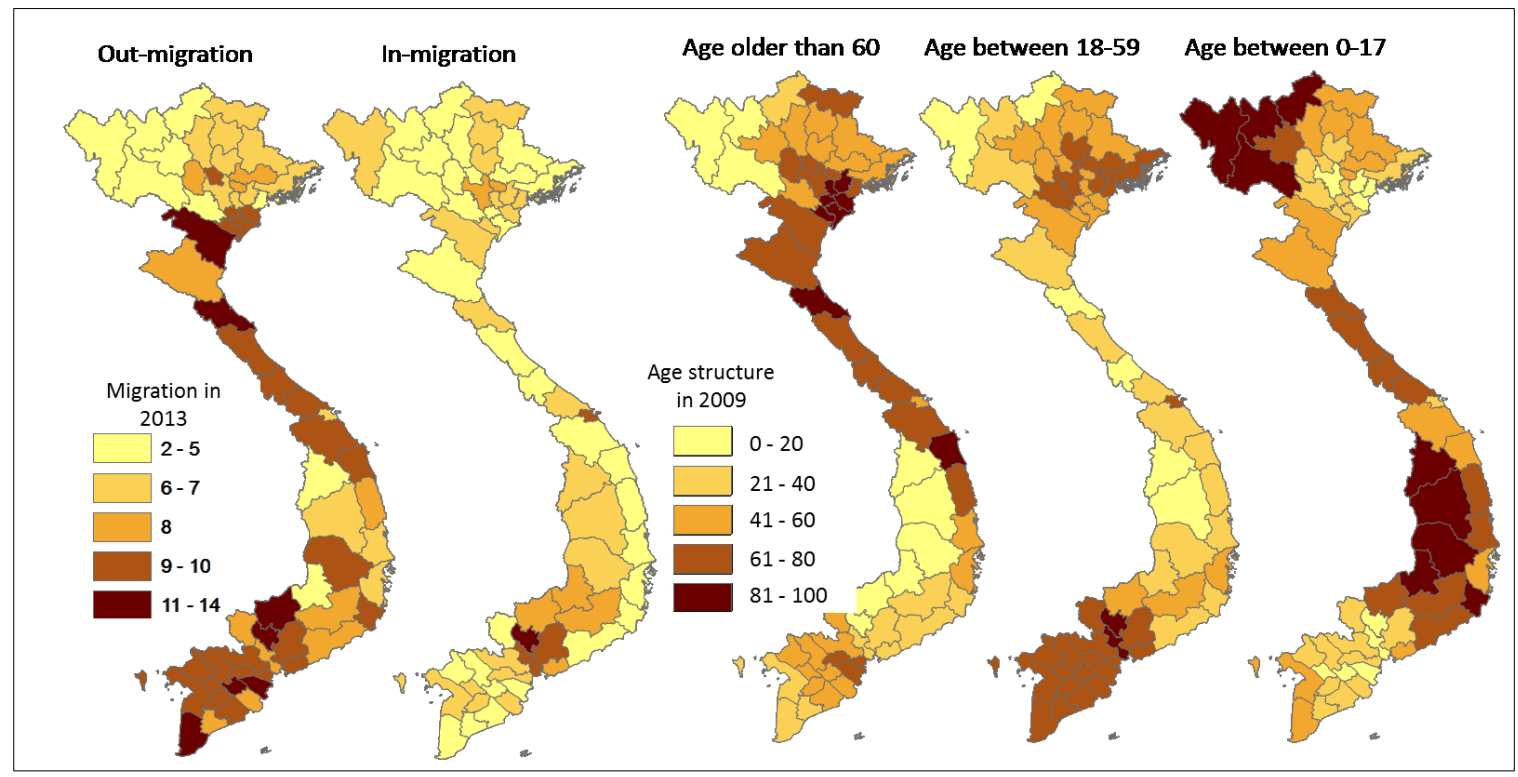

Figure 3-5: The pattern of the 2013 migration by provinces (the first two left maps) and by the 2009 age structure (the three first right maps).

Source: the author used data from (GSO 2014) and (GSO 2010) to make the ArcGIS maps of migration pattern and age structure, respectively

The resilience of coastal communities has also been eroded because their natural capital, especially coastal and marine resources, has been degraded from the rapid economic development. Recent research shows that manufacturing industries have released a large amount of pollutants, such as toxic chemicals and dusts, to coastal environments (ICEM 2007). In addition, many important coastal ecosystems have been damaged. For instance, a large area of mangrove forests was converted to shrimp farming (MARD 2009), while 
the extent of coral reefs in various places such as Nha Trang Bay and Co To Archipelago has been reduced due to explosive and dredging fisheries (Ngai et al. 2013, Nguyen et al. 2013a). The destruction of such ecosystems not only impedes the supply of ecological services, but it also makes coastal communities more exposed to climate hazards.

Although Vietnam has been successful in economic development, coastal communities have limited financial resources. For example, the national survey in 2010 reveal that over $20 \%$ of the households in the North Central Coast still lived in poverty (Arouri et al. 2015). In addition, coastal communities are highly dependent on the income from agriculture, aquaculture and fisheries (GSO 2012) and these livelihoods are highly sensitive to changing climate (IPCC 2007). Some comment that livelihoods from crops can be more secured through crop insurance schemes (Panda et al. 2013, Falco et al. 2014). The Vietnamese government launched a national program on agricultural insurance to support rural communities in the context of climate hazards, but the program is still in the pilot phase.

Vietnam has invested extensively in physical resources to reduce the adverse impacts of changing climate. For instance, approximately $8,000 \mathrm{~km}$ of dykes were built to protect coastal communities from annual floods (Chaudhry and Ruysschaert 2007). However, the availability and quality of physical resources that coastal communities use to address changing climate remain limited. For example, at the community level, the existing sea and river dykes have been degraded (UNDP 2011a), while at the household level, many families in My Ngai community of Dong Thap province did not have boats to deal with annual floods (Few and Tran 2010). 


\subsubsection{Historical and projected impacts of climate change}

Historical data reveals that Vietnam has suffered from climate-related hazards. Storms, floods, flash floods, landslides and hailstorms are rapid onset hazards that commonly cause devastating tolls of human life and properties (Table 3-4). Over the last two decades, the country has experienced more than 1,400 climate-related hazards that caused human and economic losses. These hazards killed and injured more than 110,000 people, and damaged approximately one million houses between 1989 and 2010.

Table 3-4: Human and economic impacts of key natural hazards in Vietnam during 1989 and 2010

\begin{tabular}{lrrrrrrrr} 
& \multicolumn{1}{l}{ Frequency } & \multicolumn{2}{c}{ Injuries } & \multicolumn{2}{c}{ Deaths } & \multicolumn{2}{c}{ Damaged houses } \\
\cline { 2 - 9 } Hazards & Inland & Coast & Inland & Coast & Inland & Coast & Inland & Coast \\
Storm & 71 & 157 & 1,473 & 2,122 & 770 & 1,690 & 106,621 & 119,602 \\
Flood & 292 & 400 & 2,484 & 92,380 & 3,317 & 2,589 & 170,566 & 403,851 \\
Hailstorm & 212 & 95 & 1,281 & 363 & 2,211 & 449 & 191,157 & 34,911 \\
Landslide & 51 & 9 & 448 & 45 & 881 & 91 & 7,838 & 6,172 \\
Flash flood & 86 & 20 & 592 & 38 & 584 & 78 & 38,308 & 11,007 \\
Total & $\mathbf{7 1 2}$ & $\mathbf{6 8 1}$ & $\mathbf{6 , 2 7 8}$ & $\mathbf{9 4 , 9 4 8}$ & $\mathbf{7 , 7 6 3}$ & $\mathbf{4 , 8 9 7}$ & $\mathbf{5 1 4 , 4 9 0}$ & $\mathbf{5 7 5 , 5 4 3}$ \\
\hline
\end{tabular}

Source: the author used data from the Disaster Information Management Systems - (DesInventar 2012) to produce the table

Besides the rapid onset hazards, previous research reveals that many communities, especially those in coastal provinces, have also been impacted by gradual and prolonged stressors (UNDP 2011b). For instance, droughts and salinization are seen as key threats to the livelihoods of coastal communities in Mekong Delta and central provinces (Bastakoti et al. 2013, Nguyen et al. 2013b). However, the losses from gradual and prolonged hazards are seldom recorded in Vietnam's formal programs of disaster risk management (Kirsch-Wood 2015).

The impacts of climate hazards on communities are expected to vary with types, location and frequency of the events. Floods are considered as the most devastating because of their frequency as well as their resulting human and economic losses (Table 3-4). Floods 
have accounted for approximately $50 \%$ of total deaths, $55 \%$ of damaged houses, and especially $95 \%$ of total human injuries. The second most important hazards are storms, which caused nearly 6,000 human incidences including deaths and injuries. Over the two decades, Vietnam has been threatened by more than 500 floods, 300 hailstorms and 220 storms.

Climate hazards have not threatened coastal and inland communities in the same way. Storms and floods were more deadly in coastal provinces than inland communities, while hailstorms and flash floods in coastal provinces have occurred more frequently and been more deadly than in the inland. More injuries and damaged houses from climate hazards were recorded in coastal communities than inland provinces, but the reverse pattern was the case for human deaths. Between 1989 and 2010, climate hazards killed over 7,700 and 4,900 people in inland and coastal provinces, respectively. Among the three coastal zones, the Central Coast suffered most from the deaths (Figure 3-6).

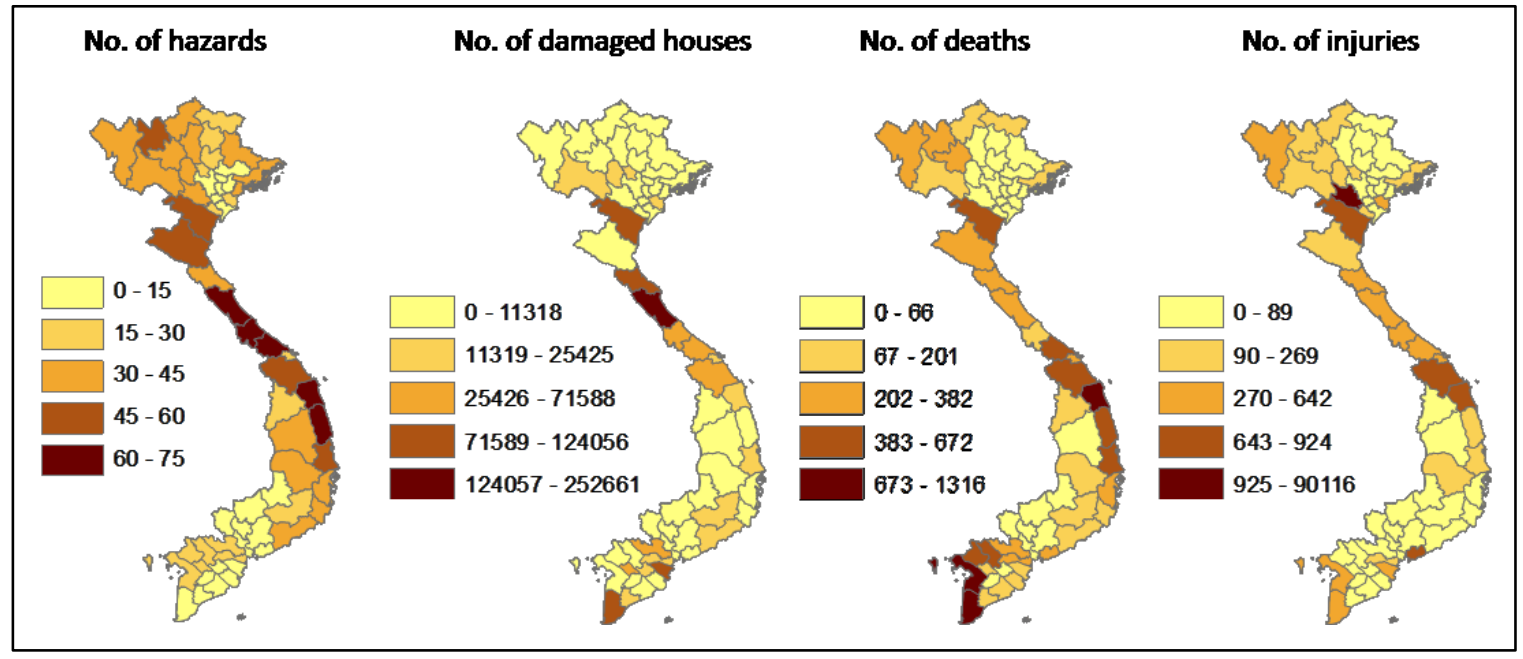

Figure 3-6: Spatial impacts of climate hazards in Vietnam between 1989 and 2010

Source: the author used data from Disaster Information Management Systems - DesInventar (2012) to produce the maps and graphs 
Impacts of climate hazards in Vietnam vary throughout the year. The lowest number of hazards was recorded during January and April, while the peak for many climate hazards is between June and November. Droughts mainly occur between November and March (Vu-Thanh et al. 2013), while a majority of storms and floods take place between May and December (ISPONRE 2009). The country, especially coastal provinces (Figure 3-7), is annually hit by 7 out of 11 storms that develop in the South China Sea (ISPONRE 2009). Besides this pattern, hailstorms also threaten the country in the early spring.

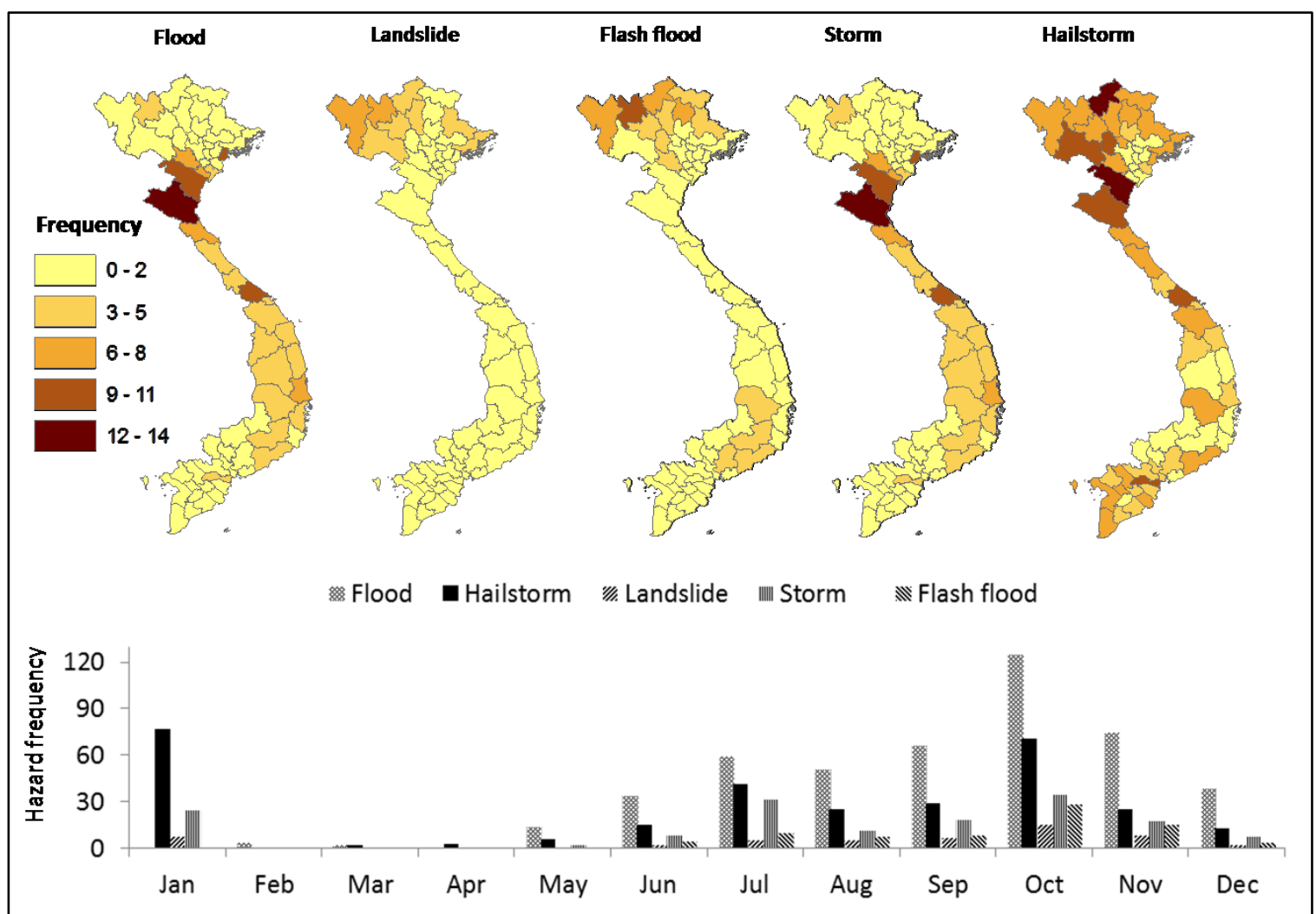

Figure 3-7: Spatial pattern (map) and frequency (graph) of flood, landslide, flash flood, storm and hailstorm disasters across Vietnam between 1989 and 2010

Source: the author used data from Disaster Information Management Systems - DesInventar (2012) to produce the ArcGIS maps and graphs

Historical data reveals that the number of human deaths caused by climate hazards was reduced by $50 \%$ over the last two decades, from 8,000 deaths for the period of 1990 s to 
4,000 incidents for the decade of 2000s (Figure 3-8). However, human and economic security has been increasingly threatened by climate hazards between the two decades. For instance, the number of human injuries induced by the five major hazards has increased by approximately $17 \%$, from 2.5 thousand people during the 1990 s to 3.5 thousand people for the 2000s, while financial losses have doubled.

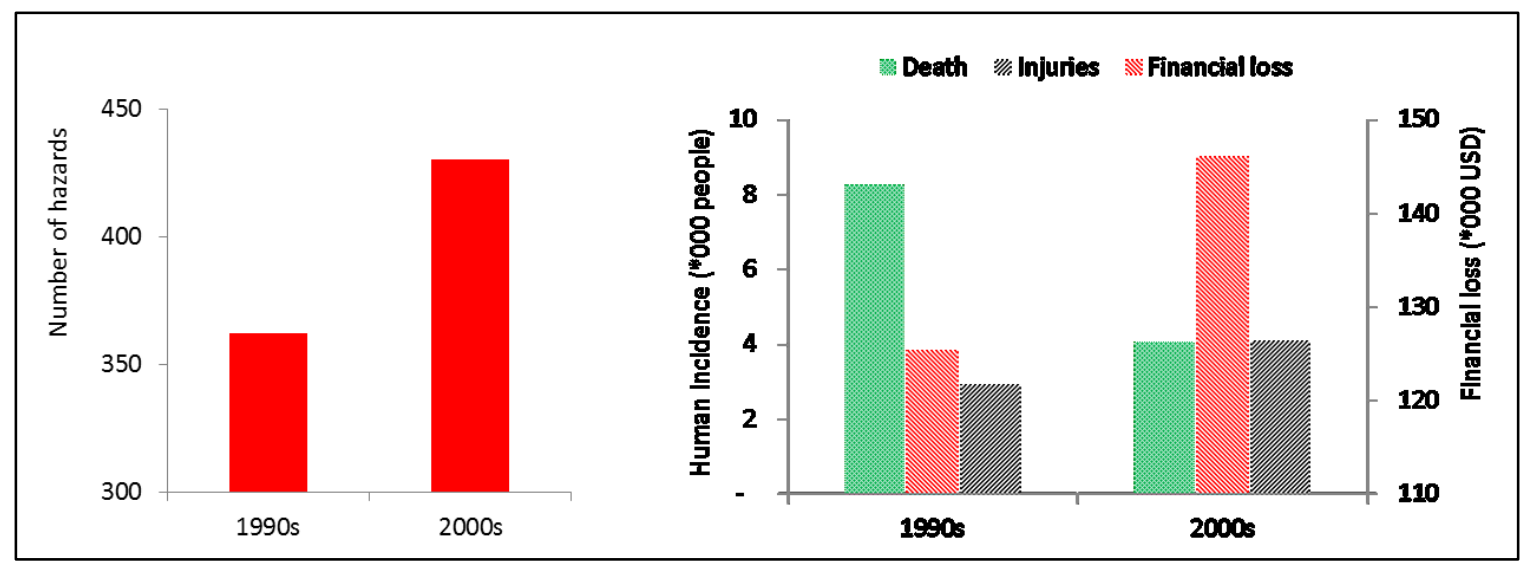

Figure 3-8: The disaster frequency (left graph) as well as human and economic impacts (right graph) of natural hazards in Vietnam during 1989 and 2009.

Source: the author used data from EM-DAT (2012) and DesInventar (2012) to make the graphs In the long-term, Vietnam, especially coastal communities, is projected to be increasingly threatened by climate change. Based on the medium emission scenario (B2), the average annual temperature in 2100 is predicted to rise by about $2.3^{\circ} \mathrm{C}$ compared to the last decade (MONRE 2009). Recently, rising sea levels have been observed in many locations along Vietnam's coast such as the Mekong Delta and the Red River Delta. One meter of mean sea level rise by 2100 will likely inundate $5.3 \%$ of Vietnam's total land area, nearly $82 \%$ of which is in the Mekong Delta, $9 \%$ of the Red River Delta and over $4 \%$ of each of the North Central Coast and South East regions (UNDP 2011b).

The weather is expected to become more extreme. Historically, Vietnam has experienced an increase of 0.14 per decade over the last 50 years (ISPONRE 2009), while the seasons 
of storms and floods are longer than they used to be (Carew-Reid 2007, ISPONRE 2009, UNDP 2011b). In future, the frequency and severity of many climate hazards such as storms, floods and droughts will likely be aggravated by climate change (ISPONRE 2009). MONRE (2009) estimates that the annual rainfall is expected to increase by $6.6 \%$ on average for the twenty-first century, but the rainfall will concentrate in the rainy season and reduce in the dry months. In addition, the probability of extreme rainfall events in the rainy seasons is likely to rise, leading to increased risks of landslides and floods, while in dry seasons, the predicted decrease of $20 \%$ in the average rainfall will likely cause increased risks of drought (MONRE 2009, UNDP 2011a).

\section{Synthesis of Chapter 3}

Chapter 3 provided an empirical foundation for this research by critically reviewing climate risks facing Vietnam's coastal communities and efforts that the country has adopted over the last three decades to reduce the risks. The review shows that Vietnam's coastal communities have been threatened by a wide range of climate-related hazards, which involve both rapid and prolonged processes. Many climate events such as storms and floods are recurrent and rapid-onset threats, while others are relatively new to the coastal communities, for instance sea level rise and its resulting salinization.

Historical data show that among rapid onset hazards, storms and floods have been the most important threats to coastal provinces, especially those in the central coast as they have killed and injured more than 100,000 people and damaged nearly 600,000 houses across the coast of the country over the last two decades. Besides these threats, the coastal communities have also been impacted by a diverse set of gradual and prolonged stressors. Although the impacts of these stressors are not regularly recorded (Kirsch- 
Wood 2015), recent research reveals that they have impacted the livelihoods and wellbeings of coastal communities (UNDP 2011a).

Vietnam has made significant effort over the last three decades to address the changing climate. DRR and CCA are key strategies that Vietnam has adopted to enhance CR and reduce the adverse impacts of the changing climate, but most efforts had focused on recurrent and rapid onset hazards until 2008 when the NTP was launched by the Vietnamese government. Two groups of measures including structural and non-structural interventions have been deployed to enhance five forms of capital including physical, natural, financial, human and social resources, which provide the communities with a source of capacity to address climate hazards. Both autonomy-based and policy-oriented approaches have been used to implement DRR and CCA projects.

The NSD and NTP are two important programs of Vietnam to reduce the adverse impacts of future climate change. The former is the key DRR policy to reduce natural disasters, especially storms and floods, while the NTP is used as a guiding framework in response to climate change including CCA. All provinces and relevant ministries have implemented their action plan for the NSD, but the development of most NTP action plans was recently completed (Kirsch-Wood 2015). The two programs are executed by two separated and complex institutional systems, which involve diverse actors and sectors across multiple jurisdictional levels. Some effort has been made to connect the two programs, but their integration remains limited.

Vietnam's DRR and CCA have provided the country with significant success. The most important achievement is the remarkably reduced loss of human lives, from 8,000 deaths during the 1990 s to 4,000 deaths for the period of 2000s. However, it is also noted that 
the financial loss and human injuries continues to grow for the period. In addition, the evidence reveals increasing vulnerability or eroding resilience of communities across the country despite an impressive economic growth of the country. In future, the adverse impacts of climate hazards on the coastal communities are also expected to be magnified by future climate change.

The review in this chapter has revealed both the success and limitations of Vietnam's recent efforts to enhance the resilience of its coastal communities and reduce the adverse impacts of changing climate. However, there remain important questions: what factors and how they have shaped the success of the recent interventions and what alternative strategies could provide Vietnam's coastal communities with opportunities to enhance $\mathrm{CR}$ and reduce risks of future climate change. Chapters $5-9$ will use empirical evidence to address these concerns. 


\section{CHAPTER 4: RESEARCH FRAMEWORK AND METHODOLOGIES}

Chapter 4 introduces the investigative framework and methodologies used in the empirical parts of this research. The chapter is structured in 5 sections, starting with rationales for the selection of a coastal village in Quang Tri province as a case study. The second section briefly describes the study site with a view to locating the village within the biophysical and social-economic contexts of its province. Section 4.3 introduces the investigative framework that guided the fieldwork as described in Section 4.4. The final section presents how the empirical data were analysed and interpreted.

\subsection{Methodological decisions}

The purpose of this study is to investigate and evaluate factors shaping the success of recent responses of central Vietnam's coastal communities to a changing climate, and to determine alternative strategies that will provide the communities with opportunities to enhance their resilience and reduce risks of future climate change. A single coastal village in Vietnam was selected as a case study for two reasons. First, the case study is helpful to answer the 'what, why and how' types of questions. Secondly, the focus on a single village fosters an in-depth analysis of complex and dynamic phenomena across global to local levels, which shape community resilience.

Community-based participatory action research approaches were also used for the field research as they provided the community with opportunities to be involved actively throughout the research process. Specifically, members of the community identified and analysed climate threats, and then developed solutions to tackle these problems that were carefully situated in their local contexts. In Vietnam, all provinces developed action plans 
in response to future climate change, but the development of these plans was mainly based on regional and global climate models (Kirsch-Wood 2015). This effort is essential, but it does not fully reflect local contexts (van Aalst et al. 2008). By contextualizing local conditions, the participatory approaches were used to reduce the limitations of the effort based on large-scale climate models.

Quang Tri province was selected for three reasons. First, Quang Tri is one of the poorest provinces of the central coast (Arouri et al. 2015), and one of the five coastal provinces that have suffered the most from climate hazards (see Chapter 3). Secondly, the province has adopted two national policies in response to changing climate: the National Strategy on Disaster Prevention, Response and Mitigation to 2020 (NSD) in 2007, and the National Target Program on Response to Climate Change (NTP). Thus the selection offers opportunities to evaluate the role of disaster risk reduction (DRR) and climate change adaptation (CCA) across multiple scales in enhancing $\mathrm{CR}$ and reducing climate impacts. Finally, Quang Tri was chosen in order to utilize the author's strong pre-existing relationships with a number of governmental agencies in the province, which is one of the prerequisites for successful community engagement in the field research.

\subsection{Understanding the study area}

\subsubsection{The context of Quang Tri province in the face of changing climate}

\subsubsection{Social-economic conditions and climate impacts}

Quang Tri is located in the North Central Coast of Vietnam (Figure 4-1) and covers a total area of 4,700 square kilometres. Mountains and hills are concentrated to the west and they occupy $80 \%$ of the provincial territory. The remaining quarter of the province is 
covered by plains and sandy areas along the coast, where agriculture, aquaculture and fisheries are concentrated (QT-SO 2011). The province has nearly 600,000 inhabitants living in 10 districts (QT-SO 2011), four of which are bordered by the South China Sea.

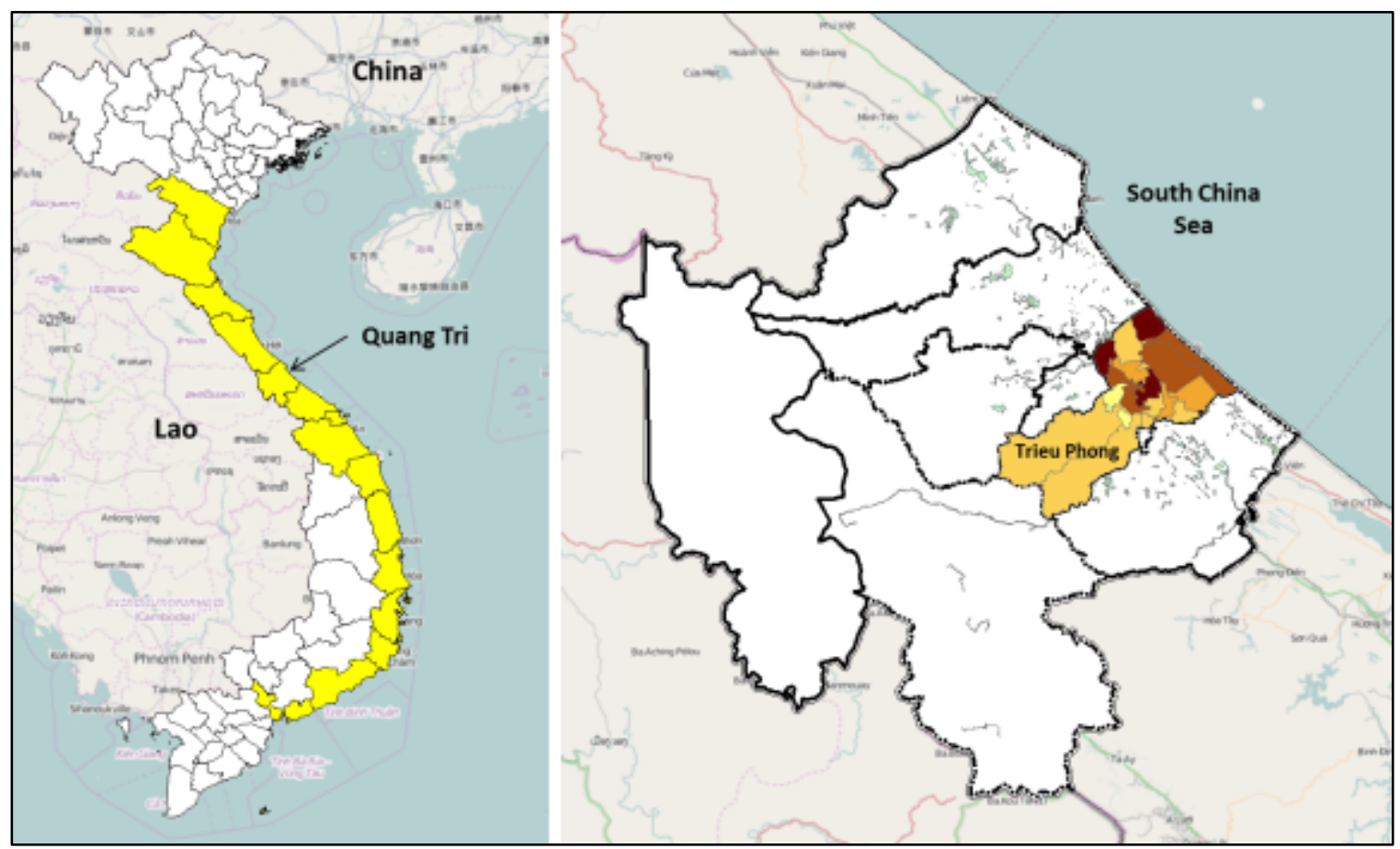

Figure 4-1: Maps of central Vietnam (shaded area of the left map) and Quang Tri province (right)

The annual average GDP of the province grew by $10.7 \%$ for the period from 2006 to 2011, but its average income per capita remained low at US\$ 1,000 (QT-SO 2011). Between $25 \%$ and $45 \%$ of the population was classified as poor for the period of 2004 to 2010 and Quang Tri is one of the four poorest provinces in the central coast (Arouri et al. 2015). There was a shift in the economic structure of the province over the last two decades. The economy of the province was characterized by the extensive development of agriculture, aquaculture and fisheries during the 1990s, but then it has gradually been supplanted by the construction and manufacturing sectors (QT-SO 2011). In 2014, the agriculture, aquaculture and fishery sectors contributed a smaller portion, approximately 
$25 \%$, to the provincial GDP, but they provided employment to $66 \%$ of the provincial population (QT-SO 2015).

Quang Tri has a tropical monsoon climate, with the daily maximum temperature varying between 7.7 and $42.1^{\circ} \mathrm{C}$ (QT-PPC 2010a). The rainy season usually lasts from September to December and is characterized by heavy rains, storms and floods. The dry season typically starts in March and ends in late August and it is characterized by hot and dry southwest monsoons and droughts (Nguyen et al. 2010). The province has been impacted by a wide range of climate hazards, of which floods and storms are considered as the key threats (QT-PPC 2008).

Fifty-six major climate events, especially storms and floods, leading to human and economic losses have happened over the last two decades (Figure 4-2). The most disastrous flood (1999) killed 58 people and damaged 3,000 houses across the province, while the most devastating storm (Ketsana in 2009) damaged 42,000 houses, with 12 human deaths and 33 injuries. Overall, the number of human deaths during the 2010s was reduced by $50 \%$ in comparison to the 1990 s, but the number of damaged houses and human injuries increased considerably over the same period.

Trieu Phong and Hai Lang districts are the most vulnerable to climate hazards because they are directly exposed to large rivers and the South China Sea (Nguyen et al. 2010). Trieu Phong has been more susceptible to storms and floods in terms of economic loss and human injuries (QT-PPC 2008), thus it was selected for this research. Besides storms and floods, this district has also been affected by gradual and prolonged stressors such as droughts, sea level rise, and salinization of ground water and soil (QT-DONRE 2010). These stressors have not caused loss of human life, but recent reports reveal significant 
impacts on human health and the livelihood of local communities across the province (QT-DONRE 2010).

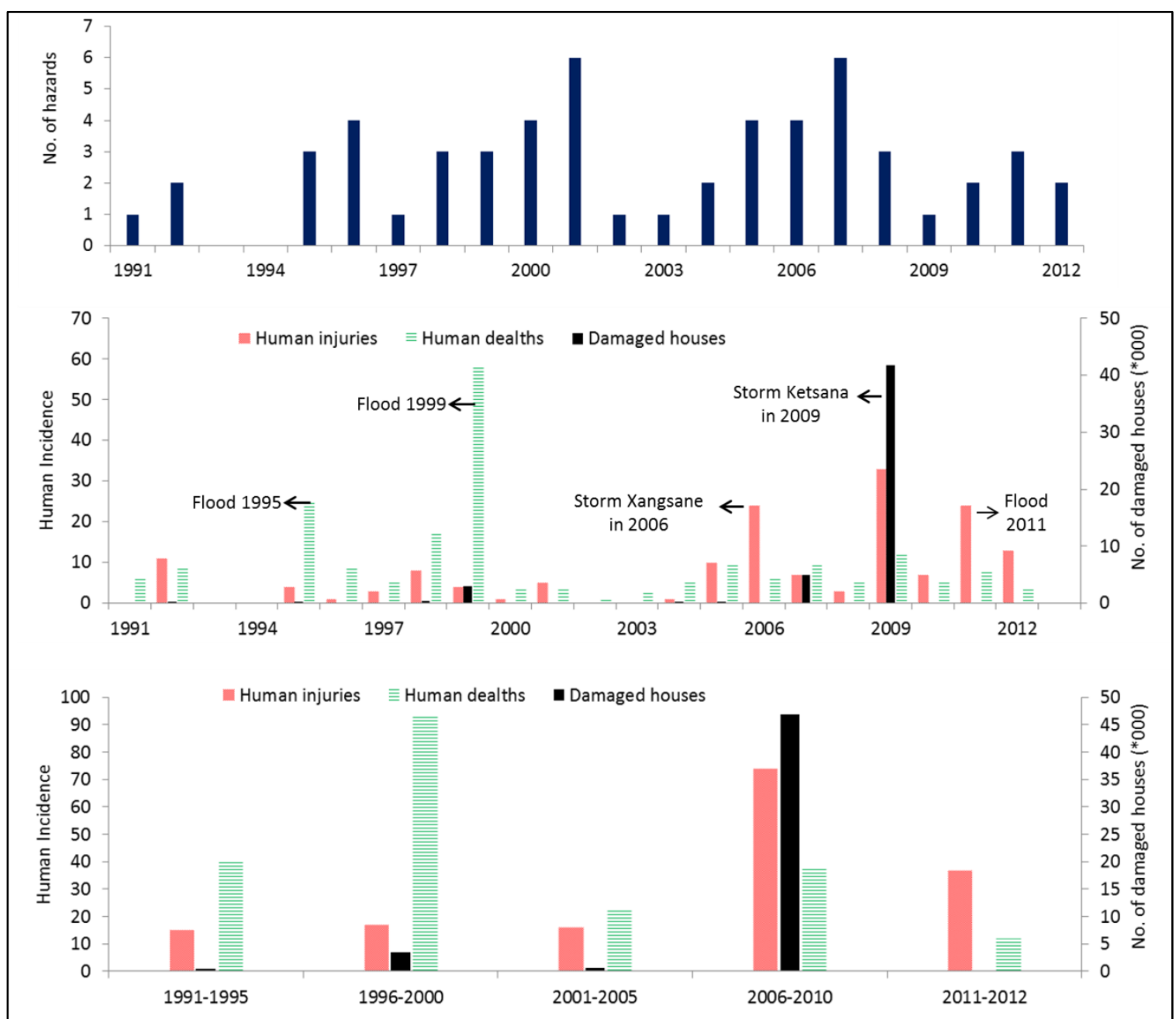

Figure 4-2: Climate impact trends in Quang Tri province for the period of 1991 and 2012

Source: Disaster Information Management Systems and the Quang Tri government (QT-PPC 2008, DesInventar 2012) and the graph was made by the author

\subsubsection{Recent efforts of Quang Tri in response to the changing climate}

\section{Quang Tri's institutional adaptation to changing climate}

The Quang Tri provincial government issued a number of important policies to address changing climate over the last four decades (Table 4-1). Since 1973 when Quang Tri obtained liberty from the Vietnam War against the United States of America, the 
provincial government formed a Committee for Flood and Storm Control, Search and Rescue (CFS-SR). The committee was led by the Quang Tri Department of Agriculture and Rural Development (DARD) with support from military units in the province.

Table 4-1: An overview about important changes of Quang Tri policies in response to the changing climate over the last three decades

\begin{tabular}{|c|c|c|c|c|c|}
\hline $\begin{array}{l}\text { Vietnam } \\
\text { (National) }\end{array}$ & & $\begin{array}{l}\text { The National Strategy } \\
\text { on Disaster } \\
\text { Prevention, Response } \\
\text { and Mitigation to } \\
2020 \text { (NSD) }\end{array}$ & $\begin{array}{l}\text { The National } \\
\text { Target Program } \\
\text { on Response to } \\
\text { Climate Change } \\
\text { (NTP) }\end{array}$ & & $\downarrow$ \\
\hline $\begin{array}{l}\text { Quang Tri } \\
\text { (Provincial) }\end{array}$ & $\begin{array}{l}\text { Institutional and } \\
\text { operational } \\
\text { regulation for the } \\
\text { Quang Tri Committee } \\
\text { for Storm and Flood } \\
\text { Control, Search and } \\
\text { Rescue (CFS-SR) }\end{array}$ & & $\begin{array}{l}\text { Quang Tri } \longrightarrow \\
\text { action plan for } \\
\text { the NSD }\end{array}$ & $\begin{array}{l}\text { Integrative } \\
\text { management } \\
\text { for natural } \\
\text { disaster risk } \\
\text { reduction }\end{array}$ & $\begin{array}{l}\text { Action plan } \\
\text { for the NTP }\end{array}$ \\
\hline $\begin{array}{l}\text { Trieu Phong } \\
\text { (District) }\end{array}$ & $\begin{array}{c}\downarrow \\
\text { Trieu Phong CFS-SR }\end{array}$ & & $\downarrow$ & 5 & $\downarrow$ \\
\hline \multirow[t]{2}{*}{$\begin{array}{l}\text { Trieu An } \\
\text { (Commune) }\end{array}$} & $\begin{array}{c}\downarrow \\
\text { Trieu An CFS-SR }\end{array}$ & & $\downarrow$ & & \\
\hline & 2004 & 2007 & 2008 & 2010 & 2013 \\
\hline
\end{tabular}

Sources: public policies (QT-PPC 2004a, TA-CPC 2004, TP-DPC 2004, QT-PPC 2008, 2013)

Although Quang Tri province adopted the policy on storm and flood DRR in 1973 and many DRR activities have been conducted, significant reforms of its institutional framework have begun since 2001 when the Decision 127 on institutional and operational regulation in storm and flood DRR was issued by the CC-FSC. In 2004, the provincial government restructured the institutional framework of its CFS-SR. In the former CFSSR, action plans for DRR were developed and implemented mainly by DARD, but the new framework requires involving multiple provincial sectors in the process of formulating and implementing DRR action plans (QT-PPC 2004a, b). The institutional framework for DRR is updated annually by adjusting participating members and their 
responsibilities in order to fit to the provincial need and the requirements from the national government.

In 2008, the Quang Tri government issued a provincial action plan to implement the NSD and started developing an action plan for the NTP. Although the action plan for the NTP is expected to provide the province with opportunities to address a wider range of climate hazards, this plan was not completed and issued until 2013. Since the provincial action plan for the NSD focuses on storms and floods and the plan for the NTP was not available, the provincial government launched the "Integrative management of natural hazards" plan in 2010. This latest plan was developed by complementing some actions that help to address gradual and prolonged stressors to the provincial action plan for the NSD (QT-PPC 2010a).

At lower levels of government, the CFS-SR of Trieu Phong district and Trieu An commune were required by the provincial CSF-RS to adjust their institutional framework for DRR. In order to implement the provincial action plan for the NSD, the district and communal CFS-SRs are required to develop and implement annual rather than long-term plans. As for May 2013, besides the action plan for the NSD, Quang Tri also has an action plan for the NTP. As a formal procedure, all districts and communes in the province are required to develop their own plans to implement the NTP action plan. However, there is no firm timeline for the completion of these plans.

\section{The institutional framework for the provincial action plans of the NSD and NTP}

The provincial CFS-SR is chaired by the Quang Tri Provincial People's Committee with assistance from a wide range of provincial departments or participating members (Figure 4-3). This committee leads and makes decisions for all flood and storm DRR activities. 
The CFS-SR has a standing office managed by DARD. The office provides its committee with advice on activities of flood and storm control, search and rescue. Participating members of the CSF-RS are assigned to oversee and coordinate DRR activities in certain districts.

Quang Tri has invested heavily in developing and implementing CCA actions since the national government launched the NTP in 2008. For instance, with the assistance of Hong Kong Oxfam, Quang Tri conducted studies to assess climate risks and the capacity of local communities to adapt to climate change (QT-DONRE 2010). Hence a wide range of important CCA projects were subsequently integrated into the provincial action plan for the NSD in order to address both natural disasters as well as gradual and prolonged stressors such as droughts and salinization (QT-PPC 2010a).

In May 2013, the provincial government approved an action plan for the NTP (QT-PPC 2013). The plan is led by the Quang Tri Provincial Steering Committee for the NTP (Figure 4-3). The committee is chaired by the Quang Tri Provincial People's Committee, with the assistance from the provincial Department of Natural Resources and Environment (DONRE) as a standing chair and three other provincial departments. DONRE plays key roles in coordinating, implementing and evaluating the plan and is assisted by other provincial departments and districts. 


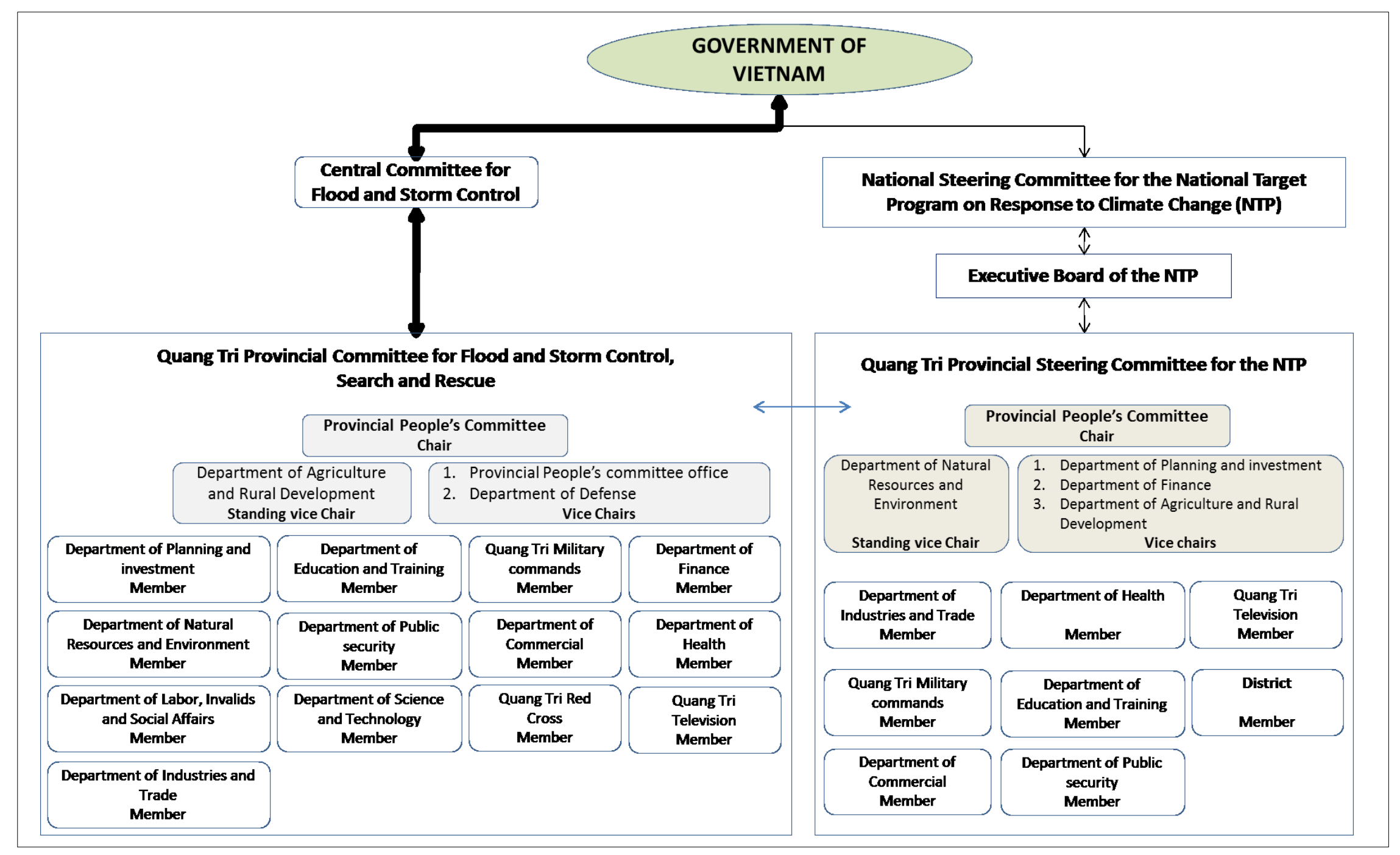

Figure 4-3: The institutional framework for Quang Tri to implement the National Strategy on Disaster Prevention, Response and Mitigation to 2020 and the National Target Program on Response to Climate Change.

Source: summarised from Quang Tri provincial policies (QT-PPC 2004a, 2008, 2013) 


\section{Government policies other than the NSD and NTP programs}

Besides the NSD and NTP programs, Quang Tri has also implemented a number of social-economic policies to enhance the resilience of its local communities (Table 4-2). For instance, during the 1980, through the national policy on development of new economic zones, the province provided financial support to households, which were vulnerable to climate hazards, to migrate to Binh Duong and Dak Lak provinces. In addition, the Quang Tri province also received support from international agencies to enhance the resilience of local communities as well as reduce poverty and environmental degradation. For example, World Visions and Asian Development Banks supported concrete road systems in many villages of Trieu Phong and Hai Lang districts in order to promote the access of local communities to public services such as city markets and provincial hospitals, whereas the Norwegian government funded many coastal villages of the province to plant $\mathrm{Tram}^{2}$ trees on sandy hills.

\footnotetext{
${ }^{2}$ Tram is the local name of a plant species, which belongs to Melaleuca genus. Tram trees are used for oil and commercial wood production.
} 
Table 4-2: Example policies other than DRR and CCA programs used by Quang Tri to enhance community resilience over the last three decades

\begin{tabular}{|c|c|c|}
\hline Key policies & Timing & Example impacts of the policies \\
\hline $\begin{array}{l}\text { Decision } 95-\text { CP on } \\
\text { development of new } \\
\text { economic zones }\end{array}$ & $1980-1990$ & $\begin{array}{l}\text { Province supported households in areas vulnerable to } \\
\text { climate hazards or with high density of population, to } \\
\text { migrate to central highland provinces such as Binh Duong } \\
\text { and Dak Lak. }\end{array}$ \\
\hline \multirow[t]{2}{*}{$\begin{array}{l}\text { National program on } \\
\text { poverty reduction }\end{array}$} & Since 1998 & $\begin{array}{l}\text { Provincial support for poor households such as cash, rice } \\
\text { seed and training to develop livelihoods. }\end{array}$ \\
\hline & & $\begin{array}{l}\text { Through this program, World Vision and Asian Development } \\
\text { Bank supported local communities to build road systems, } \\
\text { while Tram forestation was promoted on sandy areas. }\end{array}$ \\
\hline Law on biodiversity & Issued in 2001 & $\begin{array}{l}\text { The province applied this law to ban destructive exploitation } \\
\text { of natural resources and promote activities that protect and } \\
\text { restore important ecosystems and species. For instance, } \\
\text { destructive fishing was forbidden. }\end{array}$ \\
\hline $\begin{array}{l}\text { National Strategy for } \\
\text { Rural Clean Water } \\
\text { Supply and Sanitation }\end{array}$ & $2006-2010$ & $\begin{array}{l}\text { The program aimed to improve the access to safe water; } \\
\text { reduce water-related diseases; develop water supply } \\
\text { systems }\end{array}$ \\
\hline $\begin{array}{l}\text { National program on } \\
\text { new rural } \\
\text { development }\end{array}$ & $2010-2020$ & $\begin{array}{l}\text { The province used this program to improve road systems, } \\
\text { electricity system, irrigation system at the community level }\end{array}$ \\
\hline
\end{tabular}

Source: Quang Tri government reports (QT-PPC 1990, 2000, 2005, 2010b)

\subsubsection{Trieu An commune and Tuong Van village: social-economic conditions and climate vulnerability}

Trieu An commune of Trieu Phong district was chosen for the field research because it is not only quite vulnerable to climate change, but also has most of the rural livelihoods that occur within in the province (TP-DPC 2004, TPSO 2010). The commune is threatened by rapid onset hazards including storms and floods in the rainy seasons due to its direct exposure to the Thach Han River and the South China Sea (Figure 4-4). In addition, the commune has also been affected by gradual and prolonged stressors such as droughts and salinization during summers (TA-CPC 2008, 2013). 


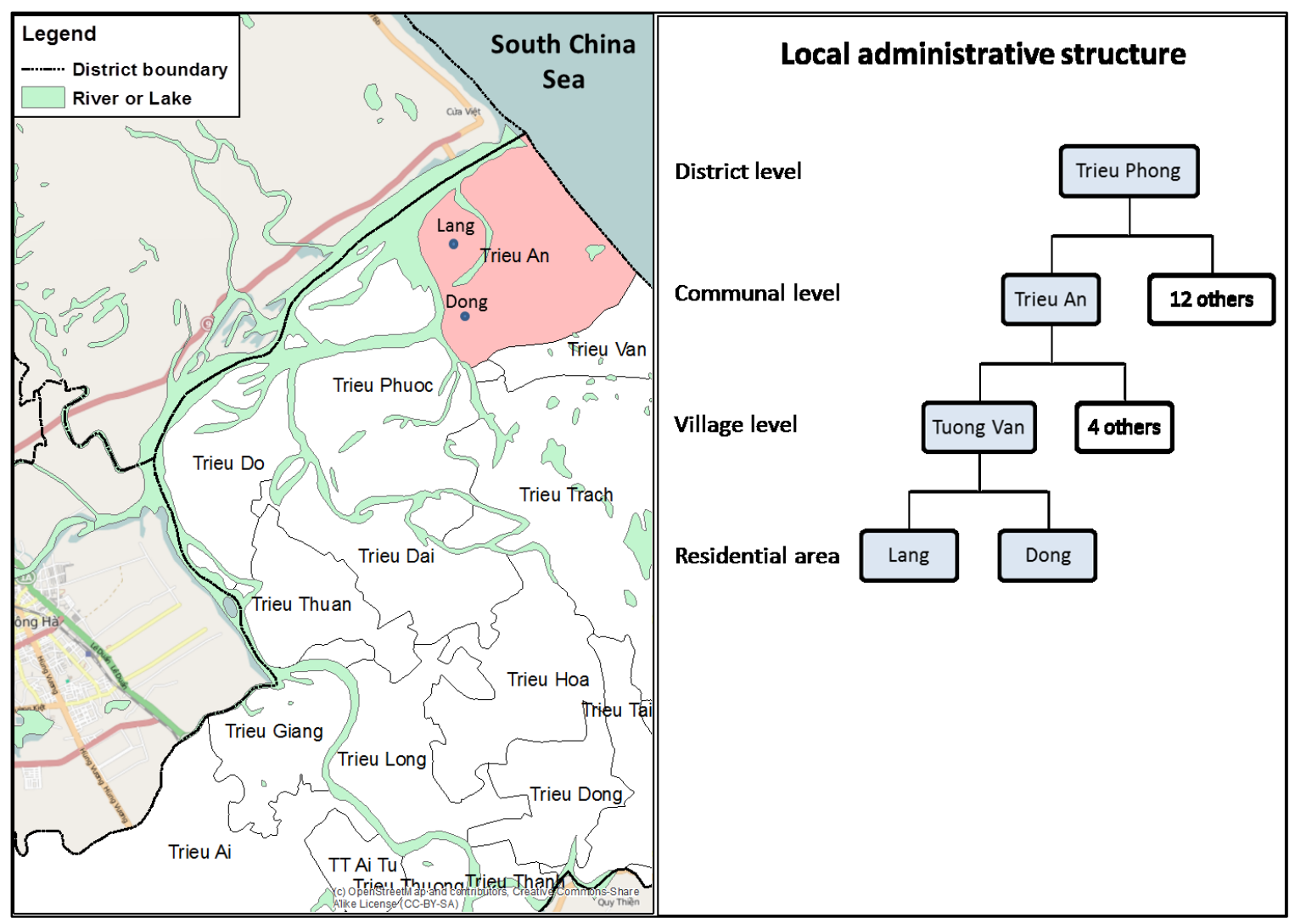

Figure 4-4: Location of Trieu An commune and local administrative structure

Trieu An has a total land of approximately $14 \mathrm{~km}^{2}$ (QT-SO 2011). In 2012, the population of the commune was 7,000 residents living in 1,600 households across five villages (Table 4-3). Agriculture, shrimp farming, coastal and marine fisheries, and forestry are key economic sectors of the commune. Two coastal villages of Trieu An mainly depend on marine fisheries, while the three others are involved in agriculture (rice, peanuts, cassava production and livestock production), forestry as well as inland and freshwater and brackish-water aquaculture and fisheries. 
Table 4-3: Demographic characteristics of Trieu An commune in 2012

\begin{tabular}{lccc} 
Village & No. of villagers & No. of households & No. of poor households \\
\hline Ha Tay & 3302 & 787 & 125 \\
Phu Hoi & 1460 & 385 & 95 \\
Tuong Van & 1478 & 344 & 62 \\
An Loi & 427 & 95 & 33 \\
Thanh Xuan & 76 & 32 & 11 \\
Total & $\mathbf{6 7 4 3}$ & $\mathbf{1 6 4 3}$ & $\mathbf{3 2 6}$ \\
\hline
\end{tabular}

Source: Trieu An commune (Duong 2013)

Over the last three decades, the commune has been threatened by six storms and floods (Table 4-4). Most floods and storms occurred during October and November. The flood in 1983 was the most disastrous, not only killed 148 people but also damaged over 4,500 houses. Some floods occurred following storms. For instance, the storms in 1999 and 2005 not only damaged houses, but also induced subsequent floods, which swept away many houses.

Table 4-4: Impacts of key storms and floods on Trieu An commune between 1983 and 2006

\begin{tabular}{|c|c|c|c|c|c|}
\hline Impacts & $\begin{array}{c}\text { Flood } \\
\text { Oct, } 1983\end{array}$ & $\begin{array}{c}\text { Storm } \\
\text { Oct, } 1985\end{array}$ & $\begin{array}{c}\text { Storm, } \\
\text { flood } \\
\text { Nov, } 1999\end{array}$ & $\begin{array}{c}\text { Storm, } \\
\text { flood } \\
\text { Nov, } 2005\end{array}$ & $\begin{array}{c}\text { Flood } \\
\text { Nov, } 2006\end{array}$ \\
\hline
\end{tabular}

\begin{tabular}{|c|c|c|c|c|c|}
\hline Human deaths & 148 & 17 & 7 & - & 5 \\
\hline Human injuries & 256 & 25 & 21 & - & - \\
\hline Subsidiary crops (ton) & 2,550 & 915 & 1,318 & 486 & 790 \\
\hline Rice loss (ton) & 20,600 & 6,750 & 890 & - & 95 \\
\hline Affected residents & 3,540 & 3,540 & 1,690 & 1,690 & 1,540 \\
\hline Fishing boats damaged & 125 & 15 & - & 2 & - \\
\hline Aquaculture households affected & 760 & 217 & 185 & 51 & 65 \\
\hline Aquaculture area affected (ha) & 350 & 206 & 150 & 35 & 41 \\
\hline Cows and buffalos (pieces) & 2,600 & 65 & 266 & - & - \\
\hline Pigs (pieces) & 10,500 & 156 & 4,911 & 125 & 195 \\
\hline Chickens and ducks (pieces) & 29,350 & 5,210 & 4,650 & 2,560 & 1,650 \\
\hline Houses damaged & 4,660 & 4,030 & 883 & 80 & 264 \\
\hline
\end{tabular}

Source: Trieu An commune (TA-CPC 2008)

In response to the changing climate, the commune has its own CFS-SR, which formulates and implements annual plans for the NSD. The communal CFS-SR is led by the chair of 
Trieu An Communal People's Committee with assistance from members of professional units of the communal government. The communal CFS-SR receives direction from the CFS-SR of Trieu Phong district, which is led by the chair of Trieu Phong District People's Committee, with support from different sectors within the district. Both Trieu Phong district and Trieu An commune do not have long-term plans for the NSD, but rather they are directed by the CFS-SR at higher levels of government.

\subsubsection{Locating the collaborating community within biophysical and social-economic contexts across multiple scales}

As mentioned earlier, Tuong Van village was selected for the field research because of its vulnerability to changing climate (TA-CPC 2008, QT-DONRE 2011) and because of its diversity of livelihoods in comparison to the other four villages in Trieu An (Duong 2013). The village has nearly 1,500 habitants living in 350 households across two residential areas, Lang and Dong. The number of households in these two residential areas is similar. Lang and Dong share social and economic activities of the community as well as family ties.

The governmental administrative system is the most important formal network of the village, and formally connects local residents with higher levels of government as well as non-governmental organizations (NGO). This system was established by higher levels of government when Quang Tri obtained liberation in 1973. The system includes a village leadership board, which executes social-economic development for the village. Tuong Van has four local associations: Unions of Youth and Women, Agriculture Association, and Fatherland Front to assist the administrative system. 
Tuong Van village does not exist in isolation of external environments and it is affected by various factors across jurisdictional, temporal and spatial scales (Figure 4-5). Tuong Van is administrated by the Trieu An government, by which the village reaches to higher levels including district, provincial and national governments. Over the last three decades, the village has received substantial supports from its provincial and national governments to implement DRR and CCA activities, especially from the NSD (TA-CPC 2013). Besides the governments, the village has also received the assistance from local and international NGOs to enhance CR and reduce climate impacts (Nguyen 2010b).

The community is not static, but changes across the temporal and spatial scales. Many events or processes in the village take place at different temporal scales (Cash et al. 2006), from daily to century. For example, local residents daily look after their crops and their land will be impacted seriously by sea level rise of 0.5 metres by 2100 (QT-DONRE 2011). In addition, many environmental processes and activities in Tuong Van also occur across multiple levels of the spatial scale. For instance, food production takes place in gardens and farming zones, while storms develop in the South China Sea and then brings strong winds and surges to the community. 


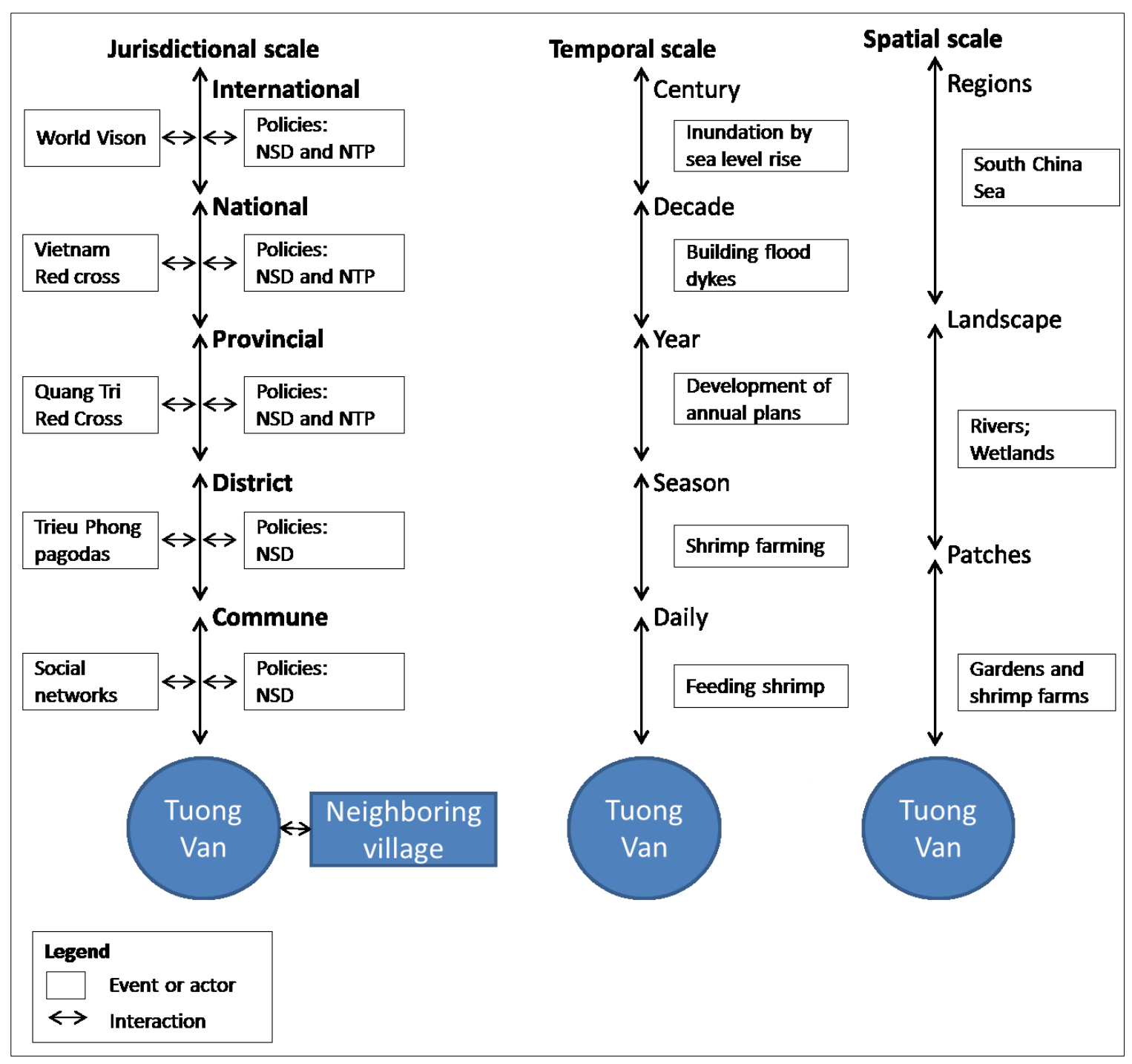

Figure 4-5: Interactions across multiple scales in Tuong Van

Source and note: the diagram adapted from (Cash et al. 2006). NSD denotes the National Strategy on Disaster Prevention, Response and Mitigation to 2020, and NTP refers to the National Target Program on Response to Climate Change.

\subsection{Development of an investigative framework}

\subsubsection{Guiding principles for the field research}

In Vietnam, procedures related to research ethics practices are not institutionalized, thus this research was conducted under the approval from the Research Ethics Board at Carleton University and implemented through a set of interconnected guiding principles 
that were used to maximize benefits and minimize risks. First, informed consent from research participants was obtained. Written invitation letters (see Appendix 1) were sent to co-researchers and potential participants at least two weeks before a commencing research in Quang Tri province in order provide sufficient time for review and taking a decision on whether or not to participate. Furthermore, the invitation letters also confirmed results would be aggregated to a level that would ensure anonymity and confidentiality, and that participants could withdraw from the research process at any time. In the field, oral consent was obtained from participants. This is the norm in Vietnam as written consent would normally be viewed with suspicion of government interference.

Secondly, the positionalities of the researcher and co-researchers were also considered in this research. The fieldwork was conducted in Quang Tri province, where professional relationships between the researcher and staff from government agencies had already been established. These connections had the advantage of building trust with and encouraging co-researchers or research participants to participate in this research, including a climate where the community was willing to participate in research design. The consent from each of the participants was requested either prior to being appointed as a co-researcher or at the start of an interview. In addition, this research did not interview any friends or acquaintances of the research team, thereby avoiding conflicts of interest.

The primary researcher had been a manager of a project in Quang Tri province on "Sustainable Livelihoods in and around Marine Protected Areas" funded by the Danish government and implemented by the province between 2006 and 2011, and, therefore, was known by members of the community and had prior knowledge of the community. However, in this current research his position and role were as a $\mathrm{PhD}$ student undertaking 
his dissertation and not a person in a position to provide and manage the financial resources for the communities' development in the province. This was communicated to local communities in advance of the first site visit in 2013. Thus the researcher clarified his role throughout the research, and negotiated mutually beneficial relationships whereby participants and co-researchers felt that they would receive appropriate benefits from their participation without creating excessive expectations about what would result from the research. It was important for the primary researcher to not be considered as an "insider" and to remain at arm's length from the community in order to retain his objectivity. However, he engaged in some community activities, such as having lunch with some families and playing volleyball games with youths of Tuong Van village, in order to develop trust with local residents.

The research also involved two officials from the provincial government and three leaders of the collaborating community as co-researchers. A number of strategies were used to manage the research team and ensured that they were facilitators rather than contributors. All co-researchers were recruited based on their professional expertise and capacity to volunteer. The recruitment took place with invitation letters and oral consent, in which their roles as facilitators rather than information providers were highlighted. When the research team was established, all its members met to gain insight into requirements of the investigation and determine their training needs on facilitation skills. The researcher held two mini-training workshops, through which all members of the team shared their knowledge and experiences on mediating conflicts during group discussions, determined their roles, and developed the detailed work-plans as well as the fieldwork protocols, such as the guide for focus group discussions at later stages of the research. 
Another guiding principle related to managing risks throughout the field investigation. The field research could have put the research team and collaborating communities at physical risk because they were involved in various outdoor activities. Thus any activities that were anticipated to be dangerous were not conducted. For instance, the research team did not go out during the tenth storm of 2013 to observe and enrich actual experiences with climate impacts and responses by the community, as danger from the storm was anticipated. However, as the storm was a rare event, opportunities were taken to gain experiences when it was possible to avoid and minimize physical harm. For instance, helmets and life vests were worn throughout visits to the community as soon as the storm ended.

Researchers and participants could also be at emotional risk stemming from multiple sources, such as attribution of blame, ongoing conflicts, and power disparity. Facilitators in the discussions played central roles in risk management (Stewart et al. 2007). In addition, none of focus group discussions and planning workshops involved governmental officials of Trieu An commune and Trieu Phong district, as it was anticipated that local residents might fear they would not receive support from their governments if they criticized their governmental officials. However, the leadership board of Trieu An commune was invited to host two workshops, in which its communal professionals had opportunities to share experiences and provide feedback to the research findings.

Finally, the transparency principle was used to gain acceptance and trust from the collaborating communities. The collaborating communities and the government agencies were not only consulted in the development of the research proposal, but also participated 
in workshops to give their feedback to the research findings. For instance, the vicedirector of Quang Tri DARD was consulted through emails while the researcher developed the research proposal during his stay at Carleton University, while staff of Quang Tri DONRE, Trieu An commune and leaders of the collaborating community were invited to consultative meetings and provided additional feedback when the researcher arrived in the province. Following completion of this thesis, a summary of the research results, in both Vietnamese and English languages, will be sent to Tuong Van community, Trieu An commune, DARD and DONRE.

\subsubsection{Investigative frameworks}

Figure 4-6 presents the investigative framework, which captures the overarching goal of this research (e.g. constraints and opportunities for enhancing CR) and the four more specific sub-questions which were addressed by using multiple methods of data collection. The use of multiple methods reflects the view that no single approach could address all four sub-questions. For instance, focus group discussions (FG) were helpful to obtain local experiences and of local residents about climate impacts, whereas archival research provided historical data collected by governmental agencies to validate local experiences. 


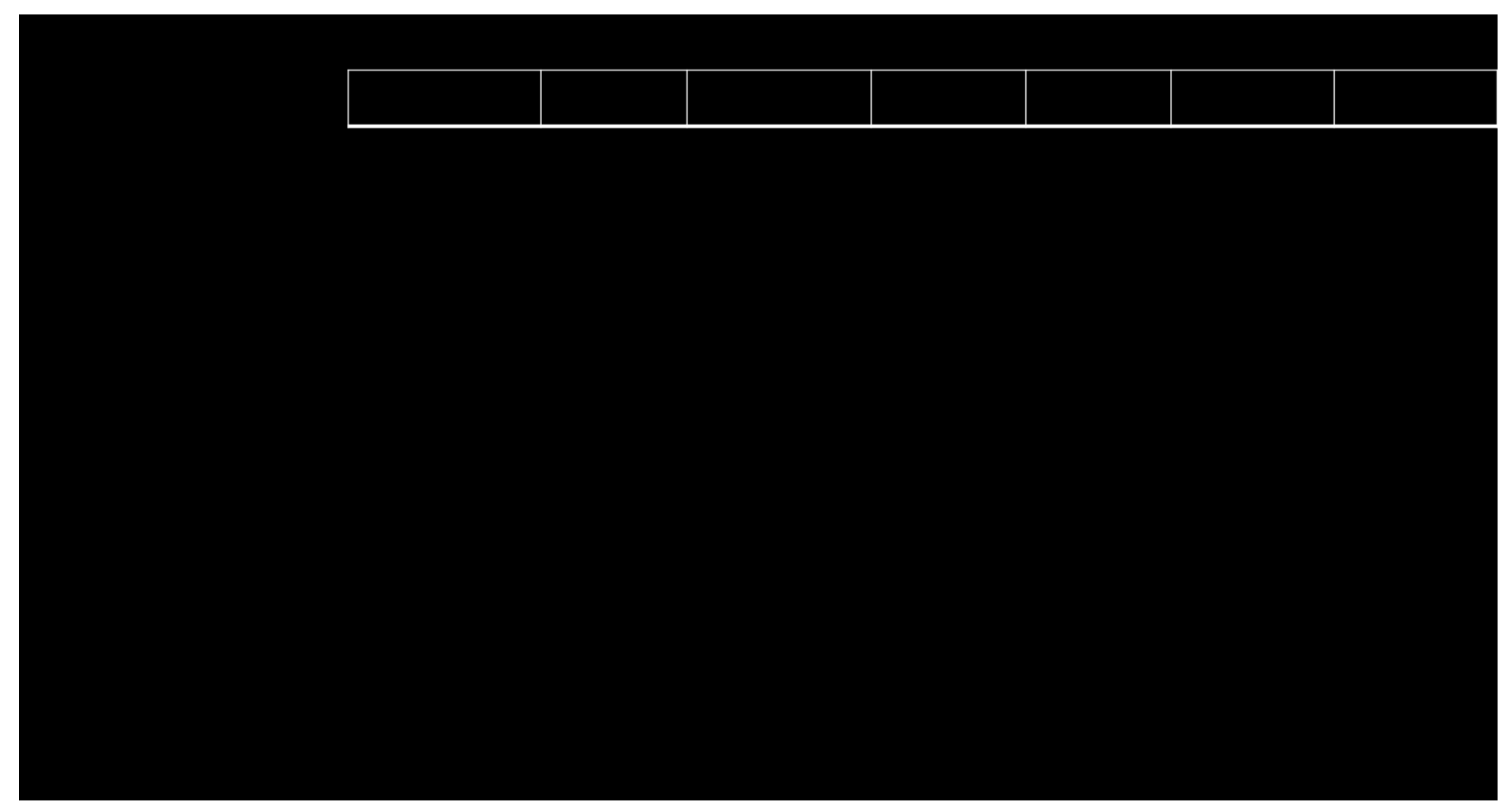

Figure 4-6: Research framework

Note: the research questions build on each other and contribute to addressing the overarching research question concerning the key constraints and opportunities to enhancing the resilience of central Vietnam's coastal communities (CVC) in the face of changing climate. The principle methods used to address each research question appear as column headers with summary notes indicating how methods are applied. DRR and CCA denote disaster risk reduction and climate change adaptation, respectively. 
Each of the four research questions was answered using different components of the data obtained from multiple methods. For example, in addressing the first question regarding how a changing climate has recently impacted central Vietnam's coastal communities, five components of data were used. Recent impacts of the changing climate were assessed by focus group discussions and they were quantified and ranked by a survey. The findings from group discussions were also complemented and validated throughout in-depth interviews with local residents who were not involved in focus groups and throughout community observations and historical data collected by governmental agencies. The timing and sequence of research activities are presented in the following section.

\subsection{Implementing the investigative framework}

\subsubsection{Research process}

The empirical research process involved two field trips with a wide range of activities in Vietnam (Figure 4-7). The first lasted for 5 months, between May and October in 2013 and the second trip took place for two weeks, November $12-26,2014$. The field trip in 2013 produced a draft report and its selected findings were presented at a number of workshops at multiple levels of government during the second trip in order to obtain feedback. The engagement of diverse actors across multiple levels included three phases. 


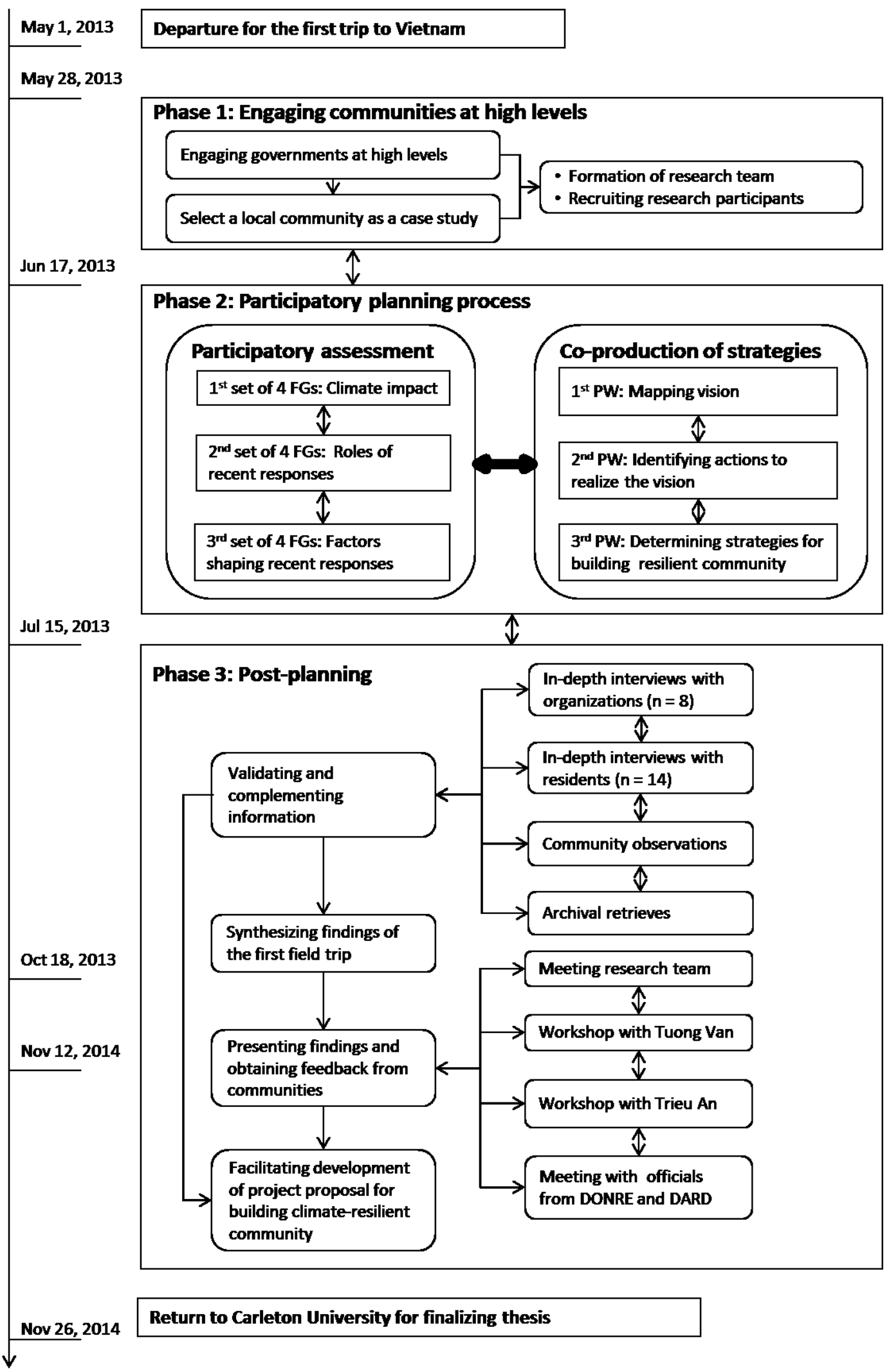

Figure 4-7: Key activities during the two field trips of the empirical research conducted in Vietnam 
In the first phase, governmental agencies from national to communal level were engaged to develop a research team. The empirical research started on May 20, 2013, but planning for the field work began during the first half of 2013 when the research proposal was finalized. This involved consultations via emails with the vice-directors of Quang Tri DARD and the Department of Science Technology and International Cooperation under Vietnam's Ministry of Agriculture and Rural Development. With their support, access to Tuong Van was obtained and the process of recruiting co-researchers to establish the research team began. As a result, two governmental officials from provincial agencies and three leaders of the village agreed to participate as members of the research team.

The second phase was the engagement with Tuong Van community in a participatory planning process, which took place between June 20 and July 1, 2013. A total of 25 community members, 13 participants from Lang and 12 members from Dong, were recruited throughout the research process using a random strategy. The planning process included two sequential components. The first involved community members in assessing recent impacts of a changing climate on the community, recent responses by the community to the changing climate and factors shaping the success of such responses. In the second component, community members used results from the assessment of existing conditions to produce strategies that help the community to enhance its resilience and reduce risks from future climate change.

The field research ended with a post-planning phase, which included three main activities. The first was additional data collection following the planning process by using in-depth interviews, community observations and archival retrievals. The second activity involved presenting selected findings of the first field trip and obtaining feedback from 
actors across multiple levels of government. In the final activity, several governmental agencies were engaged in assisting the community with seeking financial support for the implementation of the action plan that was developed in the second phase.

\subsubsection{Data collection methods}

\subsubsection{Focus group discussions}

Focus group discussions (FG) were the key instruments to address the first three research sub-questions. Twenty four villagers, 12 men and 12 women, were recruited by using a random sampling strategy, which was assisted with random numbers generated in an Excel spreadsheet and an official list of the village's households. Since Lang and Dong have a similar number of households and they have been affected differently by climate hazards, villagers were recruited with the same number and gender from each of Lang and Dong. Unexpectedly, the day before the first FG, one man from Lang came and asked to participate in the research. The research team accepted his interest, but also recognized that more requests might come and this could make the invited members uncomfortable. The research team planned for similar requests, but did not receive any additional interest.

FGs were held in the meeting room of the community for $2.5-3.5$ hours. The recruited members from each of Lang and Dong were divided into two groups. Each group had 6 7 members and its participants did not change throughout the research. Each FG was guided by semi-structured questions, as outlined in Table $4-5$, followed by a series of elaborated questions (Appendix 2). When the FG ended, the research team reviewed results of the meeting and participants were asked to remove or complement information 
if they felt adjustments were necessary. In addition, the team listened to the tape and identified any issues that needed to be clarified and complemented in the next FGs.

Table 4-5: Guiding questions for focus group discussions (FG)

Research questions

1. First set of FGs: How have climate hazards recently impacted the community?

\section{Guiding questions for FG}

- What are characteristics of the community such as livelihoods?

- What climate events have recently impacted their community?

- How have the climate events impacted different components of their community such as resources and livelihoods?

- How do community members evaluate the importance of the climate events?

- How do climate impacts vary with time and space?

- How have climate hazards interacted and co-affected their community?

2. Second set of FGs: $\quad-\quad$ To what extent is the national strategy on disaster risk reduction (NSD) How has the community recently addressed climate hazards? helpful for the community to address the changing climate?

- How has the community adopted the NSD to address storms and floods?

- How has the community addressed the changing climate in the absence of the NSD and the target national program on climate change (NTP)?

- How has the community mainstreamed their autonomous climate change adaptation into storm and flood disaster risk reduction (DRR)?

3. Third set of FGs: $\quad-\quad$ What are the successful and unsuccessful manifestations of recent Why have some of recent responses by the community reduced impacts of climate hazards, while some others been less interventions?

- How has multi-level governance of DRR and CCA determined the resilience of the community?

- How has the integration between DRR and CCA shaped the resilience of the community?

- How has the availability, quality and interplay of resources determined the success of DRR and CCA interventions? successful?

Three sets of FGs were conducted between June 20 and 27, 2013. The first set of four

FGs was used to investigate how participants perceive impacts of climate hazards on their families and the community as a whole. The research does not assume that the community is homogenous and that components of the community have been impacted by climate hazards and change in the same way. Thus, FGs first characterized components that participants perceived as important for their community, and then 
discussed spatial and temporal patterns of climate hazards and their impacts on these components and the community as a whole.

The second set of four FGs examined how the community has recently addressed climate hazards. Since the government of Vietnam introduced DRR and CCA programs across multiple levels, the assessment of recent interventions involved examining the role of the two programs, how they have been practiced, and how they could enhance the resilience of the community and reduce climate risks over the last three decades.

The final set of four FGs was used to analyse why some recent interventions have been helpful for the community to reduce impacts of climate hazards, while others have been less successful. To address these issues, each FG first probed how participants perceived the success and limitations of their responses to the changing climate. Subsequently, the FG explored and evaluated factors across multiple scales that have impeded and promoted the success of recent responses by the community. This included analysing the strengths and limitations of resources and their interplay in enhancing CR and reducing climate risks; exploring key factors shaping the process of developing and implementing DRR and CCA such as sectoral collaboration and coordination.

\subsubsection{Surveys}

Surveys were administrated to quantify and rank the importance of resources and climate hazards. Each of the 25 participants filled a survey matrix (see Appendix 3) with their perception about the importance magnitude of individual resources and the impact level of individual hazards that they identified in the first set of FGs. 
The survey matrix consisted of two components. The first was used to quantify and rank the importance of individual resources for each of Lang and Dong. The importance for a resource was scored at four scales: 0: no importance, 1 little importance, 2: moderate importance, and 3: high importance. The second component aimed to quantify the extent to which each hazard has recently impacted individual resources. The impact of a hazard on a resource was scored at four scales: 0 : no impact; 1: low impact, 2: moderate impact and 3: high impact.

Before conducting the surveys, the research team pretested and revised the matrix. At the end of the second set of FGs, the survey was conducted for $45-60$ minutes. The survey started with an explanation of its purpose, and then participants were instructed on how to record their perceptions in each cell of the survey matrix. Since some members were not very good at reading, co-researchers sat beside them and helped them fill the survey matrix. Following the surveys, all scores that each participant gave were put into an Excel spreadsheet. In order to rank the importance of resources for each of Lang and Dong, the importance indices for individual resources were calculated separately for the two residential areas. The importance index of a resource for Lang was calculated as the average score from 13 participants of Lang giving to such a resource, while the index for Lang was the average score from 12 participants of Dong giving to the resource.

In order to assess the extent to which climate hazards impacted the community, and to rank their importance, three types of index were used. The first is "overall impact index", which is defined as the impact magnitude of individual hazards on the five capitals (physical, financial, natural, human and social), each of which is a group of resources. The overall impact index of a hazard on a capital was tabulated as the sum of scores from 
25 participants given to all resources of that capital. The index was calculated for each of the five capitals in order to provide cross-capital comparisons.

When the overall impact index of a hazard on individual capitals was tabulated, the "total impact index" of individual hazards was generated. The total impact index of a hazard was calculated by summing all the overall impact indices of such a hazard. The total impact indices of hazards were then ranked in order of importance for the community.

The last type is "specific impact index" and it refers to the impact magnitude of a hazard on a resource. This index was calculated as the average score from all 25 participants given to a hazard for a resource. When all specific impact indices were generated, they were used to examine the extent to which each hazard impacted individual resources, and to compare the impact magnitude of a hazard on different resources amongst each of the five capitals.

\subsubsection{The strategic planning process}

Strategic planning was used as a systematic process to identify long-term goals and strategies that will promote critical transitions of the community to the desired conditions such as a resilient state (Grünig and Kühn 2011, Denton et al. 2014). Thus this was the key instrument to address the final research sub-question. The planning process started when the existing state of the community (the first three research sub-questions) was assessed. It included three phases, which took place in two community planning workshops. The first two phases took place for four hours in the workshop held on June 30, 2013, while the final phase was held for three hours in the other workshop that was conducted in the morning of the following day. In the planning workshops, participants sat in their own defined groups and the research team used FGs to guide participants in 
discussions. The workshops were guided by semi-structured questions as outlined in Table 4-6, followed by a series of elaborated questions (see Appendix 4).

The first phase of the planning process aimed to define a vision for the community five years in the future. While articulating a vision, individual groups first listed their own expectations, and then only one group was elected to present their own work while the other groups provided their feedback and discussed. Similar expectations for all groups were accepted, while differences were discussed further to decide if they were accepted or eliminated. When the accepted expectations were confirmed, participants classified their expectations into categories as elements of a vision in the next five years. In addition, the relationships among elements of the vision were also discussed.

Table 4-6: Guiding questions for the participatory planning process

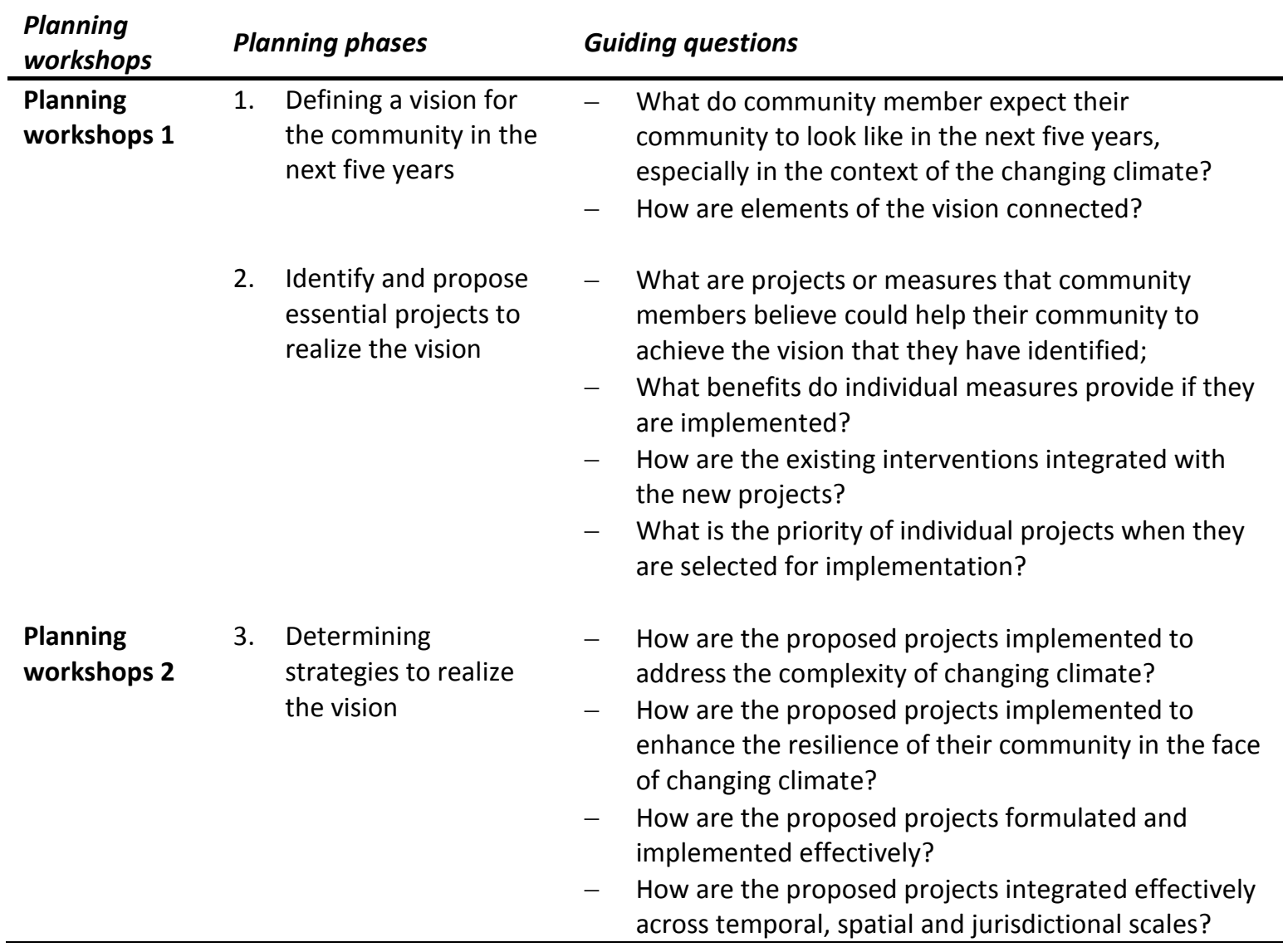


The second phase led to proposed projects or actions that participants believed could be essential inputs to realize the vision. This phase started with identifying any measures or activities that could contribute to realizing the vision, and then discussed these measures' potential benefits upon implementation.

Prioritizing the proposed projects began with identifying criteria that participants would use to rank the priority of the projects. Three criteria including urgency, availability of resources, and benefits were agreed on by participants as a whole (Table 4-7). The prioritizing exercise continued defining each criterion and indicators that were used as a reference to evaluate proposed projects. For instance, in order to evaluate benefits of a project, participants considered the extent to which the project would reduce climate impacts and improve their existing resources. The criteria were evaluated on the scale ranging from 0 to 5 .

The scoring for individual criteria is shown in Table 4-7. Each participant was provided with peanuts to score proposed projects. Participants sat in their own group and they ranked individual projects. When a project was chosen, participants individually dropped peanuts into a cup for a given criterion, and then all the peanuts in the cup were counted and recorded. When the scoring for the criterion was completed, the same process was used for the remaining criteria, and then for the other projects. The score of a project for a given criterion is the average number of peanuts from 25 participants for the criterion. Finally, participants used the scores to discuss and rank the overall priority of proposed projects. 
Table 4-7: The criteria and their definition used to prioritize proposed projects

\begin{tabular}{|c|c|c|c|}
\hline Criteria & Definition of criteria & $\begin{array}{l}\text { Example indicators of } \\
\text { criterion }\end{array}$ & Scoring \\
\hline Urgency & $\begin{array}{l}\text { Urgency criterion refers } \\
\text { to how urgent a project is } \\
\text { to be implemented. }\end{array}$ & $\begin{array}{l}\text { Right now or some years } \\
\text { later }\end{array}$ & $\begin{array}{l}\text { Dropping no peanut means } \\
\text { that the project was not } \\
\text { urgent at all; } 5 \text { peanuts } \\
\text { means very urgent. }\end{array}$ \\
\hline $\begin{array}{l}\text { Availability } \\
\text { of resources }\end{array}$ & $\begin{array}{l}\text { The criterion of the } \\
\text { availability of resources is } \\
\text { defined as how available } \\
\text { the resources such as } \\
\text { money or knowledge are } \\
\text { in the community to } \\
\text { implement a project. }\end{array}$ & $\begin{array}{l}\text { Physical resources: trucks } \\
\text { and wagons } \\
\text { Financial resources: cash, } \\
\text { fund } \\
\text { Natural resources: land, } \\
\text { freshwater; } \\
\text { Human resources: } \\
\text { knowledge and skills; } \\
\text { Social capital: collaboration } \\
\text { and regulations }\end{array}$ & $\begin{array}{l}\text { Dropping no peanut means } \\
\text { no available resources to } \\
\text { implement a project; } \\
\text { Dropping } 5 \text { peanuts means } \\
\text { sufficient resources to } \\
\text { implement the projects }\end{array}$ \\
\hline Benefits & $\begin{array}{l}\text { The criterion of benefits } \\
\text { refers to how beneficial a } \\
\text { project is to the } \\
\text { community. }\end{array}$ & $\begin{array}{l}\text { Impacts of climate hazards } \\
\text { that projects will reduce; } \\
\text { Resources that projects will } \\
\text { generate }\end{array}$ & $\begin{array}{l}\text { Dropping no peanut means } \\
\text { that the project was not } \\
\text { beneficial at all; } 5 \text { peanuts } \\
\text { means very beneficial. }\end{array}$ \\
\hline
\end{tabular}

Source: the prioritizing exercise in July 2013

In the final phase of the planning process, participants discussed how their proposed projects will be implemented effectively to realize the vision of the community five years in the future. They started by discussing about how the projects might be implemented to address the complexity of changing climate, for instance multiplicity and interactions of climate hazards. Secondly, participants identified solutions for enhancing the resilience of their community in the face of changing climate. Subsequently, they identified ways to promote the process of formulating and implementing DRR and CCA across multiple scales. Finally, community members obtained insight into how DRR and CCA projects will be integrated more effectively across temporal, spatial and jurisdictional scales. 


\subsubsection{In-depth interviews}

Following the planning process, in-depth interviews were used to complement and validate information that might not have been discussed during FGs and the planning workshops due to sensitive issues or absence of critical actors. All informants were identified by using a snowball sampling strategy, which identifies an initial participant who is used to provide the names of other actors (Browne 2005). Interviews were conducted between July and September 2013 and they were conducted for 30 - 90 minutes depending on the availability of informants.

Interviews were held using interview transcripts with prepared questions on different topics (see Appendix 5). All interviews with staff of governmental and non-governmental agencies were audio-recorded. Yet, the conversations with local residents and members

of local associations were not audio-recorded for two reasons. First, most informants felt uncomfortable with the device; and secondly they often moved around their house to do their housework, such as taking care of children, or attending to poultry; thus making the use of a recording device very difficult. Therefore, instead of audio-recording, careful notes were taken for interviews with these participants.

A total of 14 local residents including 10 Tuong Van villagers and two residents for each of An Loi and Ha La villages were interviewed. Six officials from governmental agencies across multiple levels and two officers from non-governmental organizations were also interviewed in order to assess the role of these agencies in recent and future formulation and implementation of DRR and CCA programs in the community. In addition, one member from each of the four local associations in Tuong Van was interviewed. 


\subsubsection{Community observations and archival retrievals}

Throughout the field research, a series of community observations were made to complement information that was not gathered from other methods as well as to validate information that was obtained from FGs, in-depth interviews and planning workshops. The researcher made frequent informal visits to Tuong Van, its surrounding environment and neighbouring communities. Since the research was conducted between May and October, there were excellent opportunities to observe the actual impacts of climate hazards and responses of Tuong Van community in both dry and rainy seasons. During these visits, not only were community behaviours observed but also informal conversations were held with local residents on various topics.

Secondary data and grey literature from diverse sources were also collected. For instance, historical data of hydro-meteorological and social-economic parameters were obtained from governmental agencies, while grey literature included government reports and online news of the governmental and non-governmental agencies. Some secondary data and grey literature were collected both during the development of the research proposal, but mostly obtained during the research visit in Vietnam.

\subsubsection{Bigger picture: complementarity across multiple methods}

Figure 4-8 illustrates an example of the complementarity across multiple methods that were used to collect information for assessing existing conditions and developing strategies to enhance CR. At least three methods including focus group discussions, community observations and in-depth interviews were used in combination throughout the research process to facilitate the validity and reality of information. For instance, information about dyke erosion was not only obtained from FGs, but following group 
discussions the research team and participants also went to and looked at eroded sections of the dyke, and discussed possible causes and solutions for the erosion. These causes and solutions were then used to contrast with information obtained from in-depth interviews with local residents and staff from various organizations.

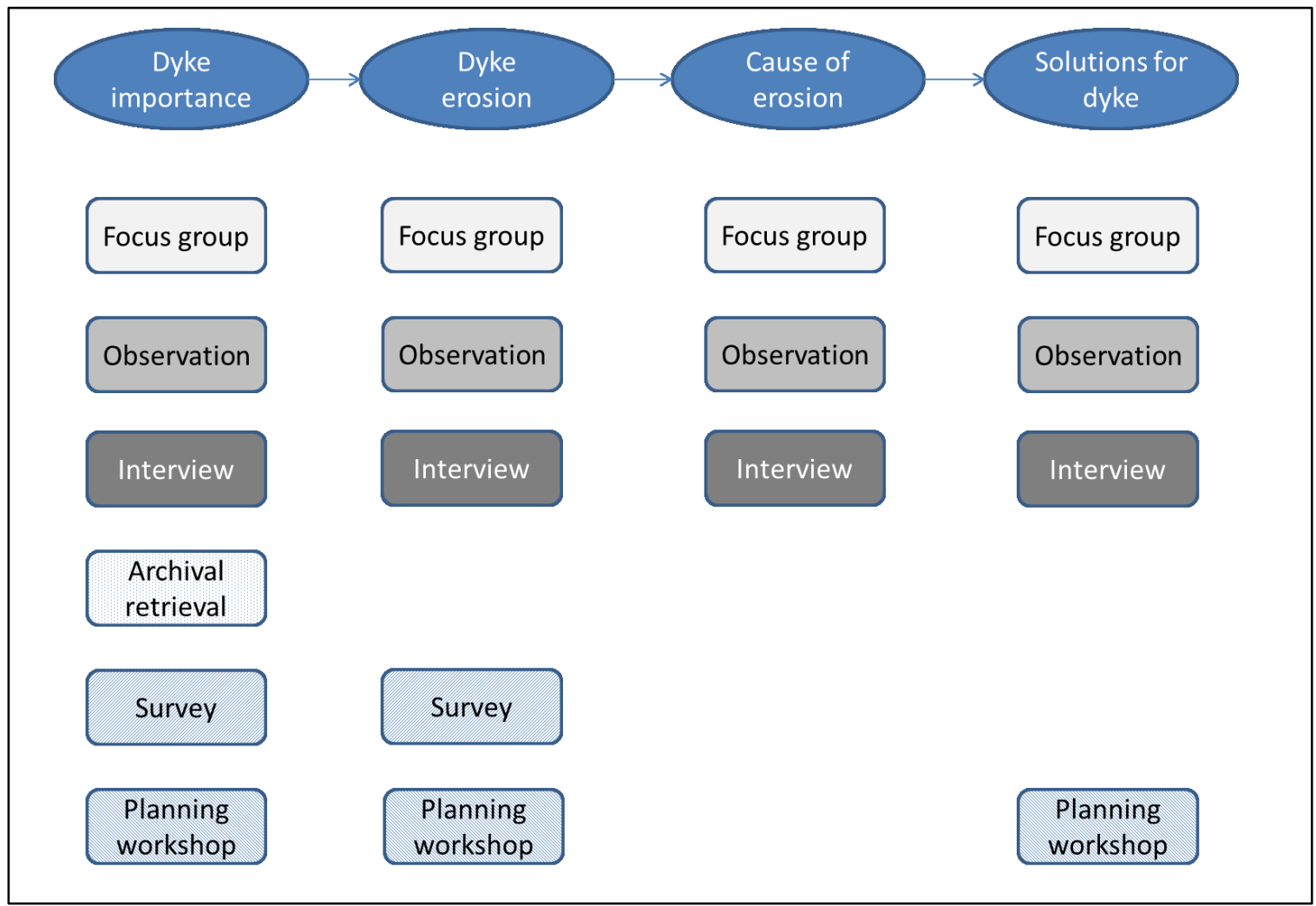

Figure 4-8: Complementarity across multiple methods for data collection

\subsection{Moving beyond data: analysis and interpretation of the}

\section{collected data}

This research involved collecting various types of information such as audiotapes and photographs and different tools were used to manage and analyse them. Throughout the fieldwork, journal notes were always used to record field experiences and they were typed up in Vietnamese as soon as possible. All audiotapes were transcribed in their entirety in the evening of the day they were recorded. Audio-data, electronic transcripts 
and notes were stored on an external hard drive that was kept in a locked filing cabinet, while printed transcripts and identification codes were kept in a separate locked cabinet.

Data analysis was conducted using a dynamic and cyclical process involved classifying or categorizing collected information into issues or themes, and constructing them around the research questions. Data analysis occurred at every step of the research process in order to share preliminary findings among members of research team and participants as well as to provide foundation for next steps.

Data analysis also involved contrasting, complementing and validating information from different sources. For instance, the findings from FGs were validated, complemented and contrasted with information that was collected during in-depth interviews, community observations and archival retrieves. In addition, some photographs were also used to illustrate information that could not be explained effectively in words. Pictures including participants who requested personal confidentiality were not used in this research.

\section{Synthesis of Chapter 4}

Chapter 4 presented the research framework and methodologies that were used for the field research. Tuong Van village in Quang Tri province was selected as a case study in order to promote an in-depth analysis of complex phenomena within the community. In addition, the field research used PAR approaches, through which multiple levels of government and members of Tuong Van community were engaged, in order to maximize the policy implications.

The field research process included two field trips. The first was conducted between May and October of 2013 in order to produce preliminary findings of the research, while the 
second was used to present the findings to diverse actors across multiple jurisdictional levels and to obtain their feedback before the thesis was completed. A combination of data collection methods was used to address multidimensional and interconnected issues of the research. FGs and community planning workshops were the primary tools, while surveys, in-depth interviews, community observations, archival retrievals were used not only to complement but also to validate the information collected during FGs and planning workshops. 


\section{CHAPTER 5: COMMUNITY PERSPECTIVES ON THE IMPACTS OF CLIMATE HAZARDS}

\section{Research sub-question 1: $\quad H o w$ have climate hazards recently impacted central Vietnam's coastal communities?}

Chapter 5 investigates how climate hazards have impacted Tuong Van community over the last three decades. The chapter builds upon the climate risk research field, and explores causes and effects from complex interactions between communities and climate events. Previous research on climate risk suggests that the extent to which a climate event impacts a community is dependent on the characteristics of both climate events and the community (Thomalla et al. 2006). Thus, the chapter is structured into two sections. The first provides an overview of the community's biophysical and social-economic characteristics setting a foundation for deeper analysis and discussion at later stages. The second section characterises climate-related hazards and assesses their impacts on the community.

\subsection{Recent characteristics of Tuong Van community}

Tuong Van community is viewed as a complex system consisting of diverse entities interacting with each other and with external environments. Humans are the essential component of the community and they cannot live without their resources such as freshwater and foods. This section starts with an overview of the human component and its connection with external environment, and will then characterize resources that are 
used as the critical base for livelihood development, key determinants of the vulnerability and resilience of the human component in climatic conditions (Tompkins and Adger 2004, Brklacich 2006, Marschke and Berkes 2006).

\subsubsection{An overview of geographical and social-economic conditions}

As described in the methods chapter, Tuong Van is one of the five villages that are

administrated by Trieu An commune under Trieu Phong district. Two residential areas, Lang and Dong, have socially close relationships and share a number of social and economic activities. They not only share the same local-level governmental administrative system and formal social networks such as unions of farmers and women, but many families in one residential area have relatives in the other.

Lang and Dong have similar social and economic characteristics, but the former has a higher level of exposure to hazardous zones including the Thach Han River and the Cua Viet Sea (Figure 5-1). Lang is located closer to the Thach Han River, which annually brings floods to local residents. In addition, Lang is on low land and near the river mouth opening to the Cua Viet Sea, which commonly receives strong winds and storm surges. In contrast, Dong residents not only live on higher land, but are also shielded from the more hazardous zones by An Loi village and Lang.

Tuong Van is connected formally and informally with its neighbouring villages. For instance, the community is not only joined with the other four villages of the Trieu An community in the governmental program of storm and flood disaster risk reduction, but many families in the community have relatives in Ha Tay and Thanh Xuan villages. In addition, Tuong Van is connected with villages of other neighbouring communes. For 
example, Lang residents are involved in some livelihoods on the Bac Phuoc alluvial islet of Trieu Phuoc commune, despite being separated by the Thach Han River.

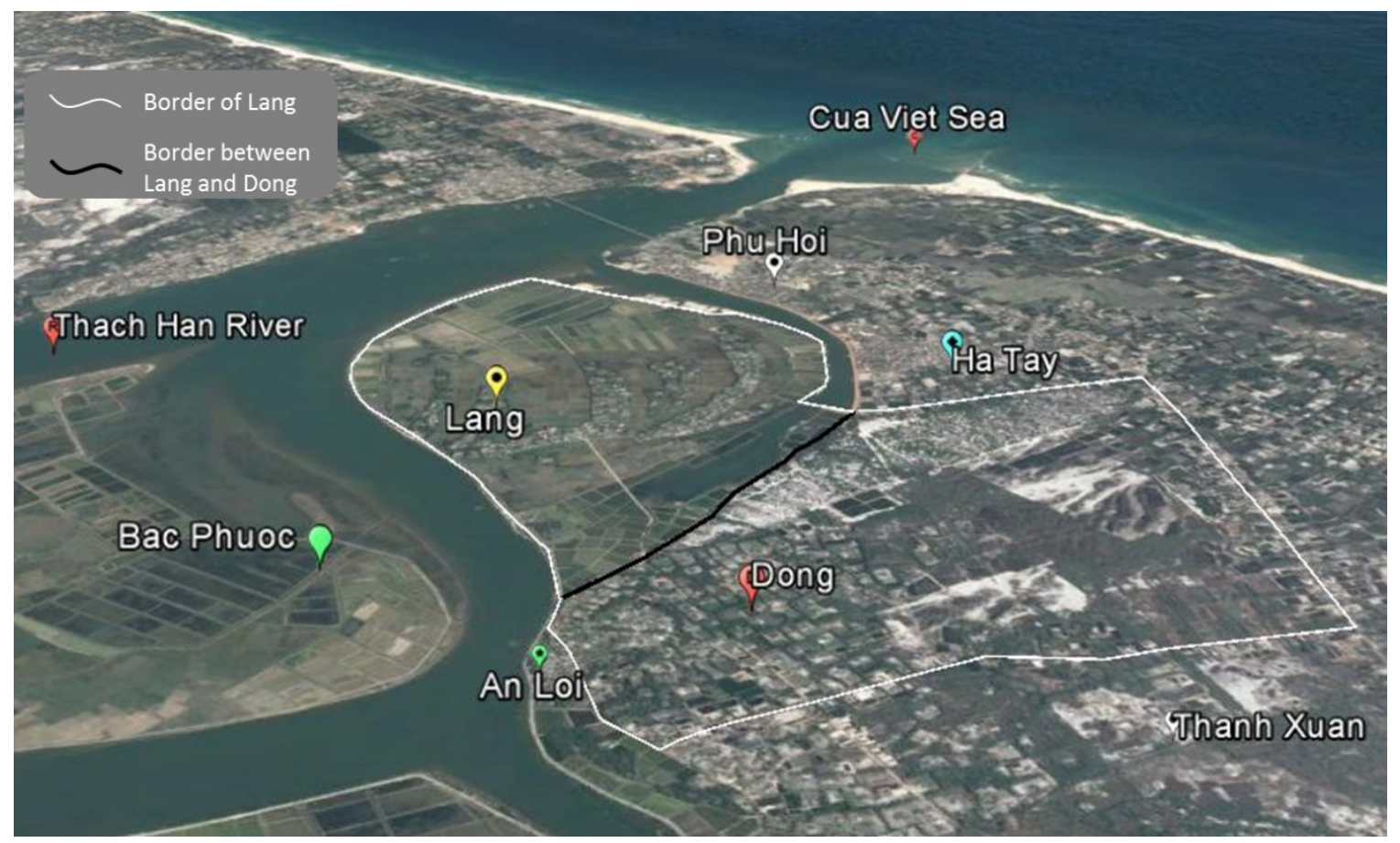

Figure 5-1: Geographical location of Tuong Van and its connection with other villages of Trieu An

Source: the map was adopted from the Google Earth

Focus group discussions (FG) showed that the village depends on at least 12 livelihoods, which provide local residents with financial resources and food. Survey data showed most households in Tuong Van had a diversity of livelihoods, but agriculture was the key sector. The agriculture sector consists of animal production including poultry (e.g. chickens and ducks), husbandry (e.g. pigs and cows) and subsidiary crop ${ }^{3}$ and rice production. In addition to agriculture, the survey data showed about $50 \%$ of the households in the community were involved in aquaculture and forestation and a small number of households participated in exploitation of aquatic resources such as wild

\footnotetext{
${ }^{3}$ Subsidiary crops include vegetables, sweet potatoes, beans and peanuts
} 
shrimps and river clams as well as collection of pharmacy materials, for instance Coc Thanh Thao and nut-grass.

Figure 5-2 shows several important features about livelihoods in Lang and Dong. First, residents in both residential areas are economically diverse and routinely involved in several key activities. The most important livelihoods for both Lang and Dong are rice (L2), subsidiary crop (L3) and animal (L10) production, remittance (L5) and collection of Coc Thanh Thao ${ }^{4}$ (L9) as they provide at least $30 \%$ of households with major sources of food and income.

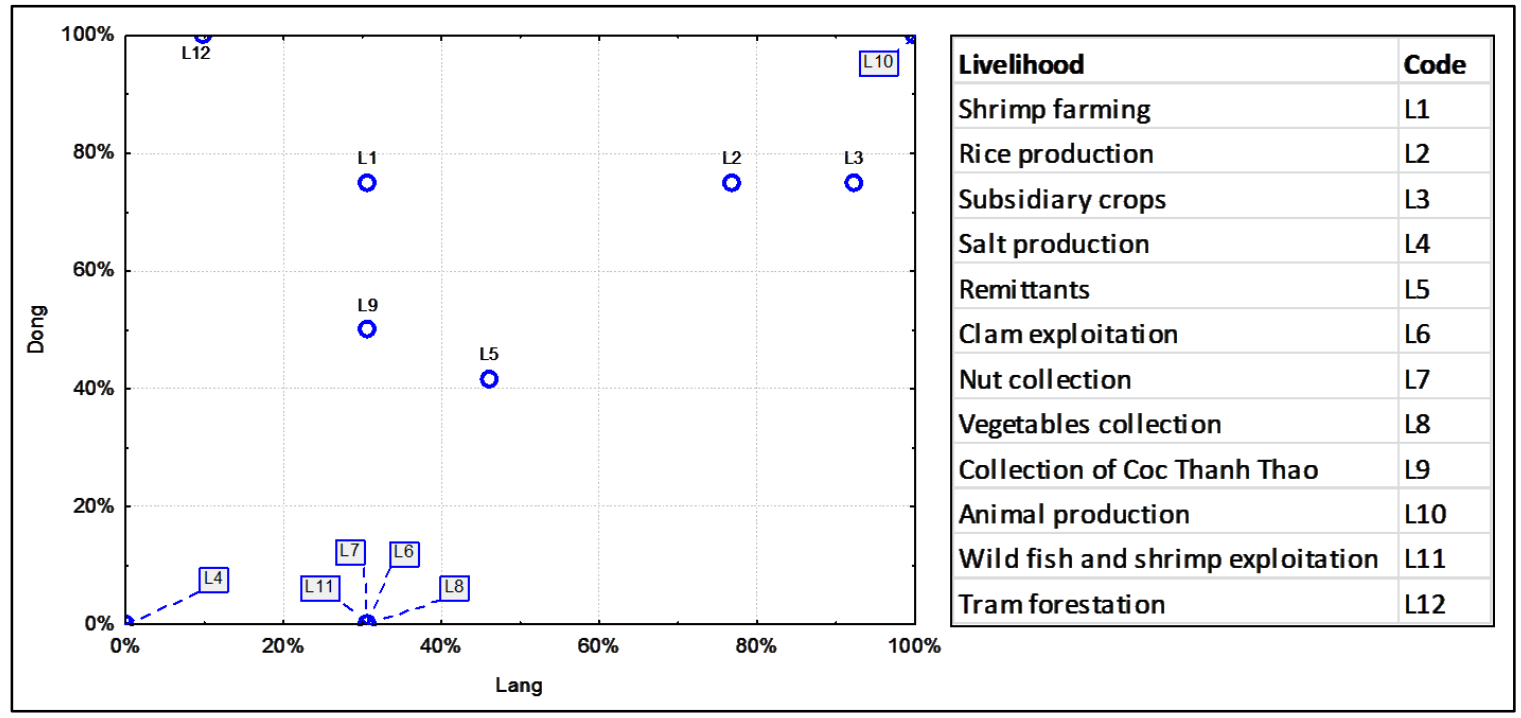

Figure 5-2: The proportion of households involving in different livelihoods in Lang against Dong Source: the survey to focus group participants in June 2013

There are some differences in livelihood development between Lang and Dong. Most households in Dong have planted Tram trees (L12) on their gardens since the early 2000s to generate additional income because land in Dong is mostly covered with sand and is not suited to subsidiary crops. In contrast, land in Lang is of rich soil and more suited to

\footnotetext{
${ }^{4}$ Coc Thanh Thao is a local name of a plant species, which belong to Eriocaulaceae genus. Coc Thanh Thao is collected by local residents and sold to pharmacy factories;
} 
subsidiary crops, thus Lang residents tend to lease their shrimp farms (L1) to Dong residents and they concentrate on subsidiary crop production on their gardens.

Besides common livelihoods for villagers in the two areas, only Lang residents are involved in exploiting wild fish and shrimps (L11) as well as bitter vegetables (L8) in their post-harvest farms, and nut-grasses (L7) because they live close to such resources. Dong villagers are not involved in such livelihoods, but they predominate in Coc Thanh Thao collection as a source of pharmacy materials for sales because these plants only grow well on sandy hills in Dong and its neighbouring villages.

\subsubsection{Resources and their importance}

Through FGs, at least 50 resources $^{5}$ were identified as the most important resources for the community to develop livelihoods and address climate hazards. This section does not describe every resource, but provides an overview of the typology, distribution and importance of resources in order to set a foundation for a deeper analysis at later stages. The question about how these resources have been impacted by climate hazards will be discussed in Section 5.2, while the concern about how they have been invested and used to enhance $\mathrm{CR}$ and reduce climate impacts is addressed in the next chapter.

\subsubsection{Resource classification}

Participants classified their resources into five groups under two broader categories: human and non-human resources. These two categories were similar to those addressed (structural and non-structural) in public policies across multiple levels of government. Human resources were separated to two groups, collective and personal resources. The

\footnotetext{
${ }^{5}$ These resources will be summarized later in this section.
} 
former was seen as social resources such as regulations and associations, while the latter was viewed as the belongings of individuals, for instance personal health and skills. Nonhuman resources were divided into three groups including financial, natural and manmade resources. Natural resources were seen as materials produced by nature, while manmade resources were resources created directly or indirectly by someone, for instance flood dykes and houses. The last group is financial resources, which participants conceived as a special form of other resources when they were sold. Some examples of financial resources in Tuong Van include cash, insurance and credits.

When participants were asked to contrast the five groups of resources they defined with the five capitals (financial, physical, natural, human and social capitals) classified by Porritt (2007), they affirmed that these two systems of classification were almost the same. In addition, participants suggested using the five groups rather than individual resources for later discussions and this advice was followed. However, this also posed challenges as some resources might fall into more than one category. Take the example of leadership. Most participants referred to leadership as a group of leaders such as the leadership boards of a village or a commune and viewed leadership as a social resource. Nonetheless, they also argued that leadership can refer to the resource of a person and thus can be considered a human resource. This suggests the confusion with the classification of a resource into social or human capital might occur if the description of the resource is not specified.

\subsubsection{The five capitals: diversity, distribution and ownership of resources}

Community members identified at least 14 natural resources as important to enhance the capacity of their community and reduce climate impacts (Table 5-1). Some natural 
resources such as underground water and gardens are common for both Lang and Dong, but many other resources are not distributed evenly. For instance, bamboos and land for rice and shrimp farming are mainly found in Lang, while Tram forests and Coc Thanh Thao are more available in Dong. In addition, the quality of some natural resources is different between Lang and Dong. As an example, gardens in Lang have rich soil, while those in Dong are mostly covered with sand. The availability and quality of some natural resources varies over time. For example, freshwater is more available and better quality in rainy seasons, but it is scarce and salinized in dry months.

Resources also have different types of ownership (Table 5-1). Some resources, for instance bamboo and Tram forests, are owned by individual households, while others such as freshwater and wild fish are common pools. In addition, the time of ownership varies among natural resources. For example, bamboo and gardens are permanent resources of local residents, but aquaculture land is allocated by the communal government through tenure to shrimp farmers for some years. 
Table 5-1: Distribution and ownership of natural resources across Tuong Van community

\begin{tabular}{|c|c|c|c|c|}
\hline \multirow[t]{2}{*}{ Natural resources } & \multirow[t]{2}{*}{ Mode of ownership } & \multicolumn{2}{|c|}{$\begin{array}{l}\text { Proportion of households } \\
\text { owning resources (\%) }\end{array}$} & \multirow[t]{2}{*}{ Location } \\
\hline & & Lang & Dong & \\
\hline Paddy rice land & Public for $20-30$ years & 77 & 83 & $100 \%$ in Lang \\
\hline Aquaculture land & Public for 2 - 5 years & 31 & 75 & $100 \%$ in Lang \\
\hline Salt production land & Public for $3-5$ years & 0 & 0 & $100 \%$ in Lang \\
\hline $\begin{array}{l}\text { Subsidiary crop land } \\
\text { (garden) }\end{array}$ & Permanent & 92 & 75 & Majority in Lang \\
\hline Bamboos & Permanent $^{6}$ & 100 & 100 & Majority in Lang \\
\hline Tram forest & Permanent & 38 & 83 & Majority in Dong \\
\hline Domestic use water & Public $^{7}$ & & & Majority in Dong \\
\hline Production water & Public & & & Majority in Dong \\
\hline Coc Thanh thao & Public & & & Majority in Dong \\
\hline Salt-tolerant trees & Public & & & $100 \%$ in Lang \\
\hline Wild fish and shrimp & Public & & & $100 \%$ in Lang \\
\hline River clam & Public & & & $100 \%$ in Lang \\
\hline Nut grass & Public & & & $100 \%$ in Lang \\
\hline Bitter vegetable & Public & & & $100 \%$ in Lang \\
\hline
\end{tabular}

Source: the survey to focus group participants and interviews with local residents in June 2013

Tuong Van has a wide range of physical resources and they are owned by either individual households or by the community as a whole (Table 5-2). For instance, flood dykes and roads are the properties of the whole community, while drilled wells and life vests are properties of individual households. Physical resources are unevenly distributed across the community. Some resources, for instance a system of concrete roads is available in both Lang and Dong, but others such as flood dykes and shrimp farms are located in either Lang or Dong although they have been used by residents in both the residential areas.

The community has a diverse set of financial resources including cash, loans, bank saving, credit and insurance. However, bank saving, credit and insurance are not common in the village. In contrast, local residents commonly keep some cash from sales of crops

\footnotetext{
${ }^{6}$ Private

${ }^{7}$ Open access
} 
for daily expenses and livelihood reinvestment. In addition, survey data showed that approximately a half of the community had loans from different sources such as banks and their relatives.

Table 5-2: Distribution and ownership of physical resources across Tuong Van community

\begin{tabular}{|c|c|c|c|c|}
\hline \multirow[t]{2}{*}{ Physical resources } & \multirow[t]{2}{*}{$\begin{array}{c}\text { Mode of } \\
\text { ownership }\end{array}$} & \multicolumn{2}{|c|}{$\begin{array}{l}\text { Proportion of households } \\
\text { owning resources (\%) }\end{array}$} & \multirow[t]{2}{*}{$\begin{array}{l}\text { Major place of } \\
\text { resources }\end{array}$} \\
\hline & & Lang & Dong & \\
\hline Flood dykes & Public & & & $100 \%$ in Lang \\
\hline Bridges & Public & & & $100 \%$ in Lang \\
\hline Drainage system & Public & & & Dong and Lang \\
\hline Roads & Public & & & Dong and Lang \\
\hline Commune clinic centre & Public & & & Ha Tay village \\
\hline Water tower & Public & & & $100 \%$ in Lang \\
\hline Electricity system & Public & & & Dong and Lang \\
\hline Drilled wells & Private & 85 & 83 & Dong and Lang \\
\hline Ground wells & Private & 69 & 50 & Dong and Lang \\
\hline House with floors or shelves & Private & 69 & 75 & Dong and Lang \\
\hline $\begin{array}{l}\text { Home communications } \\
\text { equipment }\end{array}$ & Private & 100 & 100 & Dong and Lang \\
\hline Storm shelters (household) & Private & 0 & 17 & $100 \%$ in Dong \\
\hline Life vests & Private & 0 & 8 & $100 \%$ in Dong \\
\hline
\end{tabular}

Source: the survey to focus group participants and interviews with local residents in June 2013

Besides natural, physical and financial resources, Tuong Van also has social and human resources that are essential for enhancing community capacities and reduce climate impacts. Throughout the FGs, seven forms of social capital were identified, but interviews and archival retrievals showed that the community also has some other critical resources such as legal documents and informal norms that promote the process of formulating and implementing projects to reduce climate impacts. In addition to social resources, all residents have their own personal resources to deal with climate hazards, for instance personal health as well as knowledge on livelihood development and disaster risk reduction. These human and social resources will be illustrated later in this section. 


\subsubsection{Ranked Importance of Resources}

Through the first set of FGs, participants identified resources that are critical for the community to develop livelihoods and reduce climate risks, but which resources are the most important for Lang and Dong were not identified in these FGs. In addition, the reason why resources play different roles between the two residential areas remains unclear. The first concern is addressed in this section, while the second question will be discussed in Chapters 6 and 7. In order to examine the importance level of resources, the importance indices for individual resources are tabulated separately for Lang and Dong and they are used to compare the role of resources between the two residential areas (Figure 5-3). 

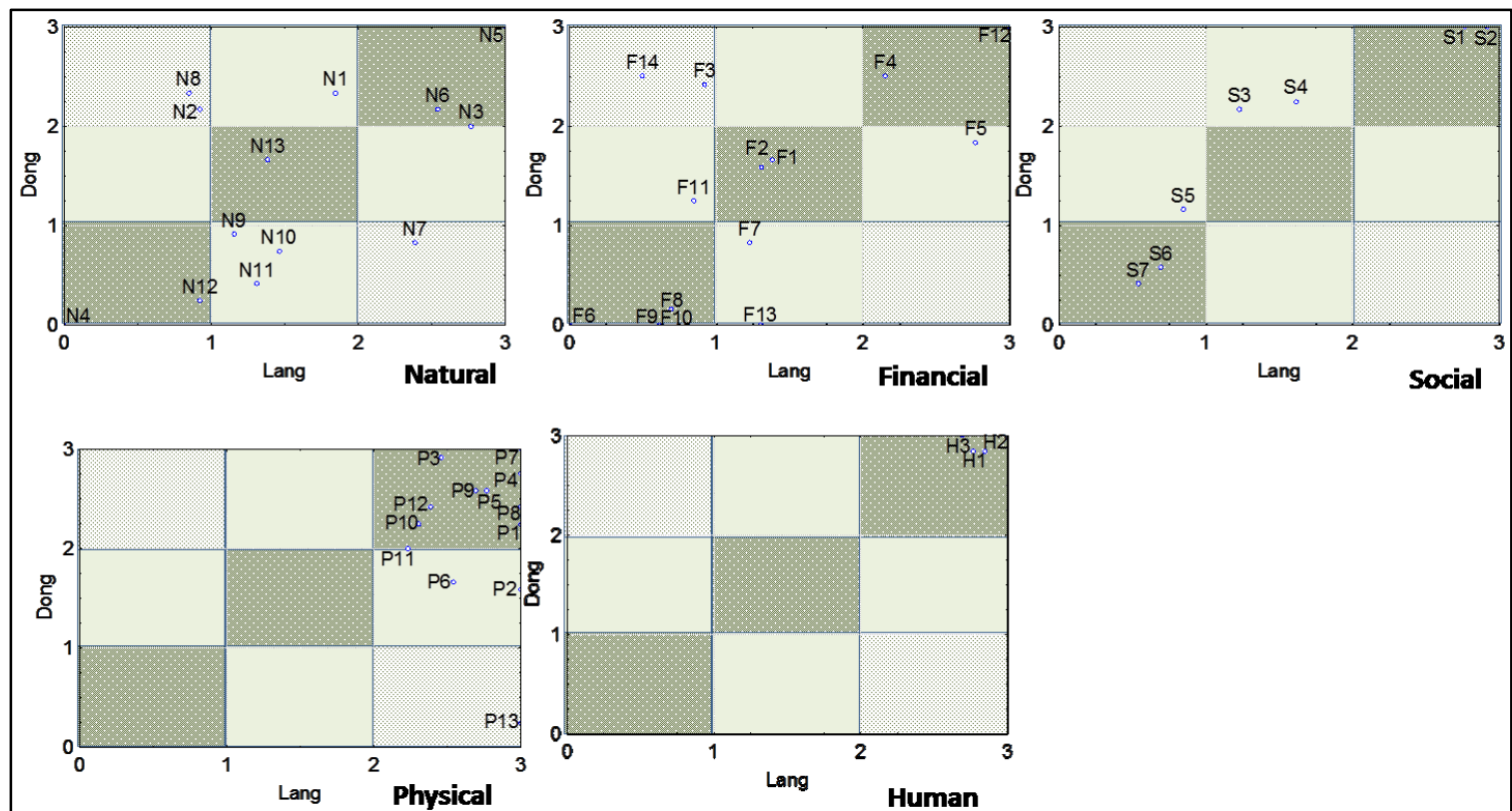

\section{Legend}

0-1: No importance; 1-2: Little importance; 2-3: High importance

Very similar

Quite similar

Very different

\begin{tabular}{|l|l|l|l|l|l|l|}
\hline Natural & Code & Physical & Code & Financial & Code & Social \\
\hline Rice land & N1 & Dykes & P1 & Loans & F1 & Neighborhood \\
\hline Shrimp land & N2 & Bridge & P2 & Village funds & F2 & Kinship \\
\hline Crop land & N3 & Drainage & P3 & Shrimp farming & F3 & Farmers' Union \\
\hline Salt land & N4 & Roads & P4 & Rice production & F4 & Women Union \\
\hline Domestic water & N5 & Drilled wells & P5 & Subsidiary crops & F5 & Veteran \\
\hline Crop water & N6 & Ground wells & P6 & Salt production & F6 & Youth Union \\
\hline Bamboo & N7 & House & P7 & Remittance & F7 & Fatherland Front \\
\hline Tram & N8 & Electricity & P8 & Clam exploitation & F8 & Human \\
\hline Salt trees & N9 & Equipment & P9 & Nut collection & F9 & Knowledge about DRR \\
\hline Clam & N10 & Clinic center & P10 & Vegetable collection & F10 & Knowledge about livelihood \\
\hline Nut grass & N11 & Life vests & P11 & Collection of CT & F11 & Health \\
\hline Bitter vegetable & N12 & Storm shelters & P12 & Animal production & F12 & \\
\hline Coc tinh thao (CTT) & N13 & Water tower & P13 & Wild fish exploitation & F13 & \\
\hline & & & & Tram forestation & F14 & \\
\hline
\end{tabular}

Figure 5-3: The importance index for individual resources perceived separately by Lang and Dong.

Source: the survey to focus group participants in June 2013

\section{Natural Capital}

Among 13 forms of natural capital, land for subsidiary crop (N3) as well as water for crop production (N6) and domestic use (N5) are highly important for both Lang and Dong, while land for salt production (N4) and bitter vegetables (N12) are not appreciated 
by residents in both the two residential areas. However, many resources were evaluated differently. Bamboos (N7), salt-tolerant trees (N9), clams (N10) and nut grasses (N11) were important for Lang, but less so for Dong. In contrast, land for rice production (N1), shrimp farms (N2) and Tram forests (N8) were highly critical for Dong, but they were of low importance for Lang.

\section{Financial Capital}

Paddy rice, subsidiary crop and animal productions (F4, F5 and F12, respectively) were highly important for both Lang and Dong because they involved and provided most households with main sources of food and income. In contrast, the exploitation of river clams (F8), the collection of but grasses (F9) and vegetables (F10) had a low level of importance. However, discussions from FGs showed that these resources were particularly important for the poor and women. Some financial resources were ranked differently between Lang and Dong. Shrimp farming (F3), Coc Thanh Thao collection and wild fish exploitation (F14) were highly important for Dong, but they were less appreciated by Lang residents.

\section{$\underline{\text { Social Capital }}$}

As illustrated earlier, there were at least seven social resources that participants identified in FGs as the important capacities to address climate hazards. The importance of these resources varied slightly between Lang and Dong. Informal networks such as kinship and neighbourhood had the highest scores and they were highly important for both Lang and Dong, while formal networks including the veteran's association, youth's union and the Fatherland were evaluated at the low level of importance. One of the reasons for the different importance between the formal and informal networks is related to benefits and 
needs of the community. Formal networks have existed for the interest of the governments rather than community members, while neighbourhood and kinship were fully based on their actual needs. Chapters 6 and 7 will examine in more detail reasons why the importance of social resources was evaluated differently.

\section{Physical Capital}

Unlike natural, financial and social capitals, most resources of physical capital were ranked as highly important for both Dong and Lang. Some physical resources including the bridge between Lang and Ha Tay village, as well as the system of fresh water supply were only highly important for Dong. The difference in the importance of the two resources between the two residential areas was accounted for with two reasons. First, the utility of these resources was different between Lang and Dong. For instance, Lang residents used the bridge for daily transport and evacuation more often than Dong. Secondly, the difference was explained by the availability of alternative resources. The system of freshwater supply was less important for Dong residents, because their drilled and dug wells could provide enough water for their daily use, while water from this type of wells in Lang was severely salinized and aluminized during the summers.

\section{Human Capital}

Six human resources were identified, but only knowledge about DRR and livelihoods as well as personal health were selected for analysis. All the three selected resources were evaluated as highly important for both Lang and Dong. The three others including leadership, attitudes and behaviours of community members towards disaster risk reduction were excluded because they were identified after the questionnaire was 
developed. Although they were not evaluated in this section, their importance will be further discussed in the next two chapters.

In summary, local residents live on agriculture, aquaculture, forestry and exploitation of natural resources. Agriculture is the key sector as it provides almost all households in the community with a major source of food and income. Agriculture includes diverse activities, but most households live on subsidiary and rice cultivation as well as on livestock and poultry production. In addition to the agriculture sector, local residents also have some alternative livelihoods such as exploitation of river clams and wild shrimp.

The community has a diverse set of resources and participants classified them into five groups (financial, physical, natural, human and social), which are consistent with the five capitals defined by (Porritt 2007). These resources are the essential base for livelihoods and human security and unevenly distributed across the community. For instance, wild fish and clams are concentrated in Lang, while others such as Tram forests and Coc Thanh Thao are mainly distributed in Dong. Many other resources, for instance the land for rice and shrimp production and flood dykes, are concentrated in Lang.

The importance of some resources is similar between Lang and Dong. For instance, most physical and human resources that were identified in the FGs were ranked as highly important for both Lang and Dong. However, some resources were not equally acknowledged by residents in the two residential areas. For instance, bamboo trees are vital for Lang, but they are less appreciated by Dong residents. The reasons why resources are evaluated differently will be examined further in Chapters 6 and 7.

The five capitals and livelihoods are two key components of the community. Discussions from FGs and interviews revealed that elements within and between these components do 
not exist independently, but are interconnected. For instance, the community built flood dykes and planted bamboos to protect the life and the livelihood of local residents from annual floods and storms. Given secured livelihoods, local residents might have more and better quality foods to enhance their life and build houses that are more resistant to storms and floods.

\subsection{Complex impacts of climate hazards on Tuong Van community}

\subsubsection{Characteristics of climate hazards in Tuong Van community}

\subsubsection{Diversity and spatial patterns of climate-related hazards}

Climate-related hazards are too numerous to count. However, if you write them on the board, we can list the most important ones that have impacted our community. (LDPV, 71)

Tuong Van is exposed directly to the Thach Han River, which is approximately 800 meters wide (Table 5-3 and Figure 5-1) and annually brings floods to the community. The village is about $1.5 \mathrm{~km}$ away from the mouth of the river opening to the Cua Viet Sea, which commonly receives strong winds and storm surges. Moreover, the community is frequently flooded by high tides because most of its land is no more than 4 meters above sea level.

Community members identified at least nine climate-related hazards that have threatened their community over the last three decades. These hazards involve rapid onset events such as storms and floods as well as gradual and prolonged stressors, including droughts, salinization, erosion, northeast and southwest monsoons, flooding ${ }^{8}$ induced by heavy rains and high tides. Some other hazards such as hailstorms and whirlwinds have

\footnotetext{
${ }^{8}$ Local residents refer flooding to inundation that persists for a long period, $1-3$ months, while they conceive a flood as a rapid overflow of water from the river onto their plains and houses.
} 
frequently occurred in Quang Tri and many central provinces (GOV 2007b, QT-PPC 2013), but residents claimed that their community has rarely experienced such threats.

Table 5-3: The differences in biophysical conditions between Tuong Van Lang and Tuong Van Dong

\begin{tabular}{lll} 
Biophysical characteristics & Tuong Van Lang & Tuong Van Dong \\
\hline Area of land (ha) & 110 & 100 \\
Land for shrimp culture (ha) & $50-55$ & $10-15$ \\
Land for rice production (ha) & $48-52$ & $0-1.5$ \\
Land for salt production (ha) & $7-8$ & 0 \\
Land for subsidiary crops and vegetables (ha) & $10-12$ & $18-20$ \\
Land for forestation (ha) & $0.5-1$ & $15-25$ \\
Elevation (m above sea level) & $0-4$ & $0-5$ \\
Distance from the East Sea (km) & 1.5 & 2.5 \\
Geographical conditions & Flat & Many dunes and valleys \\
Flooding & By high tides & By heavy rains \\
Soil & Alluvial & Sandy \\
\hline
\end{tabular}

Source: Land-use from Nguyen (2010b) and Pham (2012), the elevation and distance from the sea was estimated from the Google Earth, and other information from community observations

Despite being in the same village, Lang and Dong have been impacted by climate hazards in different ways due to biophysical and social-economic differences. Lang is more likely to experience annual floods because of its more exposure to the river. In addition, Lang is located closer to the sea and most of its land is no more than four meters above sea level. As such, Lang is not only inundated by high tides, but also threatened by storm surges coming from the sea. Further discussion on impacts of climate hazards on the community will be presented later in this section.

Unlike Lang, Dong is not threatened by annual floods and tidal flooding due to its location on higher land. However, Dong suffers more from heavy rain-induced flooding. Dong residents live in valleys below sandy dunes, where most of their livelihoods mainly take place. Dong has a number of canals draining water to the Thach Han River, but they are too narrow and regularly blocked by brush and debris from nearby erosion. Thus, not only are the lives of Dong residents threatened annually by flooding throughout the rainy 
seasons, but their livelihoods from gardens are as well. During summers, Dong residents suffer from the southwest monsoons (extremely hot and dry) and droughts.

\subsubsection{Temporal patterns of climate hazards}

Climate hazards threaten the community throughout the year, but most losses have been recorded during the dry and rainy seasons (Table 5-4 and Figure 5-4). Between April and August is the driest period and the village suffers from the compounding effects of prevailing southwest monsoons, droughts and salinization. However, most participants affirmed that the southwest monsoons have become less dry and hot over the past three decades because rains occur more often in these seasons. The interactions amongst climatic events will be discussed later in this section.

Table 5-4: Temporal pattern of climate-related events in Tuong Van

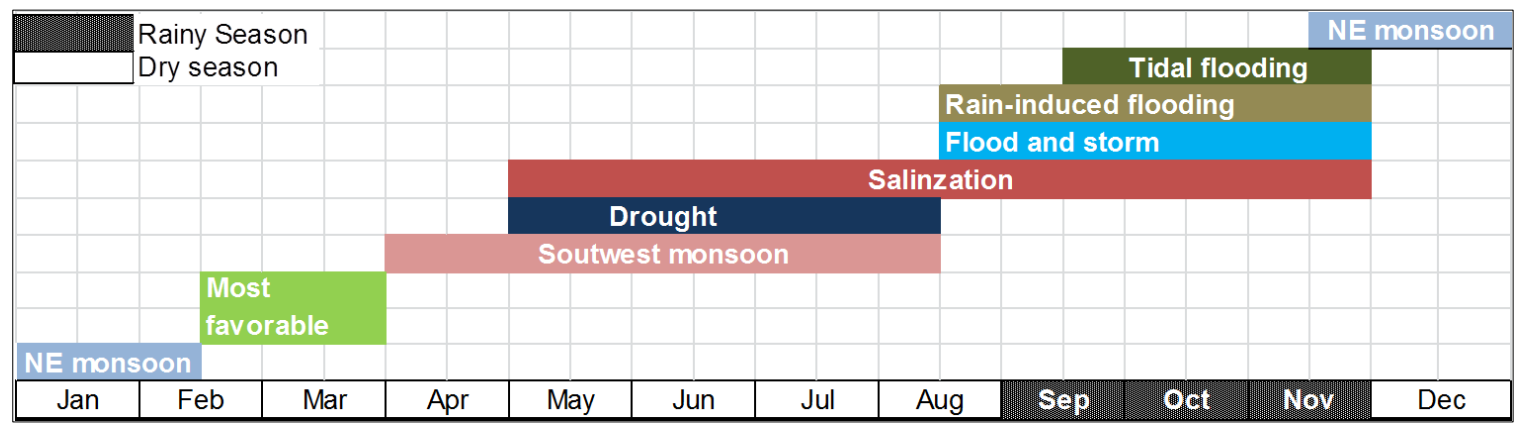

Source and note: FGs in June 2013; NE denotes north east 


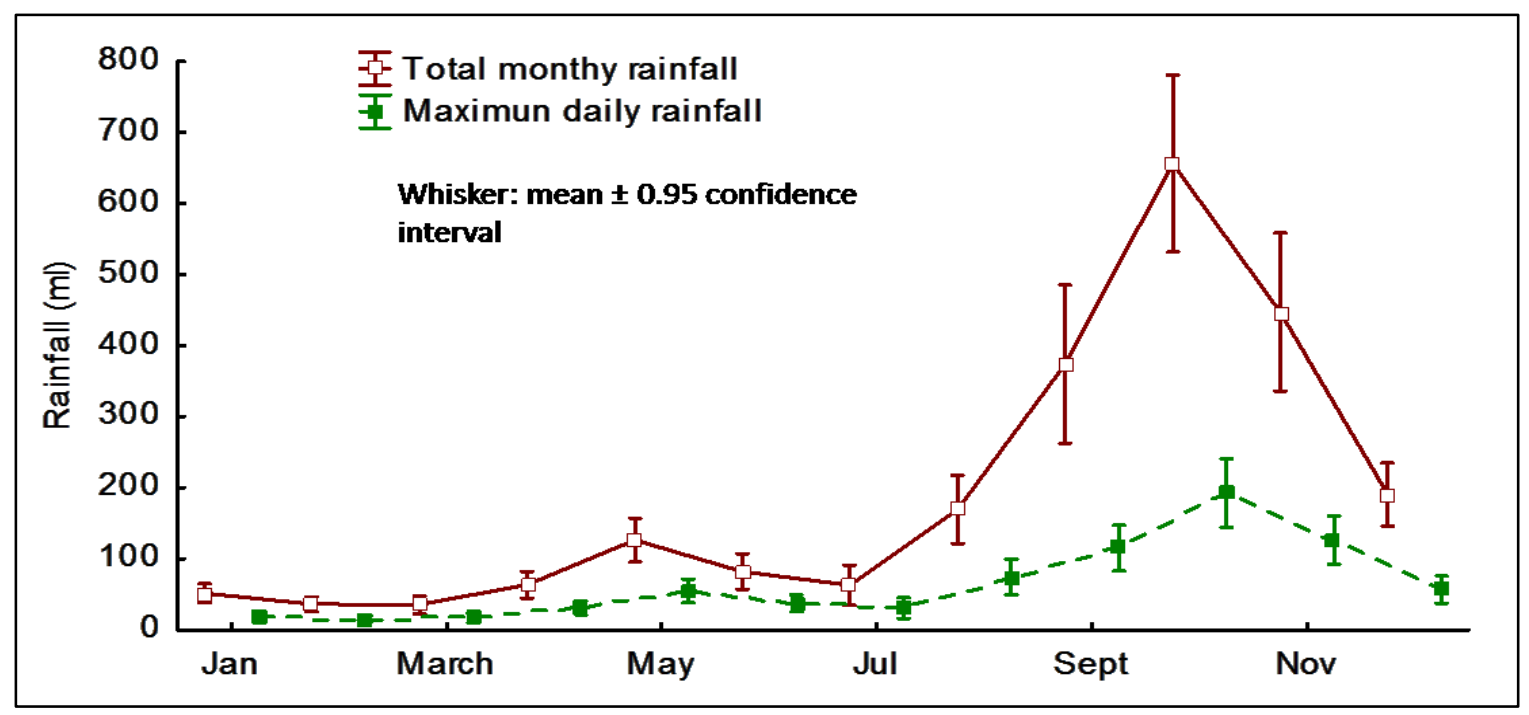

Figure 5-4: Monthly pattern of rainfall at Dong Ha station of Quang Tri between 1976 and 2012

Source: Vietnam's National Hydro-meteorological Centre

The rainy season, characterized by heavy rains, floods and storms, takes place between September and December. Most participants claimed that the rainy season has been extended and the frequency of rains has been increased over the last three decades. The most extreme period in this season lasts from late September to mid-November because storms and floods have not only caused human loss and injuries, but also damaged valued resources. Besides storms and floods, Tuong Van has also been affected by flooding induced by heavy rains and high tides during the rainy seasons.

Tuong Van has experienced storms, floods and droughts for many decades, but recently the community has been impacted by other emerging threats such as rising sea level and salinization. Residents in Dong did not recognize and had no concern about sea level rise, but Lang villagers claimed that tidal flooding has significantly increased over the last two decades as they noticed many dunes near their houses are now submerged at a higher level than $15-20$ years ago. Besides sea level rise, Lang residents also found that underground water resources in their area have also been increasingly salinized. One 
resident claimed that "Water from drilled wells in most households tasted more salty than about 5 years ago" (DNTH, 55).

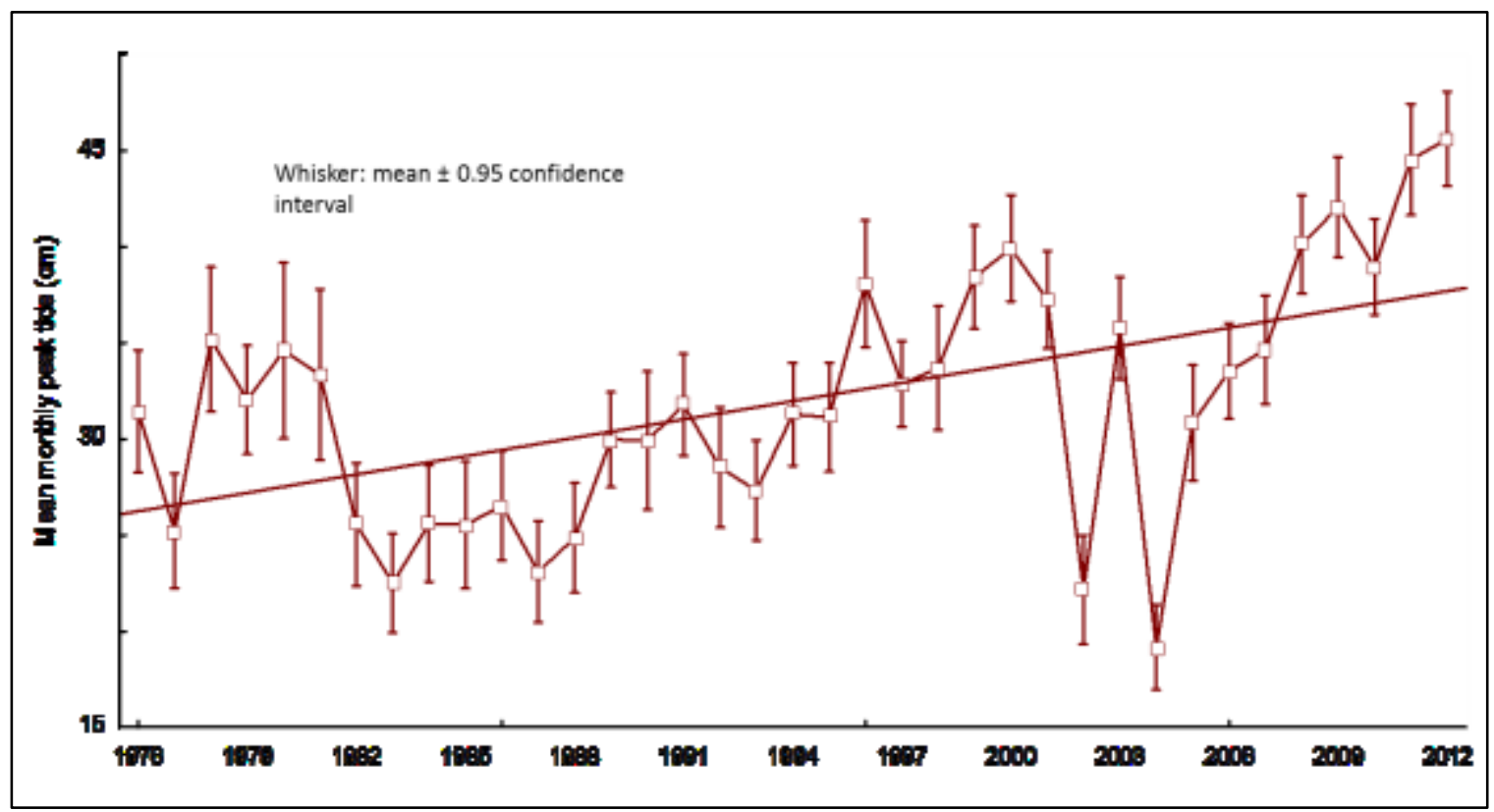

Figure 5-5: Rising sea level observed at Dong Ha hydrological station during 1976 to 2012

Data source: Vietnam's National Hydro-meteorological Centre

Evidence of the rising sea level observed by Lang residents is supported by scientific data, which shows an increase in the mean height of monthly maximum tides between 1976 and 2012 (Figure 5-5). Quang Tri DONRE (2011) estimated that the sea level is expected to have risen by $60-71 \mathrm{~cm}$ by the year 2100 in comparison to the early $2000 \mathrm{~s}$. Such a rise of sea level likely inundate about $0.9 \%$ to $1.4 \%$ or $4,200-6,600$ ha of total land area of Quang Tri. Currently, Quang Tri Department of Natural Resources and Environment (DONRE) has no specific estimate of how much of Tuong Van is likely to be submerged, but most of its land area, especially Lang is low. As such sea level rise is a long-term threat to the community. 


\subsubsection{Climate impacts on the five capitals of the community}

Three types of indexes are used to assess the impact magnitude of individual hazards, and to rank their importance: the Overall impact index, the Specific impact index and the Total impact index. The overall impact index and total impact index for individual hazards on the five capitals are illustrated in Table 5-5, while the specific impact indices of individual hazards on individual resources within each of the five capitals are shown from Table 5-6 through Table 5-9.

Floods, droughts and salinization were ranked highest, while southwest and northeast monsoons and erosion were evaluated as the least important (Table 5-5). Storms were considered less important hazards than salinization and droughts, even though flooding induced by hide tides and heavy rains although they were reported as one of the top two hazards across the coast of Vietnam and in Quang Tri province (GOV 2007b, QT-PPC 2008). Most participants explained that storms could cause human losses and damage to their houses, but these have occurred with low frequency, while some of the gradual stressors such as flooding and salinization have impacted them annually for a longer period.

The number of resources that were identified as impacted varied among the nine hazards. Floods impacted 25 out of 50 resources identified by participants in the first set of FGs, while storms, southwest and northeast monsoons as well as erosion impacted 11 resources or less. Findings in the Table 5-5 also reveal that the more resources a hazard threatened the more significant is its total impact. However, the total impact of a hazard on a capital might also be determined by the extent to which the hazard threatens individual resources. This concern will be discussed further later in this section. 
Table 5-5: Overall impact index of individual hazards on the five capitals in Tuong Van community

\begin{tabular}{lrrrrrrr} 
Hazards & \multicolumn{2}{c}{ Overall impact index of hazards on individual capitals } & $\begin{array}{l}\text { No. of } \\
\text { impacted } \\
\text { resources }\end{array}$ & $\begin{array}{l}\text { Total impacts } \\
\text { (ranked) }\end{array}$ \\
\cline { 2 - 8 } & Physical & Natural & Financial & Human & Social \\
Flood & 423 & 230 & 118 & 48 & 0 & 25 & $\mathbf{8 1 9}(\mathbf{1})$ \\
Drought & 81 & 334 & 162 & 51 & 0 & 20 & $\mathbf{6 2 8}(\mathbf{2})$ \\
Salinization & 179 & 231 & 90 & 41 & 0 & 22 & $\mathbf{5 4 1}(\mathbf{3})$ \\
Tidal flooding & 177 & 172 & 84 & 17 & 0 & 21 & $\mathbf{4 5 0}(4)$ \\
Rain flooding & 195 & 97 & 104 & 36 & 0 & 20 & $\mathbf{4 3 2}(5)$ \\
Storm & 90 & 101 & 105 & 46 & 0 & 11 & $\mathbf{3 4 2}(6)$ \\
SW monsoon & 28 & 140 & 63 & 35 & 0 & 11 & $\mathbf{2 6 6}(\mathbf{7})$ \\
Erosion & 176 & 11 & 49 & 8 & 0 & 11 & $\mathbf{2 4 4}(\mathbf{8})$ \\
NE Monsoon & 28 & 19 & 61 & 37 & 0 & 10 & $\mathbf{1 4 5}(\mathbf{9})$ \\
Total scores & $\mathbf{1 , 3 7 7}$ & $\mathbf{1 , 3 3 5}$ & $\mathbf{8 3 6}$ & $\mathbf{3 1 9}$ & $\mathbf{0}$ & & \\
\hline
\end{tabular}

Source: the survey to focus group participants in June 2013

Note: the overall impact index of a hazard for a capital was a sum of scores from 25 participants given to all resources of that type capital. The total impact of a hazard is a sum of all overall impact indices for such a hazard. NE and SW denote northeast and southwest, respectively.

Table 5-6 shows the extent to which climate hazards individually impacted 13 physical resources. Overall, physical resources were threatened the most by floods, salinization, flooding and erosion, but they were much less impacted by droughts, storms, southwest and northeast monsoons. Climate hazards threatened physical resources at different levels. Floods had the highest impact because they not only threatened more resources but also at higher levels than other hazards, while southwest and northeast monsoons had no impact on most physical resources. Erosion heavily damaged dykes (P1) and bridges (P2), while storms mainly damaged houses (P7) and electricity systems (P8) at moderate levels. Of 13 physical resources, dykes and bridges were impacted the most by hazards, whereas communication equipment, the clinic centre, life vests and storm shelters were not threatened. 
Table 5-6: Specific impact indices of climate hazards on physical resources in Tuong Van community

\begin{tabular}{l|cccccccccccccr} 
& \multicolumn{1}{c}{ Hazards } & \multicolumn{1}{c|}{ Specific impact index of a hazard on individual physical resources } \\
\cline { 2 - 6 } & P1 & P2 & P3 & P4 & P5 & P6 & P7 & P8 & P9 & P10 & P11 & P12 & P13 & Total \\
\hline Flood & 2.9 & 2.8 & 2.4 & 2.2 & 1.0 & 1.9 & 2.1 & 1.6 & 0.0 & 0.0 & 0.0 & 0.0 & 0.0 & $\mathbf{1 6 . 9}$ \\
Rain flooding & 1.7 & 1.0 & 1.0 & 1.9 & 0.0 & 0.9 & 1.3 & 0.0 & 0.0 & 0.0 & 0.0 & 0.0 & 0.0 & $\mathbf{7 . 8}$ \\
Salinization & 1.6 & 1.8 & 0.0 & 0.5 & 1.6 & 1.4 & 0.3 & 0.0 & 0.0 & 0.0 & 0.0 & 0.0 & 0.0 & $\mathbf{7 . 2}$ \\
Tidal flooding & 1.7 & 2.2 & 1.0 & 1.2 & 0.0 & 0.7 & 0.4 & 0.0 & 0.0 & 0.0 & 0.0 & 0.0 & 0.0 & $\mathbf{7 . 1}$ \\
Erosion & 2.6 & 2.5 & 0.0 & 1.8 & 0.0 & 0.0 & 0.2 & 0.0 & 0.0 & 0.0 & 0.0 & 0.0 & 0.0 & $\mathbf{7 . 0}$ \\
Storm & 0.0 & 0.0 & 0.0 & 0.0 & 0.0 & 0.0 & 1.8 & 1.8 & 0.0 & 0.0 & 0.0 & 0.0 & 0.0 & $\mathbf{3 . 6}$ \\
Drought & 0.0 & 0.0 & 0.0 & 0.0 & 1.3 & 1.7 & 0.3 & 0.0 & 0.0 & 0.0 & 0.0 & 0.0 & 0.0 & $\mathbf{3 . 2}$ \\
SW monsoon & 0.0 & 0.0 & 0.0 & 0.0 & 0.0 & 0.0 & 0.3 & 0.8 & 0.0 & 0.0 & 0.0 & 0.0 & 0.0 & $\mathbf{1 . 1}$ \\
NE monsoon & 0.0 & 0.0 & 0.0 & 0.0 & 0.0 & 0.0 & 0.5 & 0.6 & 0.0 & 0.0 & 0.0 & 0.0 & 0.0 & $\mathbf{1 . 1}$ \\
Total score & $\mathbf{1 0 . 4}$ & $\mathbf{1 0 . 2}$ & $\mathbf{4 . 4}$ & $\mathbf{7 . 6}$ & $\mathbf{3 . 9}$ & $\mathbf{6 . 5}$ & $\mathbf{7 . 3}$ & $\mathbf{4 . 7}$ & $\mathbf{0 . 0}$ & $\mathbf{0 . 0}$ & $\mathbf{0 . 0}$ & $\mathbf{0 . 0}$ & $\mathbf{0 . 0}$ & \\
\hline
\end{tabular}

Source: the survey to focus group participants in June 2013

Note: the specific impact index of a hazard on a physical resource was calculated as the average score from all 25 participants given to the impact magnitude of the hazard on the resource. Cells filled with white background indicate low impact. Cells with lighter and darker background illustrate moderate and high levels of impact, respectively. The last column and row is the total score for individual hazards and physical resources, respectively. Physical resources are coded as in the Figure 5-3. NE and SW denote northeast and southwest, respectively.

The extent to which hazards individually impacted 13 natural resources is illustrated Table 5-7. Overall, floods, droughts, salinization, and tidal flooding had the highest impact on natural resources, but droughts and salinization were ranked on top. Natural resources were impacted by hazards at different levels. Freshwater for domestic use and crop production (N5 and N6, respectively) suffered the most as it was highly impacted throughout much of the year and by a wider range of threats, especially by droughts and floods. In contrast, shrimp and salt production land (N2 and N4) as well as river clams and Coc Thanh Thao were least impacted and by only a few hazards. 
Table 5-7: Specific impact indices of climate hazards on natural resources in Tuong Van community

\begin{tabular}{|c|c|c|c|c|c|c|c|c|c|c|c|c|c|c|}
\hline \multirow{2}{*}{ zarc } & \multicolumn{14}{|c|}{ Specific impact index of a hazard on individual natural resources } \\
\hline & N1 & N2 & N3 & N4 & N5 & N6 & N7 & N8 & N9 & N10 & N11 & N12 & N13 & Total \\
\hline & 2.0 & 0. & 2.4 & 0.0 & 2.1 & 2.2 & 0.0 & 0.9 & 6 & .4 & 0.8 & 0.1 & 1.4 & 13.4 \\
\hline & 1.8 & 0.0 & 1. & 0.0 & 1.6 & 1.3 & 1.0 & 6 & b & + & t & 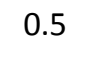 & 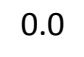 & .2 \\
\hline $\mathrm{FI}$ & -1 & 1.0 & 0.0 & 0.2 & 2.2 & 1.4 & 0.0 & .7 & 1.0 & 2 & 6 & 8 & 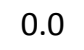 & 9.2 \\
\hline & 1.1 & 0.0 & 1.1 & 0.0 & 0.9 & 9 & 1 & 0.2 & 0.0 & 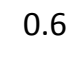 & & 0.6 & 0.0 & .9 \\
\hline su & 0.0 & 0.0 & 1.8 & 0.0 & 1.6 & 1. & 0.0 & 0.7 & 0.0 & 0.0 & .0 & 0.0 & 0 & 5.6 \\
\hline Storm & 0.0 & 0.0 & 0.0 & 0.0 & 0.0 & 0.0 & 1.0 & 1.4 & 1.6 & 0.0 & 0.0 & 0.0 & 0.0 & 4.0 \\
\hline Rain & 1.0 & 0.0 & 0.0 & 0.1 & 1.2 & 1.0 & 0.0 & 0.1 & 0.0 & 0.0 & 0.3 & 0.2 & 0.0 & 3.9 \\
\hline NE monsoon & 0.0 & 0.0 & 0.0 & 0.0 & 0.0 & 0.0 & 0.0 & 0.0 & 0.0 & 0.0 & 0.0 & 0.7 & 0.0 & 0.8 \\
\hline Erosic & 0.0 & 0.0 & 0.0 & 0.0 & 0.0 & 0.0 & 0.0 & 0.0 & 0.4 & 0.0 & 0.0 & 0.0 & 0.0 & 0.4 \\
\hline Total score & 6.9 & 1.0 & 6.7 & 0.3 & 9.5 & 8.3 & 3.0 & 4.6 & 4.2 & 1.5 & 3.0 & 3.0 & 1.4 & \\
\hline
\end{tabular}

Source: the survey to focus group participants in June 2013

Note: The specific impact index of a hazard on a natural resource was calculated as the average score from all 25 participants given to the impact magnitude of the hazard on the resource. Cells are filled with the background as in the Table 5-7. The last column and row is the total score for individual hazards and physical resources, respectively. Natural resources are coded as in the Figure 5-3. NE and SW denote northeast and southwest, respectively.

Table 5-8 illustrates the impact of individual hazards on 11 financial resources. Of the nine hazards, droughts, floods, storms and rain flooding were the most important to the financial capital. Similar to the natural capital, droughts was ranked at the top. Among 11 financial resources, rice and subsidiary crops (F4 and F5, respectively) suffered much more than the other resources because the crops were killed by the shortage of freshwater as well as by floods and salinization. In contrast, loan (F1), village fund (F2) and remittent (F7) were not directly impacted by climate hazards. 
Table 5-8: Specific impact index of climate hazards on financial resources in Tuong Van community

\begin{tabular}{lllllllllllllr}
\multirow{2}{*}{ Hazards } & \multicolumn{10}{c}{ Specific impact index of hazard on individual financial resources } \\
\cline { 2 - 14 } & F1 & F2 & F3 & F4 & F5 & F6 & F7 & F8 & F9 & F10 & F11 & Total \\
\hline Drought & 0.0 & 0.0 & 1.0 & 2.1 & 2.4 & 0.0 & 0.0 & 0.0 & 0.0 & 0.0 & 0.9 & $\mathbf{6 . 5}$ \\
Flood & 0.0 & 0.0 & 0.9 & 0.9 & 2.4 & 0.1 & 0.0 & 0.0 & 0.2 & 0.2 & 0.0 & $\mathbf{4 . 7}$ \\
Storm & 0.0 & 0.0 & 0.8 & 0.9 & 2.4 & 0.0 & 0.0 & 0.0 & 0.0 & 0.0 & 0.0 & $\mathbf{4 . 2}$ \\
Rain flooding & 0.0 & 0.0 & 0.7 & 1.4 & 1.8 & 0.1 & 0.0 & 0.0 & 0.0 & 0.1 & 0.0 & $\mathbf{4 . 2}$ \\
Salinization & 0.0 & 0.0 & 0.0 & 1.7 & 1.5 & 0.1 & 0.0 & 0.0 & 0.0 & 0.2 & 0.0 & $\mathbf{3 . 6}$ \\
Tidal flooding & 0.0 & 0.0 & 0.8 & 1.3 & 1.0 & 0.0 & 0.0 & 0.0 & 0.0 & 0.2 & 0.0 & $\mathbf{3 . 4}$ \\
SW monsoon & 0.0 & 0.0 & 0.2 & 0.7 & 1.6 & 0.0 & 0.0 & 0.0 & 0.0 & 0.0 & 0.0 & $\mathbf{2 . 5}$ \\
NE monsoon & 0.0 & 0.0 & 0.5 & 0.8 & 0.8 & 0.0 & 0.0 & 0.0 & 0.0 & 0.3 & 0.0 & $\mathbf{2 . 4}$ \\
Erosion & 0.0 & 0.0 & 0.6 & 0.6 & 0.7 & 0.0 & 0.0 & 0.0 & 0.0 & 0.0 & 0.0 & $\mathbf{2 . 0}$ \\
Total score & $\mathbf{0 . 0}$ & $\mathbf{0 . 0}$ & $\mathbf{5 . 6}$ & $\mathbf{1 0 . 4}$ & $\mathbf{1 4 . 7}$ & $\mathbf{0 . 3}$ & $\mathbf{0 . 0}$ & $\mathbf{0 . 0}$ & $\mathbf{0 . 4}$ & $\mathbf{1 . 2}$ & $\mathbf{0 . 9}$ & \\
\hline
\end{tabular}

Source: the survey to focus group participants in June 2013

Note: the specific impact index of a hazard on a financial resource was calculated as the average score from all 25 participants given to the impact magnitude of the hazard on the resource. Cells are filled with the background as in the Table 5-7. The last column and row is the total score for individual hazards and financial resources, respectively. Financial resources are coded as in the Figure 5-3. NE and SW denote northeast and southwest, respectively.

Table 5-9 illustrates the extent to which individual hazards impacted three human resources. Among the three surveyed human resources, only personal health (H3) was impacted by climate hazards. Droughts were particularly detrimental to personal heath and the other two hazards had a moderate impact. Participants gave zero scores to the other two human resources including knowledge on disaster risk reduction (DRR) and livelihoods. Participants interpreted the term "impact" used in the questionnaires as a negative connotation rather than a positive meaning. They argued that climate hazards did not affect negatively the two resources. Some participants added that climate events also have positive impacts on the knowledge. They claimed that their knowledge and skills about storm and flood prevention was much improved from experiences with the flood in 1983 and the storm in 1985. 
Table 5-9: Impact indices of hazards by individual human resources in Tuong Van community

\begin{tabular}{lcccr}
\multirow{2}{*}{ Hazards } & \multicolumn{3}{c}{ Specific impact index of a hazard on individual human resources } \\
\cline { 2 - 5 } & H1 & H2 & H3 & Total \\
\hline Drought & 0 & 0 & 2.1 & $\mathbf{2 . 1}$ \\
Salinization & 0 & 0 & 1.9 & $\mathbf{1 . 9}$ \\
Flood & 0 & 0 & 1.8 & $\mathbf{1 . 8}$ \\
Storm & 0 & 0 & 1.6 & $\mathbf{1 . 6}$ \\
Rain flooding & 0 & 0 & 1.5 & $\mathbf{1 . 5}$ \\
Tidal flooding & 0 & 0 & 1.4 & $\mathbf{1 . 4}$ \\
SW monsoon & 0 & 0 & 1.4 & $\mathbf{1 . 4}$ \\
NE monsoon & 0 & 0 & 0.68 & $\mathbf{0 . 7}$ \\
Erosion & 0 & 0 & 0.32 & $\mathbf{0 . 3}$ \\
Total score & $\mathbf{0}$ & $\mathbf{0}$ & $\mathbf{1 2 . 7 6}$ & \\
\hline
\end{tabular}

Source: the survey to focus group participants in June 2013

Note: the specific impact index of a hazard on a human resource was calculated as the average score from all 25 participants given to the impact magnitude of the hazard on the resource. Cells are filled with the background as in the Table 5-7. The last column and row is the total score for individual hazards and human resources, respectively. Human resources are coded as in the Figure 5-3. NE and SW denote northeast and southwest, respectively.

Participants gave zeros for the impact of climate events on all social resources because they argued that these events did not directly threaten these resources. Yet, two contesting explanations were given during the FGs with respect to the climate impacts on these resources. First, climate events had some positive impacts on social capital. For instance, kinship and neighbourhood seemed to become tighter when villagers provided their neighbours and relatives with financial support or labour to repair houses or buy medicines following storms and floods. However, group discussions also revealed that hazards also have negative impacts on social capital. For example, the connections between some villagers were interrupted by the conflicts occurred when aid was not delivered fairly after the storm in 2005. 


\subsubsection{Impacts from interactions among climate hazards}

\subsubsection{Interactions among climate hazards and geographical conditions}

Discussions during the FGs revealed that climatic events seldom occur independently, but rather they interact with one another in complex patterns (Figure 5-6). Some hazards are considered primary events such as storms and monsoons and others are seen as results or outcomes of the primary threats. As an example, surges are induced by storms and northeast monsoons. Primary hazards could induce a series of resulting threats, sequentially or simultaneously. For instance, floods mainly cause serious erosion along the Thach Han River, whereas storms might create high surges and tidal flooding, which then induce erosion and salinization. Besides combined or cumulative effects, discussions also showed that interactions amongst climate events can be inhibitive. For instance, river floods could reduce salinization of rice farms and gardens that is annually induced by tidal flooding.

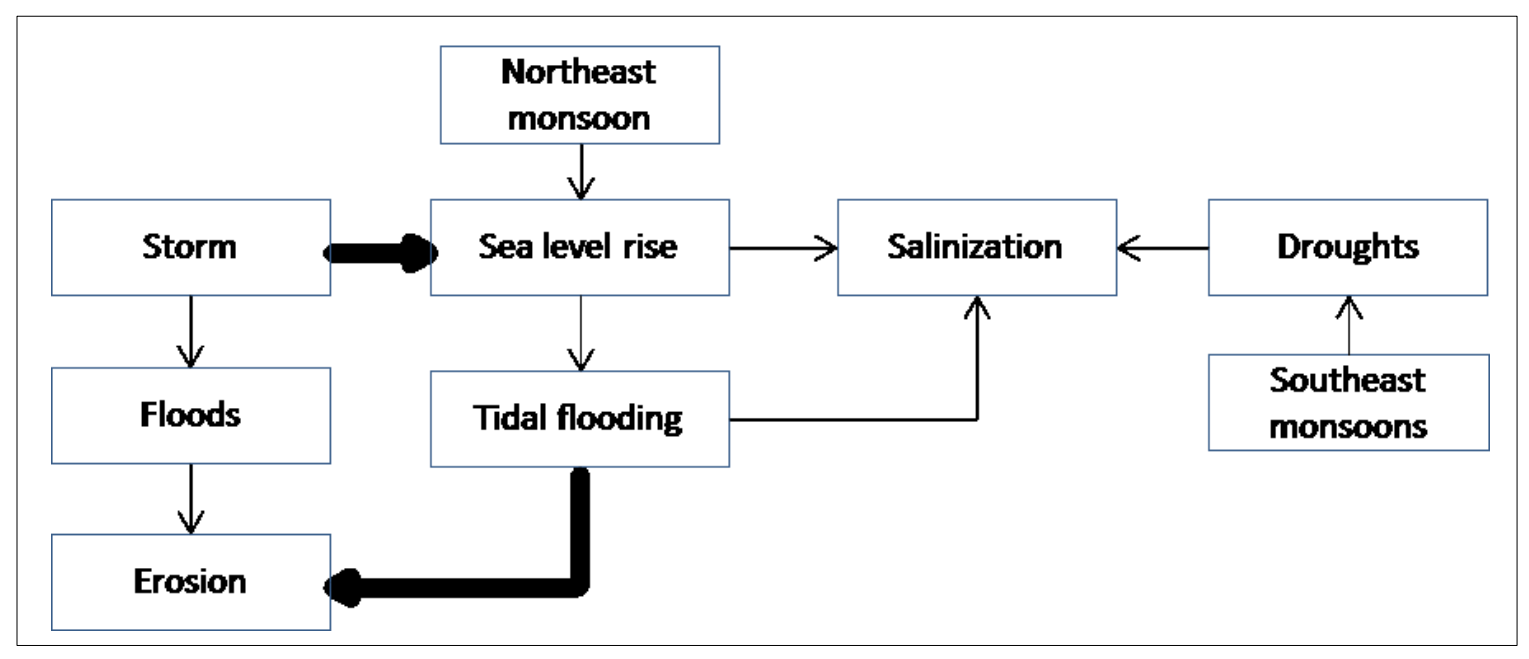

Figure 5-6: The relationships of climate-related hazards in Tuong Van

Source: focus group discussions in June 2013 
Climate change research tends to focus on negative impacts of changes in climate, especially when the magnitude and/or frequency of events such as floods and droughts are expected to increase (IPCC 2014a). Yet, group discussions revealed that climate change over the last three decades has not always harmed the community, but diverse benefits are possible. For instance, most participants claimed that heavy rains occur more often and over a longer period than was the norm over the past $15-20$ years. The changing pattern of rainfall not only provides the community with more rainwater for domestic use during dry seasons, but it also reduces adverse impacts of droughts and salinization. One man claimed:

Our location is not always unfavourable. Living near the large river and the sea provides us with benefits such as wild shrimps and fish to eat and additional income. The river and the sea bring us with climate risks only when climatic phenomena become extreme. For instance, heavy rains could cause violent floods, but we have no freshwater for our daily life and we cannot survive if there are no rains. We might be threatened by violent floods, but such impacts could be avoided or minimized if we reduce our physical contact with these threats by evacuating to our public shelter for some days. (LTNT, 46)

This quote provides evidence of both the risks and benefits that climatic events might bring to the community, but more importantly, highlights the conditions that put the community at climate risk. The quote suggests that the risks facing the community are a result of interactions from topological, climatic and community conditions (Figure 5-7). The community might be at higher risk when it faces climate hazards and is located in geographically unfavourable conditions. For example, Lang is at higher risks than Dong when violent floods occur because it is closer to hazardous zones, while Dong faces lower risks as it is less exposed to such conditions. 


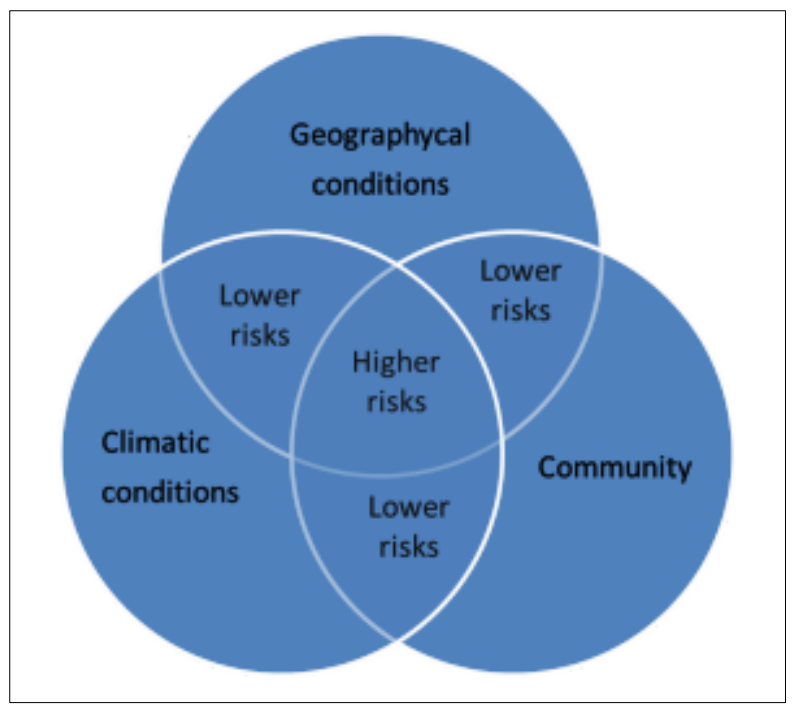

Figure 5-7: Local perspectives on climate risks

Source: feedback from Tuong Van community in November 2014

\subsubsection{Impacts from interactions of storms and floods with other hazards}

Storms and floods are major threats to the community during rainy seasons. Storms do not occur often in Tuong Van village, but their rapid occurrence and violent destructivity cause human loss and damage of valued properties. Since 1985, the community has been threatened by three significant storms, which occurred in 1985, 2005 and 2013. The 1985 storm was viewed as the most disastrous. This storm not only injured 10 people, but also damaged valued properties such as many houses and hundreds of tons of rice and poultry.

Storms themselves not only threatened human security and damaged properties, but they also created new hazards, leading to increased losses. For instance, the $10^{\text {th }}$ storm in 2013 not only collapsed the roofs of 85 houses, but also induced floods, which in turn seriously eroded about 150 meters of the flood dykes. Local residents claimed that storms commonly induced high surges and this is supported by historical data, which show sea level at Cua Viet has risen up to $115 \mathrm{~cm}$ high (Figure 5-8). As a consequence of the 
storm, besides human injuries and house damage, the surges also swept away nearly all of rice, livestock and poultry of the village.

As illustrated earlier, floods were ranked as the most important hazards to the village. Annually, the community faces up to four floods and they often occur with storms. Over the last three decades, the most dangerous event was the flood in 1983, followed by the flood in 1999. The former not only washed away rice, pigs, chickens and cattle of most families, but it also killed three people and injured about 35 others. Such severe losses were a result from two factors. First, the flood broke the Thach Han dyke system at night time when local residents were sleeping. As such many villagers did not realize the arrival of the flood and they were forced to escape without protecting their properties to avoid losses. Secondly, the historical data show that the flood occurred during high tides, which might block the flow of the flood into the ocean, leading to a higher level of water during the flood (Figure 5-8).

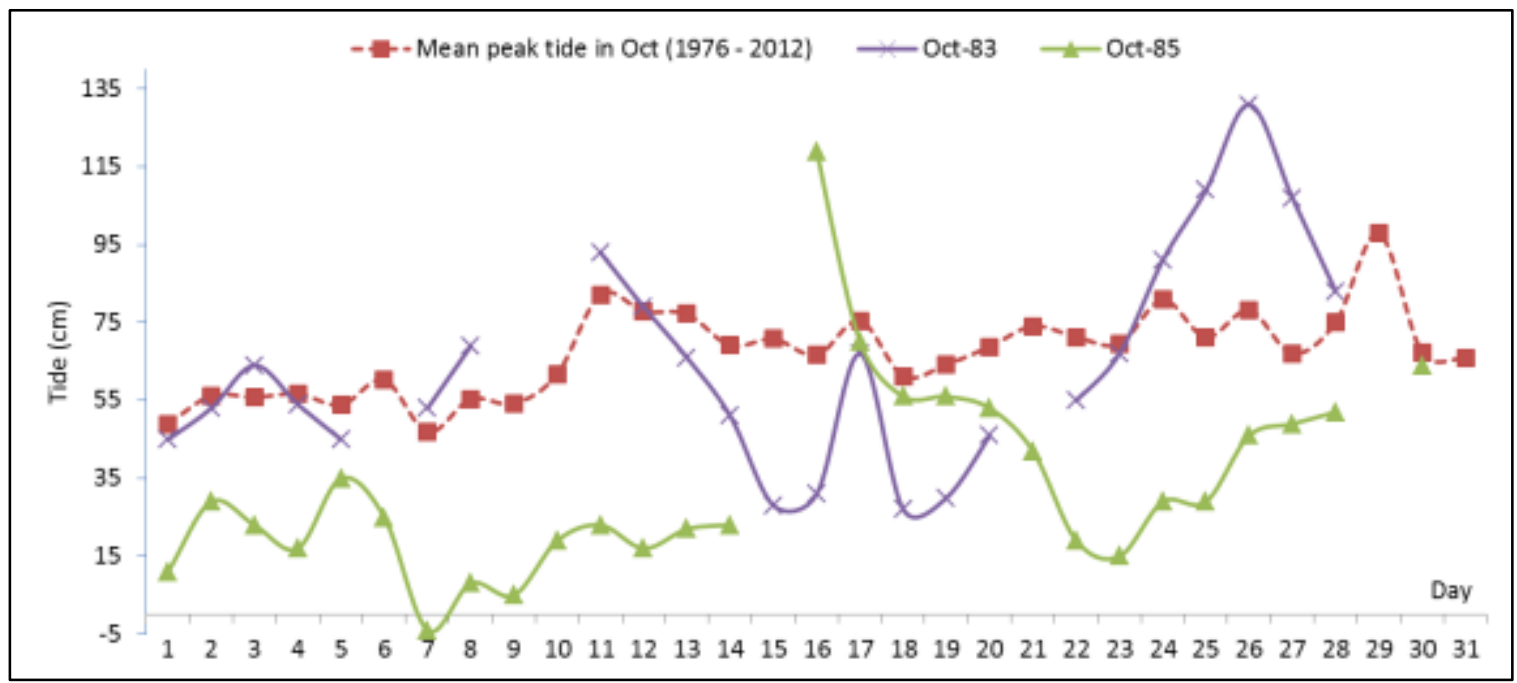

Figure 5-8: The mean of daily peak tides observed at Dong Ha hydrological station in October during 1976 and 2012 and of daily peak tides in October of 1983 and 1985

Source: Vietnam's National Hydro-meteorological Centre. Disconnected points are a result from unavailable data. 


\subsubsection{Impacts from interactions among gradual and prolonged stressors}

While storms and floods are major threats during rainy seasons, droughts are the most important hazards between April and August. Annual droughts persist for long periods, thus villagers cannot grow the second crop of paddy rice between May and August and their income is dependent on subsidiary crops on their gardens. Villagers claimed that droughts often magnify adverse effects of salinization induced by tidal flooding on rice and subsidiary crops because they increase evaporation.

In rainy seasons, besides violent floods from the upstream on the Thach Han River, annually villagers also face flooding induced by high tides and heavy rains between September and November (Figure 5-9). Flooding often persists for $1-3$ months as drainage systems within the village have been seriously degraded and blocked by wild plants and erosion. Although this flooding is not deadly like river floods, it usually affects garden livelihoods and daily life of the community. For instance, the flooding not only kills subsidiary crops, but it is also difficult for the daily travels of villagers, and promotes infectious epidemics such as diarrhoea and dengue fever.

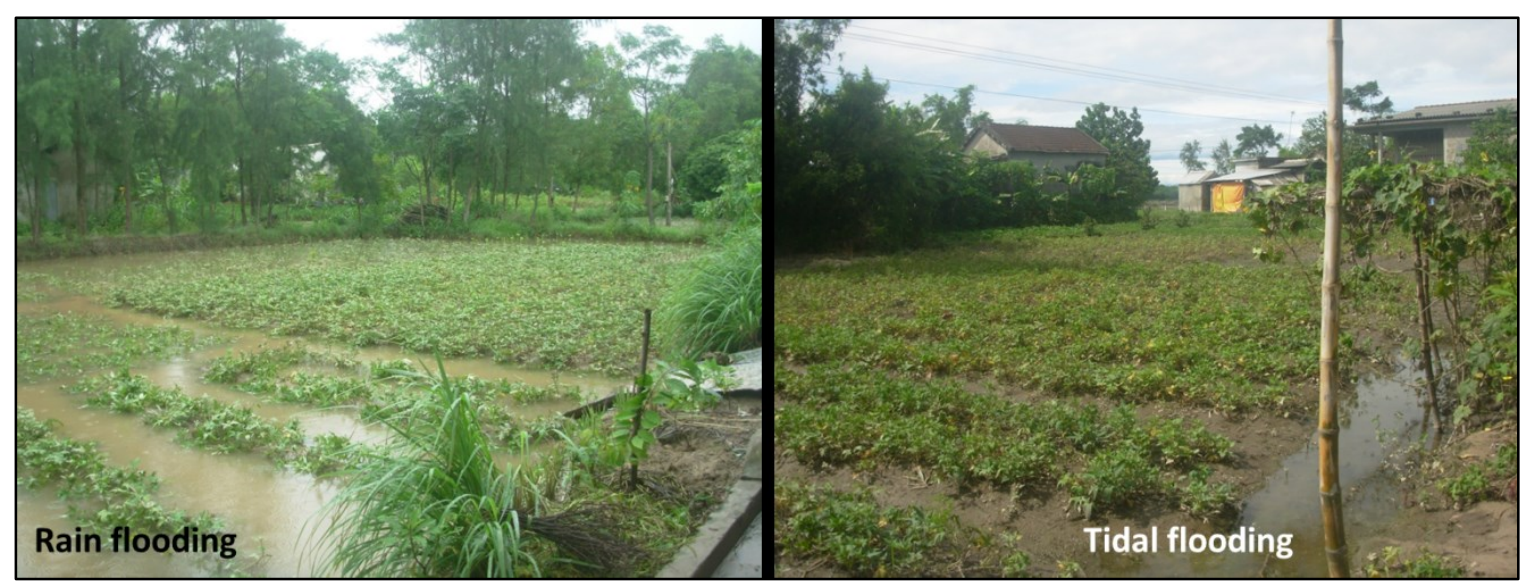

Figure 5-9: Example impacts of rain and tidal flooding in Tuong Van

Source: both photos were taken by the author in September 2013 


\section{Synthesis of Chapter 5}

Chapter 5 illustrated how climate hazards have impacted Tuong Van village over the last three decades. The chapter began with characterizing biophysical and socio-economic components of the community, and then analysed how the hazards have impacted these components and the village as a whole. The field research used both local experiences and scientific data to examine changing patterns of climate and their impacts. Drawing on information from the FGs and interviews with villagers, the interactions between climatic events, a changing climate and the community are synthesized in Figure 5-10.

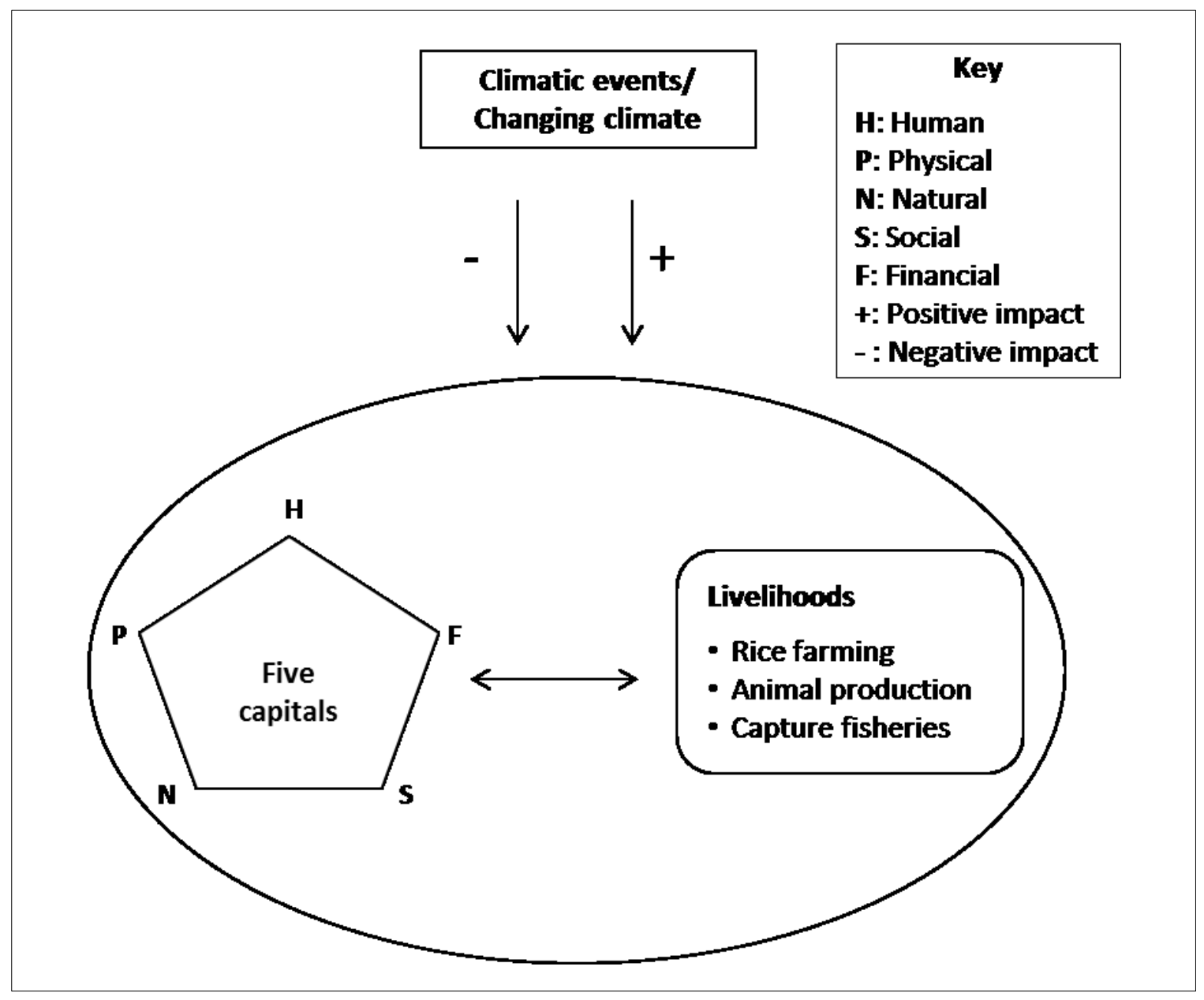

Figure 5-10: Interactions between climate change and Tuong Van community

Sources: Synthesis from discussions in FGs and interviews with Tuong Van residents in 2003 
The village is impacted by at least nine climate-related hazards and their interactions vary over time. The community is not only threatened by recurrent hazards including storms, floods, erosion and flooding, but has also begun to suffer from emerging effects of climate change including sea level rise and its resulting salinization. Climate hazards impact the village throughout the year, but most losses are commonly recorded in rainy (between September and November) and dry (between May and August) seasons. During the rainy season, the community is particularly threatened by storms and floods, and during the dry season by droughts and salinization.

Climatic events and the changing climate have impacted the community through its five capitals and livelihoods. Climatic events and their changing patterns not only threaten the community but also provide benefits. For instance, the increased frequency of rains and the expansion of rainy seasons might cause violent floods, leading to losses of life and valued property, but has also offered villagers more freshwater for domestic use and reduced salinization of rice farms. This example also illustrates the importance of considering interactions amongst the five capitals. That is, changes in natural capital (e.g. length of the rainy season) can adversely impact human capital (e.g. potential increase in human injuries) and be of benefit to natural capital (e.g. reducing soil salinization).

Uneven impacts of recent events are also evident. Human security and physical resources are commonly threatened the most by floods and storms, while livelihoods and natural resources are more impacted by droughts, salinization and flooding. Lang suffers more from floods, storms (surge), tidal flooding and salinization since it is located closer to the the river and the sea. In contrast, Dong is less vulnerable to these hazards as it is shielded 
by An Loi and Lang, but it suffers more from rain flooding as its residents live in the valleys among sandy hills, which are annually inundated by heavy rains.

Overall, through the analysis of multidimensional, uneven and interactive effects of climate hazards and change on livelihoods and five capitals of a local community, findings in this chapter reinforced studies that unpack complex impacts of global climate change. Several manifestations of climate change and their impacts including the precipitation and temperature increases, the extension of rain seasons as well as sea level rise perceived by local residents are consistent with findings from studies that are based on regional and global climate models (MONRE 2009, IPCC 2013). Moreover, evidence from Tuong Van enhanced the current knowledge about local impacts of global climate change. While recent studies tend to blame climate change for its adverse impacts (IPCC 2014b), local experiences suggested that the negative effects can also be offset by diverse opportunities owing to the changing climate. 


\section{CHAPTER 6: DISASTER RISK REDUCTION AND CLIMATE CHANGE ADAPTATION IN TUONG VAN COMMUNITY}

\section{Research sub-question 2: $\quad$ How have coastal communities in central Vietnam recently responded to climate hazards?}

Findings from Chapters 3 and 5 illustrated that central Vietnam's coastal communities have suffered from climate-related hazards over the last three decades and they will be impacted by future climate change. A large body of studies highlights the importance and complementary roles of disaster risk reduction (DRR) and climate change adaptation (CCA) programs in addressing climate hazards (UNISDR 2005a, IPCC 2007, 2012). Yet, there is a growing concern about how these two programs are practiced to collectively and successfully enhance community resilience (CR) and reduce adverse impacts of a changing climate (Lei and Wang 2014, Kirsch-Wood 2015, Rivera et al. 2015). Chapter 6 addresses this concern by examining how Tuong Van community has recently deployed the two programs in response to the changing climate.

In Vietnam, the National Strategy on Disaster Prevention, Response and Mitigation to 2020 (NSD) is the key DRR policy that the country has used to reduce disaster risks from natural hazards, especially storms and floods (see Chapter 3). Local communities are required to implement the NSD through formal procedures across all levels of government. Besides the NSD, earlier research shows that many local communities have also deployed their own measures or community-based DRR to address the two threats 
(Tong et al. 2012). Thus the first section of Chapter 6 examines the roles that the NSD and community-based DRR have played and how they have been adopted to reduce risks from storms and floods. The next section focuses on the mutual reinforcement between DRR and CCA approaches by investigating how Tuong Van has incorporated CCA with DRR to reduce the adverse impacts of the changing climate.

\subsection{Flood and storm DRR efforts in Tuong Van community}

\subsubsection{Local need for combining policy-driven and community-based approaches to addressing storms and floods in Tuong Van}

Discussions from the second set of FGs and interviews with local residents showed that the community has used various strategies to address climate hazards, but decisions on which strategies are adopted depends on the combined characteristics of the climate threats and the governmental policies. In Tuong Van, storm and flood DRR has been given a highest priority because it is imposed by higher levels of government to implement the NSD and storms and floods are also the biggest human security concern of the community. In this case, there are strong synergies between the issue and the policy.

All participants in the second set of FGs appreciated the various benefits provided by the NSD to their community. They also claimed assistance from the NSD was critical to implement a number of important DRR projects. For instance, building a system of concrete dykes as protection against annual floods and installing thousands of meters of concrete roads would not have been possible without support from the NSD.

The NSD also had several limitations. For example, the NSD was rarely deployed outside the rainy seasons and this is at odds with local customs of building and/or maintaining 
infrastructure in dry seasons rather than storm and flood seasons. In addition, the allocation of NSD resources occurred away from the community and many important DRR projects were not funded. For example, rebuilding a bridge for emergency evacuation and strengthening several eroding sections of new concrete dykes were overlooked.

Many participants also argued that the NSD could not support every activity that their community needs, but rather their community and individual households should be responsible to carry out smaller projects that fit to their capacities. They claimed that their community members supplemented NSD projects by developing and implementing their own measures to address storms and floods. For instance, the community built earthen dykes and most families planted bamboo rings around their households before 1945 when the NSD was introduced.

\subsubsection{Multi-level community engagement for storm and flood DRR}

Tuong Van does not address storms and floods alone, but it engages diverse actors across multiple levels through a formal procedure to address multiple issues (Figure 6-1). The community annually adopts the NSD from higher levels of government. Activities of the NSD in Tuong Van are executed by the village's Committee for Flood and Storm Control, Search and Rescue (CFS-SR), which is annually elected by its villagers. The CFS-SR not only leads the six units of the village, but it also coordinates a wide range of external actors in developing and implementing DRR activities, for instance receiving and delivering food and clothing from local pagodas and Quang Tri Red Cross. 


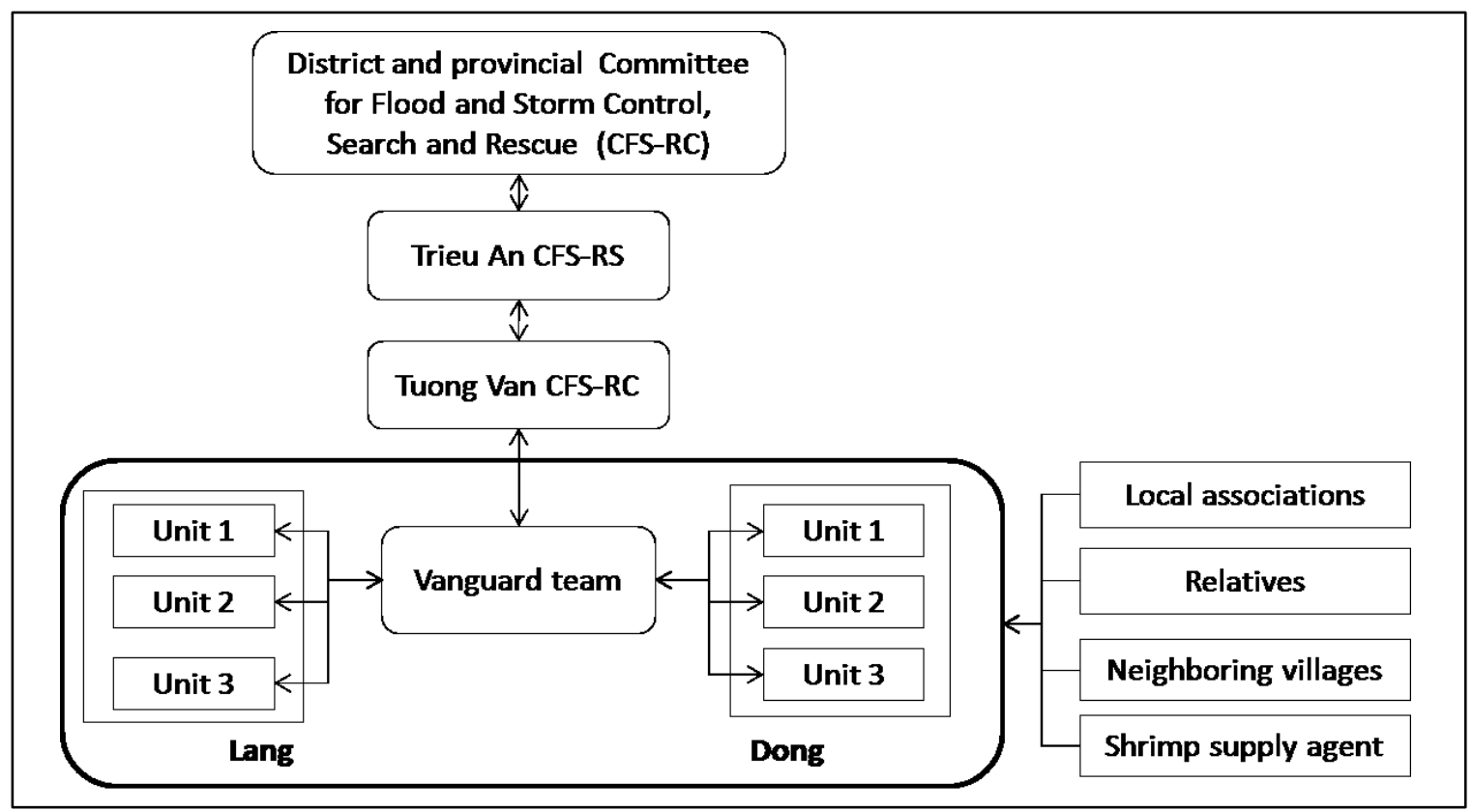

Figure 6-1: Institutional arrangement for storm and flood DRR in Tuong Van community

Source: meetings with leaders of Trieu An commune and Tuong Van village in May 2013

The village CFS-SR plays leading roles in storm and flood DRR of the community and it involves its local residents. The CFS-SR receives substantial support from a patrol team, which is annually established and consists of $10-12$ voluntary villagers from the six units of the community. This effort started in 2004 when the Quang Tri government issued an institutional framework for storm and flood DRR (QT-PPC 2004a). The patrol team is important as it undertakes various activities to enhance human security and reduce loss of valued properties. One participant in a FG expressed the important roles of the team as follows:

Our patrol team not only evacuated Lang residents to safer places when storms and floods occurred, but also repaired many damaged houses following the storms (DDPX, 71).

The CFS-SR engages the community in developing annual plans for storm and flood DRR. Prior to storm and flood seasons, the CFS-SR holds community meetings, in which all villagers are invited to raise and discuss their concerns as well as contribute their ideas 
to developing annual DRR plans for the village. Following the meetings, the CFS-SR develops draft plans with duties for its members and the patrol team. The draft plans are finalized after discussing with the communal CFS-SR and the patrol teams of the other four villages in Trieu An commune. The final DRR plans for the village are approved by the communal government and they are then implemented by the village.

At the household level, most families prepare their own plans in response to storms and floods and these plans are developed in two main ways. In some families, husbands play the main role in making decisions and implementing DRR plans, while in a majority of households, their plans are developed with the participation of most or all adults, including mature children, but husbands commonly play the leading role. Most families combine short and long term measures in their DRR plans. One woman explained the combination of short and long-term measures in their family as:

In 2008, we planned to build a house with brick walls and tile roofs to live safer in the seasons of storms and floods, thus we needed to save money from shrimp farming, animal production and my son's remittance for two years. Hence, in 2010, we had a stronger house (LTNT, 46).

When annual DRR plans of the village have been developed, they are deployed with the participation of villagers and the support from higher levels of government. The village CFS-SR not only directs its community, but it also receives the official direction and support from its communal CFS-SR, which connects Tuong Van with the other villages as well as with higher levels of government and non-governmental organizations (NGO). The communal CFS-SR directs Tuong Van and coordinates DRR activities and resources among its five villages. In turn, it receives the support and direction from the CFS-SR of Trieu Phong district and Quang Tri province. 


\subsubsection{Practices of storm and flood DRR program in Tuong Van}

\subsubsection{DRR during the dry season}

The process of DRR formulation and implementation in Tuong Van is divided into two periods, accordingly to dry and rainy seasons (Figure 6-2), with different foci. The DRR prior to rainy seasons (September to November) aims to provide the community with three "readies" for DRR activities during rainy seasons: ready for prevention; ready for emergency response; and ready for dissolution of storm and flood consequences. These three readies will be discussed further later in this section. Diverse activities to address storms and floods are conducted prior to rainy seasons and participants classified them into three groups of actions: reviews, planning and capacity building.

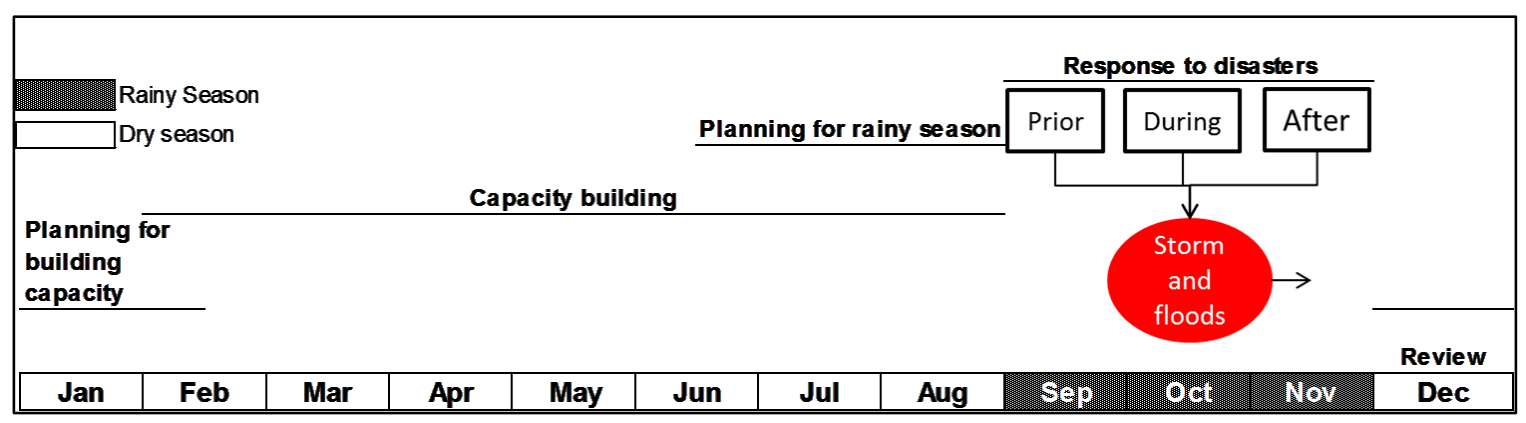

Figure 6-2: DRR process in Tuong Van

Source: meetings with leaders of Trieu An commune and Tuong Van village in June 2013

Reviews are used to evaluate the DRR process. These are conducted throughout the year, but evaluations following individual hazards are viewed as the most important. Posthazard evaluations under the NSD are mandatory for all villages and they provide important inputs for DRR reviews of the whole rainy seasons, so-called seasonal reviews. The reviews involve numerous activities across multiple jurisdictional scales with the aim to obtain information on human and economic losses. At the household level, all families are requested to evaluate their losses from individual hazards, which will in turn be 
checked and recorded by an evaluation team of the village. Finally, the collected data are reported to and used by higher levels of government in the next steps of the DRR process. When the impacts of a hazard have been evaluated, results from the evaluation are used to develop recovery plans if the hazard caused disasters such as human injuries or house damage. In addition, the evaluation results are also used for seasonal reviews, which are then employed to formulate a DRR plan for the coming year. Following individual hazards or rainy seasons, the village develops plans for building community capacity such as reparation and maintenance of roads and flood dykes. The proposal will be then submitted for the review and approval by higher levels of government, with the approval depending on the availability of governmental resources. In some cases, agencies such as Quang Tri Red Cross and World Vision have requested the community to develop project proposals for funding, for instance rebuilding concrete roads and training courses.

Some months before rainy seasons, plans for DRR during storm and flood periods are developed at all levels of government. At the community level, the CFS-SR of Tuong Van prepares the draft of its annual DRR plan, and then organizes meetings at which all households are invited to provide their comments and ideas to finalize their plan before submission to its communal government. When all villages have submitted their DRR plans to the commune, the communal CFS-SR organizes meetings at which all village leaders are invited to discuss and identify the best integration and collaboration amongst villages. At communal meetings, all the five villages receive the direction from higher levels of government before implementing their DRR plan for rainy seasons. 
Close to the start of each rainy season and before the onset of individual storms and floods, the community adopts the principle of "Four-on-spot", which has been included in the NSD for several decades. The principle aims to build community capacity through making four groups of resources available on the spot: leadership, human resources, means, and logistics. Participants claimed that the availability of resources at their community is particularly important as storms and floods happen suddenly and it might be too late to mobilize or obtain resources that are far away. By adopting the four-on-spot principle, five forms of capital to address storms and floods are mobilized and used (Table 6-1). For instance, the community uses loud speakers as a means to announce the occurrence of storm and floods and to mobilize its healthy men to form a patrol team to search for and rescue victims if the threats are realised.

Table 6-1: Examples of resources mobilized and used for DRR during rainy seasons

\begin{tabular}{lll} 
Group of resources & Example resources on the spot & $\begin{array}{l}\text { Resource classification by } \\
\text { participants (capital) }\end{array}$ \\
\hline Leadership & - Village CFS & Collective (social) \\
& - Patrol team & \\
& - Head of 6 units of the village & \\
& - Heads of local associations & Personal (human) \\
\hline Human resources & - Head of households & Collective (social) \\
& - Members of the village CFS-SR & \\
& - Young and healthy men for patrol teams & \\
& - Local clinicians & Personal (human) \\
& - Heads of local associations & Physical \\
& - All individual members of the community & \\
\hline Means & - Loud speakers & \\
\hline Logistics & - Wagons & Physical \\
& - Raincoats & \\
\hline & - Bags of sands & Natural \\
\hline & - Medicines & Financial \\
\hline & - Instant foods & \\
\hline & - Fresh water & \\
\hline
\end{tabular}

Source: consultative meetings with village leaders and FGs in June 2013

\footnotetext{
9 “Four-on-the-spot” or "Phương châm 4 tại chỗ: chỉ huy/lãnh đạo, lực lượng, phương tiện và hậu cần tạichỗ" refers to the leadership, manpower, means and supplies and logistics on the spot.
} 


\subsubsection{DRR during the rainy season}

The second part of DRR in Tuong Van takes place during rainy seasons, between September and November. DRR during this period involves a wide range of activities and participants classified their DRR activities during these seasons into three groups: responses before, during, and following storms and floods.

\section{$\underline{\text { Responses prior to storms and floods }}$}

Various terms are used to name the response before the occurrence of storms and floods. Some participants called this the planning phase, while others referred to it as preparation, proactive prevention, or resistance phase. Although there was no common term, most participants agreed that actions in this phase aim to provide the community with preparedness including the five capitals needed to avoid or reduce impacts of storms and floods when they happen.

Prior to each rainy season, diverse measures are adopted to reduce the vulnerability and enhance the capacity of the community (Table 6-2). At the household and community levels, resources needed for responses during and following disasters are prepared. For instance, at the community level, village leaders recruited healthy and experienced men of their community to form a patrol team, and then together developed and implemented annual plans in response to floods and storms. At the household level, local residents commonly fixed the roofs of their houses before storms occur.

The community has adopted short and long-term interventions for storms and floods at the household and community levels. For instance, in response to floods, local residents not only bought candles when they heard about the likely strike of the floods, but for 
longer term, they elevated their house floors to a level higher than the water level of the violent flood in 1999 in order to address future floods. At the community level, not only was the patrol team formed to help the community throughout rainy seasons, but a system of concrete dykes along the Thach Han River was also built to protect the community from annual floods and future sea level rise.

Table 6-2: Example measures to mobilize and use resources for the responses prior to the occurrence of storms and floods

\begin{tabular}{ll} 
Group of resources & DRR activities prior to the occurrence of storms and floods \\
\hline Leadership & Village CFS-SR coordinate and direct their villagers and local associations; \\
& connect with and receive external assistance from higher levels of government \\
& and NGOs; \\
- & Head of households direct their family members in preparing for DRR such as \\
& strengthening the roofs of houses; harvesting shrimps; cutting large trees near \\
& houses before storms \\
\hline Human resources & Recruit $10-15$ local healthy and experienced men to form a patrol team, which \\
& helps to develop an annual DRR plan and monitor and rescue during storms and \\
& floods; \\
- & Disadvantaged households were supported by their neighbours and relatives in \\
& strengthening the roof of houses \\
- & Loud speakers of the village were prepared or repaired to provide \\
& announcement about the progress of storms and floods; \\
- & Wagons of households were mobilized to carry stuff for storm and flood DRR \\
\hline Means & Instant food and medicines were prepared at the public shelter for emergency \\
& evacuation; \\
- & All households prepared drinking water and instant food before storms and \\
floods;
\end{tabular}

Source: consultative meetings with village leaders and FGs in 2013.

DRR strategies vary across the village. Despite being in the same community, Lang and Dong do not always adopt the same measures to address storms and floods as they have geographically and topographically different characteristics. For instance, Dong residents built semi-underground shelters on the top of their sandy dunes to avoid floods, while Lang residents could not use this innovation as they live on low land. Lang is more vulnerable to floods and storms than Dong, and this has prompted its residents to be more proactive in response to such threats. For example, almost every household in Lang has 
elevated their floors, while about $40 \%$ in Dong have done so. Another example is that residents in Lang commonly left their house earlier than in Dong to get to safer places when floods and storms occurred.

Different strategies in response to storms and floods were also found amongst groups of residents. Different livelihood-based groups of households do not prepare for storms and floods in the same ways. As examples, shrimp farms were the most vulnerable because of their high values and direct exposure to storms and floods, thus most shrimp farmers harvested their shrimps when it was announced that storms or floods would likely come. In contrast, rather than avoiding the floods, many residents in Lang took advantage of the events, prepared fishing gears such as traps and fish nets in advance to capture wild shrimps and fish during flood seasons.

\section{$\underline{\text { Responses during storms and floods }}$}

The main purpose of responses during storms and floods is to minimize human loss and damage to properties. During this phase, the village uses a diverse set of measures across multiple scales to provide rapid and timely actions (Table 6-3). For instance, the elderly and children are routinely evacuated first to the public shelter, while healthier members of families remain home to quickly move their belongings to safer places and delay their departure until they receive the "all evacuate" announcement from the patrol team.

Evacuation to safer places is the most important action to avoid human loss when the threats strike, with evacuation being mandatory for all residents when wind velocity is over the level 8 (62- $74 \mathrm{~km}$ per hour). Emergency evacuation procedures do however vary. A few years ago, some families in Dong used their own semi-underground shelters, whereas Lang residents went to their relatives in Dong and Ha Tay village to avoid floods 
and storms. Today, most residents in both Lang and Dong prefer evacuation to the primary school of the village as a public shelter, which was built in 2011 on the highest area of Trieu An commune.

Table 6-3: Example measures to mobilize and use resources for responses during storms and floods

\begin{tabular}{ll} 
Group of resources & DRR activities during storms and floods \\
\hline Leadership & Village CFS-SR directed the community to take emergency evacuation such as \\
& regularly announcing the progress of storms and floods; members of the patrol \\
& team helped disadvantaged people and families to evacuate to the public \\
& shelter; \\
- & Household heads directed their family in emergency response to storms and \\
& floods such as moving stuff to safer locations and evacuating to public shelters \\
\hline Human resources & Patrol team regularly monitored, rescued and brought victims to public shelter, \\
& where clinical officers were visited; \\
- & Elderly and children were first evacuated to public shelter, while experienced \\
& people stayed home to move stuff to safer places \\
\hline Means & Life vests and equipment that were prepared prior to storms and floods were \\
collected to public emergency; & - Life vests and helmets were allocated for patrol team members \\
\hline Logistics & - Every households brought their essential materials for emergency aid such as \\
& medicines, instant foods and drinking water when evacuated to safer places \\
\hline
\end{tabular}

Source: consultative meetings with village leaders and FGs in 2013

Storms and floods often cause human injury and damage to properties, thus emergency aids during the hazards are essential for Tuong Van. For example, the patrol team not only assisted their residents, especially children and the elders while they were evacuating to the public shelter, but also undertook continuous patrols along the river and rescued whoever was in danger. In some cases, the team also visited residents who were exposed to storms and floods but were reluctant to leave their home, in order to encourage them to evacuate to the public shelter.

\section{$\underline{\text { Response following storms and floods }}$}

Various activities were implemented in order to resolve the consequences of storms and floods when the threats had gone (Table 6-4). Of the most important activities during this phase are to evaluate losses following hazards and to identify timely solutions. For 
instance, following the $10^{\text {th }}$ storm in 2013 , village leaders and the patrol team visited all households and recorded important issues such as injuries and damage to houses. Local residents expressed that such activities were not just evaluations, but they brought a source of spiritual support to local residents, especially to families that had victims or property losses.

\section{Table 6-4: Example measures to mobilize and use resources for responses following storms and} floods

\begin{tabular}{ll} 
Group of resources & DRR activities following storms and floods \\
\hline Leadership & Village CFS-SR directed its community in evaluating and reporting human and \\
& economic loss to higher levels of government, and then led the recovery \\
& activities; allocated resources that were prepared prior to storms and floods to \\
& households; proposed plan for post-disaster recovery; \\
- & Household heads directed their family in addressing consequences of storms \\
& and floods such as repairing damaged roofs of houses and replanting gardens \\
\hline Human resources & - CFS-SR including the patrol team reviewed and reported human and economic \\
& losses to higher levels of government; treating environment to avoid infectious \\
& diseases such as diarrhoea and pinkeye; \\
- & Disadvantaged households were supported by their neighbours and relatives \\
& in strengthening the roof of houses \\
\hline Means & Wagons were mobilized and used to carry sand and earth for road and dyke \\
reparation; & - Bricks and tiles were used to repair damaged houses; \\
\hline Logistics & - Delivered notebooks for school children \\
- & Food, drinking water and medicines, which were prepared before disasters, \\
were delivered to households suffered from disasters
\end{tabular}

Source: consultative meetings with village leaders and FGs in 2013

Post-disaster relief is particularly important to promote the ability of the community as it helps to recover from human and economic loss and damage by storms and floods, for instance the repair of damaged houses and eroded roads. As such, governments request the leadership board of all villages to report loss and damage in their communities. For instance, following the tenth storm in 2013, like other villages, Tuong Van leaders sent all the collected information to the communal CFS-SR before reporting to higher levels. Based on human and economic losses, the district and provincial governments made decisions about the quantity and timing of post-disaster aids. 
Various forms of post-disaster aid took place following climate-related disasters such as the flood in 1999 and storm in 2015. The relief for Tuong Van included both physical and non-physical actions. Some participants claimed that following the floods in 1999, they received rice and notebooks for their children from provincial governments and NGOs, and they were also given US\$50 - 100 to repair houses. The assistance from external actors was particularly important as following the disasters the capacity of the community was reduced or even lost, and thus in many cases local residents themselves were not able to resolve the consequences of disasters.

Local residents have also implemented various measures to enhance their capacities over the longer term. For instance, following the disastrous flood in 1983 and the violent storm in 1985 , many cottage houses have been replaced by those with brick walls, tile roofs and in-house shelters, which provide local residents with more capacity to address storms and floods. These changes can be seen as self-organization or transformations of the community for critical transitions to a more resilient state.

In summary, Tuong Van has interwoven policy-oriented and community-based DRR approaches across jurisdictional, temporal and spatial scales in order to address storms and floods. The NSD is a particularly important DRR policy for the community as it has offered various benefits such as the provision of concrete dykes and training courses on storm and flood DRR. Yet, it also has limitations, thus the community has developed and implemented their own DRR measures and reinforce the formal DRR. The NSD has provided interventions on larger scales, while most autonomous DRR measures took place at the household level. 
The DRR process is divided into two phases, dry and rainy seasons. DRR activities in these two seasons have different but interconnected foci. The DRR in dry seasons provides or invests in essential resources for prevention, emergency responses and dissolution of storm and flood consequences. The DRR in rainy seasons (September through November) uses resources that the community prepared in the dry seasons to minimize human loss and property damage. Diverse actors across multiple jurisdictional scales are engaged in the DRR process, thus diverse resources within and outside of the community are mobilized and invested for DRR formulation and implementation.

\subsection{Mainstreaming CCA with DRR}

Besides floods and storms, Tuong Van has also been impacted by gradual and prolonged stressors. This section illustrates and discusses how the community has implemented CCA in order to reinforce DRR, which tends to overlook gradual and prolonged stressors. Since CCA is a relatively new concept and it is a politically and academically-driven term, the section starts with examining how local residents conceptualized CCA in their specific context, and how they distinguished CCA from DRR. It will then illustrate and discuss how the community has addressed climate hazards and the changing climate beyond floods and storms over the last three decades.

\subsubsection{CCA from local community perspectives}

The evidence from FGs showed that local residents have recently heard of the term CCA from public policies and training courses, but they seldom use it and tend to use terms that are more familiar to their own experiences and language. Some have used the term adaptation, but to "weather change" rather than "climate change". Scholars make a 
distinction between weather and climate, but local residents claimed that they equate the two terms. Scholars often use weather in the short-term, but local residents conceive it in both short and long-terms. In addition, participants confirmed that they use the term "adaptation to weather" more often and rarely use climate change adaptation although they have heard it from mass media and training courses.

When asking participants to explain the term adaptation, they described it in various ways to illustrate how they have responded to weather change. Most participants explained their adaptation as adjustment or modification with the aim of reducing climate risks and taking advantage of climatic events and the changing climate. This conceptualization is similar to the definition by the International Panel on Climate Change (IPCC 2007). Further discussions on the local adaption to climate change will be made later in this section.

Much effort has been made by scholars and policy makers to clarify the concepts of DRR and CCA (Mercer 2010). In Vietnam's governmental documents, DRR has been widely adopted over the last three decades and it is often used for responses to storms and floods, while CCA is a new concept and it has become increasingly popular since 2008 when the NTP was issued. At the local level, most villagers in Tuong Van claimed that they do not differentiate the terms of DRR and CCA although they commonly refer to DRR as responses to storms and floods. In addition, villagers viewed the two terms as formal languages and they affirmed that they seldom use them. Instead, they have their own notation of "prevention", which is associated with a specific hazard, for example flood or drought prevention. 
Findings from FGs revealed that the DRR and CCA measures that Tuong Van has used to address climate hazards could not be clearly separated from those aiming to address social-economic changes because of their interdependence and overlapping functions. For instance, some participants commented that the dredging of blocked drainages is not simply a measure to reduce adverse impacts of rain flooding on community health, but it is also a solution to enhance crop productivity, thereby improving household income and food security. In addition, participants argued that DRR and CCA measures to reduce climate impacts cannot be deployed successfully without those to address socio-economic barriers, for example self-interest and uncooperative attitudes of community members.

In short, from the perspectives of policy makers and academic scholars, DRR and CCA programs have been adopted in Tuong Van and they have attempted to make distinctions between DRR and CCA. In local community views, there is no clear conceptual distinction between DRR and CCA and local residents do not differentiate but rather integrate the two approaches to reduce impacts of climate hazards. However, some features could be used to distinguish DRR and CCA approaches in Tuong Van. DRR is used to address mainly storms and floods, while CCA is employed not only to address gradual and prolonged stressors, but also to reinforce DRR.

\subsubsection{Enhancing community resilience through DRR and CCA}

In the first set of FGs, participants identified a wide range of resources that were viewed as one of the two key components of the community. This sub-section illustrates how the five capitals (five groups of resources) have been invested and used throughout the DRR and CCA programs in order to enhance the resilience of the community over the last three decades. 


\subsubsection{Natural capital}

Tuong Van has enhanced the availability and quality of natural resources over the last three decades to reduce climate risks through the assistance from its governments and NGOs. Important natural resources in Tuong Van have been enhanced mainly from programs other than the DRR and CCA policies. Investment in freshwater resources is an example. Freshwater is evaluated as the most important resources for Tuong Van, thus national and provincial governments non-governmental organisations (NGO) have given a high priority for investment of freshwater resources in order to reduce the adversity of re-occurring droughts and salinization in the community. Through the national programs on National Strategy for Rural Clean Water Supply and Sanitation, in 1994 Oxfam Hong Kong financed most households to build cisterns to store rainwater for domestic use during dry months, whereas in 2010 provincial governments invested \$US 70,000 to build a system of domestic water supply in Lang (Nguyen 2010b).

Development of a green environment is an effective strategy to address climate hazards. Before 2000, most land in Dong was covered with sands and Dong residents were seriously threatened by droughts and extremely hot monsoons during summers. In 2000 , through the National Program on Poverty Reduction, the Norwegian government supported many provinces including Quang Tri Tram trees to plant Tram trees on their sandy areas. The plantation of exotic species is critiqued as harmful to local biodiversity (Manchester and Bullock 2000), but local residents viewed it as an adaptation strategy and an innovation for the development of local economies. All FG participants affirmed that Tram forestation has provided them with additional income from the sales of trees and has also created cooler and greener environment around their houses in summers. In 
addition, local residents viewed Tram forests as green belts against storms from the Cua Viet Sea in rainy seasons.

Besides external assistances, the community has also developed their own measures to enhance the availability and quality of their natural capital. Local residents not only exploit but also preserve their natural resources to improve their resilience and lessen climate impacts. For instance, Lang residents planted and have conserved bamboo rings around their houses for many decades, which have not only reduced the effects of strong monsoon winds during both winters and summers, but also protected them from storms and floods in rainy seasons. One resident explained as follows:

Around 10 - 15 years ago, like Tuong Van, many villages also had lots of bamboo rings surrounding houses and bamboo trees were commonly used to make household stuff such as fish traps and house roofs. But today if you go through these villages, you can see most bamboo rings in these villages have been cut down because they seldom used to make bamboo stuff, which was replaced by plastic technology. In Lang, we also use plastic stuff, but we do not clear our bamboos because they shield violent floods and storm winds (LCNV, 80).

This quote not only shows important roles of natural resource conservation in enhancing $\mathrm{CR}$ and reducing climate risks, but it also illustrates interconnections between natural and other types of capital. Natural resources provide the community with opportunities to generate physical, financial, human and social capitals. For instance, bamboo is used to produce fish traps and house roofs (physical capital), wild fish and clams not only provided Lang residents with additional income (financial capital) from sales of these resources, which are used as a source of high-protein foods to improve personal health (human capital) of local residents. In addition, some natural resources are used to develop social capital. For example, the large shade of a big ornamental plant in front of the village office was frequently used by local residents as a place for community meetings. 


\subsubsection{Human capital}

Various forms of human capital in Tuong Van have been enhanced to address climate hazards over the last three decades. Local residents conceived human life and integrity as the most important for the community and as the focus of storm and flood DRR action plans. Various activities such as emergency evacuation to safer places and patrols to rescue victims during storms and floods have been undertaken to protect human life. As a result human security has increased over the last three decades. Participants claimed that during the first half of the 1980s, storms and floods killed three people and injured about 45 others, but since then no human deaths occurred and only a few injuries were reported.

The knowledge and skills of local residents on DRR and CCA have been invested through government policies and support from NGOs. For instance, the NSD program the district CFS-SR provided village leaders and members of the patrol team with training courses on search and rescue during storms and floods, while through the National Program on Poverty Reduction many poor households were given training courses on better management of shrimp farming.

These investments, however, are not simply external to the community. For example, many shrimp farmers have recognized the benefits of improving their farm management skills and made personal investments in order to take training courses on and visit successful shrimp farms. Human capital has also been improved through personal experiences with climate hazards. Valuable lessons learned from losses have stemmed from past hazards and many members of the community have learned to not underestimate or overlook climate events. Becoming more knowledgeable, skilful and 
proactive is part of the enhancement of human capital and Tuong Van has benefitted from external programs as well as investments at the personal and community levels.

\subsubsection{Social capital}

The resilience of Tuong Van community has been improved through a number of social networks including the unions of women, youths, farmers and veterans as well as kinship and neighbourhood. The unions provided residents with both material and intangible capacities to deal with climate hazards. For instance, women's and youth's unions allocated money from their fund to help victims from storms and/or floods. Some participants said that such money could help the victims buy some medicine and good food to recover, but more important benefits from these networks were mutual support from union members. One woman expressed the importance of spiritual support her neighbourhood and the union of women as follow:

I felt very much spiritually warmer when sisters ${ }^{10}$ in our village visited when I was injured from the storm in 2005 (LNTD, 55).

Survey data showed that kinship and neighbourhood were ranked as the most important forms of social capital, while some other networks such as veterans and farmer's unions were overlooked (see Chapter 5). Evidence from FGs and interviews with local villagers revealed that the appreciation depends on mutual benefits social networks provide and such benefits determine the existence and effective operation of social networks. Most participants affirmed that the unions of youths, farmers and veterans provided their members with very little support, while kinship and neighbourhood offered a greater amount of both material and intangible benefits. One participant explained the benefits of kinship and neighbourhood as follows:

\footnotetext{
${ }^{10}$ Sisters refer to members of the Women's Union
} 
When our house collapsed by the storm in 2005, we felt mentally deteriorated. We could not overcome those problems if there were no neighbours and relatives beside us. Some came with spiritual support, while others spent several days to restore the house. Moreover, we had no safe place for our grandchildren to sleep, thus we sent them to our neighbours for a week (LHL, 65).

Tuong Van residents not only have social networks within their village, but they also have developed relationships with external actors. For instance, shrimp farmers have built relationships not only with shrimp hatcheries in other central provinces such as Da Nang and Khanh Hoa provinces, but also agencies of shrimp feed and medicines outside their village. Many shrimp farmers asserted that some hatchery and supply agencies were helpful for them because the agencies offered a policy of partial post-payment, while they were always in a situation of insufficient investment capital.

As discussed earlier, mutual benefits were an essential element for the existence and effective operation of social networks. However, group discussions and interviews with villagers revealed that mutual benefits are not sufficient; social relationships also rely on rules, norms and trust amongst parties. For instance, some participants affirmed that both shrimp farmers and their supply agencies could gain benefits from their business, but their contracts would be terminated if essential norms or rules were violated or the trust between them was lost.

A number of informal and formal regulations or norms have existed for Tuong Van to enhance CR and reduce climate impacts. For instance, the fishery law has been adopted to protect aquatic resources, while several agreements among community members, such as informal regulations for waste management and shrimp farming were developed to reduce epidemics of infectious diseases and enhance community health. Formal and informal regulations have contributed, to some extent, to enhancing $\mathrm{CR}$ and reducing 
climate impacts. For instance, participants claimed that the number of destructive fishing cases has reduced as the fishery law was enforced at the local level while the compliance of community members to local regulations of food safety helped to prevent the spread of and reduce some epidemics of diarrhoea and influenza.

\subsubsection{Physical capital}

Living in harsh conditions, the community always explores and implements physical solutions to address climate hazards. For instance, at the household level, most families not only elevated the floor of their houses and built houses with brick walls and tile roofs to better resist floods and storms, but also installed drilled wells to extract underground water for domestic use and subsidiary crop production. At the community level, some critical infrastructure for the village as a whole was erected and mainly supported by the NSD. One of the most important physical resources was the system of concrete dykes, which was built in 2010 to protect the community from annual and tidal flooding. One man expressed his mood and the important role of the dykes as follows:

Previously, Tuong Van had a dyke system, but it was earthen and very low. As such we often had to leave our houses and live with our relatives in Dong until floods had gone, often for several days. Moreover, various sections of the dyke were annually broken due to erosion, thus we were mobilized by our community to carry earth and stones to maintain and repair the dyke before and after rainy seasons. Our dream was a concrete dyke for many years and it became a truth in 2010. Today we do not have to leave our house as often as before because the dykes can protect us from annual river floods and from flooding when tides rise. (LTNV, 66)

Besides the local efforts and the NSD, the physical capacity of the community to address

climate hazards has also been enhanced through integration amongst public policies and the contribution from diverse actors. Prior to 2013, although the CCA policy (NTP) was not available in Quang Tri, some important infrastructure was supported by the Quang 
Tri provincial government and international NGOs to deal with gradual and prolonged stressors. For instance, besides rainwater cisterns, Oxfam Hong Kong also supported Tuong Van villagers with building toilets to enhance community health through the National Program on Rural Clean Water and Sanitization during the early 1990s,.

The community needs a diverse set of physical resources to address the changing climate, but not all proposed or needed resources are invested because of insufficient human and financial resources. As such the investment for important infrastructure was prioritized and it was based at least on three criteria. Some physical infrastructure was invested due to their efficiency. The government did not give priority to measures at the household level, but rather it invested in projects that are beneficial to the community as a whole, for example building a dyke system and a public shelter. Another criterion was the severity of climate hazards. As an example, floods and droughts were the most important threats to Tuong Van, thus concrete dykes and a water supply system for Lang were given a high priority despite their high costs. Finally, the investment was based on the multiple functions of physical resources. For instance, the primary school was prioritized because it was used not only for educational purposes but also as a public shelter for Lang residents and neighbouring communities during floods and storms.

Recognizing that each physical resource has its own function and a single resource cannot fully reduce impacts of climate hazards, local residents combine multiple resources to enhance their capacities and address climate threats more effectively. For instance, cisterns to store rainwater help the community to resist droughts during the summer, but they have limited capacity, thus villagers could only store rainwater and use it for 3 out of 6 dry months. In support to rainwater cisterns to address droughts, many 
households installed dug and drilled wells to exploit underground water for domestic use and crop production. However, one disadvantage of these wells is that their water is highly contaminated with alum. As such most residents installed water filters to enhance the water quality.

\subsubsection{Financial capital}

The life becomes very hard if money has run out, brother ${ }^{11}$ ! I experienced such a situation. The roof of my house collapsed in the 2005 storm. I spent all my savings to have a new one. Unluckily, two weeks upon the completion of the roof, my daughter fell seriously ill. I had to send her to the provincial hospital while I did not have any Dong ${ }^{12}$ in my pockets. I did not know what I could do if my relatives and villagers did not offer me some money as small gifts and loans. (DHPT, 55)

This quote not only reveals the important role of financial resources for local residenst to enhance their resilience, but it also highights the relationships among resources and how the community struggled with the shortage of financial resources. Money is not only essential for local residents to build or restore their houses following disasters, but it is also used to buy daily food and medicines when they got sick. In both FGs and in-depth interviews, most participants also asserted that many measures to address changing climate could not be implemented if financial resources were not available. However, the quote above also reveals that the financial deficiency of local residents can be addresssed through other resources such as neighborhood and kinship.

Local residents have explored and combined various ways to improve their financial resources. At the household level, financial resources exist in various forms (see Chapter 5), but cash, loan and saving were the most common. Some residents claimed that if they had no money, they often borrowed cash from their relatives and neighbors, while some

\footnotetext{
${ }^{11}$ The informant addressed the author like a younger brother.

${ }^{12}$ Vietnamese currency
} 
others accessed banks for loans. However, many residents commented that access to bank loans usually took time, thus they chose saving money from livelihoods as the most effective strategy. Besides cash, loans and savings, some residents used health insurance, while some others used credits when buying inputs for shrimp and rice production.

Tuong Van villagers could access various sources of finance, but choosing which sources was dependent on their need. One shrimp farmer claimed "We borrow some money from our relatives and neighbours to buy medicines when our family members are sick, but we must access governmental loans for shrimp farming because it needs a large amount of investment capital" (LLPT, 55). Some residents added that their relatives and neighhors often gave them loans of several weeks, while they needed money for a longer period to complete shrimp production cycles. In other cases, local residents used credit as a finacial resource instead of loans. For instance, some shrimp farmers paid half of the cost when they buy shrimp feed from shrimp-input suppliers and the other half would be paid when their shrimp were harvested.

At the community level, various measures to address climate hazards were implemented in Tuong Van from financial sources of governments and NGOs. For instance, the national government invested about US\$ 500,000 from the Asian Development Bank loan to erect three $\mathrm{km}$ of concrete dykes along the Thach Han River, while World Vision funded about US\$ 42,000 to build $1.5 \mathrm{~km}$ of concrete roads. Many residents argued that Tuong Van could not build such physical infrastructure without the external assistance because the required investments exceeded the financial capacity of their community.

Tuong Van had no permanent funding from its governments, thus it had to raise funds for community activities through its own financing mechanisms. Some of the village fund 
was mobilized from villagers to co-fund with donors for infrastructure projects. For instance, US\$ 3,500 or $18 \%$ of investment capital was mobilized from villagers to coinvest with the national government and World Vision to build $1.5 \mathrm{~km}$ of concrete roads (Nguyen 2010b). In addition, the village annually collected about US\$15,000 from the lease of the community's shrimp farms, which was used for regular activities of the community such as community meetings and infrastructure maintenance.

Local associations also created their own funds. For instance, the union of women collects about US\$ 1.2 per year from each of 120 members, while each member of the farmer association of some 250 members contributed about US\$ 2 per year to its association fund. The collected money was mainly used as a mutual fund for special events such as visits to families, which faced hard situations, for example deaths or serious injuries or their houses damaged from floods or storms. If the mutual fund was still available at the end of a year, then it could be used for other purposes such as meetings or carried over the next year.

In short, the ability and quality of the five capitals in Tuong Van have been promoted from combination of public policies and local efforts in order to enhance the resilience of the community and reduce adverse impacts of a changing climate. Besides support from the NSD and local investments, other public policies such as the national policies on poverty reduction and on rural clean water supply and sanitation have also been deployed to overcome the deficiency of the NSD and NTP programs. Although resources play different roles, they can reinforce one another. For instance, most households have used drilled wells (physical capital) to exploit underground water (natural capital) to enhance personal health and income (human and financial capitals, respectively). In turn, the 
money (income) can be used to pay for memberships of social networks (social capital) such as the unions of women and farmers. As a result of mutual reinforcement among resources, villagers have invested and combined various resources to address more effectively the multiplicity of climate hazards.

\subsubsection{Livelihood adaptation to climate hazards and a changing climate}

Another key component of Tuong Van community is resource-based livelihoods, which are routinely threatened by climate-related hazards throughout the year. This sub-section illustrates three common strategies that local residents have deployed to enhance their resilience and adapt their livelihoods to climatic conditions: diversification of livelihoods, modification of existing livelihoods, and temporal rotation of natural resources-based livelihoods.

\subsubsection{Diversification of livelihoods}

Livelihood diversification was seen as one of the key strategies that Tuong Van residents have used to enhance their resilience over the last three decades. Since Quang Tri province obtained liberty through the Vietnam War against the United States of America, the number of livelihood options has increased. Before 1973, local residents mainly lived on agriculture and fisheries, but today the village has many more livelihood alternatives in order to provide more income and enhance food security. For instance, 12 ha of salt production were developed at the time of liberation, while 60 ha of rice land were converted to shrimp farms since the late 1990s. More recently, most households in Dong have gained income from Tram plantation. 
Diverse livelihood activities have been developed over the last three decades. At least 12 livelihoods have been recently implemented by the community. Most households are involved in animal, rice and subsidiary crop production as their main livelihoods. In addition to these, villagers are also involved in shrimp farming, seasonal labour outside the village, and the exploitation of natural resources including fisheries and medical materials. Besides livelihood diversification, many households have also maximized the number of species and varieties in their livestock and poultry production systems. For instance, about 30 households ( $9 \%$ of the village) not only raised chicken and ducks, but they also included $2-5$ pigs and $1-3$ cows (Nguyen 2010b).

Data from the surveys reveal that livelihood diversification varied across the community. The majority of the community, $60 \%$ of households had at least 4 of the 12 livelihoods, while a low proportion of the village, $24 \%$ of households had not diversified their livelihoods as they only had one or two activities (Figure 6-3). In addition, the survey results reveal that Lang had more diverse livelihoods than Dong, 10 and 8 of 12 livelihoods, respectively (Figure 6-4). Apart from livelihoods that are common for the two hamlets, only Lang residents were involved in the exploitation of wild fish, shrimp, clams and nut grass. 


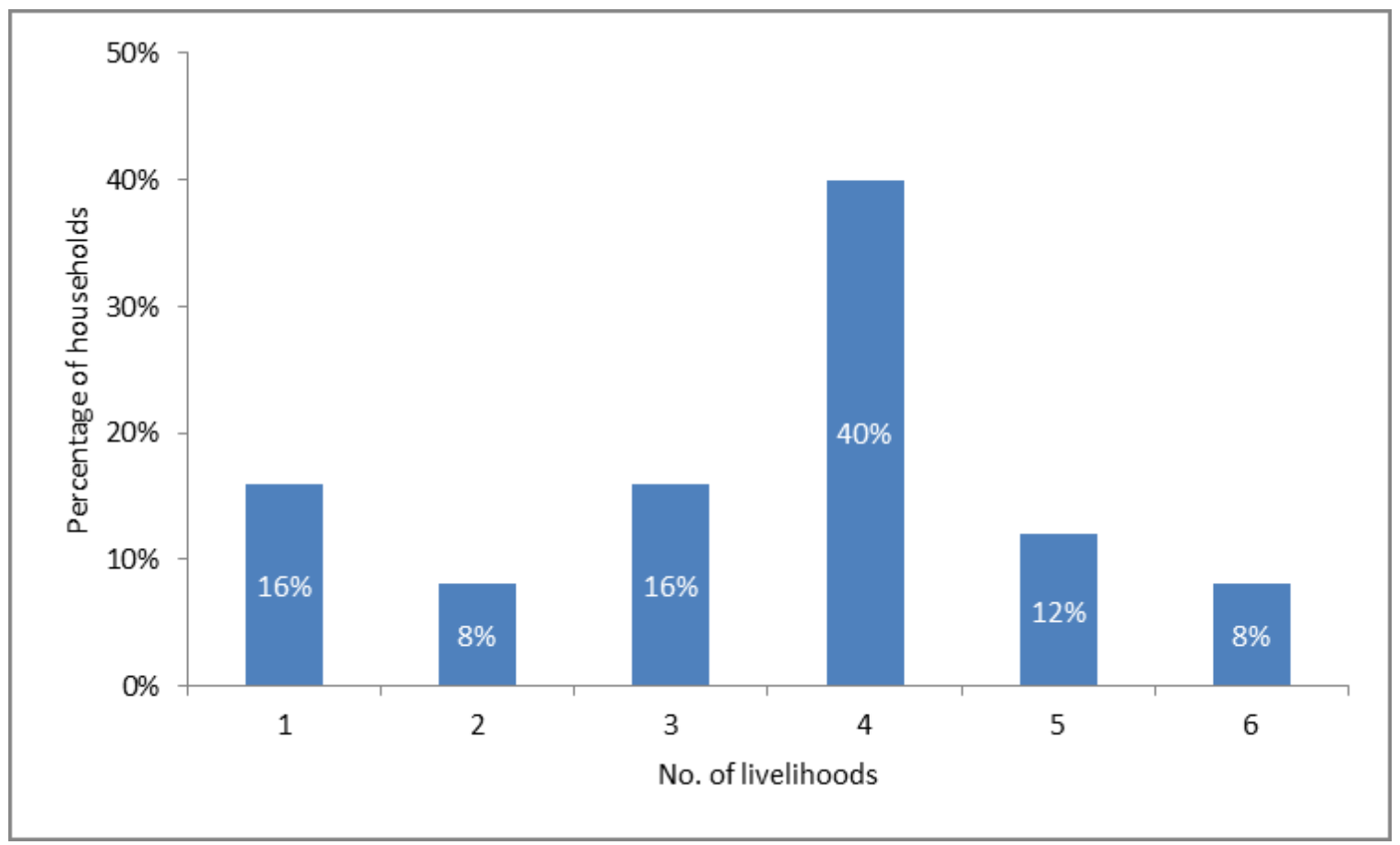

Figure 6-3: Percentage of households diversifying their livelihoods in Tuong Van

Source: survey to 25 participants of focus groups in 2013

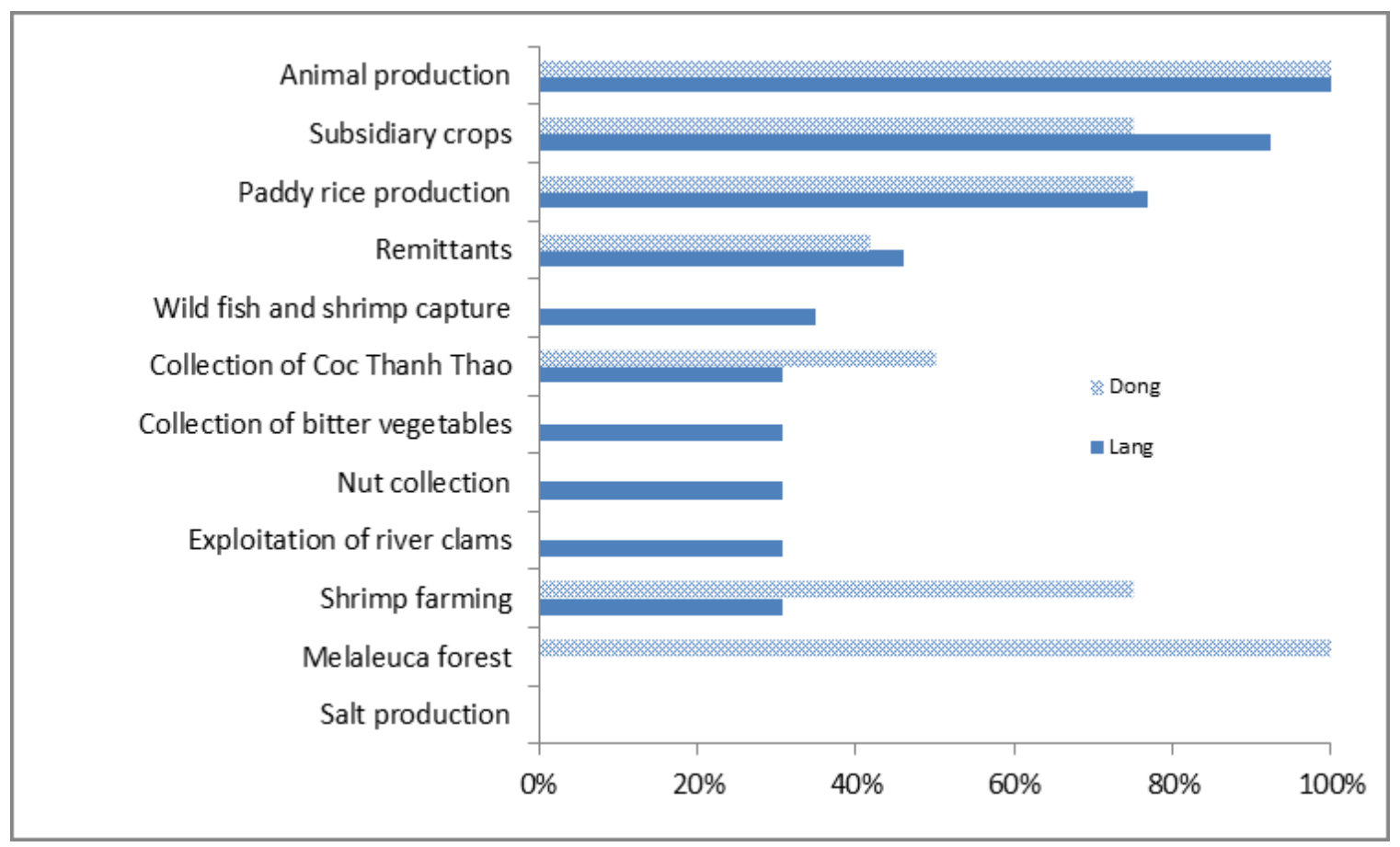

Figure 6-4: Recent involvement of Lang and Dong residents in recent livelihoods

Source: the survey to focus group participants in June, 2013 
Besides resource-based livelihoods, many households have also gained income from seasonal jobs outside their community. Many youths frequently move out of their village to work either for long or short-term contracts. Participants claimed that approximately $5 \%$ of their community had long-term contracts with garment, agricultural and fishery factories in southern provinces such as Binh Duong and Ho Chi Minh. In addition, about $10 \%$ of the residents had daily jobs at their neighbouring villages and communes, or moved to other districts of Quang Tri and Laos to work for several months per year. Short-term migrants to the distant areas are commonly paid much higher than local labours. They could earn US\$ 15 - US\$ 20 per day in Laos, while around US\$ 5 was typical for jobs in their village and nearby.

\subsubsection{Modification of existing livelihoods}

Tuong Van has only 210 ha of land area, thus its residents have explored effective patterns of their land use to adapt to environmental changes over last three decades. After the liberation, like most rural communities across northern Vietnam, Tuong Van villagers lived in poverty and rice development was the most important measure to alleviate the problem. As such the community extended their paddy-rice area to 100 ha to enhance food security.

In the late 1990s, the shrimp aquaculture technology advanced and it was widely adopted across the coast of Vietnam. In the meantime, rice in Tuong Van was always threatened by droughts and salinization and its price had been dropped for a long time. Taking advantage of technological advancement, between 1999 and 2000, a large portion of rice production area was converted to tiger shrimp farms to reduce impacts of the hazards and promote the local economy. Shrimp farmers were successful in the beginning, but then 
they frequently failed due to water pollution. Today, shrimp farming is gradually recovered as tiger shrimps were replaced by white leg shrimps, which were perceived by farmers as more resistant to infectious diseases. Besides the introduction of white leg shrimps, farmers have also adopted better aquaculture practices to adapt to environmental changes, for instance stocking at lower density and use of cleaner shrimp seeds.

The village has also changed crop varieties in order to adapt to environmental threats. About 15 years ago, villagers used local rice varieties that had high stems and tolerated saline and acidic soils. However, participants commented that such rice varieties had a long period of growth and could easily fall down upon winds, thus they have been replaced with a number of new hybrid varieties since the 1990s. Local residents commented that the current rice varieties not only grow well in the saline and acidic soil, but they also have a shorter period of growth, lower and stiffer stems, thereby they are able to resist strong winds and offer the community with higher yield of rice.

Villagers have also modified the physical structure of their gardens to reduce climate risks and enhance agricultural production. Dong villagers live in the valleys among sand dunes and their gardens are annually flooded by heavy rains for $2-3$ months. About $10-$ 15 years ago, most gardens in Dong were abandoned during the rainy seasons. Today many households in Dong have modified their gardens by creating three levels of production for the gardens and such modification provide more favourable conditions for cultivation of different species. For instance, the lowest level of the gardens, where is more frequently flooded, is used for paddy-rice, while the second level is for bitter melon and leguminous species and sweet potatoes, and the highest level is used for Tram trees. As a result of these modifications, gardens in Dong have become more productive. 


\subsubsection{Temporal rotation of natural resource-based livelihoods}

In response to climate hazards, local residents also rotate their livelihood systems as well as animal and plant species throughout the year (Table 6-5) as they have different adaptability to climate events and variations of climatic conditions. The ending and beginning of a year, between December and April, are the most favourable months for various livelihoods. Besides livestock and poultry production as well as forestry that take place year round, villagers also have seasonal livelihoods including rice and subsidiary crop production, exploitation of natural resources including wild fish and clams, and freshwater aquaculture.

In the dry season, April through August, Tuong Van is heavily impacted by droughts, southwest monsoons (extremely hot and dry) and salinization. During this period, livelihoods that are highly dependent on freshwater supply such as rice farming and freshwater aquaculture are terminated and substituted by those being more tolerant to salinization and droughts. For example, shrimp farmers operate their farms from March until late August, and other villagers exploit river clams and collected Coc Thanh Thao on sandy hills between May and July.

The months between September and November are conceived as the harshest season because of floods, storms and flooding and most livelihoods are terminated during this period. Thus development of alternative livelihoods is particularly critical for enhancing food security and household income in the community. Lang residents have developed various forms of capture fishery to exploit aquatic species that migrate from the Cua Viet Sea to the Thach Han River and into flooded post-harvest farms for spawning. Besides 
capture fisheries, many women in Lang are also involved in collecting bitter vegetable to seek for an additional source of food and income.

Table 6-5: Temporal rotation of natural resource-based livelihoods in Tuong Van community

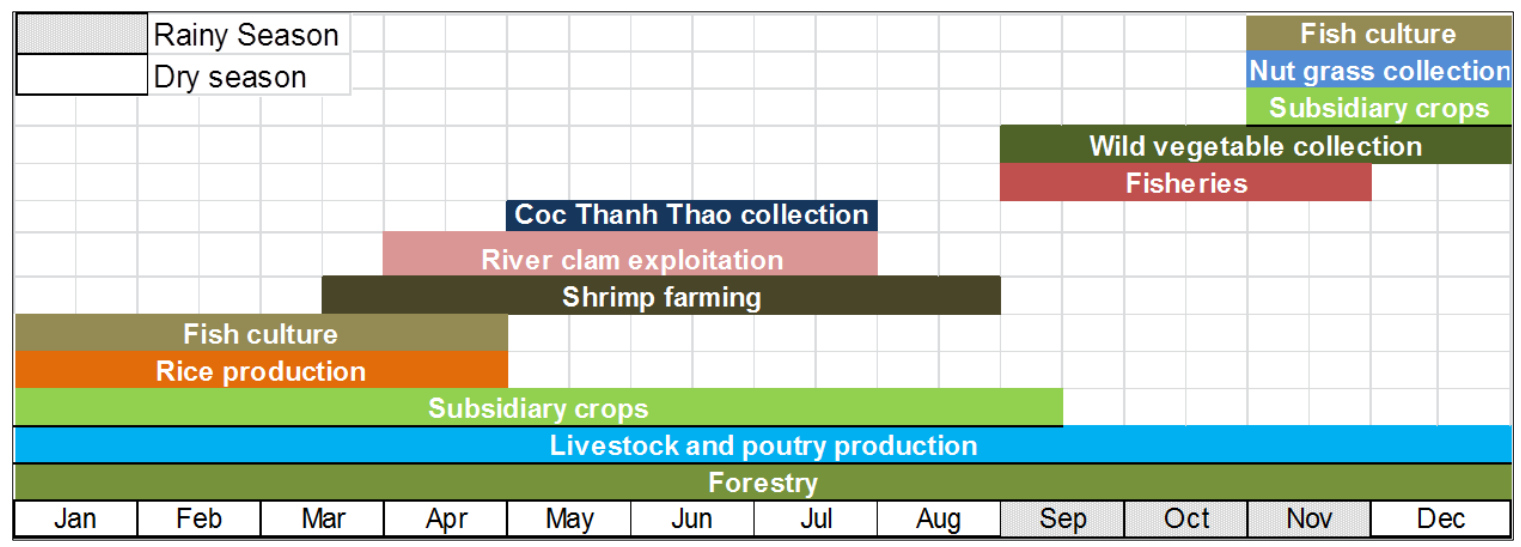

Source: Focus group discussions in Tuong Van village in June 2013

\subsubsection{Taking advantage of climatic events and a changing climate}

Heavy rains and floods do not always threaten our community, but they also help us to wash away salt brought by tidal flooding, and provide rain water to be stored for domestic use in dry summers. Many people also take advantage of annual river floods and tidal flooding to trap fish and shrimp in their post-harvest farms (LNVT, 60).

During FGs, participants argued that the changing climate does not always have negative impacts on their community, but it also provides beneficial opportunities. First, some climate events have helped the community to enhance the availability and quality of resources. For instance, heavy rains provide local residents with freshwater for domestic use in dry seasons, while floods could help to wash away salt contaminated their rice farms. As such local residents not only reduce adverse impacts but also take advantage of climatic events to enhance their resilience. For instance, most households built cisterns to store rainwater during rainy seasons for domestic use in dry summers. 
The changing climate has also provided villagers with new opportunities for livelihood development. Previously, most gardens in Dong were abandoned almost a whole year because of flooding in rainy seasons and of inadequate freshwater for crop production in dry seasons. Recently, many households in Dong viewed the increased frequency of heavy rains increased and the extension of rainy seasons as advantages rather than disadvantages of the changing climate, and thus they built ponds for freshwater aquaculture and modified their gardens for paddy-rice farming. Another example is that local residents have reduced salinization by controlling flood flows over the last many decades to wash away salt on rice farms, to recruit wild fish and shrimp to the farms, to enrich the farms with alluvial materials.

\section{Synthesis of Chapter 6}

Chapter 6 explored how the community has addressed climate hazards over the last three decades. Interventions have recently been adopted in Tuong Van to address climate hazards are synthesized in Figure 6-5. The community has combined DRR and CCA programs across jurisdictional, temporal and spatial scales as they can reinforce one another. DRR is used mainly to address storms and floods, while CCA is deployed not only to reduce adverse impacts of gradual and prolonged stressors but it also reinforces the benefits of storm and flood DRR.

The community has invested in and used the five capitals through DRR and CCA in order to enhance $\mathrm{CR}$ and reduce adverse impacts of climate hazards and change. These capitals play different roles, but they can reinforce one another. For instance, local residents installed dug and drilled wells (physical capitals) to exploit underground water (a natural capital), which is in turn used to improve personal health (human capital) and crop 
productivity. Given the improved productivity of crops, local residents have higher income (financial capital), which is used to re-invest other DRR and CCA activities. Yet, discussions in FGs also revealed that the five capitals do not always reinforce each other; they might have negative interactions. This issue will be discussed in the next chapter.

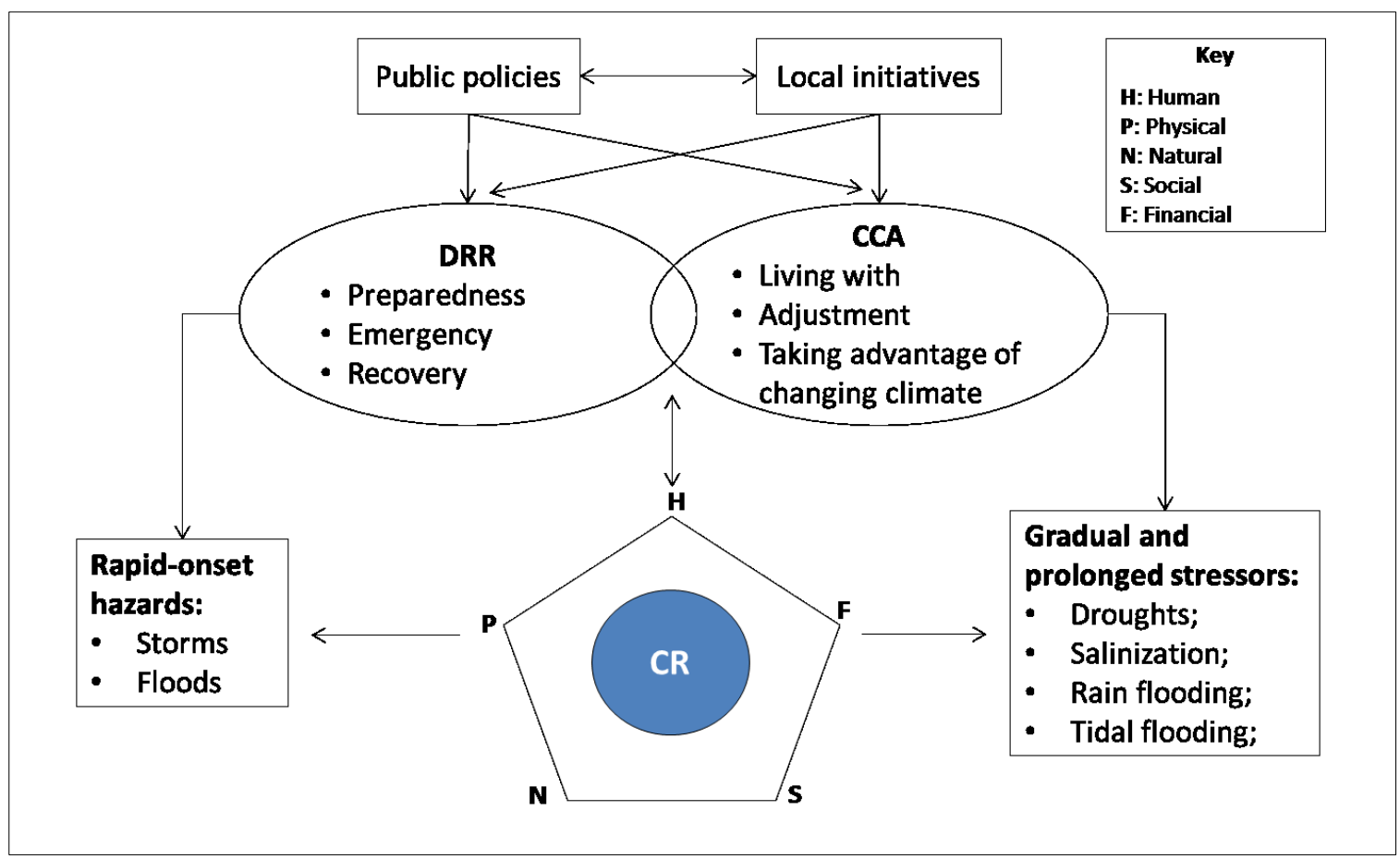

Figure 6-5: Integration between disaster risk reduction (DRR), climate change adaptation (CCA) and community resilience (CR) to address changing climate in Tuong Van

Source: synthesized from focus group discussions and interviews with local residents as well as staff of governmental and non-governmental agencies

Although DRR and CCA programs share the same goal of enhancing CR and reducing adverse impacts of climate hazards and change, they are practiced in different ways. In response to storms and floods, Tuong Van has combined policy-driven and communitybased DRR approaches across multiple jurisdictional scales. The NSD is seen as a key policy for storm and flood DRR and it is executed through formal procedures, in which diverse actors across all levels of government are engaged. The policy has provided the community with various important DRR projects such as building flood dykes and a 
public shelter. However, the NSD is not always available for the community, for instance termination of most NSD activities outside rainy seasons.

The community has developed and implemented community-based disaster risk reduction to partially reduce limitations of and reinforce the formal DRR. Villagers do not entirely rely on public policies (NSD and NTP), but rather developed their own measures in line with their capacities and situations, for instance plantation and conservation of bamboo rings and salt-tolerant trees to reduce risks from violent floods. Community-based DRR in Tuong Van has not only reduced the dependency on external resources, but also reinforced policy-oriented approaches. For instance, the NSD provided the community with a dyke system to reduce flood risks, but this dyke system does not always provide full protection and, thus before the onset of storms, shrimp farmers commonly avoid losses by advancing the shrimp harvest.

DRR is deployed mainly to address floods and storms, while the village is also impacted by a wide range of gradual and prolonged stressors. The Quang Tri provincial government issued an action plan for the NTP that is expected to address future climate change and reinforce the DRR program. Yet, the plan has not been applied at lower levels. In support of the DRR and CCA policies, the provincial government provided Tuong Van with a number of projects through other national programs to enhance CR and address stressors other than storms and floods. For instance, many rainwater cisterns and drilled wells in households were installed through the National Program on Rural Clean Water and Sanitization to address droughts and salinization, while livelihoods such as Tram plantation and shrimp farming have been developed through the National Program on Poverty Reduction. 
Besides external assistance, the community has a long history and extensive experiences on community-based CCA, which has been used not only to reduce risks from gradual and prolonged stressors but also to support DRR efforts to address storms and floods. The community-based CCA involves adjustment such as garden modifications and temporal rotation of crops in order to reduce adverse impacts and take advantage of climatic events and climate change. Most community-based CCA activities in the village are used to reduce climate impacts in the short term and small scale, but the village also has some long-term and large-scale measures such as the conservation of bamboo trees for many decades to address floods and storms, and the elevation of house floors in response to future sea level rise.

Overall, the community has integrated DRR with CCA programs across jurisdictional, temporal and spatial scales to address a changing climate as the integration between the two programs could provide various benefits. In addition, the recent interventions are a combination of policy-oriented and community-based approaches in order to enhance the availability and quality of the five capitals and reduce adverse impacts of the changing climate. The former approach tends to focus on larger scales and longer-term, while the latter concentrates on smaller scale and short-term. Besides the DRR policy, the community has also received significant support from other national programs to enhance its resilience and reduce climate risks. These observations set out a foundation for the following chapter, which explore the success and limitations of the DRR and CCA programs, as well as examine the factors shaping the success of the two programs. 


\section{CHAPTER 7: MULTIDIMENSIONAL FACTORS AFFECTING THE SUCCESS OF RECENT INTERVENTIONS}

\section{Research sub-question 3: $\quad$ Why have some of the recent responses of central Vietnam's coastal communities reduced impacts of climate hazards, while some others have been less successful?}

Chapter 7 assesses the disaster risk reduction (DRR) and climate change adaptation (CCA) programs in Tuong Van community and identifies factors that have promoted and impeded success. The chapter begins with evaluating the performance of the DRR and CCA programs over the last three decades, and then explores governance factors that have shaped the process of program formulation and implementation. The chapter concludes with an examination of how the adequacy of the five capitals have impacted the success of the two programs, and thereby influenced community resilience (CR).

\subsection{An overview about the success and limitations of DRR and CCA practices}

The evaluation of DRR and CCA programs began with participants listing projects that they viewed as the most successful and unsuccessful. Participants classified these projects into two groups. The first includes projects that their community had proposed in action plans, but were not deployed. For instance, the community proposed an irrigation system to higher levels of government, but funding restrictions prevented implementation. The other group of projects that were implemented is larger, and levels of their success were shaped by a wide range of interconnected factors. 
Table 7-1 summarizes the community's perceptions on the effectiveness of DRR and CCA programs. One of the most significant successes of the two programs is increased human security. During the early 1980s, floods and storms killed three people and injured about 45 others, but since then no human deaths occurred and only a few injuries were reported. In addition, DRR and CCA programs have enhanced the availability and quality of natural, financial, natural, human and social capitals. For instance, the community not only has new concrete dykes and better skills to reduce risks when storms and floods strike, but Tram forests are also planted as green barriers against hot and dry southwest monsoons in summers and against storms in rainy seasons.

Table 7-1 reveals that many important resources, for instance an irrigation system and a rescue boat, remained unavailable for the community even though the community had requested these resources as part of broader plans to reduce climate hazards. In addition, the quality of various resources has been declining over the past 30 years. For example, the green belts of salt-tolerant trees and many important ecosystems along the Thach Han River have been destructed, while the system of flood dykes and emergency roads have been increasingly eroded. 
Table 7-1: The success and limitations of DRR and CCA programs

\begin{tabular}{|c|c|c|c|}
\hline Five capitals & Suc & cess & Limitations \\
\hline $\begin{array}{l}\text { Human } \\
\text { capital }\end{array}$ & $\begin{array}{l}- \\
- \\
-\end{array}$ & $\begin{array}{l}\text { No human deaths and reduced } \\
\text { incidents of injury over the last three } \\
\text { decades; } \\
\text { Majority of residents had better } \\
\text { knowledge and skills on response to } \\
\text { storm and flood; } \\
\text { Majority of residents have positive } \\
\text { attitudes and behaviours towards } \\
\text { storm and flood interventions. }\end{array}$ & $\begin{array}{l}\text { - } \\
\text { Negative attitudes and behaviours of } \\
\text { mane residents towards fishery } \\
\text { - } \quad \text { Some outbreaks of diarrhoeas and } \\
\text { pinkeye occurred after floods and } \\
\text { storms; } \\
\text { - Shortage of healthy men during rainy } \\
\text { seasons. }\end{array}$ \\
\hline $\begin{array}{l}\text { Physical } \\
\text { resources }\end{array}$ & $\begin{array}{l}- \\
- \\
-\end{array}$ & $\begin{array}{l}\text { No houses swept away by floods } \\
\text { since 1986; } \\
\text { Climate protection infrastructure } \\
\text { (e.g. transportation, dykes, public } \\
\text { shelter) installed; } \\
\text { Increase in the number of houses } \\
\text { with brick walls and tile roofs }\end{array}$ & $\begin{array}{l}\text { - High proportion of houses damaged by } \\
\text { the } 10^{\text {th }} \text { storm in 2013; } \\
\text { - } \quad \text { Damage to some important physical } \\
\text { resources such as roads and flood dykes } \\
\text { is getting worse; } \\
\text { - } \quad \text { A wide range of physical resources such } \\
\text { as irrigation system and a rescue boat } \\
\text { were proposed but not implemented; } \\
\text { - Some resources such as water supply } \\
\text { system could not be used due to their } \\
\text { low quality }\end{array}$ \\
\hline $\begin{array}{l}\text { Natural } \\
\text { resources }\end{array}$ & $\begin{array}{l}- \\
- \\
-\end{array}$ & $\begin{array}{l}\text { Rainwater was stored for summer } \\
\text { use; } \\
\text { Groundwater from drilled and dug } \\
\text { wells were exploited for domestic } \\
\text { use and subsidiary crop production; } \\
\text { Environment around the houses in } \\
\text { Dong became cooler and more } \\
\text { income was generated when sandy } \\
\text { land was forested. }\end{array}$ & $\begin{array}{l}\text { - } \quad \text { Shortage of freshwater for domestic use } \\
\text { and crop production; } \\
\text { - } \quad \text { Underground water more saline; } \\
\text { - } \quad \text { Green belt of salt-tolerant trees that } \\
\text { offered natural protectors of flood } \\
\text { dykes were cut down; } \\
\text { - Water for shrimp farming was severely } \\
\text { polluted; } \\
\text { Decline in stock and catch of wild fish } \\
\text { and shrimps. }\end{array}$ \\
\hline $\begin{array}{l}\text { Financial } \\
\text { resources }\end{array}$ & - & $\begin{array}{l}\text { Diversified sources of income } \\
\text { Credits from policy banks were more } \\
\text { available. }\end{array}$ & 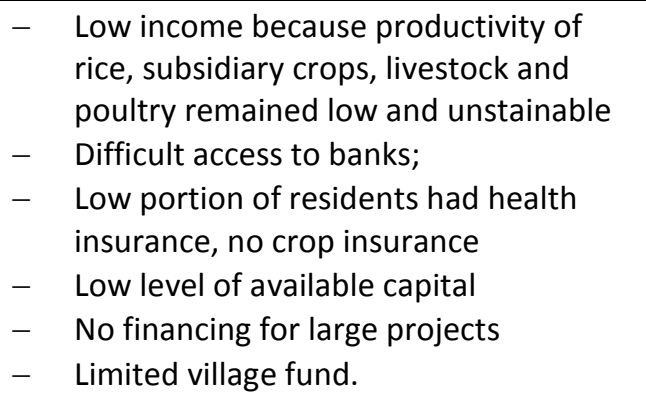 \\
\hline Social capital & - & $\begin{array}{l}\text { Material and intangible benefits } \\
\text { were generated from } \\
\text { neighbourhood and kinship } \\
\text { A number of formal and informal } \\
\text { regulations were developed. }\end{array}$ & $\begin{array}{l}\text { - Low collaboration in shrimp farming and } \\
\text { dredging blocked drainages; } \\
\text { - Ineffective enforcement of most formal } \\
\text { regulations. }\end{array}$ \\
\hline
\end{tabular}

Source: synthesized from focus group discussions and community observations in 2013 


\subsection{Multi-level governance perspectives: Six key themes}

This section draws upon the third set of FGs and interviews with local residents as well as staff from governmental agencies and non-governmental organizations (NGO) in Quang Tri province. Evidence from the group discussions and interviews showed six interconnected governance factors that have shaped the success of the DRR and CCA programs in Tuong Van.

\subsubsection{Public participation}

Diverse actors have been involved in the process of formulating and implementing DRR and CCA programs in Tuong Van. Yet, evidence revealed that such participation remains limited. For instance, the village was not fully involved in designing two key projects: concrete flood dykes and domestic water supply system. In addition, those who had opportunities to participate had only limited opportunities to influence the projects. As an example, some local residents and governmental officials claimed that they were invited to meetings for the dyke project, but they had no opportunities to critique the proposal. Others said they were invited to the meetings to listen to governmental agencies reporting on their DRR and CCA implementation plans rather than to give their comments.

The limited participation has likely impeded the success of DRR and CCA programs for several reasons. Useful knowledge and experiences of local residents were not used for important projects. Villagers acknowledged their limited professional knowledge about such projects, but they were disappointed they were not able to share knowledge on their

local conditions. Limited local participation also had indirect adverse impacts as one participant explained: 
I did not participate in the process of formulating and implementing the project of building the system of concrete dykes. Not only me but also many other villagers know that salt-tolerant trees growing along our former dykes effectively protect dykes from erosion. We were not invited to participate in any meetings, how we could provide information about the important roles of salt-tolerant plants. As a consequence, our natural barriers that protect the dykes were destroyed. (LHNV, 40)

Participants added more examples of the negative impacts stemming from limited local participation in designing the dykes, with undersized sluice-gates being a key limitation. The village used several large sluice-gates in earlier dykes to create three opportunities: enriching rice farms with alluvial materials; reducing adverse impacts of salinization on rice farms; and providing Lang residents with wild fish and shrimp during rainy seasons (see Chapter 6). The smaller sluice-gates in the new dykes significantly reduced these benefits. Overall, most participants felt limited local participation resulted in a lost opportunity to gain greater benefits from these DRR and CCA projects.

A large body of research and policies suggests local participation as an essential element for enhancing CR as it provides multiple actors with opportunities to raise and discuss their concerns (van Aalst et al. 2008). Yet, the participation is less meaningful if actors are involved passively and this was the case in Tuong Van and thereby limiting opportunities to critique others' ideas (Mistry et al. 2009, Van Tuyen et al. 2010). Even though the NSD and NTP programs emphasize local democracy and place communities at the centre of decision-making processes, the evidence suggests limited engagement with Tuong Van suppressed the overall effectiveness of recent DRR and CCA programs.

\subsubsection{Transparency}

Discussions from FGs and interviews revealed that transparency in Tuong Van DRR and CCA projects remained low. For instance, concrete dykes and the system of domestic 
freshwater supply were erected, but little information about them was open to the community. Most participants claimed that they saw the projects being implemented, but they had no information about the cost or the sources of funds, or who was responsible for the quality of the projects and how the projects were implemented and monitored to ensure high quality. Many participants also explained low transparency was a root cause for corruption, which in turn undermined the quality and functioning of projects.

In scholarly literature, transparency is commonly viewed as the degree to which actors such as governments or other political institutions discloses information about their actions in order to accurately inform the citizens (Lindstedt and Naurin 2010). Transparency is seen as an essential ingredient to promote effective partnership, government effectiveness, efficient allocation of resources, and reduce conflicts and corruption (Lindstedt and Naurin 2010, Ross et al. 2010a, Littell et al. 2012, Bauhr and Grimes 2014). The experiences shared by Tuong Van residents adds to the growing body of evidence that recommends transparency be incorporated into project design, implementation and monitoring.

\subsubsection{Responsibility and accountability}

Evidence showed low responsibility of public service providers including governmental agencies and building constructors for important projects in Tuong Van. Most participants in FGs complained that when the domestic water supply system failed, no governmental agencies and building constructors took responsibility for repairs. Local residents deemed the accountability for these projects was very weak as government agencies did not ask their contractors to correct errors or demand compensation for losses stemming from the failed project. 
FGs and interviews with staff from governmental agencies and NGOs also revealed the unclear responsibility of service providers. Most staff claimed that members involved in poor quality projects in Quang Tri and other provinces often blamed each other and shirked responsibility for losses. The staff also affirmed that they have never seen agencies and individuals autonomously acknowledge their mistakes and take responsibility to address the consequences of failed projects. The contractors also placed blame on extreme weather and therefore damage to infrastructure was beyond the contractor's control.

Evidence from local residents revealed the limited success of infrastructure projects is at least a partial responsibility of service providers. Most local residents in FGs and interviews complained that all parties including governmental agencies and contractors did not provide reasons for or unsatisfactory responses for project failure, including the root causes leading to the failure of the freshwater supply system, nor did they find solutions to overcome the problem.

A contesting view however emerged in interviews with governmental officials. Some staff at the provincial level claimed the government's responsibility was limited to implementing the projects, and local communities were responsible for maintaining installed infrastructure. The staff also added that many communities, including Tuong Van, not only undertook insufficient maintenance but also contributed to damaging installed infrastructure. For example, government staff alleged local communities did not enforce load limits on concrete roads which, in turn, shortened infrastructure lifespan. It was in this context that governmental officials argued that local communities fell short on their obligation to protect and maintain the roads and other infrastructure. 
Other research reports the limited success of recent DRR and CCA projects are tied in part to unclear and unshared responsibility amongst public service providers (Chau et al. 2014). Discussions with Tuong Van residents and staff from Quang Tri governmental agecnies not only support this report, but also highlight two other important points. First, the limitations of the recent efforts in Tuong Van resulted from the limited responsibility not only of public service providers but also local communities. Secondly, this research supports other studies that suggest when service providers perform poorly, accountability of public service providers plays an essential role in response to the problems as it enables understanding how a project may fail and to find mechanisms that make the project perform better (Peters 2007, Paul 2011).

\subsubsection{Collaboration}

Another factor that has shaped the success of recent DRR and CCA in Tuong Van is the collaboration among and across actors working at multiple jurisdictional levels. Participants in FGs and interviews argued that the collaboration across diverse actors is essential as it allows for them collectively address climate hazards. Yet, they also noted collaboration among these actors in formulating and implementing DRR and CCA projects in Tuong Van remain limited.

One example of weak collaboration at the local level and its negative impacts on CR occurred with shrimp farming. Most participants confirmed that one of main reasons for lost economic opportunities stemmed from weak collaboration. Uncooperative farmers discharge effluents infected with diseases into the public canals without giving notice to downstream resource users, thereby contributing the spread of shrimp diseases, reduced income and food security for many Tuong Van residents. 
The evidence from interviews with governmental and non-governmental officials also revealed limited collaboration at higher levels of government. For instance, most staff complained that governmental agencies were not willing to share information and data although they were essential inputs for the process of formulating and implementing the projects, as well as monitoring and evaluation. Some participants also added that several agencies stated in their project proposals they would collaborate with their offices to implement projects, but when the projects were funded and implemented such agencies ignored their proposed partners.

Weak collaboration was also found among agencies across levels of government in formulating and implementing DRR and CCA projects. Informants from agencies of Trieu Phong district complained that some provincial departments implemented projects at local communities without any discussion or consultation with district agencies although these communities are directly administered by the district government. They contended that no discussions with agencies of the district meant that provincial departments did not want to collaborate and overlooked the role of district agencies.

In brief, discussions with Tuong Van residents and governmental staff revealed weak collaboration among actors across multiple levels, which in turn limited efforts to reduce climate risks at the community level over the last three decades. These findings not only add to the knowledge about shortcomings of weak collaboration on climate risk management, but also support a growing body of research that highlights the importance of strong collaboration in producing mutual and collective supports to address complex issues stemming from a changing climate (Djalante et al. 2013, Vedeld et al. 2015). 


\subsubsection{Coordination}

I mobilized households, which were impacted by flooding, to excavate sediments and clear wild grasses along our drainage canals, but only a few households were willing to participate. Some said that they were busy, while others claimed their crops were harvested. Personally, I think that they are not very collaborative and I felt powerless to coordinate our neighbours. (DTHT, 60)

The quote illustrates both the need for local coordination and the difficulty of gaining community-wide support for a project aimed at reducing climate risks. Most participants claimed that dredging blocked drainage canals would reduce flooding risks but also required collective efforts to raise money and secure labourers. Although some discussions were made among some households, participants claimed that no formal meetings were held to bring impacted households together and then develop an action plan based on consensus and a collective effort to dredge the blocked canals.

The quote also revealed although some effort has been made to coordinate community members, limited leadership and facilitation skills adversely reduced collective efforts to reduce climate hazards. Recognising the persistent weakness, the community asked for support from its communal government, leading to the promulgation and temporary enforcement of a formal regulation for community-based shrimp farming. However, participants claimed that the regulation was used for several seasons, and then abandoned due to insufficient coordination. There was partial enforcement during the first two seasons but when several farmers broke rules and were not punished, most shrimp farmers elected to not follow the regulation.

Limited coordination is also found at higher levels of government. Coordination of Committees for Flood and Storm Control, Search and Rescue (CFS-SR) for DRR is an 
example. Group discussions revealed that the CFS-SRs at all levels of government were well coordinated during rainy seasons but mostly dissolved at other times of the year. Some argued that there was no need to retain the CFS-SRs because no storms and floods occurred following the rainy seasons, but many contended that various activities such as evaluation and development of annual and periodic plans needed leadership from the CFS-SRs. In addition, most governmental officials complained that they felt powerless if they had no support from the CFS-SRs across multiple levels.

Research elsewhere concluded weak coordination as a critical barrier to climate risk management (Vedeld et al. 2015). For example, devastating losses from the 2005 Hurricane Katrina resulted from the disarray in emergency management systems (Waugh Jr and Straib 2006). In contrast, strong coordination could provide various benefits to the efforts to reduce climate risks. For instance, coordination amongst actors across multiple levels could reduce overlaps of mandates and promote collaboration among actors in design and implementation of DRR and CCA policies (Djalante et al. 2013, Vedeld et al. 2015). Experiences shared by Tuong Van villagers and staff from Quang Tri governmental agencies not only demonstrated weak coordination across multiple scales as a barrier to $\mathrm{CR}$ and the success of DRR and CCA efforts, but also supported research that highlight the importance of strong coordination in climate risk management.

\subsubsection{Integration between DRR and CCA programs}

Chapter 6 showed that the community has integrated DRR and CCA programs in order to collectively enhance its resilience. For instance, DRR has enabled the community to reduce disaster from storms and floods, while CCA has addressed gradual and prolonged stressors such as droughts and salinization that DRR overlooked. Yet, the evidence from 
the third set of FGs and community observations also revealed that the integration between DRR and CCA does not always promote CR. In addition, it showed a number of interconnected factors that have eroded the capacity of the community to address climate hazards when DRR and CCA are combined.

The resilience of Tuong Van community has been reduced as a result of the negative interactions between DRR and CCA. Building concrete dykes is an example. The dykes were built to protect the community from violent floods and future sea level rise, but the dyke construction destroyed almost all salt-tolerant trees (Figure 7-1), which had been conserved and used as a natural protector against dyke erosion over the last three decades (CCA intervention). Some local residents have attempted to restore green belts, but they could only replant the trees along the village side of the dykes as the river side was impermeable concrete. Thus the new green belts will help their families along the rivers to prevent violent floods, but they cannot protect the dykes from future erosion.

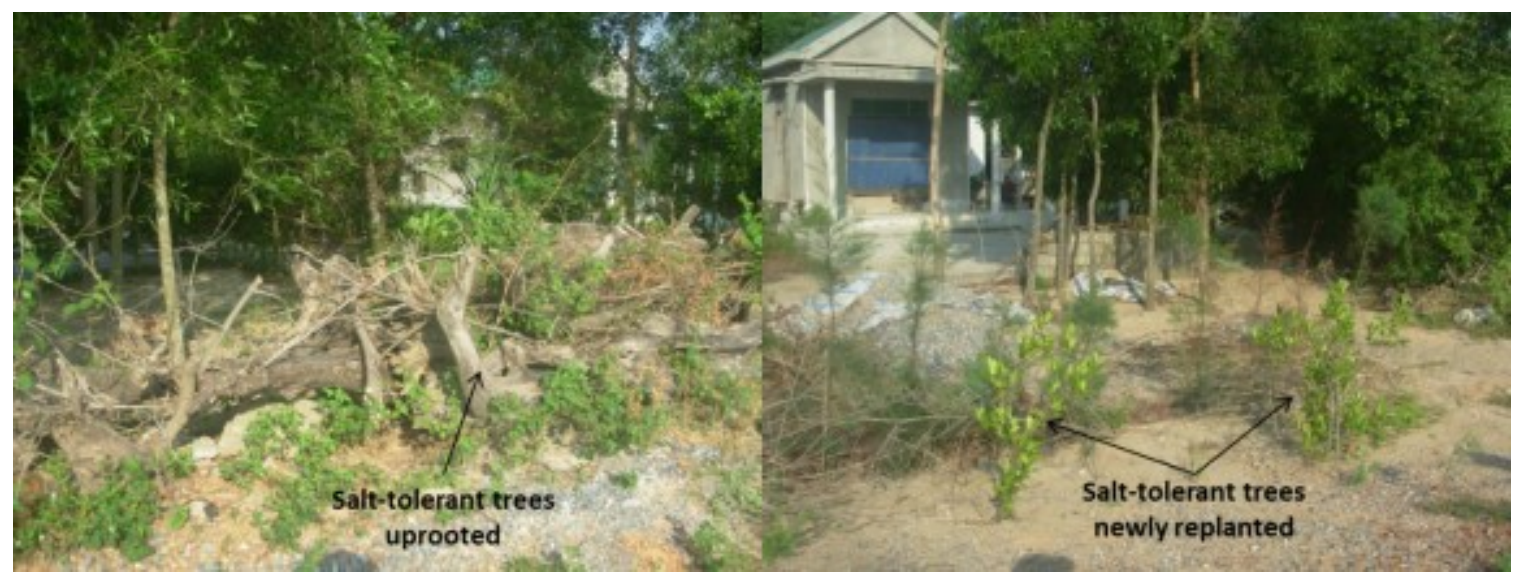

Figure 7-1: Salt-tolerant trees in Tuong Van

Source: the photos taken by the author in 2013

Group discussions and community observations also showed that not all CCA measures in Tuong Van have promoted the success of DRR. Some CCA measures have eroded the 
capacity of the community to deal with floods and storms. For instance, local residents planted trees along emergency roads in order to provide shade during summer and additional source of income, but these trees damaged the houses and roads when they were toppled during storms (Figure 7-2).
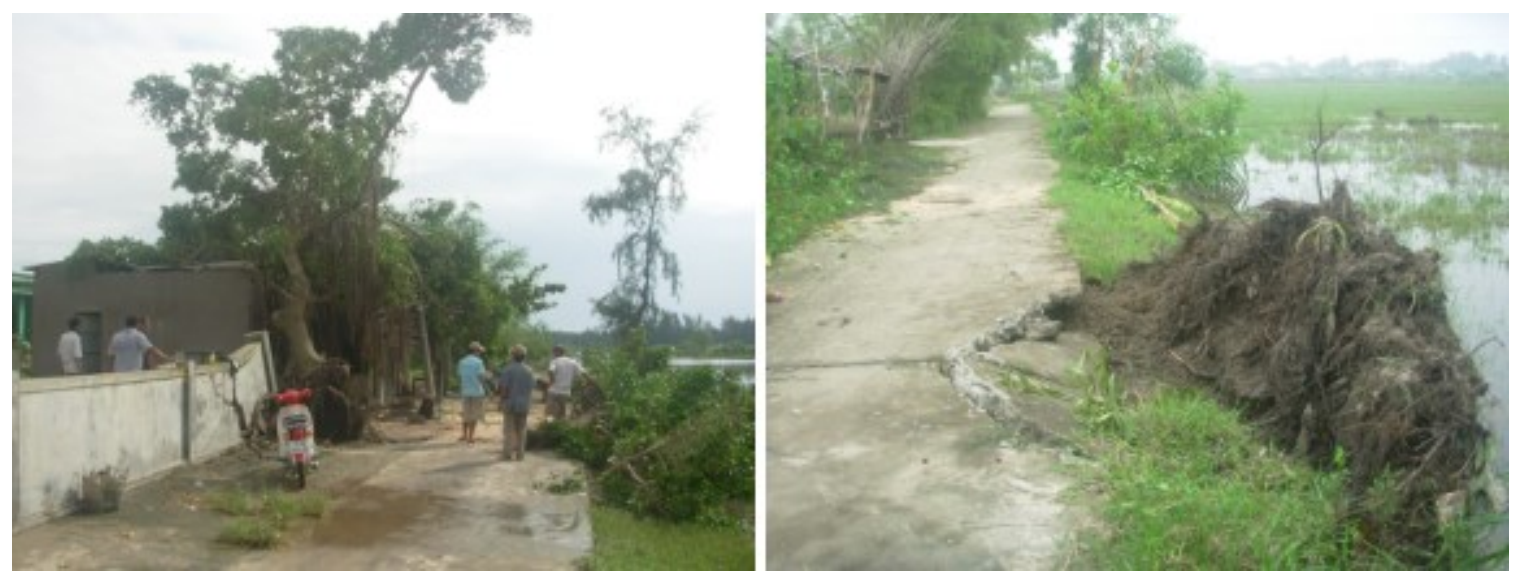

Figure 7-2: Damage to a house and a road during the storm in September 2013

Source: the photo taken by the author with oral consent of the local residents

Interviews with governmental staff showed that the negative interactions illustrated above partly resulted from a limited integration of the NSD and NTP. Before 2013, the former was formulated and implemented in the absence of the latter. A majority of informants commented that the green belts of salt-tolerant trees were removed during 2009 and 2010 as the NTP was not available to integrate in designing and constructing the system of concrete dykes. They also added that action plans for both NSD and NTP programs are now available, but there is much conceptual confusion between the two programs. One staff complained as follows: 
Even though the action plans for DRR and CCA were launched by the provincial government, we do not know what threats each of the two programs focuses on, what they mean DRR and CCA, what differences are between them, long-term and short-term or something else. We (DONRE) identified strategies and measures to reduce the impacts of climate change, but we were complained by other provincial departments that we took their tasks (e.g. DARD). Thus there have been some conflicts between DRR and CCA plans. For instance, building a storm shelter for fishing boats was a DRR measure, but it was approved in CCA action plan. (PGOV, 39)

The quote reveals two important points. First, the conceptual confusion was viewed as an obstacle for formulating and implementing DRR and CCA programs across multiple levels of government. This raises a question if it is necessary to separate the two policies when there is no clear distinction between the concepts of DRR and CCA and they share the same goal of enhancing CR and reducing climate impacts. As illustrated in Chapter 6, local residents do not differentiate but rather interweave DRR and CCA measures, thus they might not give positive answers to such a question.

Secondly, the quote illustrates the perspectives of governmental staff, who were involved in both decision making and implementing policies, about the disadvantages of separating the NSD and NTP policies. The quote reveals there have been overlap and conflicts between the two programs. Some governmental officials commented that such challenges were a result of limited dialogues and collaboration between the steering committees for the NSD and NTP programs in the process of making and implementing their action plans. The evidence for the challenges is consistent with those in the report by KirschWood (2015). 


\subsection{Adequacy of five capitals in DRR and CCA: availability, quality and interactions}

This section builds on Section 7.2 by reframing the six governance issues within the five capitals framework. This approach is taken as it provides insight into the roles and the interplay amongst various forms of capital and thereby provides insight into where future investments might be able to overcome factors that have imposed constraints on recent DRR and CCA programs.

\subsubsection{Availability and quality of five capitals}

\subsubsection{Physical resources}

Investments in physical resources at both the household and community levels over the last three decades were an essential part of reducing vulnerability to climate hazards. However, a number of important resources such as a rescue boat and life vests remain unavailable (Table 7-2). The limited availability of these resources has constrained the success of recent DRR and CCA interventions. For instance, a vast portion of the community did not have flat multi-floor houses, thus the roofs of 85 houses $(23 \%$ of the community) were damaged by the tenth storm in 2013 (TA-CPC 2014).

Table 7-2: The availability of key physical resources for DRR and CCA in Tuong Van

\begin{tabular}{lll} 
Physical resources & Role & Level of availability \\
\hline Flat multi-floor houses & Effectively resist storms and floods & Available in 5 households \\
Irrigation system & $\begin{array}{l}\text { Reduce impacts of annual droughts and } \\
\text { enhance productivity of rice and subsidiary } \\
\text { crops }\end{array}$ & Unavailable \\
$\begin{array}{ll}\text { Rescue boat, life vests, } & \text { Enhance human security during storms and } \\
\text { helmets } & \text { floods }\end{array}$ & Unavailable \\
\hline
\end{tabular}

Source: focus group discussions and community observations in 2013 
The availability of physical resources is a necessary condition to enhance CR and reduce climate impacts, but evidence showed that low quality of physical capital has also reduced CR benefits. For example, inadequate pumping capacity limited the freshwater supply to Lang residents. In the third set of FGs, participants identified at least five important resources that have low quality or have been increasingly damaged and they have negatively impacted DRR and CCA in Tuong Van (Table 7-3).

The limited availability and quality of physical resources have impeded both short and long-term responses to changing climate. For instance, daily travels and emergency responses during storms and floods have been constrained by eroded roads and dykes (Figure 7-3). In the future, Tuong Van, especially Lang is expected to be impacted by sea level rise and this is especially worrisome as the dyke system has been heavily damaged and this likely limits its effectiveness of a long-term prevention strategy against floods and sea level rise. The damage to the dyke system after the tenth storm in 2013 exposed the frailty of the dykes and has heightened concerns of the community.

Table 7-3: The quality of key physical resources for DRR and CCA in Tuong Van

\begin{tabular}{|c|c|c|}
\hline Physical resources & Role & Level of quality \\
\hline System of flood dykes & $\begin{array}{l}\text { Reduce exposure to and impacts of storms } \\
\text { and floods }\end{array}$ & Increasingly damaged \\
\hline $\begin{array}{l}\text { Transportation system } \\
\text { including roads and bridges }\end{array}$ & Daily and emergency travels & Increasingly damaged \\
\hline Water supply system & $\begin{array}{l}\text { Provide freshwater for domestic use of Lang } \\
\text { residents }\end{array}$ & $\begin{array}{l}\text { insufficient capacity to } \\
\text { pump underground water }\end{array}$ \\
\hline Village drainages & Prevent flooding induced by heavy rains & Blocked and eroded \\
\hline Power system & $\begin{array}{l}\text { Provide electricity for daily life and } \\
\text { production }\end{array}$ & Weak and vulnerable \\
\hline
\end{tabular}

Source: focus group discussions and community observations in 2013 


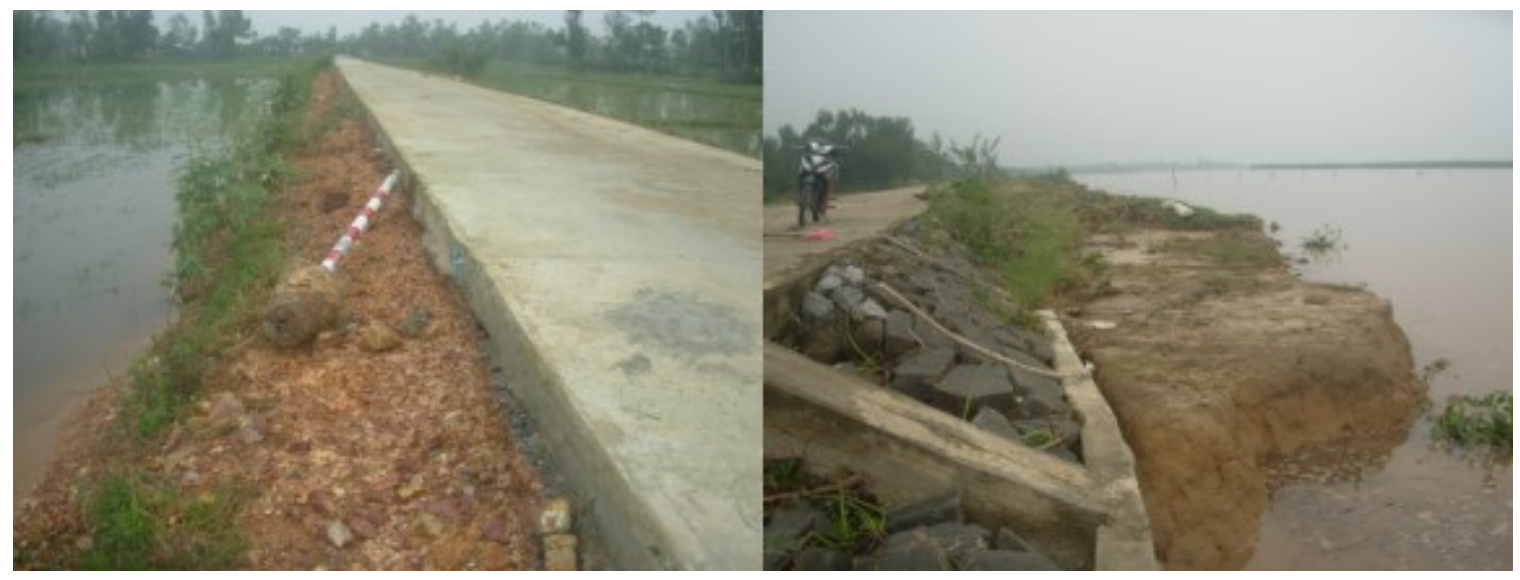

Figure 7-3: Emergency road and dyke in Lang eroded by floods and tidal flooding in 2013

Source: the photos taken by the author following the tenth storm in 2013

Some national policies other than the NSD and NTP programs could help local communities to enhance their resilience. Discussions showed that the National Program on New Rural Development between 2010 and 2020 has been implemented in many communes in Trieu Phong district and it has helped these communities to improve electricity networks and irrigation systems. However, this program has not been implemented in Tuong Van. As a result, an electricity system in Tuong Van was not improved and the shortage of electricity is still a big barrier to social-economic development and the capacity of the community to reduce climate risks.

\subsubsection{Financial resources}

Various forms of financial resources have existed in the community, but they were not always available at both the household and community levels (Table 7-4). The shortage of finances has constrained DRR and CCA interventions in both short and long-terms. For example, local residents commonly sell their crop products to buy medicine when their family members are sick, but some villagers had nothing to sell during the transitional period when they ran out of their agricultural products and new crops were 
not yet harvested. The limited finances also impeded the long-term resilience of the community. For example, about $15 \%$ of the households in Lang did not have sufficient money to elevate the floors of their houses against annual floods and inundation from future sea level rise.

Table 7-4: The availability of financial resources for DRR and CCA in Tuong Van

Financial resources

Cash in household

Loans from bank

Health insurance

Crop insurance

Village fund

Fund of women union

\section{Level of availability}

- Cash was only available when products from livelihoods were sold and remittance of children was sent home;

- Most household had no cash during transition of crops

- Many shrimp farmers could not access because their old loans have not been paid back

- Low portion of the community had health insurance

- Unavailable

- Village fund was just sufficient for some community activities, not available for maintaining roads and flood dykes

- Unavailable for activities other than spiritual visits

Source: focus group discussions and interviews with local residents in 2013

Borrowing cash from their relatives and neighbours is a common solution of local residents. However, some argued that such a solution was only short-term and it was commonly used in urgent cases, while others commented that it could not be used when they needed a larger loan for a longer time. One woman claimed that:

I could borrow some money from my relatives and neighbours to buy medicine when my daughter was sick, but I had to access bank loans for shrimp farming because it required a large amount of investment capital. $(\mathrm{DCH}, 62)$

Recent research reveals that insurance is an important financial resource for communities to deal with climate hazards as it could provide compensation when disasters occur (Lofgren et al. 2008). However, most residents in Tuong Van had no health insurance to cover medical expenses when they were sick or injured. In addition, the evidence from 
FGs showed that no households in Tuong Van had crop insurance although it could help farmers to reduce impacts of climate hazards (Falco et al. 2014). In 2011, the Vietnamese government approved a national program on crop insurance, but it is still at the pilot stage and Quang Tri was not included in this initial phase of the program.

\subsubsection{Natural resources}

Tuong Van has a wide range of natural resources that could be used to enhance CR and reduce climate impacts, but several local residents claimed that the quality of at least four important natural resources has been degraded and they have witnessed negative impacts on CR (Table 7-5). First, wetlands are one of the important natural resources for Tuong Van because they provide diverse benefits for building a resilient community. Participants explained that wetlands are not only the reproductive grounds of many aquatic species, leading to enhancement of fish catches, but they also absorb pollutants discharged from surrounding areas, especially from shrimp farms. However, provincial and national policies on economic development encouraged local residents to convert almost all natural wetlands in Tuong Van and upstream in the Thach Han River to shrimp farms during the late 1990s.

Table 7-5: Roles and the availability of key natural resources for DRR and CCA in Tuong Van

\begin{tabular}{|c|c|c|}
\hline Natural resources & Role & Availability \\
\hline Wetlands & $\begin{array}{l}\text { Absorb pollutants; habitats, spawning and } \\
\text { nursing grounds for aquatic species }\end{array}$ & $\begin{array}{l}\text { Extensively destroyed and } \\
\text { converted to shrimp farms }\end{array}$ \\
\hline Natural forests & $\begin{array}{l}\text { Protect the community from storms, } \\
\text { surges, floods; habitats for snakes, which } \\
\text { control rats }\end{array}$ & Completely cut down \\
\hline Salt-tolerant trees along rivers & Prevent erosion of flood dykes & Almost all cut down \\
\hline Wild fish and shrimp & Source of income and food & Declining abundance \\
\hline
\end{tabular}

Source: focus group discussions and community observations in June 2013 
In addition, Tuong Van used to have a natural forest with mature trees such as mangroves and $\operatorname{Tra}^{13}$, which were able to tolerate saline and acidic conditions. The forest was to the north of Lang and it provided the community with a natural barrier against storms and the resulting surges from the Cua Viet Sea. Participants claimed that the forest reduced the impacts of the violent storm in 1962. However, this forest was cut down to expand the rice production area after the 1973 liberation, and Lang became directly exposed to floods, storms and storm surges.

Local residents also claimed that after the deforestation for rice production, the surviving small trees along the river banks continued to grow, providing the community with new green belts. Although the belts were sparse and scattered, it protected their physical infrastructure such as the former earthen dykes and bridges from erosion induced by floods and tidal flooding. However, many of the new green belts were uprooted during the building of the concrete dykes in 2009 and 2010 (Figure 7-3), which in turn exposed the new concrete dykes to stress.

Tuong Van also used to have high diversity and abundance of aquatic species, which provided many households of Lang with an important source of daily food and income during rainy seasons. Lang residents claimed that before the early 1980s, wild shrimp and fish were so abundant that they only needed a quarter of hour to trap wild shrimp, crabs, and fish for the daily consumption by their families. However, aquatic resources have been overexploited for the last three decades. Some claimed that today they spent a whole night, but their catches were not enough for their family to eat a meal. In addition, others said that many aquatic species that had been highly abundant have almost disappeared.

\footnotetext{
${ }^{13}$ Local name
} 
The community had a wide range of natural resources, but many have been reduced to low quality. FG participants provided various examples of the adverse impacts of the limited or declining quality of natural resources on CR. Groundwater, which is one of the main water resources for domestic use and crop production, has increasingly been salinized and the salinization has significantly impacted daily life and crop production. Local residents not only had a shortage of quality water for domestic use, but their crops were also killed or burnt when they used the salinized water from drilled wells during summers to water their crops.

Despite a great variety of natural resources, not all of them promote CR. At least two forms of natural capital eroded CR or caused the limitations of recent DRR and CCA measures in Tuong Van. For instance, wild plants are growing between panels or stones along the banks of the concrete dykes (Figure 7-4) and have broken the dyke wall. Another example of negative impacts of natural resources on $\mathrm{CR}$ was outbreaks of rats. Rats are an essential part of the ecosystems, but they are a key obstacle for rice production as they damage crop seedlings and feed on rice buds. Participants claimed that the recent loss of rice crops was a result of a rapidly expanding rat population. Reasons underpinning the rat infestation were not fully clear but discussions revealed the importance of interactions amongst capitals. Snake species that prey on rats were lost as forests (snake's habitats) were destroyed. The absence of these snake species may be a factor supporting growth of the rat population. 


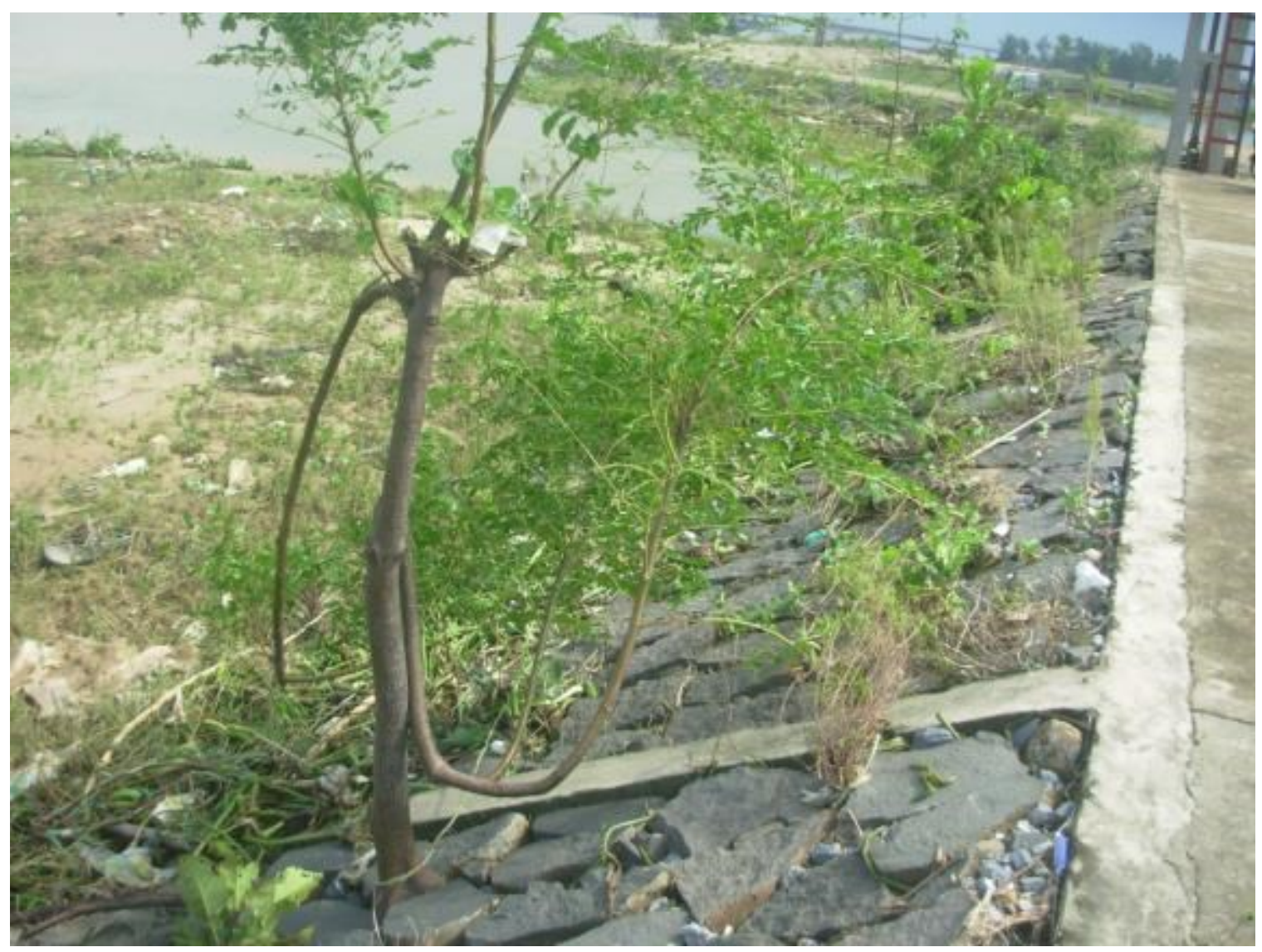

Figure 7-4: Potential impacts of wild plants growing between stones of bank protection side of flood dykes in Tuong Van

Sources: the photo taken by the author in September 2013

\subsubsection{Human resources}

The second set of FGs reflected on various forms of human capital that are essential for CR. In the final set of FGs, participants were openly excited about discussing the impacts of knowledge, skills, attitudes and behaviours on CR and the success of DRR and CCA. All participants acknowledged the efforts by the provincial government to enhance their knowledge and skills in response to changing climate. However, they felt regret for some decisions that the government had made over the last three decades. For instance, both villagers and communal officials argued that the decision on the conversion of wetlands 
to shrimp farms during late the 1990s to the 2000s in Tuong Van was wrong and the policy was made from ignorance of its potential impacts.

Group discussions showed that Tuong Van lacked various skills to promote CR. Most participants commented that although village and commune leaders have provided useful guidance, coordinating and mobilizing efforts within and outside of the community, their leadership remained limited. For instance, village leaders were not able to mobilize and facilitate villagers to dredge blocked drainage canals and enforcing regulations for community-based shrimp farming. Participants also expected that their leaders needed better skills to communicate, explain and advocate local needs to higher levels of government. They argued that commune leaders should have these skills to seek assistance from their governments to implement the action plan following this research.

Local residents were equipped with DRR knowledge and skills through training courses and such knowledge and skills have enabled the community to reduce climate risks. However, such knowledge could not ensure that local residents were fully safe if they had poor attitudes towards risks of climate hazards. For instance, a woman in a FG claimed that she was saved while she was collecting bitter herbs in a neighbouring village during floods in 2011. She was trapped and could not escape from a deep muddy puddle, which was created by the floods and was saved by three youths who came to her rescue. She affirmed that she did not heed her husband's advice to stay home and did not recognize the hazard. In addition, participants also claimed the deaths of two brothers from drowning when they went to collect river clams was most likely attributable to their ignoring warnings of the impending danger. 
All participants affirmed that the personal health of villagers have been significantly improved over the last three decades, but the shortage of healthy and young members within the community was a CR liability. Out-migration of younger, healthy adults seeking employment in more urban areas places limits on the capacity of village leaders to form patrol teams during the rainy season. The shortage of healthy and young community members has not only reduced the resilience or promoted the vulnerability of the community, but also constrained the success of DRR and CCA.

\subsubsection{Social resources}

Three key forms of social capital including social networks, social trust and regulations have existed in Tuong Van. Among social networks, kinship and sense of neighbourhood were ranked as highly important because through these networks, local residents could gain mutual spiritual and material support. In contrast, the unions of youths, veterans and farmers were little appreciated because they provided local residents with few benefits.

Social trust is essential for CR because it promotes mutual support and helps people feel safe in sharing information and values (Pretty 2003), while mistrust constrains CR as it makes people feel insecure when providing their personal information (Norris et al. 2008, Cinner et al. 2009a). In Tuong Van, mistrust was found between community members. For instance, shrimp farmers were often wary of discharges of shrimp effluents by their neighbours into their public canals when their farms were infected with disease. Mistrust was also found between local residents with their business partners. In an interview, a supplier claimed that he did not want to provide the policy of partial payment because he no longer believed his customers kept promises to pay as planned. In addition, mistrust 
was seen between villagers with parties involved in key construction projects such as the system of freshwater supply and concrete dykes, which have low quality.

A number of informal and formal regulations have existed for Tuong Van for many years and they have been used to engage and rule community members in enhancing $\mathrm{CR}$ and reducing climate impacts. However, most participants complained that these regulations have been enforced ineffectively, leading to the limited success of DRR and CCA measures. For instance, the fishery and biodiversity laws were introduced, but they have been poorly enforced at the local level. As a result, the quality of natural resources and environment remains degraded. In addition, some local regulations were developed, a few villagers complied. As an example, shrimp farmers claimed that they had a regulation for community-based shrimp farming when shrimp aquaculture sector started, but it was only used for several crops and then nobody followed the rules.

\subsubsection{Interactions among five capitals}

The discussions from FGs and interviews with local residents showed that resources of the community do not exist in isolation, but rather they interact within complex networks. Although the five capitals can reinforce each other, evidence also showed that negative interactions can occur and erode the resilience of the community. Table 7-6 provides evidence of how the availability and quality of physical resources in Tuong Van was constrained by the other capitals. For instance, an irrigation system and a rescue boat could not be secured because of financial shortage, while the reliability of the water supply system in Lang was compromised by the limited knowledge of designers and contractors as well as limited availability of underground water. 
Table 7-6: Problems of key physical resources in Tuong Van and their causes

\begin{tabular}{ll} 
Problems of physical resources & Causes of problem \\
\hline $\begin{array}{l}\text { Irrigation system and rescue boat } \\
\text { are not available }\end{array}$ & $-\quad$ Investment capital exceeding the financial capacity of the \\
Dykes are severely eroded & $-\quad$ The power of floods exceeded the physical capacity of the dykes \\
& $-\quad$ Green belts against erosion was cut down; \\
Water supply system is unusable & - No regulation of maintenance was available \\
& $-\quad$ Limited availability of underground water \\
Public canals for shrimp farming \\
are severely eroded
\end{tabular}

Source: focus group discussions and community observations in 2013

While financial resources in Tuong Van are essential for the village to invest in physical resources such as storm-resistant houses and an irrigation system, they were also constrained by other capitals (Table 7-7). For instance, income from shrimp farming was lost because local residents did not have the knowledge and skills about shrimp-disease surveillance or water supply for shrimp farms was polluted. In addition, the availability of financial resources was also dependent on physical and social resources. For example, income from livelihoods was often lost because not only the irrigation system was not available, but the existing regulation for community-based shrimp farming was also not enforced effectively. Besides the five capitals, financial resources in Tuong Van were also impacted by social-economic development outside the village. As an example, local residents terminated their salt farming because they are not able to compete with salt producers in other provinces such as Binh Dinh and Ninh Thuan, whose high technologies of large-scale salt production are invested. 
Table 7-7: Problems of financial capital in Tuong Van and their causes

Problems of livelihoods

Shrimp crops are

frequently lost
- Limited knowledge on shrimp disease and shrimp farming practices;

- Public canals for shrimp farming eroded

- Regulation for shrimp farming zone were not developed and enforced effectively

- Virus diseases due to water pollution

The productivity of _ - Shortage of freshwater

subsidiary crops is Low _ $\quad$ Underground water was salinized

Source: focus group discussions in 2013

Tuong Van has a wide range of natural resources that have been used to promote CR, but the availability and quality of these resources have been reduced by other capitals (Table 7-8). For instance, a large number of drilled wells have caused underground water salinized during summers, whereas most important ecosystems along the Thach Han River were converted to shrimp and rice farms for the purpose of not only local but also provincial economic development. Besides economic drivers, some participants argued that natural resources were degraded due to limited knowledge and ineffective enforcement of laws. For instance, wetlands and natural forests were destroyed due to ignorance about long-term impacts of these resources, while the stocks of wide fish and shrimps declined as the fishery law was not enforced at the local level.

Table 7-8: Problems of natural capital in Tuong Van and their causes

\begin{tabular}{|c|c|c|}
\hline \multicolumn{2}{|c|}{ Problems of natural resources } & Causes of problem \\
\hline- & Wetland was extensively destructed & Shrimp farming development \\
\hline- & Forests were completely cut down & Unforeseen about negative impacts in long term \\
\hline- & $\begin{array}{l}\text { Most salt-tolerant trees were cut } \\
\text { down }\end{array}$ & $\begin{array}{l}\text { - Limited knowledge about the role of green belt against } \\
\text { dyke erosion; }\end{array}$ \\
\hline- & $\begin{array}{l}\text { Stocks of wild fish and shrimps were } \\
\text { declined }\end{array}$ & $\begin{array}{l}\text { - Destructive fishing; poor attitudes and negative actions; } \\
\text { ineffective enforcement of laws }\end{array}$ \\
\hline- & $\begin{array}{l}\text { The quantity and quality of } \\
\text { groundwater have been declined }\end{array}$ & $\begin{array}{l}\text { - Overexploitation from drilled wells for farming and } \\
\text { domestic use }\end{array}$ \\
\hline
\end{tabular}

Source: focus group discussions and community observations in 2013 
While villagers needed a diverse set of human resources to address climate hazards, these resources were constrained by other capitals (Table 7-9). For instance, the shortage of clean water following storms and floods often caused outbreaks of diarrhoea and pinkeye. In FGs and interviews, participants claimed that their local clinic does not have advanced facilities and well-educated doctors to examine and cure difficult cases, thus they could be at high risk if not cured in time. In addition, human resources in the village were also constrained by financial and social capitals. For instance, many youth dropped out of high school because their families could not afford the costs, while attitudes and behaviours towards destructive fisheries persisted because of the ineffective enforcement of the fisheries law.

Table 7-9: Problems of human capital in Tuong Van and their causes

\begin{tabular}{lll} 
Problem of human resources & Causes of problem \\
\hline $\begin{array}{l}\text { Diarrhoea and pinkeye occurred } \\
\text { following floods and flooding; }\end{array}$ & $-\quad \begin{array}{l}\text { Lack of chlorine and lime to treat environment following } \\
\text { storms and floods; }\end{array}$ \\
$\begin{array}{l}\text { Difficult cases could not be cured at } \\
\text { local clinic centre }\end{array}$ & $-\quad$ So advanced facilities and well-educated doctors to examine \\
$\begin{array}{l}\text { Knowledge and skills on farming } \\
\text { remained limited }\end{array}$ & $-\quad$ No money to take training courses and visit successful farms; \\
$\begin{array}{l}\text { Behaviours towards destructive } \\
\text { fisheries remains }\end{array}$ & $-\quad$ Ineffective enforcement of fisheries law; \\
& $-\quad$ Needed food to feed children; \\
& $-\quad$ Needed money to buy clothes
\end{tabular}

Source: focus group discussions in 2013

Various forms of social capital have existed in Tuong Van, and shaped by the availability and quality of other capitals, especially human and financial resources (Table 7-10). Take an example of forming social networks. The community has the unions of women, youths, veterans and farmers, but many villagers are not members of such social networks. Participants explained that they did not get involved in these social networks 
because they did not find them economically beneficial relative to the cost of membership fees. Some villagers commented that these social networks have been operated ineffectively because their individual members were uncooperative and selfinterested.

Table 7-10: The problems of social capital in Tuong Van and their causes

Problem of social resources Causes of problem

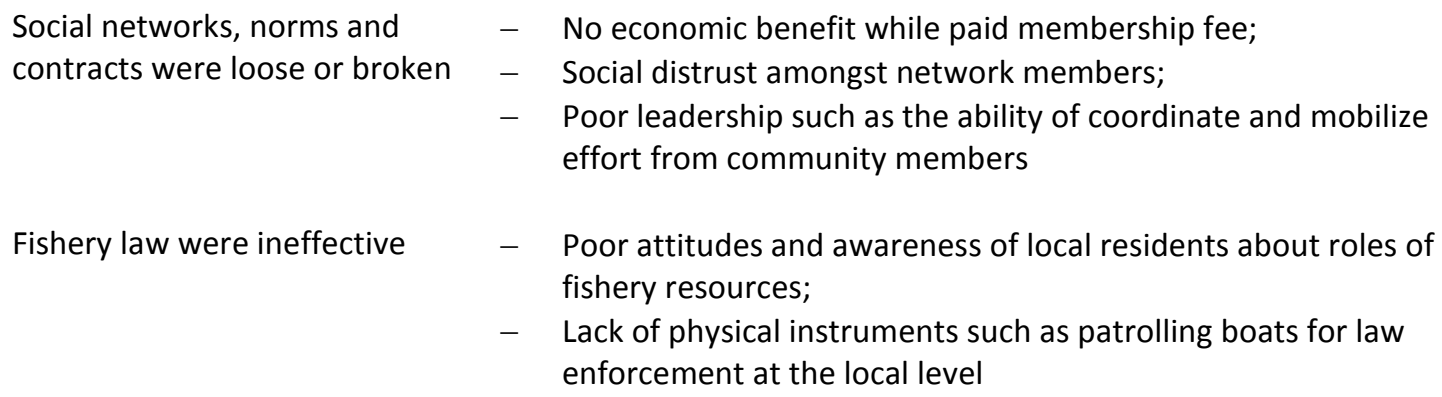

Source: focus group discussions and community observations in 2013

\section{Synthesis of Chapter 7}

Chapter 7 examined the success of recent DRR and CCA programs that Tuong Van has adopted to address climate hazards, and then it explored and evaluated factors that have shaped the success. The evaluation results showed that the DRR and CCA programs have successfully reduced human loss and injuries over the last three decades. Yet, a wide range of examples such as the incapability of the domestic freshwater supply system and loss of green belts along the Thach Han River revealed that the recent efforts to enhance $\mathrm{CR}$ and reduce climate risks in Tuong Van have not been entirely successful.

Discussions showed that the limited success resulted from the inadequacy of the five capitals. While available resources are essential for the community to enhance CR and reduce climate risks, a diverse set of basic resources such as an irrigation system and life 
vests were not available at the household and community levels. In addition, the low quality of resources such as destroyed ecosystems and salinized underground water was seen as a critical barrier to addressing the changing climate. The success of the recent efforts was also constrained by negative interactions amongst resources such as the overabundance of drilled wells contributing to salinization of underground water. These findings suggest that assessments of CR and the success of DRR and CCA should look beyond the availability of the five capitals to their quality and interplay. As such, the experiences in Tuong Van community reinforce current studies such as those conducted by Baral and Stern (2011) and Tinch et al. (2015), which assume the availability of the five capitals is proportional to CR and the success of DRR and CCA projects.

Examination of project formulation and implementation in Tuong Van revealed that the limitations of recent efforts rooted from ineffective cross-scale governance in each of the DRR and CCA programs. First, both the programs were constrained by limited public participation, which excluded important concerns of diverse actors such as Tuong Van community and Trieu Phong's government agencies. Secondly, weak collaboration and coordination across multiple scales also constrained DRR and CCA projects as they have impeded collective actions to enhance CR and reduce climate risks. In addition to these two factors, most local residents and governmental staff viewed the low level of transparency, accountability and responsibility as a key cause for the poor quality of DRR and CCA projects as it commonly results in corruption.

Alongside ineffective governance in the individual programs, the limitations could also be traced to their ineffective integration across multiple scales. The NTP is expected to be mainstreamed with the NSD in order to address climate change more effectively, but their 
connections remained weak. For instance, there was a currently mismatch between the NSD and NTP programs at the local level as the NTP remained at the provincial level. Although villagers have developed their own measures to partially reduce the deficiency of the public policies, most were at small scales and short term. Some existing measures such as the use of drilled wells by individual households have promoted CR at small scales, but they were less helpful and even erode CR in long-term and larger scales, for instance increasing salinization of groundwater across the village over the last decade.

The success of DRR and CCA programs in Tuong Van was also constrained by factors beyond the NSD and NTP policies. For instance, the resilience of the community has been eroded by provincial economic development policy, which promoted conversion of wetland to shrimp farms. In addition, the limitations of DRR and CCA efforts in the community stemmed from technological, demographical and socio-economic changes. For example, the collapse of salt farming in Tuong Van was a result of technological investments of salt producers in other provinces, while the shortage of human resources in the community stemmed from out-migration of young villagers for work in industrial zones in Binh Duong and Ho Chi Minh. Discussions also revealed that while some national programs other than DRR and CCA policies were issued that could have provided the village with a diverse set of capacities to reduce climate risks, they have not been implemented in the community. As an example, an irrigation system and an electricity network would likely have been installed if the national program on new rural development had been implemented in the village.

Overall, the success of recent DRR and CCA programs in Tuong Van has been shaped by the adequacy of the five capitals and the quality of climate risk governance across 
multiple scales. The limited success of the two programs stemmed from not only limited availability of the five capitals but also from their low quality and negative interactions. For instance, flood dykes (physical capital) have been increasingly eroded due to the loss of green belts (natural capital), which resulted from the exclusion of local knowledge (human capital) and limited compliance with environmental laws (social capital). The erosion of the dykes would be then impacted adversely other capitals such as human life (human capital) and livelihoods (financial capital). Discussions with local residents and staff from governmental agencies and NGOs also revealed that the inadequacy most likely resulted from ineffective cross-scale governance in each of and between the DRR and CCA programs. 


\section{CHAPTER 8: STRATEGIES FOR BUILDING A RESILIENT COMMUNITY IN THE FACE OF CHANGING CLIMATE}

\section{Research sub-question 4: What strategies could provide central Vietnam's coastal communities with opportunities to enhance community resilience and reduce risks from future climate change?}

Chapters 5 to 7 assessed the existing conditions of Tuong Van village and showed that the community remains vulnerable to a wide range of climate hazards and a changing climate. In addition, it is expected that without additional innovative interventions, the adversity of many climatic events will be magnified by future climate change (QTDONRE 2011, IPCC 2014a). Findings in Chapter 8 draw upon strategic planning exercises that allowed the community to identify strategies designed to facilitate transitions to a more resilient state in the face of future climate change. The chapter starts with a review of participant-defined vision for their community five years into the future, and then illustrates essential actions that participants proposed in support of the vision. The chapter concludes with a discussion of strategies that should help the community navigate critical transitions to the desired state in the future.

\subsection{A vision for Tuong Van community in the face of changing climate}

The visioning exercise was the first step in the planning process and it was initiated with

a review of the existing state of Tuong Van community. Participants affirmed two key points as they started the process: the current capacity to address climate hazards will 
certainly be eroded if no new innovative interventions are deployed; and their village remains highly vulnerable to climatic conditions.

The review set a foundation for participants to identify conditions that they want their community to experience and address in the future. Some wished their community had the full capacity to address all future impacts of climate change. However, most participants argued that such desired conditions are idealistic and they could never be realized in practice. This led the discussions towards identifying more realistic conditions that could be achievable in the next five years.

The discussions revealed two interconnected categories of expectations (Table 8-1). The first is concerned with human and property security. Participants expect that the human life and property will be secured and that climate impacts will be continuously reduced over the next five years. Yet, they also argued that the human and property security might not be realized if the capacity of their community to address climate hazards is not constantly enhanced.

Table 8-1: Vision elements identified by participants in the first set of planning workshops

\begin{tabular}{ll} 
Categories & Elements of vision \\
\hline Human life and property security & - No human deaths and injuries from storms and floods \\
& - Minimum loss and damage of properties by changing climate \\
\hline \multirow{3}{*}{ Enhancing resilience of the } & - Higher income \\
community in the face of changing & - Productive and sustainable livelihoods \\
climate & - More availability and higher quality of freshwater \\
& - Collaborative community \\
& - Clean and healthy environment \\
\hline
\end{tabular}

Source: visioning exercises in July 2013

\subsubsection{Human and property security in the face of a changing climate}

Human security over the next five years is the biggest concern for most participants although loss of human life and injuries from storms and floods has been reduced over 
the last three decades (see section 7.1 in Chapter 7). In addition, some stressed that "human life is more valuable than a big pile of gold" and all participants expect no one in their community will be killed or injured by the two threats.

Besides human security, participants were also concerned over the loss of and damage to their property, especially physical resources such as houses and electrical systems. They argued that the earlier investments made in a wide range of important structures such as flood dykes and roads have already been damaged and these may be damaged even more by climate hazards in coming years. Thus participants confirmed the importance of improving physical resources over the next five years.

The loss of income from resource-based livelihoods was secondary to loss of life and injuries, and was recognized as a serious burden induced by gradual and prolonged stressors during dry seasons, especially droughts and salinization. Participants argued that their livelihoods based on rice and subsidiary crops will be more vulnerable to the emerging impacts of future climate change, especially sea level rise and associated inland salinization. Thus they wish that their livelihoods would be constantly enhanced over the next five years.

\subsubsection{Enhancing community resilience in the face of changing climate}

Discussions revealed five interconnected conditions for enhancing CR over the next five years (Table 8-1) and each condition was rooted in the adequacy of at least one of the five capitals (financial, physical, natural, human and social). Most participants viewed financial resources as essential for their community to address future climate. They argued that without additional money, many important measures to reduce climate risks, such as building flat multi-floor houses and an irrigation system, will most likely not be 
deployed. Participants expect that the financial capacity of their community will be enhanced through sustainable and productive livelihoods. However, they argued that successful development of livelihoods, especially production of rice and subsidiary crops, relies on the availability and quality of freshwater. This view was made clear by one lady who claimed:

If we have freshwater, we will not only have higher productivity of rice and subsidiary crops, but also produce the second crop of rice. In contrast, if our freshwater is not available and poor quality, we not only face health problems such as diarrhoeas and bleeding fevers, but our subsidiary and rice crops could also be killed, leading to the low productivity and poor quality of products. (DTHT, 60)

The village also expected to become more collaborative. Discussions in the planning workshops revealed that collaboration amongst villagers is a key element of strong social networks, through which other resources can be created for climate risk reduction and productive livelihoods. However, most participants affirmed that collaborations within the community are currently limited. Thus they want their villagers to be more cooperative, not only for addressing climate hazards but also for community development in general. For example, participants argued that the success of future interventions such as shrimp farming and maintenance of roads and flood dykes following disasters will require collective efforts from their villagers, which build on collaboration amongst community members.

Finally, participants wished for a clean and healthy environment. Besides freshwater for daily life and crops, they also expect larger stocks of aquatic resources such as wild shrimps and river clams, and attaining this goal was currently compromised by polluted and damaged ecosystems along the Thach Han River. One man claimed the importance of healthier environment for enhancing the resilience of his community as follows: 
We will have more wild fish and shrimps to catch and our shrimps might not be killed if water in the river and ocean is clean. Also we will not be threatened by epidemics of infectious diseases such as diarrhoeas and bleeding fevers if we have available and clean water to drink and our garbage is stored and treated in proper manners. (LHNV, 40)

In brief, evidence in the visioning exercise reflects local aspirations to move into a more resilient state over the next five years, in which the availability, quality and mutual reinforcement of the five capitals was seen as core to enhanced CR. The resilience of the community in the future consists of various elements and realizing one element depends, in part, on others. The visioning exercise also revealed the overall optimism of the village regarding its future, but recognizing significant concerns regarding poverty reduction, new investment in infrastructure, better access to freshwater and a healthier environment currently raises questions about the transition towards a more self-reliant future.

\subsection{Portfolio of essential projects for realizing the vision}

Following the visioning exercise, participants identified efforts needed to realize the vision of their community. Besides the existing successful interventions (see Chapter 6), a set of 17 additional projects were proposed for enhancing CR over the next five years. Table 8-2 illustrates dual roles that each of the proposed projects play: enhancing the five capitals and addressing climate hazards. Most of the proposed projects aim to improve existing important resources such as flood dykes and green belts of salt-tolerant trees as they have been damaged. In addition to these projects are efforts to produce new forms of capital such as an irrigation system and a rescue boat as they are not available. Table 8-2 also shows each of the five capitals is enhanced from combinations of multiple projects. For example, natural capital can be improved from at least nine projects, while physical capital is products from most of the proposed efforts. 
Discussions revealed the roles of and interconnections across the five capitals in the enhancement of climate-resilient pathways. Each of the proposed projects first creates or improves one form of capital, which will then be used as a base to generate or enhance other forms (secondary resources). For instance, when the blocked drainage canals (physical capital) in the village are dredged, the quality of environment (natural capital), personal health (human capital) and household income (financial capital) will be improved. Thus each form of capital is not only the end product of proposed projects, but will also become a base or supporting instrument for generating other resources.

Participants recognized that most of the proposed projects focused on enhancing physical resources, while little effort is introduced to promote non-physical resources (financial, social and human). Drawing upon previous projects, participants anticipated potential consequences from the absence of non-structural resources. Thus they suggested that their community should use the proposed structural projects as a starting point to develop non-structural activities when these projects are implemented. For example, if the project "restoration of green belts" is deployed, it not only involves planting seedlings but also needs the active participation of community members in the process of designing and implementing the project as well as protecting the green belts once the trees are planted.

The capacity to address future climate change varies amongst the proposed projects. For instance, planting salt-tolerant trees potentially protects the dyke system from erosion induced by annual flooding, while re-installation of a domestic water supply system helps to reduce adverse impacts of droughts and salinization. Some projects have capacity to address a wider range of climate hazards than others. For example, installation of an 
irrigation system can address at least three climate hazards, while the improvement of rice field infrastructure is mainly used to deal with droughts (Table 8-2).

The proposed projects have different roles, but they can reinforce each other to address climate hazards more effectively. For instance, the village will address droughts more successfully if both a water supply system and an irrigation system are installed as the former can only provide residents with domestic water and the latter offers freshwater for crop production. Some proposed projects do not address directly climate hazards, but they can support others to reduce climate impacts. For instance, currently the electricity system is weak and it does not address directly droughts and extreme heat, but if the system is upgraded, it will provide local residents with sufficient power to operate their fans and drilled wells in hot and dry seasons.

The proposed projects also illustrate the importance of combining disaster risk reduction (DRR) and climate change adaptation (CCA) efforts in addressing the complex changing climate. DRR interventions such as planting salt-tolerant trees will help the community to address storms and floods, while CCA measures, for instance installation of an irrigation system, will provide freshwater to reduce adverse impacts of droughts and salinization. Some projects such as planting salt-tolerant trees and strengthening the dyke system play roles for both DRR and CCA efforts as they will be able to simultaneously address storms and floods as well as gradual and prolonged stressors. 
Table 8-2: Essential projects proposed by participants and their role in addressing climate hazards

\begin{tabular}{|c|c|c|c|c|c|c|c|c|c|c|c|c|c|c|}
\hline \multirow[t]{2}{*}{ Essential interventions } & \multicolumn{5}{|c|}{ Capital Form } & \multicolumn{9}{|c|}{ Climate hazard category } \\
\hline & $\mathrm{N}$ & $P$ & $\mathrm{~F}$ & $\mathrm{H}$ & $\mathrm{S}$ & Flood & Drought & Sal & $\begin{array}{c}\text { Tidal } \\
\text { flooding }\end{array}$ & $\begin{array}{c}\text { Rain } \\
\text { flooding }\end{array}$ & Storm & Erosion & SW & $N W$ \\
\hline Installation of irrigation system & & & & & & & & & & & & & & \\
\hline Planting salt-tolerant trees & & & & & & & & & & & & & & \\
\hline Development of waste management system & & & & & & & & & & & & & & \\
\hline Installation of water supply system & & & & & & & & & & & & & & \\
\hline Building bridge to Ha Tay village & & & & & & & & & & & & & & \\
\hline Community-based shrimp farming & & & & & & & & & & & & & & \\
\hline Strengthening dykes & & & & & & & & & & & & & & \\
\hline Improvement of public canals for shrimp zone & & & & & & & & & & & & & & \\
\hline Completion of uncompleted dykes & & & & & & & & & & & & & & \\
\hline Building underground shelters & & & & & & & & & & & & & & \\
\hline Improvement of village transportation & & & & & & & & & & & & & & \\
\hline Improvement of rice field infrastructure & & & & & & & & & & & & & & \\
\hline Improvement of roads for emergency evacuation & & & & & & & & & & & & & & \\
\hline Upgrade of electricity system & & & & & & & & & & & & & & \\
\hline Improvement of drainages & & & & & & & & & & & & & & \\
\hline Investment of facilities to address storms and floods & & & & & & & & & & & & & & \\
\hline Improvement of communication system & & & & & & & & & & & & & & \\
\hline
\end{tabular}

Source: strategic planning exercises in June 2013

Note:

$N, P, F, H$ and $S$ denote natural, physical, financial, human and social capitals, respectively. Sal, SW and NW indicate salinization, southwest and northeast monsoons, respectively.

indicates a primary form of capital that is generated directly by a project

$\square$ indicates a secondary form of capital that can be created by a primary form of capital

indicates that a project can directly address specific hazards

$\square$ indicates that a project does not produce forms of capitals or address specific hazards 


\subsection{Strategies for navigating transitions towards a resilient community in the face of a changing climate}

This section illustrates and discusses implementation strategies that help the community make successful transitions to a more resilient state. A diverse set of recommendations for effective project implementation emerged in the final phase of the strategic planning process and in the in-depth interviews as well as the meetings with governmental agencies and non-governmental organizations (NGO). These recommendations centre on five interconnected themes or strategies that help the community to constantly enhance $\mathrm{CR}$ and reduce adverse impacts of climate change over the next five years.

\subsubsection{Addressing the complexity of changing climate}

A key concern is how to navigate the community towards a more resilient state as climate change introduces multiple interactive hazards. Workshop discussions and interviews revealed that addressing this issue will require expanding the context beyond the recent focus on storms and floods. Currently, the National Strategy on Disaster Prevention, Response and Mitigation to 2020 (NSD) addresses storms and floods and tends to overlook gradual and prolonged. Workshop participants and staff from governmental agencies and NGOs argued that addressing storms and floods remain essential, but it is equally important to implement projects that help the village to address a wider range of gradual and prolonged stressors. Similarly, many important larger-scale projects identified by the community to address these stressors will unlikely be deployed as they

are not affordable at the community level. This led participants to stress that without additional assistance from the National Target Program on Response to Climate Change 
(NTP), larger-scale projects to address stressors other than storms and floods, such as the installation of an irrigation system, remain unattainable.

In addressing the complexity of the changing climate, efforts to cope with individual climate hazards remain essential, but it is equally important to implement measures that deal with multiple hazards and their cumulative impacts. Tuong Van is threatened by a wide range of climate-related events and the interactions amongst these hazards might magnify the adversity of individual events. For instance, droughts reduce the productivity and quality of rice and subsidiary crops and such adverse impacts are often exacerbated by salinization from tidal flooding and salt intrusion (see Chapter 5). Thus, besides measures to address individual hazards, participants recommended their community should also implement projects that help to reduce cumulative impacts from multiple hazards. For instance, an irrigation system for agricultural crops should be installed to reduce the adverse impacts of not only droughts but also salinization induced by tidal flooding and intrusion.

Taking advantage of the changing climate was also viewed as a useful strategy for the community to consider over the next five years. In the past three decades, the community exploited the benefits of climate events, such as enriching rice farms and reducing salinization by controlling the flows of river floods (see Chapter 6). Given the benefits, participants suggested that their community should adopt projects that take advantage of the changing climate. For example, alongside existing successful measures such as installation of rainwater cisterns and trapping wild fish and shrimps, many local residents in the community workshop in 2014 suggested that their community should modify their natural lakes to collect and store freshwater for crop production during summers. Some 
staff from governmental agencies commented that such a project might be less expensive than the installation of an irrigation system.

\subsubsection{Enhancing community resilience: availability and quality of as well as mutual reinforcement amongst the five capitals}

The proposed projects might not be implemented if essential resources are not available. As such participants suggested that enhancing the availability of the five capitals is needed to pursue a more resilient community. They recommended mobilising resources from diverse resources as an essential solution for enhancing the availability of the five capitals and reducing climate risks. For instance, participants affirmed that individual households cannot dredge the entire drainage system because its cost and labours exceeds household capacity, but this can be done if labourers and money from these households are mobilized and combined.

Drawing upon their experiences, participants noted two important points for enhancing the availability of resources. First, increasing the availability of one resource does not always ensure $\mathrm{CR}$ will be enhanced because it might reduce the availability and quality of others. For instance, the use of too many drilled wells has increasingly reduced the availability and quality of underground water as the overexploitation promotes salinewater intrusion. Therefore, participants commented that enhancing the availability of some resources is essential, but it should not exceed critical thresholds beyond which negative impacts are possible.

Secondly, participants commented that future projects should enhance not only the availability but also the quality of resources. This would be of merit to enhancing the 
quality of existing important resources such as the system of concrete dykes and salttolerant trees, which have been damaged. This discussion also reconfirmed participant views that several recent efforts have enhanced CR but there is a need for continual maintenance and re-investment to ensure $\mathrm{CR}$ is protected in the future. The recent erosion of concrete dykes, stemming in part from neglected maintenance, illustrates one aspect of the relationships between various DRR and CCA projects specifically and the five capitals more generally. In this example, the inadequate financial capital (i.e. funds allocated to maintenance) has contributed to a decline in physical capital (i.e. the erosion of the concrete dyke), which is expected to adversely impact human capital (i.e. threats to human capital) should a future climate increase storm frequency and/or magnitude.

Promoting the mutual reinforcement among resources is a key to facilitating climateresilient pathways for the community over the next five years. Most proposed projects aim to enhance physical resources. These structural interventions are essential, but they might fail if efforts to promote non-physical resources are not part of the overall plan to promote $\mathrm{CR}$ into the future. Discussions about the dredging of canals highlighted the need to improve social capitals such as collaborative mechanisms and coordination amongst villagers and were supported by both local residents and governmental staff. There was overall recognition and agreement that enhancing non-physical capacities in a coordinated manner will be required to avoid potential adverse impacts stemming from an approach characterized by addressing single projects or enhancing one form of capital without considering relationships across capitals. 


\subsubsection{Promoting effective governance of DRR and CCA across jurisdictional scales}

A vast majority of participants from Tuong Van and governmental agencies and NGOs affirmed that the inadequacy of the five capitals most likely resulted, in part, from ineffective governance of DRR and CCA programs across multiple levels. From these discussions, a number of governance innovations were recommended for the community to move towards a more resilient state.

First, public participation is essential for successful project implementation in Tuong Van as many proposed projects such as building an irrigation system involve multiple interconnected issues and their success requires collective efforts from diverse actors. This recommendation is consistent with a growing body of research that shows public participation is needed for the success of a project because it provides actors with opportunities to raise and discuss their concerns during planning and to critique the outputs of projects (van Aalst et al. 2008, Mistry et al. 2009, Van Tuyen et al. 2010). Yet, participants also stressed that the participation might be less meaningful if actors are involved passively and irresponsibly.

Villagers commented that the implementation of proposed projects must include local participation as their community is not simply a beneficiary, but also bears consequences if the projects fail such as was the case with the unusable system of domestic freshwater supply in Lang. Local participation might be time-consuming (Zakus and Lysack 1998), but the experiences from Tuong Van and previous research showed that local participation could also offer enormous benefits. For example, local participation is a useful tool to incorporate knowledge and preferences of communities into decision- 
making processes, to reduce corruption, and to deliver services more effectively (Mansuri and Rao 2012). In contrast, projects can fail if local communities are excluded. The exclusion of Tuong Van from designing and implementing the dyke construction and the subsequent loss of greenbelts is one example of how the limited participation of the local community has undermined efforts to improve CR.

Discussions also showed that local participation is essential but it is not sufficient. Villagers and staff from governmental agencies explained that most projects in the proposed plan are highly complex and needed the expertise from diverse sectors in the process of designing and implementing the projects. For instance, Quang Tri DONRE can provide information about suitable locations and the techniques for planting salt-tolerant trees, while Quang Tri DARD offers professional engineering and environmental expertise on design and construction of irrigation systems. As such both local residents and governmental staff suggested that it is essential to engage professionals and scientists with the local community in designing and implementing complex projects such as restoring green belts of salt-tolerant trees and installing an irrigation system.

Secondly, discussions revealed that effective participation relies on decentralization and democracy as they provide actors with opportunities to raise their concerns in decisionmaking processes. Some NGO officials claimed that decentralization and democracy in Quang Tri have been significantly improved over the last three decades, but they remained concerned on the disparity of political powers, which often impedes public participation and induces inequality in making decisions and implementing projects. This claim is consistent with findings from recent research by Ho et al. (2015) in the Tam Giang Lagoon region, where governmental agencies ignored comments and limited the 
powers of local organizations in making decisions on coastal resources co-management. The NGO staff suggested that substantial decentralization and improvements in equality of political powers across multiple levels and democracy remains essential to promote the effectiveness of project formation and implementation over the next five years. This suggestion is also an expectation from the NSD and NTP programs (GOV 2007b, 2008).

Another suggestion is significant improvements in responsibility of parties involved in projects. Experiences from Tuong Van and many other communities such as coastal villages in Quang Nam province revealed that public participation is needed, but it is less useful if actors involved in DRR and CCA projects have limited responsibilities in addressing the failure or limited success of projects (Chau et al. 2014). In Tuong Van, some participants expressed their regret that the quality of their flood dykes, roads and the freshwater supply system could be better if the responsibility amongst both service providers and beneficiaries was shared and clear throughout the process of designing and implementing the projects. Thus they suggested that when any proposed projects are implemented, the responsibilities amongst parties involved in the projects must be clarified at the outset and shared over the project's lifespan. For instance, governmental agencies are responsible for hiring quality construction firms to build an irrigation system and for demanding compensation for losses if the project fails, while Tuong Van villagers are responsible for regular maintenance.

Finally, villagers suggested that the implementation of the proposed projects needs a higher level of transparency and accountability from public service providers such as governmental agencies and contractors in construction projects. This is consistent with the recommendation from rural communities in Quang Nam province (Chau et al. 2014). 
For instance, Tuong Van recommended that essential information for making future decisions as well as results of project monitoring and evaluation must be displayed to the public, thereby encouraging active participation, including critical feedback. In addition, participants in planning workshops recommended that project parties must also explain how and why projects may fail, and find mechanisms for better performance. This is essential as accountability is a useful means of judging whether actors have fulfilled their responsibilities, of imposing sanctions if these responsibilities have not been met, and of identifying malfeasance, especially actions that involved corruption (Grant and Keohane 2005, Peters 2007).

\subsubsection{Promoting effective integration between DRR and CCA across multiple scales}

Discussions from FGs and interviews with governmental and non-governmental agencies showed that successful transitions of the community towards a preferred state rely on effective integration between DRR and CCA programs across multiple scales. Currently,

there is a mismatch between the two programs. Some effort to mainstream the NTP (CCA policy) with the NSD (DRR policy) has been made to promote responses to changing climate, but the NTP are not available from district through local levels, leading to a mismatch between DRR and CCA programs (see Chapter 7). As such local residents commented that the NTP should be translated into local actions and mainstreamed with the NSD as well as community-based DRR and CCA initiatives in order to address more effectively the complexity of the changing climate. This also re-confirms the need for combining DRR and CCA efforts in addressing the complex changing climate. Furthermore, previous experiences also revealed that the NSD and NTP programs 
themselves would not be able to fully address a changing climate, thus incorporation with other policies, such as existing national programs on New Rural Development and Rural Clean Water Supply and Sanitation, is needed to provide the village with a fuller range of capacities to reduce risks of future climate change.

Much effort has been made to involve actors across multiple jurisdictional levels in the process of formulating and implementing DRR and CCA programs and provided some success in enhancing CR and reducing climate impacts over the last three decades. Yet, there was concern over the weak collaboration and coordination between the two programs (see Chapter 7). The majority of local residents and staff from governmental agencies and NGOs suggested that official mechanisms for collaboration and coordination among sectors and across multiple scales should be developed and used to promote the institutional integration between the two programs. For example, socialeconomic and environmental data that is needed for DRR and CCA project design and implementation should be shared among provincial departments in Quang Tri province.

Table 8-3 suggests that Tuong Van will also need to improve temporal integration when DRR and CCA projects are deployed. Over the last three decades, the community had some success in integrating DRR with CCA throughout the year to reduce impacts of climate hazards. For instance, DRR was adopted to address storms and floods during rainy seasons, while community-based CCA was deployed in dry months to address droughts and salinization. Yet, participants commented that most recent interventions are short-term and they are mainly seasonal and annual solutions. They affirmed that these measures remain essential, but it is equally important to implement projects such as 
completion of the dyke system and installation of an irrigation system that help to lessen the longer-term impacts of climate change.

Table 8-3: Temporal integration of DRR and CCA projects

\begin{tabular}{|c|c|c|c|}
\hline & & & Planting salt-tolerant trees \\
\hline & & & $\begin{array}{l}\text { Completion of dykes } \\
\text { surrounding Lang }\end{array}$ \\
\hline & & $\begin{array}{l}\text { Installation of irrigation } \\
\text { system }\end{array}$ & \\
\hline & & Installation of drilled wells & \\
\hline & & Installation of rainwater tanks & \\
\hline & Rotation of livelihoods & & \\
\hline & $\begin{array}{l}\text { Fixing the roofs of houses } \\
\text { before rainy season }\end{array}$ & & \\
\hline & Formation of patrol team & & \\
\hline \multicolumn{4}{|c|}{ Exploitation of clam in June } \\
\hline \multicolumn{4}{|c|}{$\begin{array}{l}\text { Exploitation of nut grass in } \\
\text { December }\end{array}$} \\
\hline Monthly & Seasonal & Decade & Century \\
\hline
\end{tabular}

Source: Tuong Van community workshop in November 2014

Drawing upon experiences with negative interactions between previous DRR and CCA measures across spatial scales, the village recognized the need to improve spatial integration between DRR and CCA measures over the next five years. Some suggested that their community should avoid interventions that have positive effects at one place but are harmful at others. In contrast, the community should deploy measures that provide a diverse set of benefits. For instance, the restoration of salt-tolerant trees along the Thach Han River should be promoted as the trees not only help the community to protect flood dykes from erosion, but they also enhance the quality of the environment and stocks of wild species along the river and in the ocean nearby. However, many participants argued that none of the proposed projects are perfect and that they all have some degree of negative impacts across spatial and temporal scales. Thus, they suggested that their community should pay more attention to monitoring and reducing the negative impacts of projects. 


\subsubsection{Prioritizing new proposed projects for future implementation}

Given the set of projects for the next five years, another important task in the final phase of the planning process was to prioritize project implementation. Workshop discussions were lively and it was difficult for participants to reach a consensus because each project has its own advantages and limitations, while the village does not have sufficient resources to implement all proposed projects at once. Participants identified three criteria: urgency, availability of resources, and benefits, which are used in support to evaluate and select their proposed projects for future implementation.

Table 8-4 illustrates the results of the prioritizing exercise. The findings showed that most of the 17 projects could provide the community with a high level of benefits and are of very urgent need, but the community has limited resources to implement them. The project "improvement of drainage system" was given a highest priority for two reasons. All participants affirmed that the project not only has the highest average score, but more importantly their village will have sufficient resources, through mobilization of labourers and money from villagers, to implement the project with little reliance on external resources. Similarly, building semi-underground shelters could also be adopted by local efforts. However, this project was not given the same level of priority as participants contend that local residents might not need to build their own semi-underground shelters as a public shelter is already available for their community.

All participants affirmed that their village itself will not be able to implement the other 15 projects without external assistance as the resources that are required for these projects are beyond the capacity of their community. For this reason, some participants commented that it was not necessary to rank the implementation priority of these 
projects. However, drawing upon experiences over the past decade about calls from higher levels of government and NGOs for project proposals, most participants suggested that they should rank their proposed projects so that their community will be able to react quickly should there be calls for proposals in the future.

Table 8-4: The priority of the 17 proposed projects ranked by community members

\begin{tabular}{|c|c|c|c|c|c|}
\hline \multirow[b]{2}{*}{ Actions } & \multicolumn{3}{|c|}{ Criteria score } & \multirow{2}{*}{$\begin{array}{l}\text { Average } \\
\text { point }\end{array}$} & \multirow{2}{*}{$\begin{array}{l}\text { Ranked } \\
\text { priority }\end{array}$} \\
\hline & Urgency & Availability & Benefit & & \\
\hline Improvement of drainage system & 3.2 & 3.4 & 4.4 & 3.7 & First \\
\hline Installation of irrigation system & 4.7 & 1.3 & 4.7 & 3.6 & Second \\
\hline Installation of water supply system & 4.6 & 1.4 & 4.6 & 3.5 & Second \\
\hline Rebuilding bridge & 4.6 & 1.2 & 4.7 & 3.5 & Second \\
\hline Upgrade of electricity system & 4.2 & 1.5 & 4.5 & 3.4 & Second \\
\hline Waste management system & 3.7 & 2.3 & 4.0 & 3.3 & Third \\
\hline Community-based farming & 3.9 & 2.2 & 3.9 & 3.3 & Third \\
\hline Facilities for storm and flood DRR & 3.8 & 2.0 & 4.1 & 3.3 & Third \\
\hline Improvement of canals for shrimp zone & 3.3 & 2.6 & 3.8 & 3.2 & Third \\
\hline Planting salt-tolerant trees & 3.6 & 1.6 & 4.3 & 3.1 & Third \\
\hline Building underground shelters & 2.9 & 2.9 & 3.3 & 3.0 & Third \\
\hline Improvement of communication system & 3.3 & 1.8 & 3.9 & 3.0 & Third \\
\hline Strengthening dykes & 2.7 & 2.2 & 4.2 & 3.0 & Third \\
\hline Improvement of roads for evacuation & 2.8 & 2.0 & 3.8 & 2.9 & Fourth \\
\hline Improvement of village transportation & 2.1 & 2.7 & 3.7 & 2.8 & Fourth \\
\hline Completion of uncompleted dykes & 2.7 & 1.6 & 4.0 & 2.8 & Fourth \\
\hline Improvement of rice field infrastructure & 2.0 & 2.6 & 3.6 & 2.7 & Fourth \\
\hline
\end{tabular}

Source: prioritizing exercise in July 2013

Note: value in each cell for a criterion is the average score from 25 participants given to the criterion. The average point for a resource is calculated as the mean of the three criteria score of the resource. Participants used the average scores and the criteria points to discuss and rank the priority of resources.

Participants ranked the 15 projects with an assumption that their community will respond to calls for proposals from higher levels of government or NGOs. These projects are prioritized first based on their average score, and then their urgency and benefit. As a result of the prioritizing exercises, the priority of the 15 proposed projects were classified into three groups. Following the ranking exercise, reflections by governmental staff about 
the priority of these projects was obtained in interviews as participants believed that the feedback of governmental agencies will be useful for the community to select appropriate projects for their proposals.

The second order of priority is four projects, which have similar average scores to the drainage improvement project and the score of benefits and urgency are higher than 4.0. When discussing this group with governmental officials across multiple levels, many commented that these projects will likely be funded from the NSD and NTP programs as they fit well to the purposes of reducing disaster risks from storms and floods and adverse impacts of future climate change.

Amongst the remaining projects, those with the average score equal to or higher than 3.0 were ranked as the third priority. Participants commented that not only does their community not have resources to deploy these projects but either their urgency or benefits are also not very high (lower than 4.0). Some governmental staff commented that these projects would likely be funded by some national programs. For instance, the project of planting salt-tolerant trees might be funded by the NTP, while development of waste management system and improvement of an electricity system can be supported by the National Program on New Rural Development.

The last group includes projects that have the lowest average scores. These infrastructure projects could provide some benefits if they are deployed, but are less urgent these be deployed. Most governmental staff commented this group is the least likely to be funded by the governments and NGOs for two reasons. First, higher levels of government and NGOs are commonly interested in building new infrastructure. Secondly, the proposed 
projects of the last group focus on improvement of existing infrastructure, which the governments and NGOs commonly assume as the responsibility of local communities.

The strategic planning process ended with a set of potential projects and a ranking matrix that can be used to select appropriate projects in community meetings following the planning workshop of this research. Although the ranking exercises in this research provided a foundation for designing action plans in response to changing climate, final decisions on plan implementation have been and would be made on the basis of the community as a whole. For instance, on June 7, 2013, the three leaders of the village held a community meeting, where all villagers were invited to participate, to select projects for implementation. As a result of the meeting, the community selected the project "improvement of drainages" and it was implemented just one week following the community meeting with resources mobilized from community members (Figure 8-1).

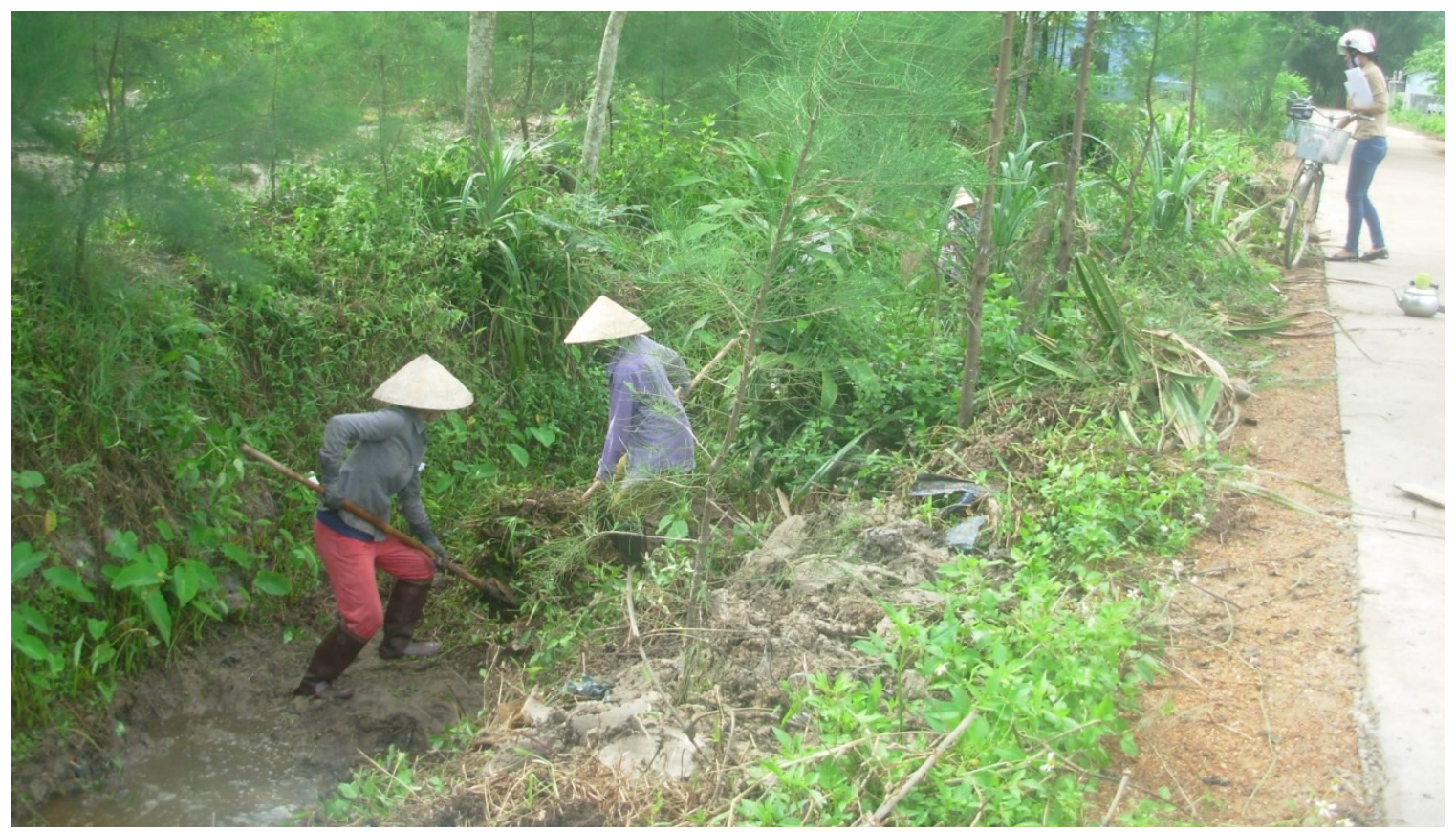

Figure 8-1: Dredging blocked drainages in June 2013

Source: the photo was taken by the author with oral consent from the participants. 


\section{Synthesis of Chapter 8}

Chapter 8 presented results of a planning process, in which participants envisioned a desired state for their community five years into the future and proposed additional projects and strategies to realize the vision. The visioning reflected a local need of critical transitions from a vulnerable to more resilient state, in which the community has the capacity to reduce successfully the adverse impacts of a changing climate. The visioning exercises revealed two overarching and potentially conflicting perspectives. While the community desires to reduce the climate impacts on human life and property, CR improvement will be constrained by the adequacy of the five capitals. Thus future plans need to find a balance between the vision and practicality.

In order to realize the vision, alongside existing successful interventions, participants proposed a set of additional projects, which include both DRR and CCA interventions. Each of the proposed projects potentially plays dual roles: enhancing the adequacy (availability, quality and mutual reinforcement) of the five capitals; and, addressing future climate. These projects have their own roles, but they could reinforce each other to effectively enhance CR and reduce climate risks. However, the proposed projects also have limitations. For instance, most of these interventions focus on enhancing physical capacity, while little effort is directed towards the improvement of non-physical resources. Thus the transitions towards a more resilient state require implementation strategies that promote the advantages and address limitations of the proposed projects.

Five interconnected strategies can facilitate the project implementation in the community. The first is addressing the complexity of the changing climate by reducing the collective impacts of climate hazards and taking advantage of the climate change. In support of this 
strategy, the availability and quality of as well as mutual reinforcement amongst the five capitals must be promoted. Discussions also revealed the adequacy of the five capitals will not be successfully improved without institutional reforms in DRR and CCA governance. These include significant improvement of participation, collaboration and coordination of actors across multiple levels, as well as the responsibility, accountability, democracy and equality of political powers in the process of designing and implementing DRR and CCA projects. In addition, the integration between DRR and CCA programs across jurisdictional, temporal and spatial scales should also be improved in order to avoid negative interactions and promote positive interplays between DRR and CCA interventions. The final part of the project development strategy was to identify priority projects based on three criteria including the urgency of projects, the benefits they provide, and the availability of resources to implement them. 


\section{CHAPTER 9: CONCLUSIONS, IMPLICATIONS AND RECOMMENDATIONS FOR FUTURE RESEARCH}

The purpose of this chapter is three-fold. First, it provides an overview of the research process, including framing of the research problems, development of conceptual foundations, specification and implementation of the investigative framework, and a summary of field methods for data collection. The chapter will then synthesize main findings of the research. Finally, it highlights contributions of the research to understanding and improving community resilience in the face of a changing climate, and recommends directions for future research.

\subsection{Overview of the Research Process}

Vietnam's coastal communities, especially those in the central provinces are routinely threatened by a wide range of climate hazards (CCFSC 2009b). Vietnam has made significant efforts including investments in disaster risk reduction (DRR) and climate change adaptation (CCA) programs over the last three decades in order to enhance the resilience of its coastal communities and reduce risks of a changing climate. Such efforts have provided some significant success, for instance a $50 \%$ decline in climate-related human deaths between the 1990s and the 2010s. However, the continued increase in human injuries and economic losses over the same period suggests that these programs have not been entirely successful (see Chapter 3). When coupled with the anticipated adverse impacts of future changes in global and regional climates (IPCC 2007, MONRE 2009), it should not be surprising that there have been calls to evaluate recent responses by central Vietnam's coastal communities, and seek alternative strategies to improve their 
resilience and reduce risks of future climate change (GOV 2007b, 2008, McCall and Dunn 2012, Kirsch-Wood 2015).

This research investigates constraints and opportunities for improving climate resilience of central Vietnam's coastal communities by addressing four interrelated questions:

1. How have climate hazards recently impacted central Vietnam's coastal communities?

2. How have coastal communities in central Vietnam recently responded to climate hazards?

3. Why have some of recent responses of central Vietnam's coastal communities reduced impacts of climate hazards, while some others have been less successful?

4. What strategies could provide central Vietnam's coastal communities with opportunities to enhance community resilience and reduce risks from future climate change?

This research was built on five interrelated areas of literature: five capitals (five groups of resources), climate risk, community resilience (CR), DRR and CCA. The research draws heavily on five capitals research as it forces the research process to separately and collectively examine the roles of financial, social, human, physical and natural capitals in the creation of vulnerabilities and resilience at the community level. This is a substantial departure from earlier CR, DRR and CCA approaches, which tend to focus on selected capitals rather than the combination of the five capitals in addressing a changing climate. Climate risk studies are used to obtain characteristics of a changing climate, and to explore how the changing climate has hindered DRR, CCA and CR. In response to climate change, DRR and CCA studies are used to explore measures that communities 
employ to enhance their resilience and reduce adverse impacts of the changing climate, whereas CR studies provide insight into the capacities that the communities have to reduce climate risks through DRR and CCA.

This research was situated in a coastal village in central Vietnam - Tuong Van - allowing for an in-depth analysis of linkages between global phenomena (e.g. anthropogenic global climatic change) and local responses (e.g. enhancing community resilience). The research deployed participatory action research approaches in order to engage the community and relevant governmental agencies in all aspects of the research process, including the design and implementation of the field research and interpretation of research findings. The approach offered the opportunity to listen to multiple voices from Quang Tri province and to then determine constraints and opportunities for enhancing CR. The field research included two components, starting with an assessment of existing conditions followed by the development of practical strategies that help the community to navigate its critical transitions to a preferred, more resilient state. Field research from May through October 2013 generated preliminary findings, while the second trip in November 2014 allowed the community and governmental agencies to comment on the findings and contribute to the development of strategies to improve CR in the future.

The research questions tackled in this project cut across several disciplines and no single conceptual framework or data collection method would have been fully satisfactory. The study carefully selected and employed several data collection methods in combination, including focus group discussions, participatory planning workshops, surveys, in-depth interviews, community observations and archival retrieval. Group discussions were used as a primary tool to assess the existing status of the community including climate impacts 
and its responses to a changing climate, while planning workshops were a key instrument in the co-production of practical strategies for enhancing the resilience of the community. The research also employed a survey to rank the importance of climate hazards and resources. In-depth interviews were used to complement information from the group discussions and allowed for the probing of sensitive issues and to address omissions stemming from the absence of important actors who could not participate in focus groups. Community observations and archival retrievals such as historical data of hydrological measurements collected by governmental agencies were also deployed to complement and validate information obtained from group discussions. Briefly, the combination of these methods allowed for a blending of perspectives that provided interdisciplinary insights into existing conditions of the community including climate impacts and the effectiveness of recent DDR and CCA programs, and for developing strategies that help to ameliorate recent and future climate-related stresses.

\subsection{Research findings}

\subsubsection{Complex multidimensional, interactive and uneven impacts of climate hazards and change on central Vietnam's coastal communities (Research Sub-question \# 1)}

Scientific data collected regularly by governmental agencies between 1975 and 2013 coupled with the experiences of Tuong Van residents (see Chapter 5) provided insight into the local impacts of climate hazards. Tuong Van community has faced complex impacts of climate hazards over the last three decades. It has been threatened by a wide

range of hazards, including rapid-onset events such as storms and floods as well as 
gradual and prolonged stressors, for instance droughts and salinization induced by tidal flooding and sea level rise. Evidence from both the local experiences and historical data showed that these climate hazards include both recurring events such as floods and droughts as well as emerging events associated with climate change, especially sea level rise and resulting salinization of groundwater and crop lands.

Recent studies based on large-scale climate models project that impacts of many climate hazards on coastal communities across the country will be exacerbated by expected changes in future climate (ISPONRE 2009, MONRE 2009). This is true for some hazards in Tuong Van, especially sea level rise and the resulting salinization. However, the experiences from this community also revealed that the severity of some hazards has been lessened by climate change. For instance, northeast monsoons have become less adverse over the past 15 years as the weather is no longer as cold, while southwest monsoons are less hot and dry because the rainy season has been extended.

The literature reviews (see Chapter 3) and the empirical evidence from Tuong Van showed that climate hazards and associated disruptions facing coastal communities in central Vietnam have occurred unevenly. These events happen at different times throughout the year, in different locations and in varying intensities. Climate hazards pose threats to the communities throughout the year, with the most devastating losses in the rainy and dry seasons. Rapid onset hazards such as storms and floods happen in rainy seasons and they have caused human deaths and injuries as well as damage to physical infrastructure. Unlike storms and floods, gradual and prolonged stressors have not killed people and resulted in less damage to physical resources, but they routinely affect natural resource-based livelihoods and the well-being of the community. 
Among climate hazards, Tuong Van citizens ranked floods as the most substantial threat to their community because these occur annually and can cause devastating loss of life and property damage. Storms are viewed as one of the top two threats to coastal communities across Vietnam by several government agencies (GOV 2007b, QT-PPC 2008). However, it is interesting that storms are evaluated as less important by the community when compared to many other hazards including drought, salinization, and flooding induced by high tides and heavy rains. Local residents explained that storms were less important as they seldom occur, while droughts, salinization and flooding annually threaten their community for a long period. This suggests attention to spatial variability and importance of location in the assessment of climate hazards.

In the effort to address climate change, it will be necessary to move away from viewing coastal villages across Vietnam as homogenous units with shared climate experiences. The research in Tuong Van unpacked two main components of the community including five capitals and livelihoods and it evaluated how these components have been impacted by climate hazards. During group discussions, it was apparent that elements within each of the three components have been threatened differently by the same hazards due to different levels of vulnerability and resilience. In addition, the two components are interdependent, and when one component suffers from climate hazards, the other can also be impacted accordingly. For instance, if a violent flood broke the dyke system of the community, not only would livelihoods be at risk but the lives of villagers could also be threatened.

Besides characterizing the spatial and temporal patterns of individual climate hazards, impacts from complex interactions amongst these climate hazards were also unpacked 
through the analysis of recorded experiences of Tuong Van residents and historical data, revealing that hazards do not occur independently, but rather they interact with one another. Each hazard has its own impacts and the overall impacts are often exacerbated when hazards interact. For instance, salinization can limit crop growth, but plants can be killed if salinization occurs with droughts. However, some climate-related events might inhibit the impacts of others. For example, the adverse impacts of salinization can be reduced by heavy rains and river floods.

Recent climate change studies tend to focus on negative impacts of climate change on communities, and to underestimate its positive effects. In addition, based on global and regional climate models, it is expected that adverse impacts of climate-related events such as floods and droughts have been magnified by climate change, thus adding to the threats faced by many communities across Vietnam (MONRE 2009). The research conducted in Tuong Van revealed that although recent changes to climate adversely impacted the community, they have also provided local residents with benefits. For instance, the extension of rainy seasons and the increased frequency of heavy rains over the last two decades have not only provided the villagers with more freshwater to be stored for domestic use during the dry seasons, but also have helped the community by washing away salt that had contaminated production land.

In summary, central Vietnam's coastal communities have faced multidimensional and interactive impacts of climate hazards over a lengthy period. They have been impacted by a diverse set of hazards, which include rapid onset events and gradual and prolonged stressors. The communities have not only been impacted by routine hazards but also by emerging threats as a result of climate change. Interactions across climatic events have on 
occasion magnified the severity of hazards. The impacts of climate hazards vary across space and over time, owing to changes in the hazard itself as well as differing levels of vulnerability and resilience of the communities. In future, based on global and regional climate models, impacts of climate hazards are expected to accelerate and recent experiences from Tuong Van community suggest these adverse impacts might also be partially offset by new beneficial opportunities.

\subsubsection{Recent efforts of central Vietnam's coastal communities to address the climate hazards: integration between DRR and CCA across multiple scales (Research Sub-question \# 2)}

Evidence showed that Tuong Van has interwoven DRR and CCA programs in order to enhance CR as well as to reduce adverse impacts and take advantage of opportunities stemming from recent climate trends. The recent DRR program at the community level is a combination of policy-driven and community-based approaches to reduce potentially adverse consequences of storms and floods. Like many villages in Quang Nam province (Chau et al. 2014, Kirsch-Wood 2015), Tuong Van viewed the National Strategy for Natural Disaster Prevention, Response and Mitigation to 2020 (NSD) as an important DRR policy for their community leading to several benefits including improvements in human capital (e.g. training courses to enhance the knowledge and skills about DRR) and physical capital (e.g. concrete dykes and a public shelter).

As is often the case with public programs, the NSD also has limitations. First, most activities and support from the NSD for Tuong Van were terminated when storm and flood seasons were over, while the community needed a wide range of measures outside the rainy seasons to address storms and floods or these measures required longer recovery 
periods. Secondly, the NSD tends to overlook gradual and prolonged stressors such as salinization and sea level rise (GOV 2007b). In support of the NSD, many provinces including Quang Tri have used other national policies, such as the National Program on Rural Clean Water Supply and Sanitation and the National Program on Poverty Reduction, to assist its coastal communities with enhancing community resilience and addressing stressors other than storms and floods. In 2008, the Vietnamese government launched the National Target Program on Response to Climate Change (NTP) to reinforce the NSD and these two programs have been gradually integrated to reduce storm and flood disasters as well as emerging impacts of climate change (GOV 2011). Like many other coastal provinces (Kirsch-Wood 2015), Quang Tri issued an action plan for the NTP in 2013, but it has not been applied at lower levels.

Community-based DRR and CCA are viewed as complementary strategies that Tuong Van has used to partially overcome deficiencies in the NSD and NTP policies. Tuong Van has self-organized such as developing and integrating its own DRR and CCA measures to enhance $\mathrm{CR}$ and reduce climate risks. In addition, the villagers employed their human and social capitals to tap into the process of NSD implementation. The community-based DRR involves active prevention or preparedness (e.g. elevation of household floors), emergency responses (e.g. harvest shrimps when the patrol team announced the likely strike of storms and floods), and post-disaster recovery (e.g. repairs to damaged houses and roads).

The community-based CCA in Tuong Van has been integrated with DRR interventions. It involves the adjustment or modification or transformation of biophysical and socialeconomic components in the community. Some examples include planting bamboo rings 
around houses to reduce the force of violent floods and storm surges, elevating floors in houses, or/and replacing cottages with houses of bricks that are more resistant to floods and storms. It is also important to note that Tuong Van residents do not differentiate, but rather they manage to interweave DRR and CCA approaches, although policy makers and scholars attempt to make distinction between the two approaches.

The DRR and CCA formation and implementation in Tuong Van routinely involves investing in and applying a combination of financial, physical, natural, human and social capitals in order to enhance CR and reduce impacts of climate hazards. Tuong Van residents are well aware that single "fixes" rarely lead to significant improvements in CR. In addition, the villagers realized resources play different roles and a single resource cannot successfully address climate hazards. Thus they have combined multiple resources to reduce climate risks, especially collective impacts from interactions among climatic events. For instance, besides dug and drilled wells that are used to address droughts, most households also installed water filters to enhance water quality as underground water resources are aluminized.

The climate hazards and a changing climate have not always harmed Tuong Van, but it has also provided new opportunities. The community has exploited benefits owing to the changing climate to enhance its resilience and address climatic threats. Two examples for this strategy include: 1) use of annual floods over agricultural land to reduce salinization, enrich soil and enhance recruitment of wild fish and shrimp; and 2) harvest and storage of rainwater for domestic use in the dry season. It is doubtful these benefits were envisioned in formal DDR and CCA action plans, but clearly Tuong Van community has applied its 
detailed understanding of local natural and socio-economic conditions in order to find new opportunities under a changing climate.

In summary, central Vietnam's coastal communities have used a combination of DRR and CCA programs, which involves both policy-driven and community-based approaches across multiple scales, in order to address climate hazards and a changing climate. DRR and CCA programs have different foci, but they can complement each other. DRR has been adopted to address rapid onset climate hazards including storms and floods, while CCA has been deployed to reduce adverse impacts of gradual and prolonged stressors and take advantage of the changing climate. The NSD and NTP are key policies in response to the changing climate, but they are not always available at the local level. As such the community has relied heavily on its own resources to develop and implement its own DRR and CCA measures and interweave these with the NSD and NTP programs in order to promote $\mathrm{CR}$ and reduce climate risks.

\subsubsection{Factors impeding the success of recent responses by central Vietnam's coastal communities to changing climate (Research} Sub-question \# 3)

The evidence from the evaluation of recent interventions in Chapters 3 and 7 showed that DRR and CCA programs provided coastal communities in central Vietnam with some significant success, but the two programs also had limitations resulting from interactions across a diverse set of factors. In addition, it also revealed that the root causes for the limitations of the recent interventions in the communities are embedded in the five capitals as well as the process of DRR and CCA formulation and implementation across multiple scales. 
First, the success of the recent efforts has been constrained by the limited availability of resources such as lack of an irrigation system and freshwater to reduce adverse impacts of droughts and salinization on agricultural crops. In addition, the empirical evidence also showed that the availability of resources is essential, but it does not always ensure that CR will be enhanced for at least two reasons. An available resource might be less helpful if it is of low quality. For instance, the system of domestic water supply in Lang cannot be used because of its inability to pump underground water. In addition, resources often interact and these interactions are not necessarily synergistic. As an example, the overabundance of drilled wells (a physical capital) contributed to the salinization of underground water (a natural capital), which in turn adversely impacted livelihoods and personal health (financial and human capitals, respectively).

Second, the limited success of recent efforts stemmed from negative interactions between DRR and CCA measures. While the combination of DRR and CCA programs is expected to enhance $\mathrm{CR}$ and reduce climate risks, some measures of one program adversely impacted the other, leading to erosion of CR. The erection of concrete dykes in Tuong Van is an example. Before building concrete dykes (a DRR measure), the community had capacity to lessen salinization and enrich soil of rice farms through controlling sluice gates of its former dykes, but this capacity was significantly reduced after the the dykes were erected. One example of negative impacts of CCA interventions on DRR is the planting of trees along emergency roads and houses in Lang. The trees could provide local residents with additional income, but they damaged various sections of the roads and collapsed many houses in the $8^{\text {th }}$ storm of 2013. 
Another possible cause for the limitations of recent efforts in Tuong Van was ineffective governance of DRR and CCA projects, which stemmed from six main factors. First, limited participation of the public in designing and implementing key DRR and CCA projects led to the exclusion of concerns and experiences of actors. For example, salttolerant trees helped to reduce the force of floods and storm surges in Tuong Van, and the clearance of those trees represents a significant consequence of limited local participation. The other five factors include weak coordination and collaboration of actors across multiple levels, as well as low levels of transparency, responsibility and accountability in the process of DRR and CCA project formation and implementation (see Chapter 7).

Finally, experiences from Tuong Van revealed that the limitations of recent responses to the impacts of climate change resulted from interactions across spatial and temporal scales. The community has deployed a wide range of DRR and CCA projects to address recurrent hazards, but it had limited effort to reduce long-term impacts of climate change such as sea level rise and the resulting salinization. Additionally, some DRR and CCA measures were useful for addressing climate hazards in the short-term, but they were less helpful and even have eroded the long-term CR across larger spatial scales. For instance, the extraction of underground water is an essential solution for individual households to address annual droughts and promote crop productivity, but it has reduced the quality of the water resource across the community over the last $15-20$ years due to salt intrusion. The resilience of the community has also been constrained by technological and socialeconomic changes from outside the community. For instance, industrialisation in Binh Duong and Ho Chi Minh attracted the out-migration of many of Tuong Van's young 
men, leading to the shortage of human resources and increased vulnerability of the community; while advanced technology in salt production in Binh Dinh and Ninh Thuan collapsed the traditional salt farming in the community. Furthermore, the empirical evidence also revealed that the resilience of the community and the success of its DRR and CCA interventions were constrained by provincial and national policies on economic development, such as decisions on land conversion for shrimp farming.

Briefly, the success of recent interventions that coastal communities in central Vietnam have used to enhance $\mathrm{CR}$ and reduce climate risks was determined by a set of multidimensional and interconnected factors, which are embedded in the five capitals and the process of DRR and CCA formulation and implementation. The success of recent efforts was constrained not only by limited availability and quality of but also by negative interactions amongst the five capitals. In addition, ineffective governance of DRR and CCA programs across multiple scales impeded not only the success of individual programs but also their mutual reinforcement.

\subsubsection{Towards an integrative framework for understanding and enhancing the resilience of central Vietnam's coastal communities in the face of climate change (Research Sub-question \# 4)}

Vulnerability to climate hazards and a changing climate has not been eradicated by recent DRR and CCA programs and it is anticipated that existing efforts will not be sufficient to meet the challenges stemming from future climate change (IPCC 2014a). Drawing upon findings from strategic planning exercises in Tuong Van as well as interviews with staff from governmental agencies and NGOs, the framework presented in Figure 9-1 is 
designed to assist with understanding and enhancing the resilience of central Vietnam's coastal communities in the face of climate change.

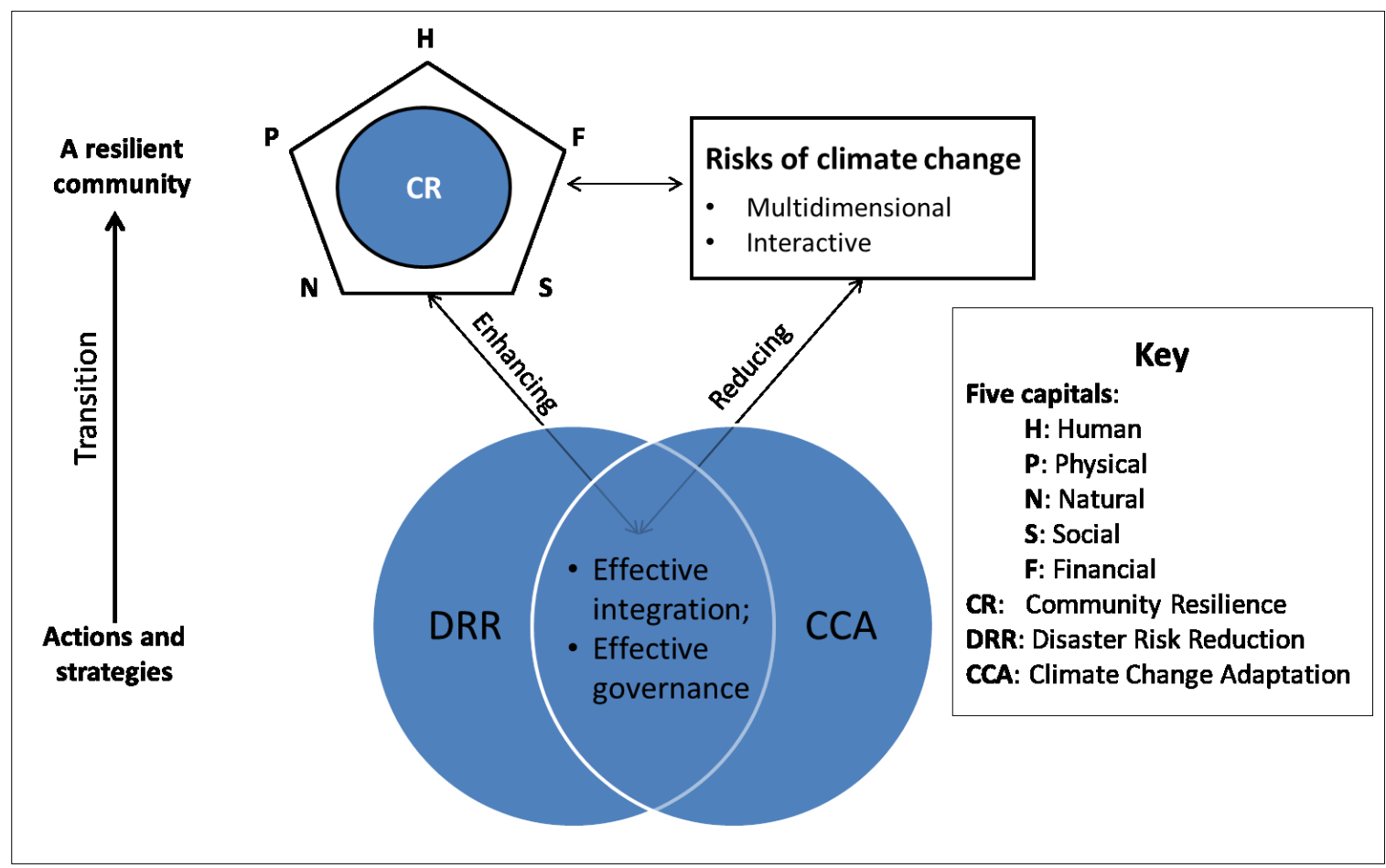

Figure 9-1: A framework for understanding and enhancing community resilience in the face of climate change

Source: synthesis from the strategic planning process in Tuong Van and interviews with staff from governmental and non-governmental agencies during the field research in 2013 and in November 2014

Discussions in the planning exercises and interviews with staff from governmental and non-governmental agencies revealed a need for navigating significant transitions towards a more resilient state where coastal communities in central Vietnam have "sufficient" financial, physical, natural, human and social capitals to successfully reduce risks of future climate change. The sufficiency of the five capitals is not simply their availability, but also the quality of and positive interactions amongst the resources.

In order to transition successfully towards the desired condition, the communities need to continue combining DRR and CCA. This need is consistent with the expectation from the 
NSD and NTP programs (GOV 2009, 2011), and with suggestions from the Intergovernmental Panel on Climate Change (IPCC 2014b) and the United Nations Framework Convention on Climate Change (UNISDR 2015). The foundation for these recommendations stems from mutual reinforcement between DRR and CCA. However, drawing upon the evidence from Tuong Van, it is important to note that DRR and CCA also have negative interactions, and therefore require more effective integration between the two programs.

Given the current mismatch between the NSD and NTP programs across multiple levels of government (Kirsch-Wood 2015), effective integration should start with institutional connections across multiple jurisdictional levels by simultaneously translating the NTP and interweaving it with the NSD from national to local levels. In addition, such connections need stronger collaboration and coordination amongst actors from the two institutional frameworks of the DRR and CCA programs. When the institutional connections are established, collective efforts must be generated to interweave the NSD and NTP programs with community-based initiatives. Furthermore, negative interactions among interventions including DRR, CCA and other social-economic development programs across multiple scales must be monitored and addressed throughout the process of program implementation.

The successful transitions also require transformations of DRR and CCA governance. First, the transitions need promoting active participation of the public in project design, implementation and monitoring in order to include concerns and interests of actors rather than being imposed from above. Secondly, experiences from Tuong Van and many communities in Thua Thien Hue (Ho et al. 2015) suggest that the improvement in 
decentralization and democracy across multiple levels remain essential to promote active public participation. In addition, the effectiveness of DRR and CCA implementation and integration requires improving and sharing responsibility amongst actors. For instance, governmental agencies in Quang Tri should be more responsible for employing quality contractors for infrastructure projects and for disciplining the contractors if they violate contracts, while local residents must take responsibility of regular maintenance of the installed infrastructure. The final transformation of DRR and CCA governance calls for significant improvements in accountability and transparency throughout the process of making decisions and implementing the two programs because they help to reduce corruption, and to deliver services more effectively (Mansuri and Rao 2012).

Finally, a more resilient state will need to find a balance between avoiding adverse impacts and capitalizing on beneficial opportunities owing to a changing climate. Recent investments in DRR and CCA programs focus on reducing adverse impacts of climate events but tend to be less sensitive to capitalizing on potential benefits. Exploring beneficial opportunities and taking advantage of the changing climate is a significant strategy for enhancing community resilience. However, it is important to note that challenges and opportunities of a changing climate are not equal amongst actors or communities because impacts of the changing climate vary across spaces and time.

In summary, navigating successful transitions of central Vietnam's coastal communities from the prevent vulnerability into a more resilient state, in which the communities have sufficient capacity to take advantage of and reduce risks from climate change, requires improvement in the five capitals and effective integration between DRR and CCA programs. Improving the availability of resources needs to be coupled with improving 
resource quality, the positive interplay amongst the five capitals, and cross-scale integration between DRR and CCA programs. These include significant improvement in public participation, collaboration, coordination and responsibility of diverse actors across multiple jurisdictional levels, as well as considerable enhancement in transparency, accountability and democracy in the process of program formulation, implementation and monitoring.

\subsection{Research contributions}

Contributions of this doctoral research to existing literature are summarized in Table 9-1. First, the research contributes to five areas of literature including climate change, five capitals, CR, DRR and CCA. It provided a new model for examining the roles of and interactions among the frameworks of these five research areas, which will be used as fundamental foundation for addressing complex environmental changes. The research supports calls for the application of CR, DRR and CCA approaches for improving CR in the face of climate change (O'Brien et al. 2012, Denton et al. 2014), but it also highlights that these approaches will be less helpful if their negative interactions are not constantly monitored and addressed.

Secondly, this research furthers the knowledge about local impacts of global climate change. Many previous studies used large-scale climate models as a main instrument to assess impacts of future climate change facing coastal communities across Vietnam and develop action plans in response to future climate change (Kirsch-Wood 2015). Such efforts have the advantage of setting broader parameters for planning, but the climate models do not fully reflect local contexts as they are disconnected to local communities and they contain a high level of uncertainty (Dowlatabadi and Morgan 1993, van Aalst et 
al. 2008). This research used both local experiences and historical data to unpack the complex impacts of climatic events and a climate change over the last three decades and reduce the uncertainty of climate risk assessment at the community level.

Table 9-1: Summary of research contributions to five areas of existing literature: climate change, the five capitals, community resilience, disaster risk reduction, and climate change adaptation

\begin{tabular}{|c|c|c|}
\hline \multirow[t]{2}{*}{ Theme } & \multicolumn{2}{|c|}{ Research contributions to existing literature } \\
\hline & Additional support & New research stream \\
\hline $\begin{array}{l}\text { Framework for a } \\
\text { climate-resilient } \\
\text { community }\end{array}$ & $\begin{array}{l}\text { The important role of climate } \\
\text { risk frameworks, five capitals, } \\
\text { disaster risk reduction (DRR), } \\
\text { climate change adaptation (CCA) } \\
\text { and community resilience (CR) } \\
\text { approaches to address climate } \\
\text { change }\end{array}$ & $\begin{array}{l}\text { The research provided a new model for } \\
\text { collective examination of the role and the } \\
\text { interaction among climate change, five } \\
\text { capitals, DRR, CCA and CR. }\end{array}$ \\
\hline Climate risks & $\begin{array}{l}\text { Multidimensional, interactive } \\
\text { and uneven impacts of climate } \\
\text { change }\end{array}$ & $\begin{array}{l}\text { Recent climate change studies tend to } \\
\text { emphasize negative impacts, while positive } \\
\text { impacts are often overlooked. Besides } \\
\text { negative impacts, this research also provided } \\
\text { various examples of positive effects of } \\
\text { climate change on the community. }\end{array}$ \\
\hline $\begin{array}{l}\text { Roles of the five } \\
\text { capitals }\end{array}$ & $\begin{array}{l}\text { Resources are essential for } \\
\text { enhancing } C R \text { and reducing } \\
\text { climate risks }\end{array}$ & $\begin{array}{l}\text { CR and the success of DRR and CCA are not } \\
\text { only dependent on the availability of the five } \\
\text { capitals but also their quality and interplay. }\end{array}$ \\
\hline Roles of DRR and CCA & $\begin{array}{l}\text { DRR and CCA are essential tools } \\
\text { for enhancing CR and reducing } \\
\text { climate risks and they can } \\
\text { complement one another } \\
\text { because the strengths of one } \\
\text { tool could reduce limitations of } \\
\text { the other. }\end{array}$ & $\begin{array}{l}\text { DRR and CCA do not always reinforce each } \\
\text { other, but one approach might also hinder } \\
\text { the other. DRR and CCA as well as their } \\
\text { negative interactions might erode CR. The } \\
\text { success of DRR and CCA programs in } \\
\text { enhancing CR and reducing climate risk were } \\
\text { constrained by ineffective governance of } \\
\text { DRR and CCA. }\end{array}$ \\
\hline $\begin{array}{l}\text { Strategies for } \\
\text { enhancing } C R\end{array}$ & $\begin{array}{l}\text { The five capitals, DRR and CCA } \\
\text { remain essential for central } \\
\text { Vietnam's coastal communities } \\
\text { to transition toward a more } \\
\text { resilient state. }\end{array}$ & $\begin{array}{l}\text { The transition of a community towards a } \\
\text { more resilient state requires governance } \\
\text { reforms that promote effective integration } \\
\text { between DRR and CCA across multiple scales } \\
\text { and enhance the five capitals (availability, } \\
\text { quality and positive interplay). }\end{array}$ \\
\hline
\end{tabular}

This research also contributes to the understanding about the roles of the five capitals in enhancing CR. Previous studies tend to assume that promoting the availability of capitals is proportional to $\mathrm{CR}$ improvement and the success of DRR and CCA interventions. In addition, earlier studies on CR, DRR and CCA tend to focus on selected capitals rather 
than collective examination of all the five capitals, thus their roles and interplays are underestimated. The research conducted with Tuong Van community re-examined this assumption and it offers better insight into the five capitals. Looking beyond the simple availability of the five capitals, this research suggests that the quality and interplay amongst the five capitals should also be considered for CR and the success of DRR and CCA, because an available capital might be less helpful or even harmful if it has poor quality or negative impacts on others.

Earlier studies suggest integration between DRR and CCA as an essential strategy to address future climate change (Wilbanks 2005, O’Brien et al. 2012), but it remains unclear about how they might be integrated in order to successfully enhance CR and reduce climate risks (Birkmann and von Teichman 2010, Lei and Wang 2014, KirschWood 2015). Drawing upon the analysis of advantages and limitations of climate trends as well as interactions between DRR and CCA programs in Tuong Van over the last three decades, this research suggests that climate-resilient pathways requires reforms of DRR and CCA governance across multiple scales. These innovations include promoting participatory and democratic research rather than being imposed from above, strengthening collaboration and coordination, and significant improvement in responsibility, accountability and transparency in the process of making decisions, implementing and monitoring DRR and CCA programs.

Finally, this research responded to calls from local communities and levels of government in Vietnam for studies that identify root causes that limit DDR and CCA effectiveness, and the search for practical strategies for improving CR and reducing risks of future climate change (GOV 2007b, 2008, McEvoy et al. 2014, Kirsch-Wood 2015). 
Currently, many coastal provinces in Vietnam have completed the first phase of the NSD and NTP, and they are developing action plans for the new phase of the two programs. Thus this research will assist with this review process and preparation of action plans for the NSD and NTP and contributes to efforts to integrate the two programs in response to future climate change.

\subsection{Research limitations and future research}

\subsubsection{Limitations of the research}

Like all research approaches, the qualitative case study in this empirical research had its own limitations. The first was reliance on interviewees who recalled historical details from their memory as only a few of them kept written records. The field research used a combination of various methods to maximize the validity and reality of findings by checking for similar results across multiple data collection methods, and while this checking for consistency did not reveal obvious disconnects, it is important to recognize the research was based on the subjective ideas and opinions of the interviewees.

Secondly, there is not sufficient confidence to generalize the findings of this research for other communities. Coastal communities have their own biophysical and socialeconomical characteristics and they are impacted by different types, severity and patterns of climate hazards. As such the specific results from one community might be based upon circumstances that do not exist in another village.

In addition, this research focused on the lowest level of Vietnam's government system and its research approaches were bottom-up, thus it might have limitations if applied at broader scales. Although the research offered insightful knowledge about the 
collaborating community, it might miss important observations about the factors within and across higher levels of government, which could shape the success of DRR and CCA programs. Additionally, the research had limited opportunities to evaluate the interactions among communes and across ecosystems.

Finally, this participatory action research also had limitations. The community is not homogeneous and the random selection of 25 local residents throughout the planning process and 10 others in in-depth interviews was intended to recruit a relatively random sample in each location however one can expect some level of bias in the finding given a relatively random recruit process. This research was expected to provide the community with an action plan and a set of implementation strategies and this expectation was met. However, the research was and will not able to implement the action plan although several proposed projects in this projects such as improvement of electricity system and development of waste management system were funded by the provincial government for implementation, suggesting this doctoral research has indeed "given back" to the village.

\subsubsection{Future research}

At least four themes for future research were identified following this doctoral research. This research represents the first comprehensive study in the rural context of Vietnam to understand interactions among climate risk, CR, DRR and CCA. As such the next step for this research would be to enlarge the analysis to other contexts such as mountainous and peri-urban communities through comparative case studies. This theme for future research is needed as communities across Vietnam are biophysically, social-economically diverse and they might be threatened differently by climate change. In addition, the 
across-case approach could provide comparisons and contrasts about constraints and opportunities for building climate-resilient communities across Vietnam.

Secondly, this research focused on a village as the entry point to the research process. (bottom-up approach), thus constraints and opportunities at higher levels of government might be missed. Findings from this research revealed that local communities need considerable assistance from their governmental agencies, but the knowledge about the capacity of these agencies to help the communities with enhancing their resilience and reducing climate risks remains limited. As such it is essential to assess the resilience of the institutions, which have served and will assist local communities in addressing changing climate; the extent to which they are up to their DRR and CCA tasks; if and how they are investing in their own resilience such as institutional adaptation and transformation.

Another concern is the process of translating national policies on DRR and CCA into local actions. Further studies could begin with an analysis of how DRR and CCA programs (the NSD and NTP, respectively) have been formulated and adopted by higher levels of government, and how they are adapted and integrated with other existing important policies such as national programs on "New rural development", "Poverty alleviation", and "Rural clean water and salinization". Such analysis would offer better insight into the constraints and opportunities for successful translation of national policies into local actions.

Finally, the focus of this research was on a broad picture of constraints and opportunities for addressing climate risks did not allow deeper analysis of individual factors. Several important issues including gender, demographic changes, democracy, corruption and the 
voices of local communities to be heard and responded have not been fully addressed in this research, thus studies following this research will need to focus on how these factors have shaped climate-resilient pathways of these communities. The research identified a great variety of factors that have shaped the success of DRR and CCA, but it remains unclear which factors and their interconnections are the most important for enhancing CR and reducing climate risks. Addressing these questions is critically important as it could help policy makers and practitioners to identify foci and appropriate solutions for enhancing $\mathrm{CR}$ in the face of climate change.

\section{Concluding remarks}

Central Vietnam's coastal communities are routinely threatened by multiple climate hazards. They have significantly invested in DRR and CCA over the last three decades in order to enhance their resilience and reduce climate risks, but their investments have not been fully successful. It is expected that impacts of many climate hazards on the communities will be aggravated by future climate change (MONRE 2009). The observed and projected impacts of climate change has increasingly sparked calls from local communities and levels of government for research that determine factors shaping the recent responses, and to seek strategies to improve $\mathrm{CR}$ and reduce risks of future climate change (GOV 2007b, 2008, McCall and Dunn 2012, Kirsch-Wood 2015). In response to the broader goal, this doctoral research engaged with a coastal community in central Vietnam in order to evaluate constraints and co-produce strategies to navigate critical transitions towards a more resilient state.

Findings from literature reviews and the empirical research showed that the limited success of recent efforts in central Vietnam to reduce climate risks has been determined 
by a set of multidimensional and interconnected factors across multiple jurisdictional, temporal and spatial scales. First, DRR and CCA efforts have partially failed to reverse climate impacts because coastal communities in central Vietnam have a shortage of basic resources, which are used as an essential source of capacity to address climate hazards. Although many resources were invested, they were of poor quality, and thus they became less helpful or even useless. In addition, some available resources negatively impacted others, leading to the failure or limited success of DRR and CCA interventions. Secondly, the recent efforts were constrained by ineffective governance, which most likely resulted from limited participation, week collaboration and coordination among actors across multiple jurisdictional levels, as well as limited transparency, responsibility and accountability throughout the process of designing, implementing and monitoring DRR and CCA projects. Finally, the limitations of recent interventions resulted from the negative interactions between DRR and CCA measures.

In response to future climate change, five nested frameworks including climate change, the five capitals, CR, DRR and CCA are needed for understanding and addressing climate risks. In future, DRR and CCA programs remain essential to navigate critical transitions towards a more resilient state as they will provide a source of CR that the communities need to simultaneously reduce the adverse impacts and take advantage of a changing climate. However, it is also important to note that DRR and CCA programs cannot be successful in reducing risks of future climate change without improving the availability and quality of as well as interplays among the five capitals. Alongside the enhancement in the five capitals is a significant improvement in the integration between the two programs through governance innovations across multiple scales. In short, 
successful transitions of coastal communities in central Vietnam towards a more resilient state requires governance reforms, which promote mutual reinforcements between DRR and CCA across multiple scales and enhancements of the availability, quality and positive interplay amongst the five capitals. 


\section{REFERENCES}

Adger, W. N. 2000. Social and ecological resilience: Are they related? Progress in Human Geography 24:347-364.

Adger, W. N. 2003. Social capital, collective action, and adaptation to climate change. Economic Geography 79:387-404.

Adger, W. N. 2006. Vulnerability. Global Environmental Change 16:268-281.

Adger, W. N., N. W. Arnell, and E. L. Tompkins. 2005a. Successful adaptation to climate change across scales. Global Environmental Change 15:77-86.

Adger, W. N., T. P. Hughes, C. Folke, S. R. Carpenter, and J. RockstrÖm. 2005b. Socialecological resilience to coastal disasters. Science 309:1036-1039.

Adger, W. N., P. M. Kelly, A. Winkels, Q. H. Luong, and C. Locke. 2002. Migration, remittances, livelihood trajectories, and social resilience. Ambio 31:358-366.

Aldrich, D. P. and M. A. Meyer. 2015. Social Capital and Community Resilience. American Behavioral Scientist 59:254-269.

Almany, G. R., R. J. Hamilton, D. H. Williamson, R. D. Evans, G. P. Jones, M. Matawai, T. Potuku, K. L. Rhodes, G. R. Russ, and B. Sawynok. 2010. Research partnerships with local communities: Two case studies from Papua New Guinea and Australia. Coral Reefs 29:567-576.

Alongi, D. M. 2002. Present state and future of the world's mangrove forests. Environmental Conservation 29:331-349.

Arouri, M., C. Nguyen, and A. B. Youssef. 2015. Natural Disasters, Household Welfare, and Resilience: Evidence from Rural Vietnam. World Development 70:59-77.

Baral, N. and M. J. Stern. 2011. Capital stocks and organizational resilience in the Annapurna Conservation Area, Nepal. Society and Natural Resources 24:10111026.

Bastakoti, R. C., J. Gupta, M. S. Babel, and M. P. van Dijk. 2013. Climate risks and adaptation strategies in the Lower Mekong River basin. Regional Environmental Change:1-13.

Bauhr, M. and M. Grimes. 2014. Indignation or Resignation: The Implications of Transparency for Societal Accountability. Governance 27:291-320.

Bebbington, A. 1999. Capitals and Capabilities: A Framework for Analyzing Peasant Viability, Rural Livelihoods and Poverty. World Development 27:2021-2044.

Birkmann, J. and K. von Teichman. 2010. Integrating disaster risk reduction and climate change adaptation: Key challenges-scales, knowledge, and norms. Sustainability Science 5:171-184.

Brklacich, M. 2006. Advancing our understanding of the vulnerability of farming to climate change. Erde 137:181-198. 
Brondizio, E. S., E. Ostrom, and O. R. Young. 2009. Connectivity and the governance of multilevel social-ecological systems: The role of social capital. Annual Review of Environment and Resources 34:253-278.

Brooks, N., W. N. Adger, and P. M. Kelly. 2005. The determinants of vulnerability and adaptive capacity at the national level and the implications for adaptation. Global Environmental Change 15:151-163.

Browne, K. 2005. Snowball sampling: Using social networks to research nonheterosexual women. International Journal of Social Research Methodology: Theory and Practice 8:47-60.

Bryant, E. 2005. Natural hazards. Cambridge University Press, Cambridge.

Byg, A. and J. Salick. 2009. Local perspectives on a global phenomenon-Climate change in Eastern Tibetan villages. Global Environmental Change 19:156-166.

Cardona, D. O. 2011. Disaster Risk and Vulnerability: Concepts and Measurement of Human and Environmental Insecurity.in H. G. Brauch, U. O. Spring, C. Mesjasz, J. Grin, and P. Kameri-Mbote, editors. Coping with Global Environmental Change, Disasters and Security: Threats, Challenges, Vulnerabilities and Risks. Springer.

Carew-Reid, J. 2007. Rapid Assessment of the Extent and Impact of Sea Level Rise in Viet Nam. Climate Change Discussion Paper 1, International Centre for Environmental Management (ICEM), Brisbane, Australia.

Cash, D. W., W. N. Adger, F. Berkes, P. Garden, L. Lebel, P. Olsson, L. Pritchard, and O. Young. 2006. Scale and cross-scale dynamics: governance and information in a multilevel world. Ecology and Society 11:8.

CCFSC. 2001. Second National Strategy and Action Plan for Disaster Mitigation and Management in Viet Nam - 2001 to 2020. Central Committee for Flood and Storm Control (CCFSC). Ministry of Agriculture and Rural Development, Hanoi.

CCFSC. 2009a. The implementation Plan of the National Strategy for National Disaster Prevention, Response and Mitigation to 2020. The Government of Vietnam (GOV), Hanoi, Vietnam.

CCFSC. 2009b. Summary of damages caused by natural disasters in 2009. Central Committee for Flood and Storm Control (CCFSC), Hanoi.

Chau, V. N., J. Holland, and S. Cassells. 2014. Institutional structures underpinning flood management in Vietnam. International Journal of Disaster Risk Reduction 10:341-348.

Chaudhry, P. and G. Ruysschaert. 2007. Climate Change and Human Development in Viet Nam: a case study. United Nations Development Program.

Chen, S. C., J. W. Ferng, Y. T. Wang, T. Y. Wu, and J. J. Wang. 2008. Assessment of disaster resilience capacity of hillslope communities with high risk for geological hazards. Engineering Geology 98:86-101. 
Christopher, S., V. Watts, A. K. H. G. McCormick, and S. Young. 2008. Building and maintaining trust in a community-based participatory research partnership. American Journal of Public Health 98:1398-1406.

Cinner, J., M. M. P. B. Fuentes, and H. Randriamahazo. 2009a. Exploring social resilience in Madagascar's marine protected areas. Ecology and Society 14.

Cinner, J. E., T. R. McClanahan, T. M. Daw, N. A. J. Graham, J. Maina, S. K. Wilson, and T. P. Hughes. 2009b. Linking Social and Ecological Systems to Sustain Coral Reef Fisheries. Current Biology 19:206-212.

Cinner, J. E., T. R. McClanahan, N. A. J. Graham, T. M. Daw, J. Maina, S. M. Stead, A. Wamukota, K. Brown, and ö. Bodin. 2011. Vulnerability of coastal communities to key impacts of climate change on coral reef fisheries. Global Environmental Change.

Colten, C. E., R. W. Kates, and S. B. Laska. 2008. Three years after Katrina: Lessons for community resilience. Environment 50:36-47.

Costanza, R. and H. E. Daly. 1992. Natural capital and sustainable development. Conservation Biology 6:37-46.

Cutter, S. L., L. Barnes, M. Berry, C. Burton, E. Evans, E. Tate, and J. Webb. 2008. A place-based model for understanding community resilience to natural disasters. Global Environmental Change 18:598-606.

Dakubo, C. Y. 2010. Community-Based Participatory Research for Ecohealth. Pages 5769 Ecosystems and Human Health. Springer New York.

Das, T. K. and B. S. Teng. 1998. Between trust and control: Developing confidence in partner cooperation in alliances. Academy of Management Review 23:491-512.

De La Paix, M. J., L. Lanhai, C. Xi, S. Ahmed, and A. Varenyam. 2011. Soil Degradation And Altered Flood Risk As A Consequence Of Deforestation. Land Degradation and Development.

Denton, F., T. J. Wilbanks, A. C. Abeysinghe, I. Burton, Q. Gao, M. C. Lemos, T. Masui, K. L. O'Brien, and K. Warner. 2014. Climate-resilient pathways: adaptation, mitigation, and sustainable development. Pages 1101-1131 in C. B. Field, V. R. Barros, D. J. Dokken, K. J. Mach, M. D. Mastrandrea, T. E. Bilir, M. Chatterjee, K. L. Ebi, Y. O. Estrada, R. C. Genova, B. Girma, E. S. Kissel, A. N. Levy, S. MacCracken, P. R. Mastrandrea, and L. L. White, editors. Climate Change 2014: Impacts, Adaptation, and Vulnerability. Part A: Global and Sectoral Aspects. Contribution of Working Group II to the Fifth Assessment Report of the Intergovernmental Panel of Climate Change. Cambridge University Press, Cambridge, United Kingdom and New York, NY, USA.

DesInventar. 2012. Disaster Information Management System.

Djalante, R., C. Holley, F. Thomalla, and M. Carnegie. 2013. Pathways for adaptive and integrated disaster resilience. Natural Hazards 69:2105-2135.

Dowlatabadi, H. 1995. Integrated assessment models of climate change: an incomplete overview. Energy Policy 23:289-296. 
Dowlatabadi, H. and M. G. Morgan. 1993. Integrated assessment of climate change. Science 259:1813-1932.

Duong, T. K. 2013. Poor and near-poor households in 2012. Trie An communal People's Communittee

EM-DAT. 2012. EM-DAT Database. Université Catholique de Louvain, Brussels, Belgium.

Ewing, L., R. E. Flick, and C. E. Synolakis. 2010. A review of coastal community vulnerabilities toward resilience benefits from disaster reduction measures. Environmental Hazards 9:222-232.

Falco, S. D., F. Adinolfi, M. Bozzola, and F. Capitanio. 2014. Crop Insurance as a Strategy for Adapting to Climate Change. Journal of Agricultural Economics.

Few, R. and P. G. Tran. 2010. Climatic hazards, health risk and response in Vietnam: Case studies on social dimensions of vulnerability. Global Environmental Change 20:529-538.

Gaillard, J. C., E. Maceda, E. Stasiak, I. Le Berre, and M. Espaldon. 2009. Sustainable livelihoods and people's vulnerability in the face of coastal hazards. Journal of Coastal Conservation 13:119-129.

Gero, A., K. Méheux, and D. Dominey-Howes. 2011. Integrating community based disaster risk reduction and climate change adaptation: Examples from the Pacific. Natural Hazards and Earth System Science 11:101-113.

Gerring, J. 2004. What is a case study and what is it good for? American Political Science Review 98:341-354.

Gibson, C. C., E. Ostrom, and T. K. Ahn. 2000. The concept of scale and the human dimensions of global change: A survey. Ecological Economics 32:217-239.

Goodman, R. M., M. A. Speers, K. McLeroy, S. Fawcett, M. Kegler, E. Parker, S. R. Smith, T. D. Sterling, and N. Wallerstein. 1998. Identifying and Defining the Dimensions of Community Capacity to Provide a Basis for Measurement. Health Education and Behavior 25:258-278.

GOV. 2007a. Master plan for electricity 2006 - 2015. The government of Vietnam (GOV).

GOV. 2007b. The National Strategy for National Disaster Prevention, Response and Mitigation to 2020. The Government of Vietnam (GOV), Hanoi, Vietnam.

GOV. 2008. The National Target Program to Respond to Climate Change. The Government of Vietnam (GOV), Hanoi, Vietnam.

GOV. 2009. Community Awareness Raising and Community-Based Disaster Risk Management Program for the period of 2013 and 2015. The Government of Vietnam (GOV), Hanoi, Vietnam.

GOV. 2011. National Strategy for climate change. The Government of Vietnam (GOV), Hanoi. 
Grant, R. W. and R. O. Keohane. 2005. Accountability and Abuses of Power in World Politics. American Political Science Review 99:29-43.

Grünig, R. and R. Kühn. 2011. Process-based Strategic Planning. Springer.

GSO. 2010. The 2009 vietnam population and housing census: Completed results. Statistical Publishing House, Hanoi, Vietnam.

GSO. 2012. Statistical Yearbook of Vietnam. Statistical Publishing House, Hanoi, Vietnam.

GSO. 2014. Statistical Yearbook of Vietnam. Statistical Publishing House, Hanoi, Vietnam.

Hardcastle, D. A., P. R. Powers, and S. Wenocur. 2011. Community Practice: Theories and Skills for Social Workers. Oxford University Press.

Ho, N. T. T., H. Ross, and J. Coutts. 2015. Power sharing in fisheries co-management in Tam Giang Lagoon, Vietnam. Marine Policy 53:171-179.

ICEM. 2007. Analysis of pollution from manufacturing sectors in Vietnam. International Centre for Environmental Management (ICEM), Indooroopilly, Queensland, Australia.

IDRC. 2012. New pathways to resilience: Outcomes of the Climate Change Adaptation in Africa research and capacity building program 2006-2012. International Development Research Centre (IDRC).

IPCC. 2007. Climate Change 2007: impacts, adaptation and vulnerability: contribution of Working Group II to the fourth assessment report of the Intergovernmental Panel on Climate Change. Cambridge University Press.

IPCC. 2012. Managing the Risks of Extreme Events and Disasters to Advance Climate Change Adaptation. A Special Report of the Intergovernmental Panel on Climate Change. Cambridge University Press.

IPCC. 2013. Summary for Policymakers. Pages 1-30 in T. F. Stocker, D. Qin, G.-K. Plattner, M. Tignor, S. K. Allen, J. Boschung, A. Nauels, Y. Xia, V. Bex, and P. M. Midgley, editors. Climate Change 2013: The Physical Science Basis. Contribution of Working Group I to the Fifth Assessment Report of the Intergovernmental Panel on Climate Change. Cambridge University Press, Cambridge, United Kingdom and New York, NY, USA.

IPCC. 2014a. Climate Change 2014: Impacts, Adaptation, and Vulnerability.

IPCC. 2014b. Climate Change 2014: Impacts, Adaptation, and Vulnerability. Part A: Global and Sectoral Aspects. Contribution of Working Group II to the Fifth Assessment Report of the Intergovernmental Panel on Climate Change [Field, C.B., V.R. Barros, D.J. Dokken, K.J. Mach, M.D. Mastrandrea, T.E. Bilir, M. Chatterjee, K.L. Ebi, Y.O. Estrada, R.C. Genova, B. Girma, E.S. Kissel, A.N. Levy, S. MacCracken, P.R. Mastrandrea, and L.L. White (eds.)]. Cambridge University Press, Cambridge, United Kingdom and New York, NY, USA. 
ISPONRE. 2009. Viet Nam Assessment Report on Climate Change. Institute of Strategy and Policy on natural resources and environment (ISPONRE), Viet Nam, Hanoi, Vietnam.

Israel, B. A., A. J. Schulz, E. A. Parker, and A. B. Becker. 1998. Review of communitybased research: Assessing partnership approaches to improve public health. Annual Review of Public Health 19:173-202.

Kelly, K. and C. Tullio. 2011. Community: A Contemporary Analysis of Policies, Programs, and Practices. University of Toronto Press.

Keogh, D. U., A. Apan, S. Mushtaq, D. King, and M. Thomas. 2010. Resilience, vulnerability and adaptive capacity of an inland rural town prone to flooding: A climate change adaptation case study of Charleville, Queensland, Australia. Natural Hazards 59:699-723.

Khailani, D. K. and R. Perera. 2012. Mainstreaming disaster resilience attributes in local development plans for the adaptation to climate change induced flooding: A study based on the local plan of Shah Alam City, Malaysia. Land Use Policy 30:615627.

Kirsch-Wood, J. 2015. Viet Nam: National progress report on the implementation of the Hyogo Framework for Action (2013-2015). United Nations Development Programme - Viet Nam (UNDP Viet Nam).

Klein, R. J. T., R. J. Nicholls, and F. Thomalla. 2003. Resilience to natural hazards: How useful is this concept? Global Environmental Change Part B: Environmental Hazards 5:35-45.

Kouadio, I. K., S. Aljunid, T. Kamigaki, K. Hammad, and H. Oshitani. 2012. Infectious diseases following natural disasters: Prevention and control measures. Expert Review of Anti-Infective Therapy 10:95-104.

Lechat, M. F. 1990. The International Decade for Natural Disaster Reduction: Background and Objectives. Disasters 14:1-6.

Lei, Y. and J. Wang. 2014. A preliminary discussion on the opportunities and challenges of linking climate change adaptation with disaster risk reduction. Natural Hazards 71:1587-1597.

Lin, N. 2001. Social Capital : A Theory of Social Structure and Action (Structural Analysis in the Social Sciences). Cambridge University Press.

Lindstedt, C. and D. Naurin. 2010. Transparency is not enough: Making transparency effective in reducing corruption. International Political Science Review 31:301322.

Littell, J. S., D. L. Peterson, C. I. Millar, and K. A. O'Halloran. 2012. U.S. National Forests adapt to climate change through Science-Management partnerships. Climatic Change 110:269-296.

Lofgren, C., N. X. Thanh, N. T. K. Chuc, A. Emmelin, and L. Lindholm. 2008. People's willingness to pay for health insurance in rural Vietnam. Cost Effectiveness and Resource Allocation 6. 
Luong, N. O., T. T. T. Nguyen, I. Wilderspin, and M. Coulier. 2011. A preliminary analysis of flood and storm disaster data in Viet Nam. United Nations Development Programme - Viet Nam (UNDP Viet Nam), Hanoi.

Macaulay, A. C., L. E. Commanda, W. L. Freeman, N. Gibson, M. L. McCabe, C. M. Robbins, and P. L. Twohig. 1999. Participatory research maximises community and lay involvement. British Medical Journal 319:774-778.

Manchester, S. J. and J. M. Bullock. 2000. The impacts of non-native species on UK biodiversity and the effectiveness of control. Journal of Applied Ecology 37:845864.

Mansuri, G. and V. Rao. 2012. Localizing Development: Does Participation Work? World Bank, Washington, D.C.

Manyena, S. B. 2006. The concept of resilience revisited. Disasters 30:433-450.

Mapfumo, P., S. Adjei-Nsiah, F. Mtambanengwe, R. Chikowo, and K. E. Giller. 2013. Participatory action research (PAR) as an entry point for supporting climate change adaptation by smallholder farmers in Africa. Environmental Development 5:6-22.

MARD. 2009. Announcing the Current Forest Resource Management of the Country. Ministry of Agriculture and Rural Development (MARD), Hanoi, Vietnam.

Marschke, M. J. and F. Berkes. 2006. Exploring strategies that build livelihood resilience: A case from Cambodia. Ecology and Society 11.

Mayunga, J. S. 2009. Measuring the Measure: A Multi-dimensional Scale Model to Measure Community Disaster Resilience in the U.S. Gulf Coast Region. Texas A\&M University.

McCall, M. K. and C. E. Dunn. 2012. Geo-information tools for participatory spatial planning: Fulfilling the criteria for 'good' governance? Geoforum 43:81-94.

McEvoy, D., I. Ahmed, A. Trundle, L. T. Sang, N. N. Diem, L. T. T. Suu, T. B. Quoc, F. H. Mallick, R. Rahman, A. Rahman, N. Mukherjee, and A. Nishat. 2014. In support of urban adaptation: a participatory assessment process for secondary cities in Vietnam and Bangladesh. Climate and Development 6:205-215.

Mercer, J. 2010. Disaster risk reduction or climate change adaptation: Are we reinventing the wheel? Journal of International Development 22:247-264.

Minkler, M. 2005. Community-based research partnerships: Challenges and opportunities. Journal of Urban Health 82:ii3-ii12.

Mistry, J., A. Berardi, and M. Simpson. 2009. Critical reflections on practice: The changing roles of three physical geographers carrying out research in a developing country. Area 41:82-93.

MONRE. 2003. Viet Nam Initial National communication Under the United Nations Framework Convention on Climate Change. Ministry of Natural Resources and Environment of Viet Nam (MONRE), Ha Noi. 
MONRE. 2009. Climate change, sea level rise scenarios for Viet Nam. Vietnam's Ministry of Natural Resources and Environment (MONRE).

MPI. 2014. Vietnam employment survey in 2013. Vietnam Ministry of Planning and Investment (MPI).

Mustafa, D. 2002. To each according to his power? Participation, access, and vulnerability in irrigation and flood management in Pakistan. Environment and Planning D: Society and Space 20:737-752.

Nelson, D. R., W. N. Adger, and K. Brown. 2007. Adaptation to environmental change: contributions of a resilience framework. Annual Review of Environment and Resources 32:395-419.

Ngai, N. D., N. D. Cu, and D. A. Tuyet. 2013. Coral degradation and ability of rehabilitation of coral reefs in Co To Archipelago, Quang Ninh province, Vietnam. Deep-Sea Research Part II: Topical Studies in Oceanography 96:50-55.

Nguyen, A. D., J. Zhao, Y. Feng, W. Hu, K. Yu, M. Gasparon, T. B. Pham, and T. R. Clark. 2013a. Impact of recent coastal development and human activities on Nha Trang Bay, Vietnam: Evidence from a Porites lutea geochemical record. Coral Reefs 32:181-193.

Nguyen, H. P. 2010a. Viet Nam: National progress report on the implementation of the Hyogo Framework for Action (2009-2011) - interim. Disaster Management Center, Ministry of Agriculture and Rural Development, Ha Noi, Vietnam.

Nguyen, Q., M. H. Hoang, I. Öborn, and M. van Noordwijk. 2013b. Multipurpose agroforestry as a climate change resiliency option for farmers: An example of local adaptation in Vietnam. Climatic Change 117:241-257.

Nguyen, T. O., R. Few, L. D. Phung, L. T. Sen, N. N. Phuoc, V. C. Tien, N. V. Thanh, N. V. Chung, D. T. Hang, L. T. D. Trang, D. C. Anh, N. M. Dung, C. V. Thanh, N. V. Hoa, B. P. M. Phuong, N. H. Phuong, N. P. Quoc, and N. H. Nam. 2010. Climate change: agriculture impacts, adaptation and policy responses in Quang Tri province. Hue University.

Nguyen, V. T. 2010b. Report on social-economic development of Tuong Van village between 2008 and 2010 and the village plan for the period of 2010 and 2012. Tuong Van village, Trieu An, Trieu Phong, Quang Trị.

Norris, F. H., S. P. Stevens, B. Pfefferbaum, K. F. Wyche, and R. L. Pfefferbaum. 2008. Community resilience as a metaphor, theory, set of capacities, and strategy for disaster readiness. American Journal of Community Psychology 41:127-150.

O’Brien, K., M. Pelling, A. Patwardhan, S. Hallegatte, A. Maskrey, T. Oki, U. OswaldSpring, T. Wilbanks, and P. Z. Yanda. 2012. Managing the Risks of Extreme Events and Disasters to Advance Climate Change Adaptation. A Special Report of the Intergovernmental Panel on Climate Change.in C. B. Field, V. Barros, T. F. Stocker, D. Qin, D. J. Dokken, K. L. Ebi, M. D. Mastrandrea, K. J. Mach, G.-K. Plattner, S. K. Allen, M. Tignor, and P. M. Midgley, editors. Cambridge University Press. 
OECD. 2001. The Well-being of Nations The Role of Human and Social Capital: The Role of Human and Social Capital. Organisation for Economic Co-operation and Development (OECD) Publishing.

Okamoto, Y., H. Kobayashi, and U. Tanaka. 2013. Environmental adaptation of a lagoon village living with floods: A case study in van quat dong village located in a flood-prone area, central Vietnam. Journal of Disaster Research 8:173-174.

Olsson, P., L. H. Gunderson, S. R. Carpenter, P. Ryan, L. Lebel, C. Folke, and C. S. Holling. 2006. Shooting the rapids: Navigating transitions to adaptive governance of social-ecological systems. Ecology and Society 11.

Oxfam. 2008. Viet Nam: Climate Change, Adaptation and Poor People. Oxfam.

Panda, A., U. Sharma, K. N. Ninan, and A. Patt. 2013. Adaptive capacity contributing to improved agricultural productivity at the household level: Empirical findings highlighting the importance of crop insurance. Global Environmental Change 23:782-790.

Paris, T. R., M. F. Rola-Rubzen, J. S. Luis, T. N. C. Truong, C. Wongsamun, and D. Villanueva. 2010. Interrelationships between labour outmigration, livelihoods, rice productivity and gender roles. The International Fund for Agricultural Development (IFAD).

Paul, S. 2011. Stimulating Activism through Champions of Change. Pages 347-357 Accountability through Public Opinion.

Pennings, J. M., K. Lee, and A. Van Witteloostuijn. 1998. Human capital, social capital, and firm dissolution. Academy of Management Journal 41:425-440.

Peters, B. G. 2007. Performance-Based Accountability.in A. Shah, editor. Performance Accountability and Combating Corruption. World Bank.

Pham, X. T. 2012. Report on social-economic stutus 2011 - 2012 and plan for 2013. Tuong Van village office, Trieu An, Trieu Phong, Quang Tri.

Poortinga, W. 2012. Community resilience and health: The role of bonding, bridging, and linking aspects of social capital. Health and Place 18:286-295.

Porritt, J. 2007. Capitalism as if the world matters. Earthscan.

Powell, T., D. Hanfling, and L. O. Gostin. 2012. Emergency preparedness and public health: The lessons of hurricane sandy. JAMA - Journal of the American Medical Association 308:2569-2570.

Prentice, D. E. and G. B. Gordon. 2001. Institutional Review Board Assessment of Risks and Benefits Associated Research. Ethical and Policy Issues in Research Involving Human Participants. United States. National Bioethics Advisory Commission.

Pretty, J. 2003. Social Capital and the Collective Management of Resources. Science 302:1912-1914.

Putnam, R. D. 1995. Tuning in, tuning out: The strange disappearance of social capital in America. PS, Political Science \& Politics 28:664-664. 
QT-DONRE. 2010. Vulnerability and adaptation capacity assessment and solutions for integrating natural disaster risk reduction and climate change adaptation into social-economic development plan 2011 - 2015., Quang Tri Department of Natural Resources and Environment (DONRE).

QT-DONRE. 2011. Climate change scenarios and sea level rise in Quang Tri. Quang Tri Department of Natural Resources and Environment (DONRE).

QT-PPC. 1990. Report on social-economic development in Quang Tri for the period 1985 - 1990. Quang Tri provincial people's communittee (QT-PPC), Quang Tri, Vietnam.

QT-PPC. 2000. Report on social-economic development in Quang Tri for the period 1995 - 2000. Quang Tri provincial people's communittee (QT-PPC), Quang Tri, Vietnam.

QT-PPC. 2004a. Decision 2064/2004/QĐ-UB on foundation of the Committee for Flood and Storm Control, Search and Rescue. Quang Tri provincial people's communittee (QT-PPC), Quang Tri, Vietnam.

QT-PPC. 2004b. Decision 3236/2004/QĐ-UB on the approval for organizational and operational regulation of the Quang Tri Committee for Flood and Storm Control, Search and Rescue. Quang Tri provincial people's communittee (QT-PPC), Quang Tri, Vietnam.

QT-PPC. 2005. Report on social-economic development in Quang Tri for the period 2000 - 2005. Quang Tri provincial people's communittee (QT-PPC), Quang Tri, Vietnam.

QT-PPC. 2008. Quang Tri provincial action plan for implementation of the National Strategy for National Disaster Prevention, Response and Mitigation to 2020. Quang Tri provincial people's communittee (QT-PPC), Quang Tri, Vietnam.

QT-PPC. 2010a. Decision 05/2010/QĐ-UBND on approval for the provincial plan for integrative management of natural disaster risk up to 2020. Quang Tri provincial people's communittee (QTPPC).

QT-PPC. 2010b. Report on social-economic development in Quang Tri for the period 2005 - 2010. Quang Tri provincial people's communittee (QT-PPC), Quang Tri, Vietnam.

QT-PPC. 2013. Decision 876/2013/QĐ-UB on Quang Tri action plan for climate change for the period of 2012 and 2015. Quang Tri provincial people's committee (QTPPC), Dong Ha, Vietnam.

QT-SO. 2011. Quang Tri Statistical yearbook. Quang Tri Statistical Office, Dong Ha.

QT-SO. 2015. Quang Tri Statistical yearbook. Quang Tri Statistical Office, Dong Ha.

Ragin, C. C., D. Shulman, A. Weinberg, and B. Gran. 2003. Complexity, Generality, and Qualitative Comparative Analysis. Field Methods 15:323-340.

Ring, P. S. and A. H. Van De Ven. 1994. Developmental Processes of Cooperative Interorganizational Relationships. Academy of Management Review 19:90-118. 
Rivera, C., H. Tehler, and C. Wamsler. 2015. Fragmentation in disaster risk management systems: A barrier for integrated planning. International Journal of Disaster Risk Reduction.

Rogers, D. P. 1987. The Development of a Measure of Perceived Communication Openness. Journal of Business Communication 24:53-61.

Ross, L. F., A. Loup, R. M. Nelson, J. R. Botkin, R. Kost, G. R. Smith Jr, and S. Gehlert. 2010a. The challenges of collaboration for academic and community partners in a research partnership: Points to consider. Journal of Empirical Research on Human Research Ethics 5:19-31.

Ross, L. F., A. Loup, R. M. Nelson, J. R. Botkin, R. Kost, G. R. Smith Jr, and S. Gehlert. 2010b. Human subjects protections in community-engaged research: A research ethics framework. Journal of Empirical Research on Human Research Ethics 5:517.

Scheffer, M. 2009. Critical Transitions in Nature and Society. Princeton University Press.

Sekhar, N. U. 2005. Integrated coastal zone management in Vietnam: Present potentials and future challenges. Ocean and Coastal Management 48:813-827.

Serrao-Neumann, S., F. Crick, B. Harman, G. Schuch, and D. L. Choy. 2015. Maximising synergies between disaster risk reduction and climate change adaptation: Potential enablers for improved planning outcomes. Environmental Science and Policy 50:46-61.

Sherrieb, K., F. H. Norris, and S. Galea. 2010. Measuring Capacities for Community Resilience. Social Indicators Research 99:227-247.

Simons, H. 2009. Case Study Research in Practice. SAGE Publications.

Smil, V. 1983. Deforestation in China. Ambio 12:226-231.

Smit, B. and J. Wandel. 2006. Adaptation, adaptive capacity and vulnerability. Global Environmental Change 16:282-292.

Smyle, J. 2014. Comprehensive environment and climate change assessment in Viet Nam. The International Fund for Agricultural Development (IFAD).

Sperling, F. and F. Szekely. 2005. Disaster Risk Management in a Changing Climate. Discussion Paper prepared for the World Conference on Distaster Reduction on behalf of the Vulnerability and Adaptation Resource Group (VARG). Reprint with Addendum on Conference outcomes. Washington, D.C.

Stewart, D. W., P. N. Shamdasani, and D. W. Rook. 2007. Focus groups: Theory and practice ( 2 nd ed.). Sage Publications, Inc, Thousand Oaks, CA, US.

TA-CPC. 2004. Decision 12/2004/QĐ-UB on the approval for organizational and operational regulation of the Trieu An Communal Committee for Flood and Storm Control, Search and Rescue. Trieu An communal people's communittee (TA-CPC), Trieu An, Trieu Phong, Quang Tri.

TA-CPC. 2008. Report on major disasters in Trieu An between 1980 and 2007. Trieu An Commune People's Committee (TA-CPC), Trieu An, Trieu Phong, Quang Ti. 
TA-CPC. 2013. Report on natural disasters in Trieu An for 2012. Trieu An Commune People's Committee (TA-CPC), Trieu An, Trieu Phong, Quang Ti.

TA-CPC. 2014. Report on natural disasters in Trieu An for 2013. Trieu An Commune People's Committee (TA-CPC), Trieu An, Trieu Phong, Quang Ti.

Thomalla, F., T. Downing, E. Spanger-Siegfried, G. Han, and J. Rockström. 2006. Reducing hazard vulnerability: Towards a common approach between disaster risk reduction and climate adaptation. Disasters 30:39-48.

Tinch, R., J. Jäger, I. Omann, P. A. Harrison, J. Wesely, and R. Dunford. 2015. Applying a capitals framework to measuring coping and adaptive capacity in integrated assessment models. Climatic Change 128:323-337.

Tompkins, E. L. and W. N. Adger. 2004. Does adaptive management of natural resources enhance resilience to climate change? Ecology and Society 9.

Tong, T. M. T., H. Nguyen, R. Shaw, and P. Tran. 2012. Chapter 13: Community-Based Disaster Risk Reduction in Vietnam.in R. Shaw, editor. Community Based Disaster Risk Reduction. Emerald.

TP-DPC. 2004. Decision 1232/2004/QĐ-UB on the approval for organizational and operational regulation of the Trieu Phong Committee for Flood and Storm Control, Search and Rescue. Trieu Phong district people's communittee (TPDPC), Treu Phong, Quang Tri, Vietnam.

TPSO. 2010. Trieu Phong Statistical yearbook. Trieu Phong Statistical Office (TPS0), Dong Ha.

Tri, N. H., W. N. Adger, and P. M. Kelly. 1998. Natural resource management in mitigating climate impacts: The example of mangrove restoration in Vietnam. Global Environmental Change 8:49-61.

UNDP. 2004. Reducing disaster risk: a challenge for development. United Nations Development Programme (UNDP), Bureau for Crisis Prevention and Recovery.

UNDP. 2011a. Climate change fact sheet: The effects of climate change in Viet Nam and the UN's responses. United Nations Development Program (UNDP).

UNDP. 2011b. Fact sheet: the global assessment report for disaster risk reduction 2011. United Nations Development Program (UNDP).

UNDP. 2012. Putting Resilience at the Heart of the Development: Investing in Prevention and Resilient Recovery. United Nations Development Programme (UNDP).

UNISDR. 2005a. Hyogo Framework for Action 2005-2015: Building the Resilience of Nations and Communities to Disasters. United Nation International Strategy for Disaster Reduction (UNISDR).

UNISDR. 2005b. Proceedings of the conference: Building the Resilience of Nations and Communities to Disasters. United Nation International Strategy for Disaster Reduction (UNISDR).

UNISDR. 2015. Sendai Framework for Disaster Risk Reduction. United Nation International Strategy for Disaster Reduction (UNISDR). 
UNISDR and UNDP. 2012. Disaster Risk Reduction and Climate Change Adaptation in the Pacific: An Institutional and Policy Analysis. United Nations Development Programme - Headquarters (UNDP) and United Nations Office for Disaster Risk Reduction (UNISDR), Suva, Fiji.

Urwin, K. and A. Jordan. 2008. Does public policy support or undermine climate change adaptation? Exploring policy interplay across different scales of governance. Global Environmental Change 18:180-191.

van Aalst, M. K., T. Cannon, and I. Burton. 2008. Community level adaptation to climate change: The potential role of participatory community risk assessment. Global Environmental Change 18:165-179.

Van Tuyen, T., D. Armitage, and M. Marschke. 2010. Livelihoods and co-management in the Tam Giang lagoon, Vietnam. Ocean \& Coastal Management 53:327-335.

Vedeld, T., A. Coly, N. M. Ndour, and S. Hellevik. 2015. Climate adaptation at what scale? Multi-level governance, resilience, and coproduction in Saint Louis, Senegal. Natural Hazards.

Vu-Thanh, H., T. Ngo-Duc, and T. Phan-Van. 2013. Evolution of meteorological drought characteristics in Vietnam during the 1961-2007 period. Theoretical and Applied Climatology:1-9.

Walker, B., C. S. Holling, S. R. Carpenter, and A. Kinzig. 2004. Resilience, adaptability and transformability in social-ecological systems. Ecology and Society 9.

Waugh Jr, W. L. and G. Straib. 2006. Collaboration and leadership for effective emergency management. Public Administration Review 66:131-140.

Well-Dang, A. 2012. Civil society and climate change in Vietnam: Actors, roles, and possibilities. Pact, Vietnam Country Office.

Wilbanks, T. J. 2005. Issues in developing a capacity for integrated analysis of mitigation and adaptation. Environmental Science and Policy 8:541-547.

Wisner, B. 2004. At risk: natural hazards, people's vulnerability and disasters. Routledge, New York, NY.

Wüstenhagen, R., M. Wolsink, and M. J. Bürer. 2007. Social acceptance of renewable energy innovation: An introduction to the concept. Energy Policy 35:2683-2691.

Yin, R. K. 1994. Case Study Research: Design and Methods. SAGE Publications.

Zakus, J. D. L. and C. L. Lysack. 1998. Revisiting community participation. Health Policy and Planning 13:1-12. 


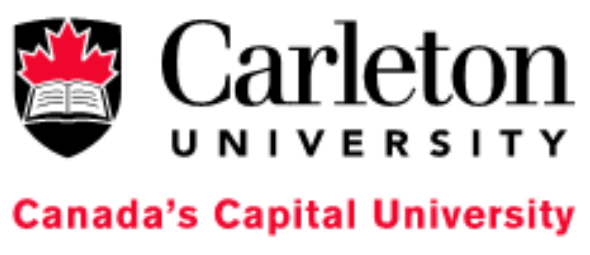

\author{
Carleton University \\ 1125 Colonel By Drive \\ Ottawa, Ontario, K1S 5B6 \\ Canada
}

\section{Letter of invitation to participate in research}

(To be translated into Vietnamese)

Title of research project:

Resilience of central Vietnam's rural coastal communities in the face of climate change: Evaluating constraints and opportunities to local responses

Date of ethics clearance: To be determined

Ethics Clearance for the Collection of Data: Expires: August 31, 2015

\section{Dear Co-researcher,}

I am a Ph.D. Candidate in the Department of Geography and Environmental Studies at Carleton University, Ottawa, Canada. I am working under the supervision of Professor Mike Brklacich. As part of my research, I am conducting a study on evaluating factors that have promoted and impeded the success of recent responses of local communities to climatic hazards, and to explore alternative strategies for enhancing their resilience to reduce adverse impacts of future climate change.

Community-engaged research approaches will be used for this study. Extension officers working in this community will be recruited to form a research team. The research team will develop a research agenda, conduct a number of community workshops and focus 
group discussions, during which participants will contribute to assessing impacts of climatic hazards, analysis the underlying causes to failures of their recent interventions, and developing applicable strategies for enhancing their capacity to cope with the natural hazards. In addition, the research will use group-based problem solving tools such as participatory mapping and transect walks. Farms and households will also be visited. Group discussions will be tape-recorded and photographs taken.

The fieldwork for this study will take three months, with up to 20 focus group discussion and six community workshops. Although your active participation will be appreciated through the entire research process, you are free to withdraw at any time, or participate at your own convenience. Any information you provide will be confidential, and I will not refer to you by name or describe you in any way that will let others identify you, thus complete anonymity will be guaranteed in the study. Further, you will not be identified by your name, photographs and recordings in my thesis, reports or publication resulting from this study.

This project has been reviewed by, and received ethics clearance from Carleton University Ethics Committee. If you have any question about the study, or would like additional information to assist you in reaching a free decision to participate, please feel free to contact me or Professor Mike Brklacich at the address below, or the Carleton University Ethics Committee. Upon completion of the study, a summary of my thesis will be given to the community leader, and can also be accessed at the Carleton University Library, Ottawa, Canada.

Thank you for your consideration of this request. I hope this study will prove to be a learning experience for all participants.

Yours sincerely,

Nguyen Huu Trung

Department of Geography and Environmental Studies

Carleton University

A333 Loeb Building

1125 Colonel By Drive

Ottawa, Ontario, K1S 5B6

Canada

\section{CO-RESEARCHER CONSENT FORM}

By signing this form, I agree to participate as a member of a research team in a study being conducted by Nguyen Huu Trung of the Department of Geography and Environmental Studies, Carleton University, Ottawa, Canada under the supervision of Professor Mike Brklacich. I have this decision based on the information I have read in the letter of invitation.

As a member of the research team, I realize that I will participate in all stages of the research process, which include developing a research agenda for three months, 
identifying research methods to be used during the study, and participate in investigating and analysing the information collected. I will also conduct group-based problem solving exercises, such as mapping and transect walks and that my farm or home may be visited. I realize any information I collect from participants during the study mist be confidential, and no participant should be referred to in a way that will allow for identification.

I also understand that I am a volunteer and may decline to participate in any activities or answer any questions, or withdraw my consent completely. All information I provide will be confidential and I will not be identified during the research, in the thesis, report or publication. I understand that this project has been reviewed by, and received ethics clearance from Carleton University Ethics Committee and that I may contact this office at 1125 Colonel By Drive, 1325 Dunton Tower, Carleton University, Ottawa, Ontario, Canada, should I have any concerns or questions about this study, or contact the principal investigator or his supervisor at address in the cover letter.

\section{Signature of research participant}


-

Canada's Capital University
Carleton University

1125 Colonel By Drive

Ottawa, Ontario, K1S 5B6

Canada

\section{Letter of invitation to participate in research}

(To be translated into Vietnamese)

Title of research project:

Resilience of central Vietnam's rural coastal communities in the face of climate change: Evaluating constraints and opportunities to local responses

Date of ethics clearance: To be determined

Ethics Clearance for the Collection of Data: Expires: August 31, 2015

\section{Dear participants,}

I am a Ph.D. Candidate in the Department of Geography and Environmental Studies at Carleton University, Ottawa, Canada. I am working under the supervision of Professor Mike Brklacich. As part of my research, I am conducting a study on evaluating factors that have promoted and impeded the success of recent responses of local communities to climatic hazards, and to explore alternative strategies for enhancing their resilience to reduce adverse impacts of future climate change.

Community-engaged research approach will be used for this study. Extension officers working in this community will be recruited to form a research team. The research team will conduct a number of community workshops and focus group discussions, during which the participants will contribute to assessing impacts of climatic hazards, analysis the underlying causes to failures of their recent interventions, and developing applicable strategies for enhancing their capacity to cope with the natural hazards. In addition, the research will use group-based problem solving tools such as participatory mapping and transect walks. Farms and households will also be visited. Group discussion will be taperecorded and photographs taken. 
The study will take three months, with six community workshops planned. Although your active participation will be appreciated through the entire research process, you are free to withdraw at any time, or participate at your own convenience. Any information you provide will be confidential, and I will not refer to you by name or describe you in any way that will let others identify you, thus complete anonymity will be guaranteed in the study. Further, you will not be identified by your name, photographs and recordings in my thesis, reports or publication resulting from this study.

This project has been reviewed by, and received ethics clearance from Carleton University Ethics Committee. If you have any question about the study, or would like additional information to assist you in reaching a free decision to participate, please feel free to contact me or Professor Mike Brklacich at the address below, or the Carleton University Ethics Committee. Upon completion of the study, a summary of my thesis will be given to the community leader, and can also be accessed at the Carleton University Library, Ottawa, Canada.

Thank you for your consideration of this request. I hope this study will prove to be a learning experience for you and all participants.

Yours sincerely,

Nguyen Huu Trung

Department of Geography and Environmental Studies

Carleton University

A333 Loeb Building

1125 Colonel By Drive

Ottawa, Ontario, K1S 5B6

Canada

\section{RESEARCH PARTICIPANT CONSENT FORM}

By signing this form, I agree to participate in a study being conducted by Nguyen Huu Trung of the Department of Geography and Environmental Studies, Carleton University, Ottawa, Canada under the supervision of Professor Mike Brklacich. I have this decision based on the information I have read or been read to in the cover letter.

As a participant in this study, I realize that I will participate in focus group discussions and participatory planning workshops in identifying climatic impacts and strategies to enhance community resilience and reduce risks from climatic hazards, participate in group-based problem solving exercises, such as mapping and transect walks and that my farm or home may be visited. I realize group discussions will be tape-recorded. I also understand that I may decline to participate in any activities or answers any question, or 
withdraw my consent completely. All information I provide will be held in confidence and I will not be identified during the research, in the thesis, report or publication. I understand that this project has been reviewed by, and received ethics clearance from Carleton University Ethics Committee and that I may contact this office at 1125 Colonel By Drive, 1325 Dunton Tower, Carleton University, Ottawa, Ontario, Canada, should I have any concerns or questions about this study, or contact the principal investigator or his supervisor at address in the cover letter.

\section{Signature of research participant}


-

Canada's Capital University
Carleton University 1125 Colonel By Drive Ottawa, Ontario, K1S 5B6 Canada

\section{Recruitment scripts for phone or email: in-depth interviews}

(To be translated into Vietnamese)

Title of research project:

Resilience of central Vietnam's rural coastal communities in the face of climate change: Evaluating constraints and opportunities to local responses

Date of ethics clearance: To be determined

Ethics Clearance for the Collection of Data: Expires: August 31, 2015

Good day. My name is Nguyen Huu Trung. I am a Ph.D. Candidate in the Department of Geography and Environmental Studies at Carleton University, Ottawa, Canada. I am working under the supervision of Professor Mike Brklacich. I am conducting a study on resilience of local communities in the face of climate change.

For representatives of organizations

As a part of the research, I am currently conducting interviews with people who have professional expertise and experience on disaster risk reduction and climate change adaptation at local communities. As known, you are a (position and name of organization), and have been supporting local communities in Quang Tri province to enhance their resilience and reduce adverse impacts of climate change. I am happy if you could accept my invitation to an interview.

For residents of the target community:

You might be aware that our research team is conducting a number of focus group discussions in your community. I am contacting you by reference from such focus group discussions because you have a special experience on dealing with impacts of climatic hazards. I will really appreciate if you could agree to share your valuable experience.

The interview takes approximately one hour. I would very much like to meet you to discuss this research in more detailed. Would this be possible sometime in the next week? 
If no, thank you. Have a nice day.

If yes, thank you. What day, time and place would be convenient for you?

(Set up meeting details) 
-

Canada's Capital University
Carleton University

1125 Colonel By Drive

Ottawa, Ontario, K1S 5B6

Canada

\section{Informed Consent for in-depth interviews}

(To be translated into Vietnamese)

Title of research project:

Resilience of central Vietnam's rural coastal communities in the face of climate change: Evaluating constraints and opportunities to local responses

Date of ethics clearance: To be determined

Ethics Clearance for the Collection of Data: Expires: August 31, 2015

Good day. As I mentioned previously, my name is Nguyen Huu Trung. I am a Ph.D. Candidate in the Department of Geography and Environmental Studies at Carleton University, Ottawa, Canada. I am working under the supervision of Professor Mike Brklacich. I am conducting a study on the resilience of local communities in the face of climate change.

This research project has cleared the ethics research process at Carleton University. The interview will take about one hour. I will ask issues related to factors have promoted and impeded the success of recent responses of the community (name of the target community). Please remember that you can refuse to answer any questions that you are not comfortable with, or you may stop the interview at any time. You can ask for the transcripts of the interview to review, and decide to withdraw from the research project by contacting me within the next three months, with my address below. If you decide to withdraw the information you have provided will be destroyed.

The primary data gathered in this process will be securely stored and accessible only to me and the supervisor for my thesis. Your name will not be disclosed. After the research is complete, I will write my thesis and might share this research through the publication of articles or through presentations but your answers will remain anonymous and 
confidential. The data retrieved during the fieldwork may also be used in future projects of similar nature.

Do you have any question about the research or the interview?

$$
\square \text { Yes } \quad \square \text { No }
$$

(Answer questions before proceeding)

Do you agree to participate in this research?

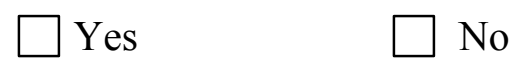

Do you agree that I take notes during the interview?

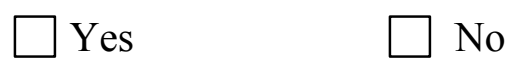

Do you agree to be recorded?

$\square$ Yes $\quad \square$ No

Would you like to review the transcript of the interview? (I can send you the transcript by email or by mail. Mailed transcripts will have self-addressed stamped envelope. Please return it to within a month of receiving it.)

$\square$ Yes $\quad \square$ No

I (as researcher) promise to respect the context of the knowledge and opinions you contribute to this project, and the terms of this consent form.

Place and Date 


\section{Climate impact assessment}

- Look at the maps on the walls and on my computer, can you please describe the features of our community?

- What resources do you think are the most important for your family and our community as a whole? And why?

- What climate-related hazards do you think are important for your family and our community as a whole?

- Explain how these hazards recently impacted the resources that were identified?

\section{Recent responses to changing climate}

- In the last meeting, we identified 9 climate-related hazards that have recently impacted our community. Can you please tell us how your family and our community as a whole have addressed these hazards?

- Can you please describe the process of formulating and implementing DRR activities in your family and our community as a whole?

- As you have said that the DRR program was initiated and led by the government across multiple levels, do you have our own measures to address storms and floods? What are they?

- You have said DRR focuses on storms and floods, how have you addressed the other climate hazards such as drought, salinization, tidal and rain flooding?

- How could you distinguish DRR and climate change adaptation?

\section{Factors shaping the success of recent responses to changing climate}

- In the last meeting, we identified and discussed the two most important programs (DRR and CCA) that our community has used to address changing climate. Can you please list measures that you think the most successful and unsuccessful for your family and our community as a whole?

- Can you please list the manifestations of the success and limitations of the measures that we have identified?

- Can you please classify the manifestations of success and limitation into six themes that our research team predetermined? The six theme include physical resources, natural resources, financial resources, and human and social resources;

- Now we take some of the most successful and unsuccessful projects to examine what factors have shaped the success of our recent intervention

- What factors do you think contributed to the success and the limitations of building a system of concrete dykes?

- Why did the system of freshwater supply to Lang fail?

o Why were the green belts of salt-tolerant trees uprooted?

- Why are our drainages not regularly dredged although they are important?

o Why were some important projects not implemented to address climate hazards? For instance, measures to address droughts and salinization? 
Appendix 3: Sample matrix for community survey

\begin{tabular}{|c|c|c|c|c|c|c|c|c|c|c|c|}
\hline \multirow[t]{2}{*}{ Resource } & \multirow[t]{2}{*}{$\begin{array}{l}\text { Access } \\
\text { (Yes/No) }\end{array}$} & \multirow[t]{2}{*}{$\begin{array}{l}\text { Importance } \\
(0-10)\end{array}$} & \multicolumn{9}{|c|}{$\begin{array}{c}\text { Levels of climate impact } \\
\text { (0: no impact; } 1 \text { : little impact; } 2: \text { moderate impact; } 3: \text { high impact) }\end{array}$} \\
\hline & & & Storm & Flood & Drought & $\mathrm{Sal}^{14}$ & Erosion & $\mathrm{NE}^{15}$ & $\mathrm{SW}^{16}$ & $\mathrm{RF}^{17}$ & $\mathrm{TF}^{18}$ \\
\hline 1 & 2 & 3 & 4 & 5 & 6 & 7 & 8 & 9 & 10 & 11 & 12 \\
\hline \multicolumn{12}{|l|}{ Natural resources } \\
\hline \multicolumn{12}{|l|}{ Paddy rice land } \\
\hline \multicolumn{12}{|l|}{ Aquaculture land } \\
\hline \multicolumn{12}{|l|}{ Subsidiary crop land } \\
\hline \multicolumn{12}{|l|}{ Salt production land } \\
\hline \multicolumn{12}{|l|}{ Domestic use water } \\
\hline \multicolumn{12}{|l|}{ Production water } \\
\hline \multicolumn{12}{|l|}{ The bamboo } \\
\hline \multicolumn{12}{|l|}{ Melaleuca forest } \\
\hline \multicolumn{12}{|l|}{ Salt-tolerant trees } \\
\hline \multicolumn{12}{|l|}{ River clam } \\
\hline \multicolumn{12}{|l|}{ Nut grass } \\
\hline \multicolumn{12}{|l|}{ Bitter vegetable } \\
\hline \multicolumn{12}{|l|}{ Coc tinh thao (CTT) } \\
\hline \multicolumn{12}{|l|}{ Physical resources } \\
\hline \multicolumn{12}{|l|}{ Flood dykes } \\
\hline Bridge & & & & & & & & & & & \\
\hline
\end{tabular}

\footnotetext{
${ }^{14}$ Sal: salinization;

${ }^{15} \mathrm{NE}$ : northeast monsoon

${ }^{16} \mathrm{SW}$ : southwest monsoon

${ }^{17} \mathrm{RF}$ : rain flooding

${ }^{18}$ Tidal flooding
} 


\begin{tabular}{|c|c|c|c|c|c|c|c|c|c|c|c|}
\hline \multirow[t]{2}{*}{ Resource } & \multirow[t]{2}{*}{$\begin{array}{c}\text { Access } \\
\text { (Yes/No) }\end{array}$} & \multirow[t]{2}{*}{$\begin{array}{l}\text { Importance } \\
(0-10)\end{array}$} & \multicolumn{9}{|c|}{$\begin{array}{l}\text { Levels of climate impact } \\
\text { (0: no impact; } 1: \text { little impact; } 2: \text { moderate impact; } 3: \text { high impact) }\end{array}$} \\
\hline & & & Storm & Flood & Drought & $\mathrm{Sal}^{14}$ & Erosion & $\mathrm{NE}^{15}$ & $s W^{16}$ & $\mathrm{RF}^{17}$ & $\mathrm{TF}^{18}$ \\
\hline 1 & 2 & 3 & 4 & 5 & 6 & 7 & 8 & 9 & 10 & 11 & 12 \\
\hline \multicolumn{12}{|l|}{ Drainages } \\
\hline \multicolumn{12}{|l|}{ Village roads } \\
\hline \multicolumn{12}{|l|}{ Drilled wells } \\
\hline \multicolumn{12}{|l|}{ Ground wells } \\
\hline \multicolumn{12}{|c|}{ House with floors or shelves } \\
\hline \multicolumn{12}{|l|}{ Electricity system } \\
\hline \multicolumn{12}{|c|}{ Communications equipment } \\
\hline \multicolumn{12}{|c|}{ Commune clinic centre } \\
\hline \multicolumn{12}{|l|}{ Life vests } \\
\hline \multicolumn{12}{|l|}{ Storm shelters } \\
\hline \multicolumn{12}{|l|}{ Water tower } \\
\hline \multicolumn{12}{|l|}{ Financial resources } \\
\hline \multicolumn{12}{|l|}{ Loans from banks } \\
\hline \multicolumn{12}{|l|}{ Village funds } \\
\hline \multicolumn{12}{|l|}{ Shrimp farming } \\
\hline \multicolumn{12}{|c|}{ Paddy rice production } \\
\hline \multicolumn{12}{|l|}{ Subsidiary crops } \\
\hline \multicolumn{12}{|l|}{ Salt production } \\
\hline \multicolumn{12}{|l|}{ Remittent } \\
\hline \multicolumn{12}{|c|}{ Exploitation of river clams } \\
\hline \multicolumn{12}{|l|}{ Nut collection } \\
\hline \multicolumn{12}{|l|}{$\begin{array}{l}\text { Collection of bitter } \\
\text { vegetables }\end{array}$} \\
\hline Collection of CTT & & & & & & & & & & & \\
\hline
\end{tabular}




\begin{tabular}{|c|c|c|c|c|c|c|c|c|c|c|c|}
\hline \multirow[t]{2}{*}{ Resource } & \multirow[t]{2}{*}{$\begin{array}{c}\text { Access } \\
\text { (Yes/No) }\end{array}$} & \multirow[t]{2}{*}{$\begin{array}{l}\text { Importance } \\
(0-10)\end{array}$} & \multicolumn{9}{|c|}{$\begin{array}{l}\text { Levels of climate impact } \\
\text { (0: no impact; } 1 \text { : little impact; } 2: \text { moderate impact; } 3: \text { high impact) }\end{array}$} \\
\hline & & & Storm & Flood & Drought & $\mathrm{Sal}^{14}$ & Erosion & $\mathrm{NE}^{15}$ & $\mathrm{SW}^{16}$ & $\mathrm{RF}^{17}$ & $\mathrm{TF}^{18}$ \\
\hline 1 & 2 & 3 & 4 & 5 & 6 & 7 & 8 & 9 & 10 & 11 & 12 \\
\hline \multicolumn{12}{|l|}{ Social capital } \\
\hline \multicolumn{12}{|l|}{ Neighbour relations } \\
\hline \multicolumn{12}{|l|}{ Kinship } \\
\hline \multicolumn{12}{|l|}{ Farmers' Union } \\
\hline \multicolumn{12}{|l|}{ Women Union } \\
\hline \multicolumn{12}{|l|}{ Veteran } \\
\hline \multicolumn{12}{|l|}{ Youth Union } \\
\hline \multicolumn{12}{|l|}{ Fatherland Front } \\
\hline \multicolumn{12}{|l|}{ Human capital (2/3) } \\
\hline \multicolumn{12}{|l|}{$\begin{array}{l}\text { Knowledge and experience } \\
\text { on DRR }\end{array}$} \\
\hline \multicolumn{12}{|l|}{$\begin{array}{l}\text { Knowledge and skills on } \\
\text { development of livelihoods }\end{array}$} \\
\hline Health & & & & & & & & & & & \\
\hline
\end{tabular}




\section{Defining a vision for the community}

We have just summarized adverse impacts of climate hazards and factors that have promoted and impeded the success of our recent measures to address climate threats.

- In the face of climate change and extreme weather, what features and conditions do you individually want your community to experience over the next five years? Or what do you think your community looks like in the next five years?

- Can you please share your own expectation with your group members, and then prepare a presentation on the expectations of your groups?

- Which group would like to present the expectation of your group to the whole?

- Please contrast the expectation that have been presented with those of your own groups to discuss what you want to add and eliminate? And why?

- As we see, we had a long list of expectations for our community, please classify them into different groups?

\section{Identifying and prioritizing actions to realize the vision}

In the first section, we have identified the vision that we wished our community to be in the next five years. Now we need to identify actions or projects that we believe will contribute to realizing the vision of our community.

- Work in your group and identify projects or measures or actions that your group think could help our community to achieve the vision that we have identified;

- What existing measures need to be improved?

- What new measures do you need to realize the vision?

- What hazards will the individual new measures address?

- What benefits do the new individual measures provide if they are implemented?

We have just identified projects that help us to realize the vision of our community. Now we need to prioritize them because we might not have enough resource to implement at the same time.

- What criteria do we use to prioritize your projects?

- What can you define the selected criteria?

- Now, please follow the instruction to prioritize our projects 


\section{Determining strategies to realize the vision}

We have just summarized the strengths and challenges that our community has been facing over the last three decades. Now we discuss how our proposed projects contribute to realizing the vision of our community. We will discuss four important questions:

- How our projects can address the complexity of changing climate, for instance multiplicity and interactions of climate hazards?

- How our proposed actions could enhance the resilience of their community in the face of changing climate?

- How are our projects integrated effectively across temporal, spatial and jurisdictional scales?

- How are our projects formulated and implemented effectively? 


\section{Sample research questions for interviews with local residents}

- How long have been living in this community?

- Do you live in the community all-year round?

- What is your main occupation?

- What is your wife or husband's occupation?

- Can you describe how climate hazards impact your family: health, education of children, livelihood activities etc.

- Can you describe how your family has address climate hazards?

- Do you think you have been successful in addressing changing climate?

- Can you please explain what factors have contributed to the success of some measures in enhancing the capacity of you family and reducing climate impacts,

- Why some other measures could not be implemented or implemented with limited success?

- In five coming years, what measures do you plan to adopt to reduce risk from climate change?

- What do you think about these proposed projects and how will they be implemented to effectively reduce risks from future climate change?

\section{Sample research questions for interviews with representatives of organizations}

- How are you involved with Tuong Van community?

- In what projects have you involved with the community?

- What do you think are key factors contributing to the success of these projects?

- What do you think are major concerns and challenges to building community capacities to address climate change?

- What activities do you think should be supported to enhance community capacities to reduce climate impacts?

- What activities have you planned to support the community?

- What other government departments and organizations do you work with to support the community to reduce climate impacts?

- What challenges might you encounter through such working relationships?

- What do you think should be done to enhance the working relationships?

- What do you think about the proposed projects and how will they be implemented to effectively reduce risks from future climate change? 